\title{
Vehicle Systems Design Optimization Study
}

Pioneer Project No. 31492

FINAL REPORT

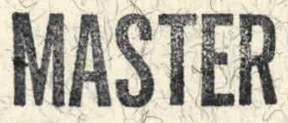

by

J.L. Gilmour

April 1980

JPL Contract No. 955498

Pioneer Engineering \& Manufacturing Company 2500 East Nine Mile Road, Warren, Michigan 48091

This work was performed for the Jet Propulsion Laboratory, California Institute of Technology, sponsored by U.S. Department of Energy through an agreement with the National Aeronautics and Space Administratiun. 


\section{DISCLAIMER}

This report was prepared as an account of work sponsored by an agency of the United States Government. Neither the United States Government nor any agency Thereof, nor any of their employees, makes any warranty, express or implied, or assumes any legal liability or responsibility for the accuracy, completeness, or usefulness of any information, apparatus, product, or process disclosed, or represents that its use would not infringe privately owned rights. Reference herein to any specific commercial product, process, or service by trade name, trademark, manufacturer, or otherwise does not necessarily constitute or imply its endorsement, recommendation, or favoring by the United States Government or any agency thereof. The views and opinions of authors expressed herein do not necessarily state or reflect those of the United States Government or any agency thereof. 


\section{DISCLAIMER}

Portions of this document may be illegible in electronic image products. Images are produced from the best available original document. 


\section{VEHICLE SYSTEMS DESIGN}

OPTIMIZATION STUDY

\section{BY}

J. L. Gilmour

April 1980

FINAL REPORT

JPL Contract No. 955498

Pioneer Project No. 31492

This work was performed for the Jet Propulsion Laboratory, California Institute of Technology, sponsored by U.S. Department of Energy through an agreement with the National Aeronautics and Space $\Lambda$ dministration. 
This report was prepared as an account of work sponsored by the United States Government. Neither the United States nor the United States Department of Energy, nor any of their employees, nor any of their contractors, subcontractors, or their employees, makes any warranty, express or implied, or assumes any legal liability or responsibility for the accuracy, completeness or usefulness of any information, apparatus, product or process disclosed, or represents that its use would not infringe privately owned rights. 


\begin{abstract}
The optimization of an electric vehicle layout requires a weight distribution in the range of $53 / 47$ to $62 / 38$ in order to assure dynamic handling characteristics comparable to current production internal combustion engine vehicles. It is possible to achieve this goal and also provide passenger and cargo space comparable to a selected current production sub-compact car either in a unique new design or by utilizing the production vehicle as a base. Necessary modification of the base vehicle can be accomplished without major modification of the structure or running gear. As long as batteries are as heavy and require as much space as they currently do, they must be divided into two packages - one at front under the hood and a second at the rear under the cargo area - in order to achieve the desired weight distribution. The weight distribution criteria requires the placement of batteries at the front of the vehicle even when the central tunnel is used for the location of some batteries. The optimum layout has a front motor and front wheel drive. This configuration provides the optimum vehicle dynamic handling characteristics and the maximum passenger and cargo space for a given size vehicle.
\end{abstract}




\section{ACKNOWLEDGEMENTS}

The author gratefully acknowledges the important technical contributions of several individuals. Mr. J. T. Benedict, Manager Technical Information, Chrysler Corporation, for supplying technical data and illustrations of the Omni base car. Mr. J. J. Bozyk of Chrysler Engineering Staff for supplying technical data on the ETV-1 electric vehicle. Dr. C. C. Christianson, Deputy Project Manager, Argonne National Laboratory, for specifications of future battery types and consultation on recommended units for this study. Mr. D. J. Segal, Mechanical Engineer, MGA Research Corporation, for consultation on the vehicle dynamic characteristics. Mr. C. Weinlein, Globe Battery Division, Globe-Union Inc. for technical data and drawing of battery vehicle systems.

Mr. H. R. Fortgang was JPL Technical Manager for the project. I wish to especially thank him for his technical guidance and enthusiastic interest in the project. 
Page No.

SUMMARY

viii

1.

INTRODUCTION

1

2.

TECHNICAL DISCUSSION

3

2.1 Alternate Battery Locations

2.2 Effect of Battery Shape

25

2.3 Dynamic and Static Analysis

36

2.4 Battery Support Structure Integration

3.

- CONCLUSIONS

68

4.

RECOMMENDATIONS

69

REFERFNCFS

71

APPENDIX A 
Figure No.

1

2

3

4

5

6
Title

Internal Combustion Engine and Drive Component Locations - Dodge Omni

Theoretical Distribution of Electric

Component Weights

Vehicle Interferences with Theoretical Weight Distribution

Optimum Electric Vehicle Layout

Recommended Electric Vehicle Layout Front Power Plant/Front Drive

Optional Spare Tire Location

Rear Power Plant/Rear Drive Layout

Front Power Plant/Rear Drive Layout

Electric Motor Clearance Requirement

Battery Size Comparison

Battery Packaging Comparison

Available Space for Batteries - Dodge Omni

Electric Vehicle Layout with future

Nickel-Zinc Batteries

Response Characteristics in Trapezoidal Steer Maneuver 40

Response Characteristics in Trapezoidal Steer Maneuver 41

Response Characteristics in Trapezoidal Steer Maneuver 42

Response Characteristies in Trapezoidal Steer Maneuver 43 
LIST OF FIGURES (CONTD.)

Figure No.

22

23

24

25

26

27

28

29

30

31

32

33

34

35

36 $\underline{\text { Title }}$

Page No.

Response Characteristics in Trapezoidal Steer Maneuver 44

Response Characteristics in Sinusoidal Steer Maneuver 45

Response Characteristics in Sinusoidal Steer Manuever 46

$\begin{array}{ll}\text { Battery Packaging Locations } & 50\end{array}$

Front Battery Pack Mounting Structure $\quad 51$

Rear Battery Pack Mounting Structure 52

Battery Support and Hold Down Structure . 53

Battery Watering and Venting System 56

Battery Vent System Flame Arrestor $\quad 57$

Battery Cooling System $\quad 58$

Electric Vehicle Mock-Up - Side View 63

Electric Vehicle Mock-Up - Front Battery Pack 64

Electric Vehicle Mock-Up - Motor Location 65

Electric Vehicle Mock-Up - Controls Location 66

Electric Vehicle Mock-IIp - Rear Rattery Pack 67 


\section{LIST OF TABLES}

Table No.

1

2

3

4

5

6
Title

U. S. Sub-Compact Vehicle Specifications

Dodge Omni Specifications

Electric Drive Component Weights

Internal Combustion Engine and

Drive Component Weights

Base Vehicle Weight Distribution

Characteristics of Battery Types
Page No.

5

6

8

8

9

26 
SUMMARY

This report covers a design study and related technical analysis that establishes the optimum vehicle configuration and component locations for an electric drive vehicle based on using the basic structure and running gear of a current production sub-compact internal combustion engine vehicle. The optimized layout retains vehicle dynamic handling characteristics, passenger space and cargo area comparable to the base vehicle

The base vehicle selected was a Dodge Omni. It provided the maximum space for batteries and optimum passenger space for a vehicle of this size. Primary studies used 18 Globe-Union EV2-13 lead-acid type batteries as used in the E'IV-1.

Proper weight distribution was established as the single most important factor for achieving dynamic handling characteristics comparable to the base internal combustion engine vehicle (ICEV). A target value of 58/42 front/rear distribution was established although current practice indicates that a range of front weight bias from 53 to 62 would be acceptable with proper suspension tuning. Although the Omni base vehicle is at the high end of the range, the final optimum electric vehicle layout was at the minimum end in order to keep front wheel loads from being excessive for steering effort. This compromise is necessary as long as batteries constitute such a large proportion of vehicle weight. This electric vehicle package for example weighs approximately $50 \%$ more ( 3000 vs 2000 lbs.) than the ICEV.

The recommended optimum layout places six batteries at the front of the vehicle under the hood and 12 at the rear under the cargo compartment floor. The electric motor, transmission/differential, and control elements are also at the front under the hood. The front motor/front wheel drive configuration was selected because it provides superior traction, better directional stability and maximum passenger space for a given vehicle size package. Other combinations of motor and drive locations were studied but did not uffer the optimum combination of characteristics provided by the recommended layout.

Several alternate hattery types ourrcntly under developinient were ulso studied. Development is aimed at increasing energy density for improved performance - primarily range. Most of the module (individual battery) sizes currently proposed for these types 
are more difficult to package particularly if constant total battery weight is used. Present lead-acid battery module size appears optimum for vehicle packaging. It was also established that the space available for battery mounting in the Omni is the maximum to be anticipated in this size (sub-compact) car. By compromising between energy gain and weight saving it was shown that one promising type (nickel-zinc) could be packaged satisfactorily and still achieve a $57 \%$ gain in watthours or more significantly a $66 \%$ gain of $W H / l b$. of vehicle weight.

Dynamic simulation tests were conducted to verify that the recommended layout performed in a manner generally similar to the base vehicle.

Detailed installation studies were conducted to verify that the recommended battery packs could be mounted in the locations indicated without significantly changing the structure of the base vehicle. Necessary changes to the structure, suspension and control components of the base vehicle to accommodate the additional weight of the electric drive components were also analyzed and specified. A mock-up was also constructed to verify the optimized installation in three-dimensional form.

In conclusion, it was demonstrated that current electric vehicle drive components can be installed in a current production ICE base vehicle without requiring significant changes and that the dynamic handling characteristics and passenger and cargo space of the base vehicle can be retained. Specifically, there is a viable alternative to the central tunnel as a location for the propulsion batteries in an electric vehicle (EV) of this type. 


\section{THIS PAGE}

\section{WAS INTENTIONALLY LEFT BLANK}


The realization that petroleum fuel will continue to be both scarce and expensive had led to renewed interest in the electric drive vehicle. The Congress of the United States has authorized a program, under the direction of the Department of Energy, to expedite development and encourage use of electric vehicles. The Program Manager for the vehicle portion of this program is the Jet Propulsion Laboratory of the California Institute of Technology. They are currently directing analytical and design studies aimed at establishing guidelines for vehicle characteristics to insure that electric vehicles (EV) have dynamic handling characteristics and passenger/cargo accommodations comparable to current internal combustion engine vehicles (ICEV).

This report documents a study, under the direction of JPL, covering the evaluation and selection of components and their location in an electric vehicle in a more nearly optimum manner. Four specific tasks are covered:

- $\quad$ Alternate Battery Locations

Studies consider locations other than the typical tunnel installation on the centerline of the vehicle. Effects of batteries in front, rear, front and rear and under the seats are investigated. Requirements of wheelbase, front and rear overhang and passenger packaging are established.

- Effect of Battery Shape

The effect that battery shape, physical dimensions and number of batteries have in vehicle packaging are studied and evaluated.

- Dynamic and Static Analysis

Static and dynamic analyses are performed to verify that the proposals resulting from the previous studies are acceptable for satisfactory vehicle handling parameters such as directional stabillty and cornering. 
- Battery Support Structure Integration

Design studies are provided to show the integration of the battery support structure into a selected production vehicle. 


\subsection{Alternate Battery Locations}

The optimum location for batteries in an electric drive vehicle is primarily influenced by the following factors:

- Type of vehicle - 2 or 4 passenger - truck

- Size of vehicle

- Type, size and weight of battery

- Number of batteries required to provide the desired performance level

In order to develop an optimum package for the electric drive components of an automotive vehicle it is therefore necessary to establish specifications for the above factors. These were established in a meeting with the JPL technical manager as follows:

- The vehicle is a four passenger car with seating and cargo space equivalent to current U. S. built internal combustion engine sub-compact vehicles. (Wheelbase range of 90 - 100 in.) Handling performance will also be comparable to these vehicles.

- The battery is the Globe-Union EV2-13 lead-acid golf cart type used in the ETV-1 vehicle built for the Department of Energy by G. E./Chrysler. Each battery weighs 60 lbs. and the package size dimensions are:

$$
\begin{array}{lr}
\text { Length } & 10.25 \text { in. } \\
\text { Width } & 7.00 \text { in. } \\
\text { Height } & 10.75 \text { in. }
\end{array}
$$

- The number of batteries to be used is 18 which is the same number provided in the ETV-1. 
The only U. S. built vehicles currently meeting the size criteria are:

- Chevrolet Chevette

- Dodge Omni/Plymouth Horizon

- Ford Pinto/Mercury Bobcat

Pertinent specifications for these vehicles are shown on TABLE 1.

Analysis of these specifications plus an examination of the vehicles led to the selection of the Omni for the base vehicle for this program. The principle reasons for this decision are:

- Both passenger space and cargo volume are better. This difference is very obvious when sitting in the vehicles. It is partially the result of the absence of a drive shaft clearance tunnel down the center of the vehicle which is not apparent from the dimensional differences. The absence of the tunnel is of course the result of using front wheel drive with a front mounted power plant.

- The wider tread of the Omni (approximately $\left.5^{\prime \prime}\right)$ vs Chevette provides significantly greater room and more flexibility for the placement of batteries.

- The front engine/front wheel drive configuration provides superior traction, better directional stability and maximum passenger space for a given vehicle size package.

- The front engine/front wheel drive configuration (Omni configuration) is being adopted for most new small vehicle designs worldwide. It therefore seems appropriate to use this latest type layout as the base for this electric vehicle study.

Additional specifications describing the Omni are shown on TABLE 2. 
TABLE 1

VEHICLE SPECIFICATIONS

SUB-COMPACT SIZE U.S. BUILT MODELS

\begin{tabular}{|c|c|c|c|}
\hline & CHEVETTE & OMNI & PINTO \\
\hline Body & 2-D Hatchback* & 4-D Hatchback & 2-D Hatchback \\
\hline Passenger Capacity & 4 & 4 & 4 \\
\hline Engine Location & Front & Front (Transverse) & Front \\
\hline Drive & Rear & Front & Rear \\
\hline Wheelbase & $94.3 \mathrm{In}$. & $99.2 \mathrm{In}$. & $94.5 \mathrm{In}$. \\
\hline Tread - Front & 51.2 & 56.1 & 55.0 \\
\hline Tread - Rear & 51.2 & 55.6 & 55.8 \\
\hline Length & 159.7 & 164.8 & 170.8 \\
\hline Width & 61.8 & 65.8 & 69.4 \\
\hline Height & 52.3 & 53.5 & 50.5 \\
\hline Front Legroom & 41.5 & 42.0 & 40.2 \\
\hline Front Headroom & 38.1 & 38.3 & 36.9 \\
\hline Front Shoulder Room & 50.1 & 51.7 & 52.5 \\
\hline Front Hip Room & 49.9 & 52.6 & 51.6 \\
\hline Rear Legroom & 30.6 & 33.0 & 30.3 \\
\hline Rear Headroom & 37.3 & 37.4 & 35.7 \\
\hline Rear Shoulder Room & 49.3 & 51.5 & 50.5 \\
\hline Rear Hip Room & 48.8 & 46.4 & 41.3 \\
\hline Cargo Volume & $26.3 \mathrm{cu} . \mathrm{ft}$. & 33.9 cu.ft. & $29.0 \mathrm{cu} . \mathrm{ft}$. \\
\hline Curb Weight & $2026 \mathrm{lbs}$ & 2154 lbs. & 2529 lbs. \\
\hline Front & $1091(53.8 \%)$ & $1340(62.2 \%)$ & $1382(54.6 \%)$ \\
\hline Rear & 935 & 814 & 1147 \\
\hline
\end{tabular}

Data from 1980 MVMA Specifications.

\footnotetext{
*Chevette also makes a 4-D. The 2-D was selected because it had been used in a previous D.O.E. study.
} 
TABLE 2

BASE VEHICLE SPECIFICATIONS

DODGE OMNI 4-Dr. HATCHBACK SEDAN

Wheelbase

Fuel Capacity

Engine

Horspeower

Torque (lb. ft.)

Suspension

Front

Rear

Brakes

Front

Rear

Tires
99.2 In.

13.0 Gal.

4 Cyl. - 1.7 Litre

65

85

MacPherson - Type Independent

Trailing Arm/Strut Independent

Disc

Drum

P155/80R13

Source: Omni Brochure and MVMA Specifications 
The most important single factor in achieving handling characteristics for the EV comparable to the latest ICEV is correct weight distribution. Proper matching of the suspension system and tires is also extremely important but the extent to which these components can compensate for poor weight distribution is limited. Suspension tailoring should be reserved to optimize the handling characteristics of a vehicle which has been designed with inherently good weight distribution. The fundamentals of this weight distribution criteria have been presented in a previous complimentary report* by MGA Research Corporation on the subject of electric vehicle handling. This study emphatically points out the desirability of a front-heavy weight distribution. The Conclusions ( $p$. 134)* state, "A most significant finding resulting from this study concerns the importance of maintaining a front heavy weight distribution on electric vehicles ..... Results ..... consistently indicate that vehicles with a front-heavy weight distribution can tolerate a wide latitude of mass and yaw moment of inertia increase.s without severly compromising handling qualities."

Curb weight distribution of the Omni is 62.2/37.8. Front/Rear weight distributions beyond 55/45 were not covered in the MGA report. However, the MGA percentages were based on sprung weight and a 2 passenger load. Revising the Omni distribution to a comparable condition changed the distribution to 61.1/38.9. Although the Omni provides very good handling characteristics it was decided to target the electric vehicle optimum curb weight distribution at a nominal $58 / 42 \mathrm{front} / \mathrm{rear}$ in order to provide some latitude for variation in a particular design. It is recognized that front engine/front wheel drive inherently produces the heavier front distribution of the Omni and this weight bias is typical of this type of vehicle layout. Although handling characteristics are slightly different, when properly designed, modern front drive vehicles have very good handling characteristics. Total weight on the front wheels of course must be limited because of the steering effort which makes this layout most appropriate for small light vehicles.

Weights of the electric drive components as supplied by JPL are shown on TABLE 3. The weights of the corresponding internal combustion engine components are shown on TABLE 4. They were obtained from an analysis** conducted by Pioneer Engineering for the Department of Transportation. Locations of the components were determined from a quarter-size vehicle layout supplied by the Chrysler Corporation and are shown in FIG. 1. Base vehicle weight distribution was established as shown on TABLE 5 .

\footnotetext{
*An Analytical Study of Electric Vehicle Handling Dynamics, MGA Research Corporation No. G8006, JPL Contract No. 955312. **Weight Study 1978 Chrysler Omni, DOT-TSC1045.
} 
TABLE 3

ELECTRIC DRIVE COMPONENT WEIGHTS - LBS.

Motor System:

237 lbs.

Motor

Misc. Drive Components

217 lbs.

20 lbs.

Transmission/Differential:

48 ibs.

Controller (microprocessor):

8 lbs.

Speed Control System:

117 lbs.

Pnwor Conditioning Unit

Misc. Power Components

$97 \mathrm{lbs}$ :

14 lbs.

On-Board Charger

6 lbs.

117 ths.

Batteries:

$1080 \mathrm{lbs}$.

TOTAL:

1490 lbs.

TABLE 4

BASE VEHCLE WEIGHTS - LBS.

INTERNAL COMBUSTION ENGINE COMPONENTS

Base Engine

194.40

Engine Accessories

54.27

Engine Electrical

39.10

Transaxle

80.28

Clutch Pedal \& Linkage

Exhaust System

26.42

Fuel Systèm

18.42

Fingine nil

6.10

Transmission Oil

$2.4 n$

Coolant Fluid

13.29

Gasoline

78.52

TOTAL

514.49

27.63

Spare Tire (Removed because relocation required) 
TABLE 5

BASE VEHICLE WEIGHT DISTRIBUTION - LBS.

\begin{tabular}{lccc} 
& FRONT & REAR & TOTAL \\
Omni Curb Weight & 1340 & 814 & 2154 \\
Less: & & & \\
Power Plant & 396 & $(30)$ & 366 \\
Radiator & 29 & $(4)$ & 25 \\
Exhaust System & 7 & 19 & 26 \\
Fuel System & 19 & 78 & 97 \\
Spare Tire & $(3)$ & 31 & 28 \\
\hline & 448 & 94 & 542 \\
Base Vehicle & $82.6 \%$ & $17.4 \%$ & 1612
\end{tabular}




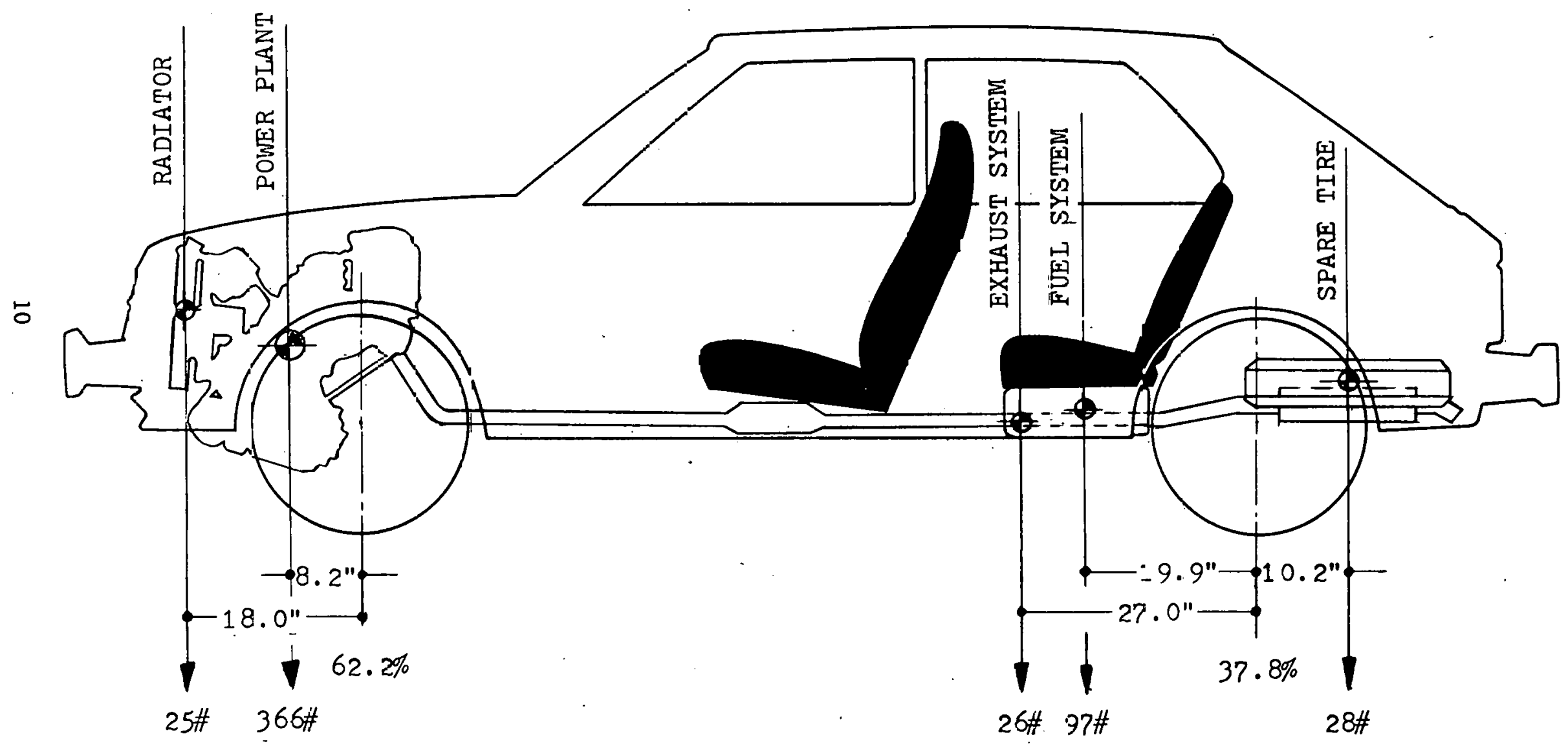

Figure 1 INTERNAL COMBUSTION ENGINE AND DRIVE COMPONENT LOCATIONS - DODGE OMNI 
Since the electric drive components are approximately three times as heavy as the corresponding I.C.E. units their front weight percentage must be less than the $82.6 \%$ of the I.C.E. units in order to achieve the vehicle target weight distribution of 58/42. The required distribution is:

$\begin{array}{lcc}\text { FRONT } & \text { REAR } & \text { TOTAL } \\ 892 & 720 & 1612 \\ & & 1490 \\ & & 3102 \\ & & \\ 1800(58 \%) & 1300(42 \%) & \\ 892 & 720 & 1490 \\ 910 & 580 & \\ 61 \% & 39 \% & \end{array}$

The above percentages apply only to the selected base vehicle and must be adjusted for the individual vehicle design weight and the relationship of electric component weights to vehicle weight.

Assuming complete flexibility and front power plant/front drive, the distribution of the electric drive components would be:

$\begin{array}{lccc} & \text { FRONT } & \text { REAR } & \text { TOTAL } \\ \text { All Electric Components } & 910 & 580 & 1490 \\ \text { Power Plant and Controls } & 410 & 0 & 410 .\end{array}$

Battery Weight

1080

$(910-410)$

500

(1080-500)

580

No. of batteries (approx.)

8

10

18 
This type of distribution is shown schematically in FIG. 2. Unfortunately, a uniform distribution of weight around each axle centerline cannot be achieved, as shown in FIG. 3 , without increasing the size of the vehicle - increasing wheelbase by moving front wheels forward and rear ones backward. Since, this would not be within the established ground rules other approaches needed to be considered. A total of 14 installation design studies were made utilizing the $1 / 4$ size vehicle layout provided by Chrysler Corporation the builder of the Omni. These were all based on the front power plant/front drive layout and considered all feasible combinations of battery locations including:

- Batteries divided in several combinations between front and rear of vehicle.

- Batterica divided in several combinations between front, tunnel and rear of vehicle.

Several variations of motor/drive position and control units position were also included. Other factors to be considered were the space envelopes available for batteries at front and rear of vehicle, location of suspension and steering components and the basic structure of the vehicle. Analysis of these studies indicated one combination which best met all the desired criteria of:

- Cürb weight distribution of approximately $58 / 42$ front/rear.

- Batteries combined in a minimum number of packages to facilitate the derign of as light. nnd compaot mounting strueturés as pussible.

- Battery groups positioned to provide ease of installation and removal for servicing.

- Battery positions to be compatible with current levels of passenger protertion in impacts.

$n \quad$ No intrugion of hatteries or uther clcctric drive cumponents in passenger or cargo compartments.

The optimum layout is shown in FIG. 4. As indicated, the desired curb weight distribution for handling (58/42) was achieved. 
$£$ FRONT WHEEL

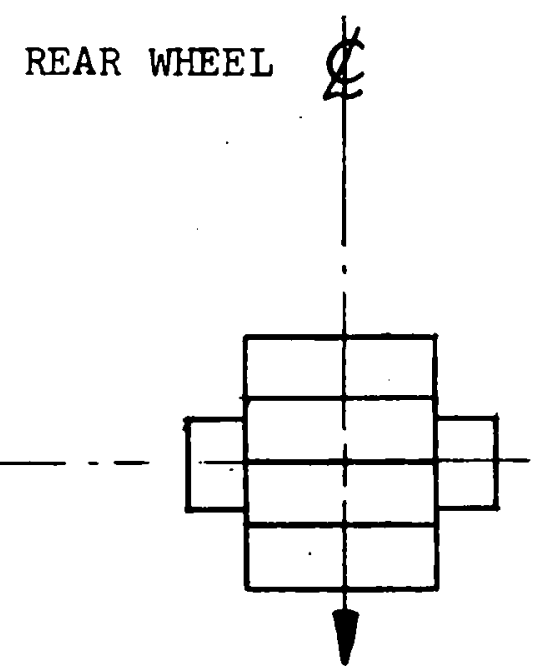

8 BATTERIES

10 BATTERIES

$480 \#$

$600 \#$

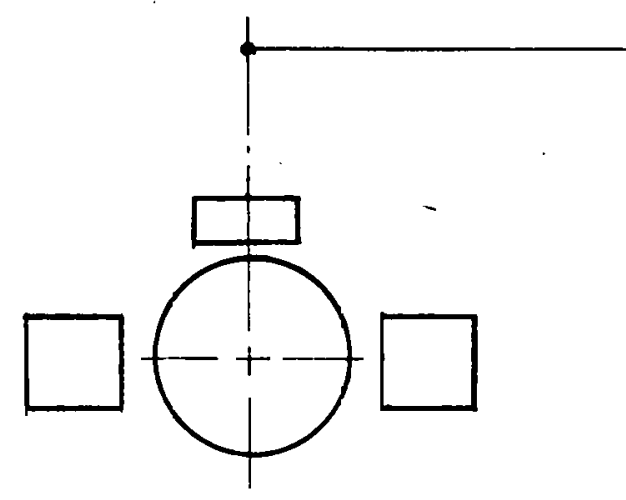

WHEELBASE

$59.7 \%$

$40.3 \%$

Figure 2 THEORETICAL DISTRIBUTION OF ELECTRIC

COMPONENT WEIGHTS 

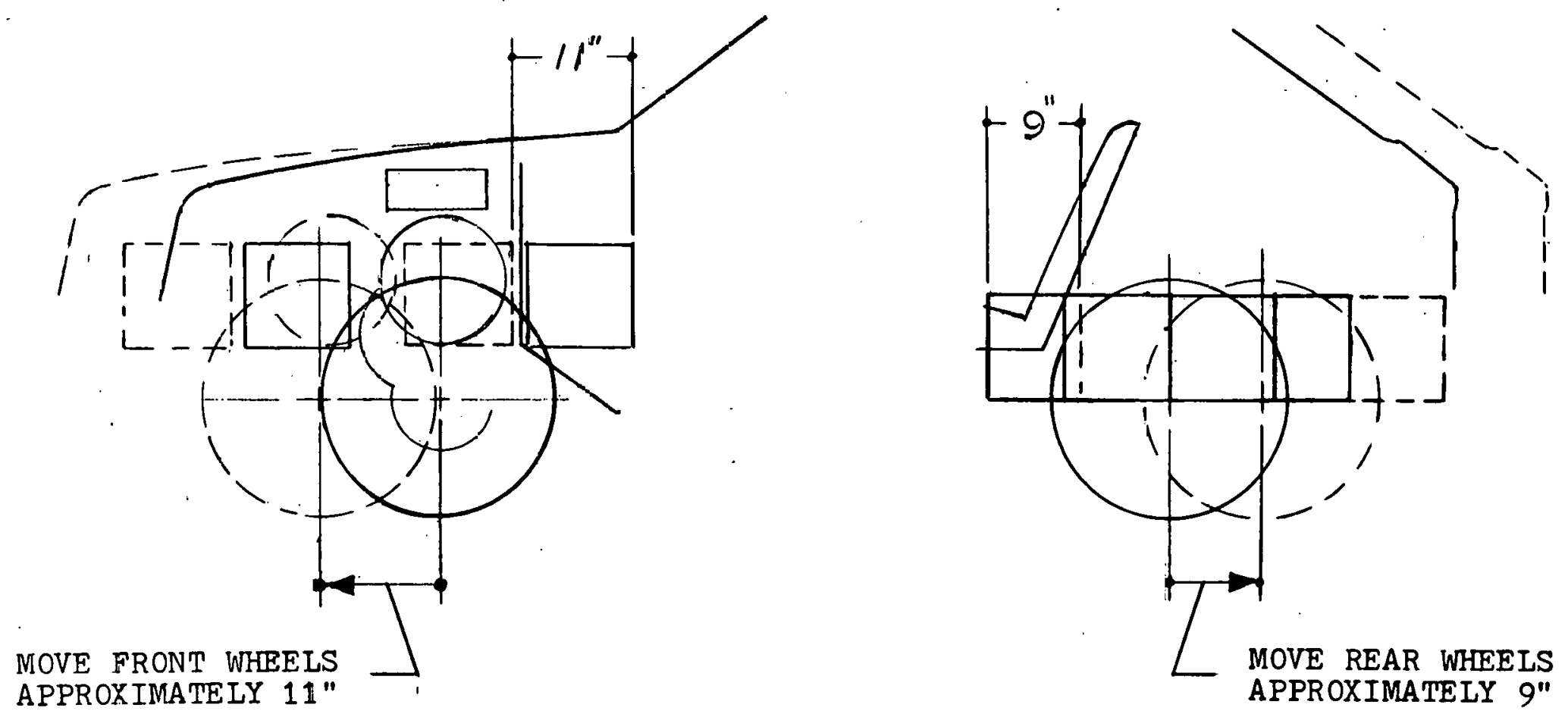

Figure 3 VEAHICLE INTERFERENCES WITH THEORETICAL WEIGHT DISTRIB JTION 

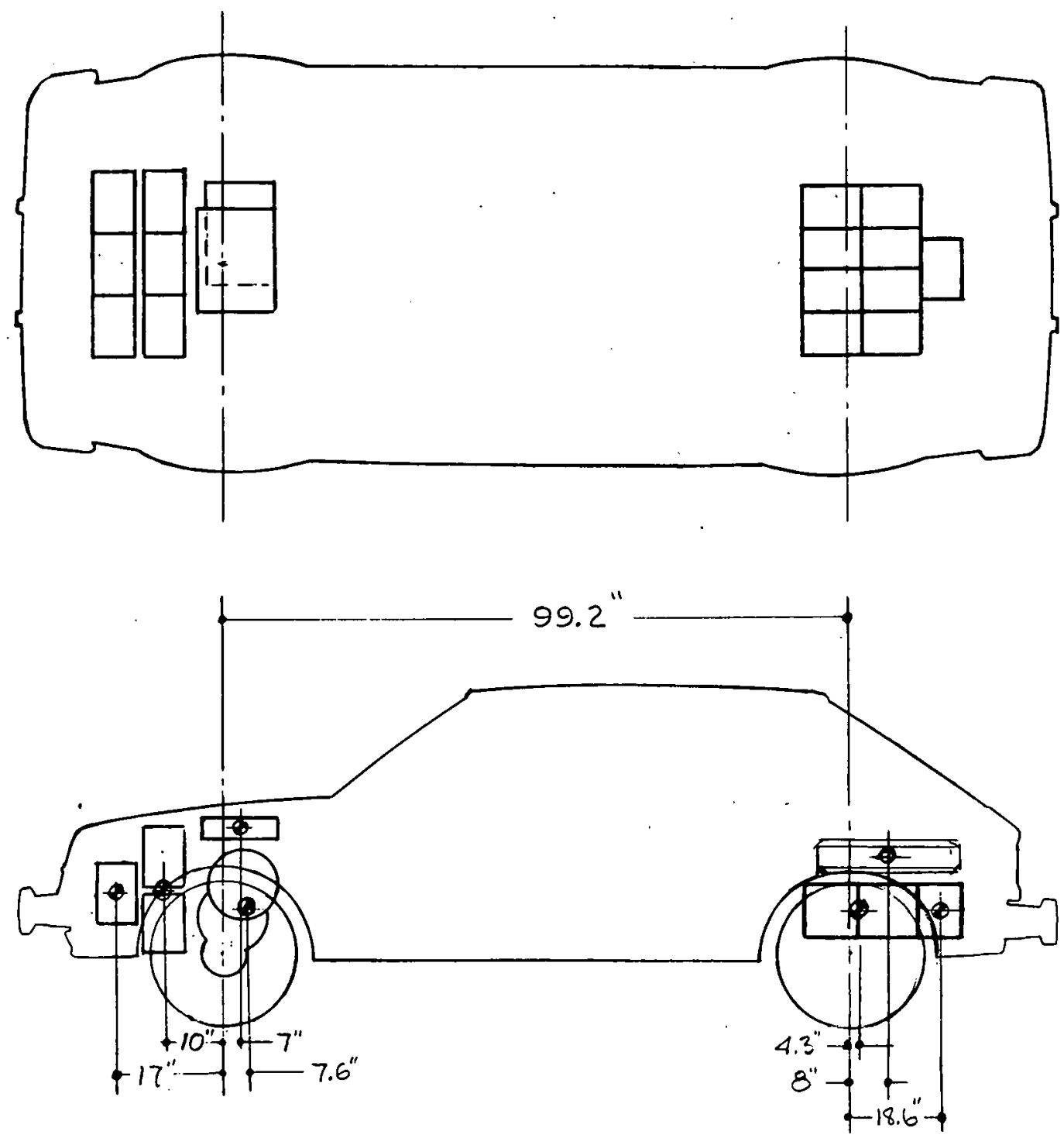

WEIGHT DISTRIBUTION

FRONTT REAR

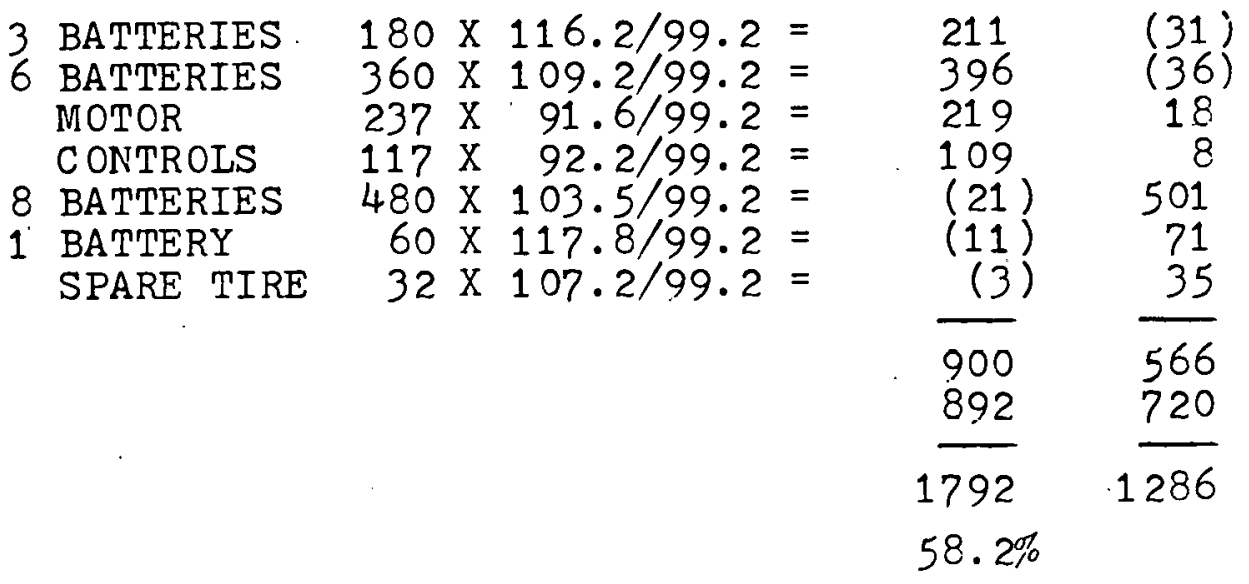

Figure 4 OPTIMUM ELECTRIC VEHICLE LAYOUT 
However, to achieve the optimum distribution, it was necessary to place approximately half the additional weight of the electric vehicle on the front wheels. This increased front loading by 460 lbs. and will result in a high level of steering effort. The problem is compounded by the larger front tires required to carry the increased load. The front weight will be further increased by the addition of the battery supporting structure which has not been considered in the preliminary analysis. The resultant manual steering effort will be marginal at best. This condition points up one of the most serious problems facing the electric vehicle designer until a substantial reduction in battery weight is achieved. In the interim, a compromise between optimum handling characteristics and steering effort will be necessary since power steering does not appear to be a viable option - lack of a suitable power source.

In order to minimize the impact on steering effort, it was decided to investigate. an alternate layout which would provide a better compromise between handling and steering effort. A front/rear distribution of 54/46 was selected. as a target. Most I.C.E. vehicles today operate in this range - the Chevette for example is 53.8/46.2. Therefore, no serious handling deficiencies would be anticipated.

The optimum layout at this distribution is shown in FIG. 5. The 53.4/46.6 front/rear distribution should provide handling within the current envelope of acceptable handling characteristics and will reduce the weight on the front wheels from 1800 to 1650 lbs. While this is only about half the desired amount of reduction (experience indicates a maximum target value of 1500 lbs, on the front wheels) it is the best somprnmise. achievable with a $3100 \mathrm{lb}$. vehicle. This compromise again points to the need for reduced battery weight. While some weight reduction in the base vehicle and electric drive and control units can be anticipated, an optimum balance between handling and steering effort cannot be achieved without a significant reduction in battery weight.

The front battery installation in this alternate layout is improved since only 6 batteries in front allows the units to be mounted in a single plane thus simplifying and lightening the support structure. The lower level of batteries in the original layout also would be vulnerable to impact damage unless a guard was provided at a further weight penalty. Rear installation is complicated because of the added length of the battery pack and more vehicle structural changes are required. It should be pointed out that this is a minor problem associated with the conversion vehicle and should not be a problem with a new unique electric vehicle design. 


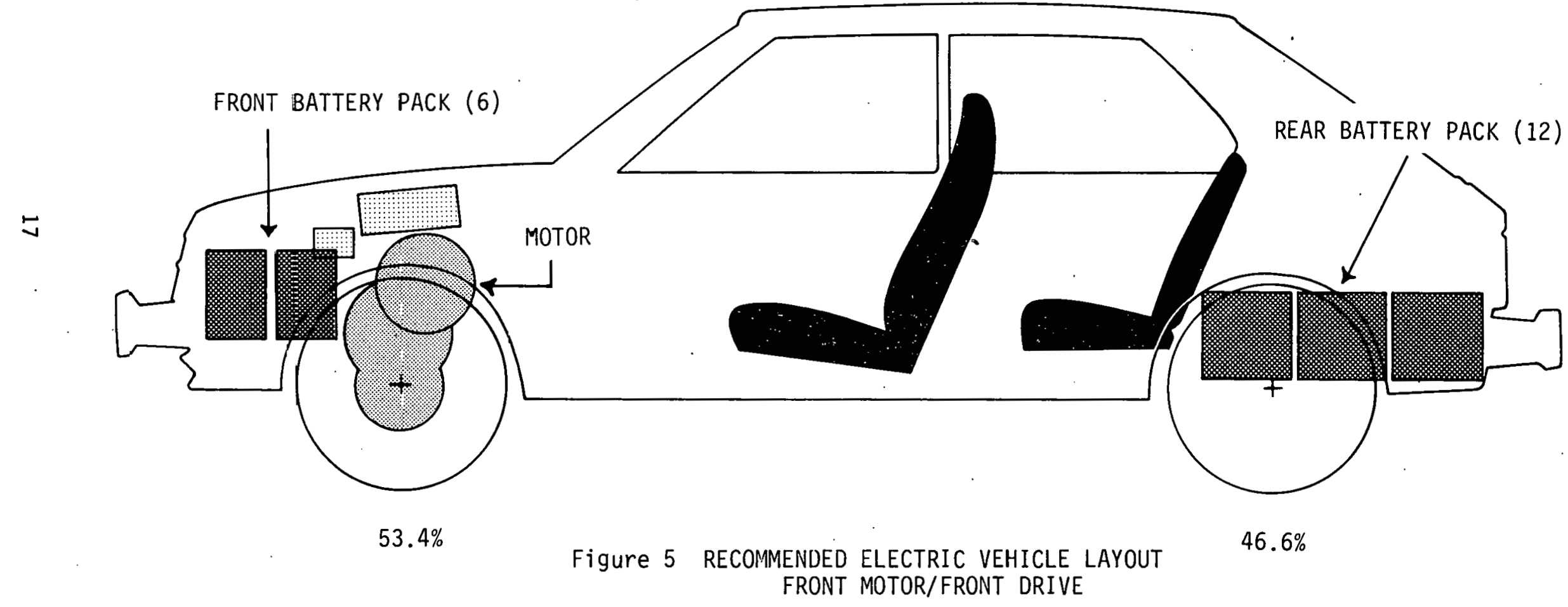


The layout, FIG. 5, is therefore recommended as the optimum for electric vehicles of this size and weight. The exact position of components in the layout would not necessarily apply to a new vehicle design. Only the guidelines of 54 to $60 \%$ front weight distribution and weight on the front wheels as light as possible (1500 lbs. target) are basic to a new design.

It will be noted that the layout, FIG. 5, does not provide for a spare tire. It is anticipated that a "run-flat" tire will be commercially available by the time this layout will be avallable in vehicle form. The additional space required and the added weight of a spare do not seem compatible with this urban use vehicle. For anyone insisting on a spare, one of the current "minimum use" light weight spares could be accommodated flat on the cargo compartment floor, FIG. 6. The addition of the spare would decrease front weight distribution by about $0.6 \%$ but only decrease the load on the front wheels by 2 lbs. It would obviously decrease the usefulness of the cargo compartment.

While the recommended layout, FIG. 5, meets the objectives and criteria established for the optimum electric vehicle layout it was recognized that other power plant/drive arrangements had not been analyzed. Therefore, several additional studies were completed to compare the merits of these alternatives.

The first studies utilized a rear power plant/rear drive. In order to keep the electric drive components from intruding into the cargo compartment, the motor had to be positioned behind the rear axle which produced a negative reaction on the front wheels. Reactions were:

FRONT $-(26$ lbs. $)$
REAR

311 lbs.

In order to achieve the desired 61/39 distribution (p. 10) of electric components it would therefore be necessary to group all batteries at the front of the vehicle. However, a symmetrical disposition of batteries about the axle cannot be achieved as discussed previously. The required shift of batteries forward results in an excessively high front distribution. Therefore, it was necessary to place some of the batteries at the rear. Available space limited the number to 3 . The optimum layout of three studies made 


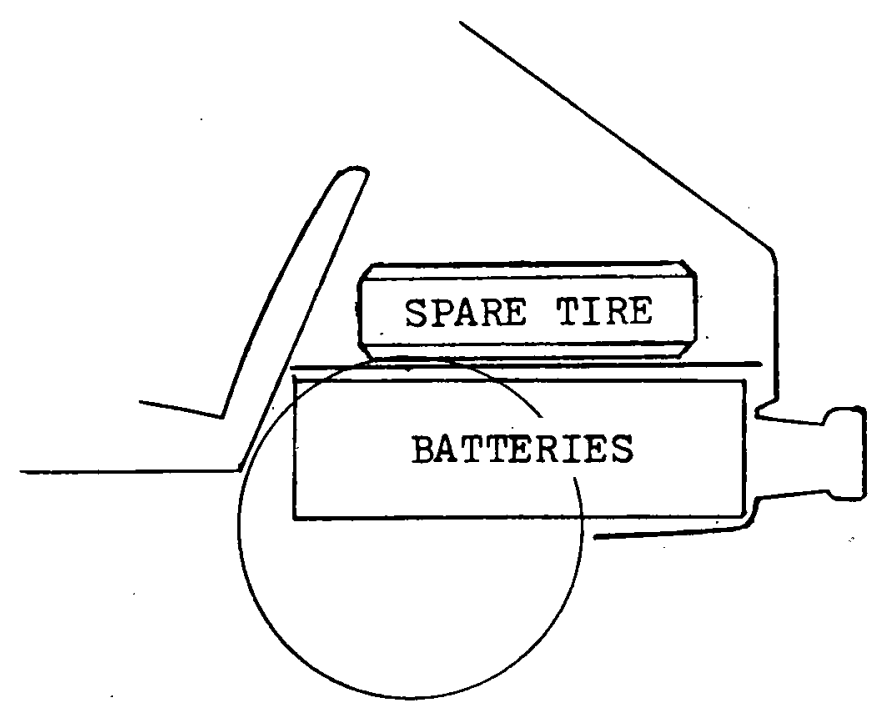

Figure 6 OPTIONAL SPARE TIRE LOCATION 
with this arrangement of components is shown in FIG. 7. This arrangement is not recommended for the following reasons:

- The front weight distribution of $62 \%$ is considered excessive for a rear drive car.

- Traction would be poor (only $38 \%$ of weight on driving wheels).

o Directional stability with rear drive would not be as good as with front drive. - Manual steering effort would be excessive - 1925 lbs. on the front wheels.

The other alternate studied utilized a front power plant with rear drive - a so-called "conventional" drive because it has been the standard layout for American I.C.E. cars. Only one feasible layout was achieved. As shown in FIG. 8, it was possible to achieve an acceptable weight distribution of $56 / 44$ front/rear. However, this type layout is not recommended for the following reasons:

- Traction is $21.0 \%$ less than with a front drive of the same weight distribution.

- Directional stability is not inherently as good as with a front drive layout.

o Manual steering effort would be high - 1770 lbs. on the front wheels.

o The need for a drive shaft to connect the power plant and rear axle results inl:

o A weight increase of approximately $60 \mathrm{lbs}$.

- A hump in the floor down the center of the car to provide clearance for the drive shaft. The presence of this hump or tunnel seriously intrudes into passenger space in a car of this size. The effect of the tunnel can be demonstrated by sitting in a Chevette and then in an Omni.

o The location of the speed control system under the cargo compartment floor limits accessibility for service. 


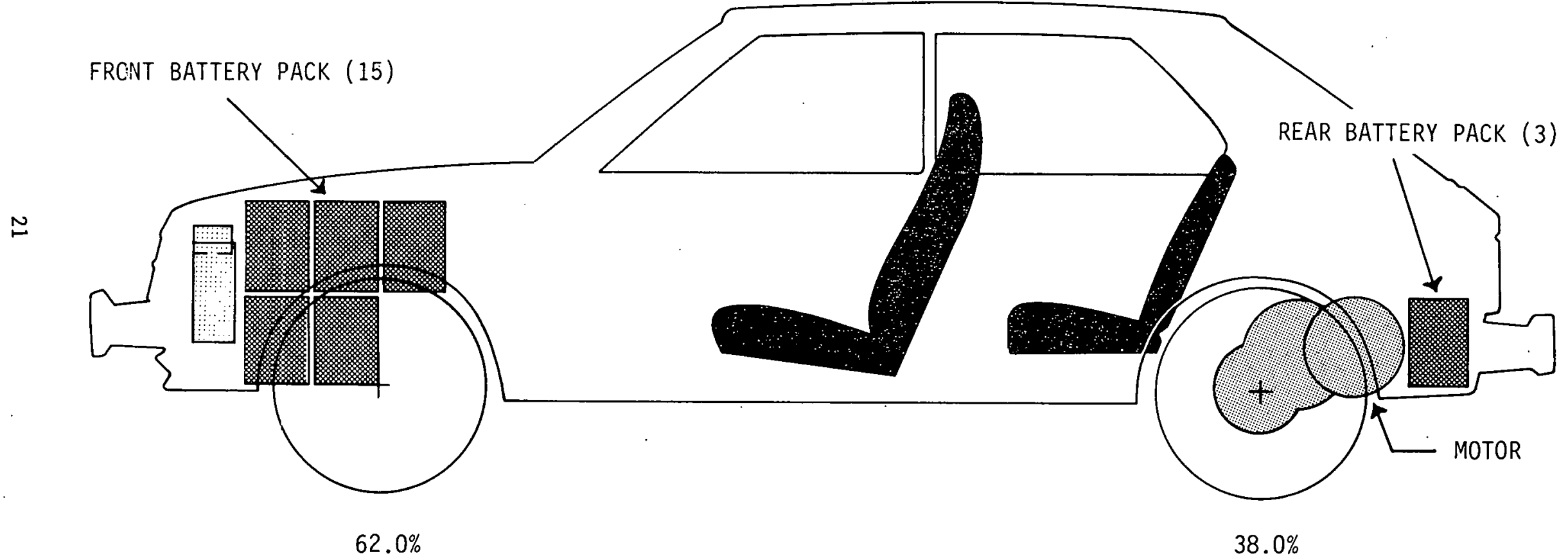

Figure 7 REAR MOTOR/REAR DRIVE LAYOUT 


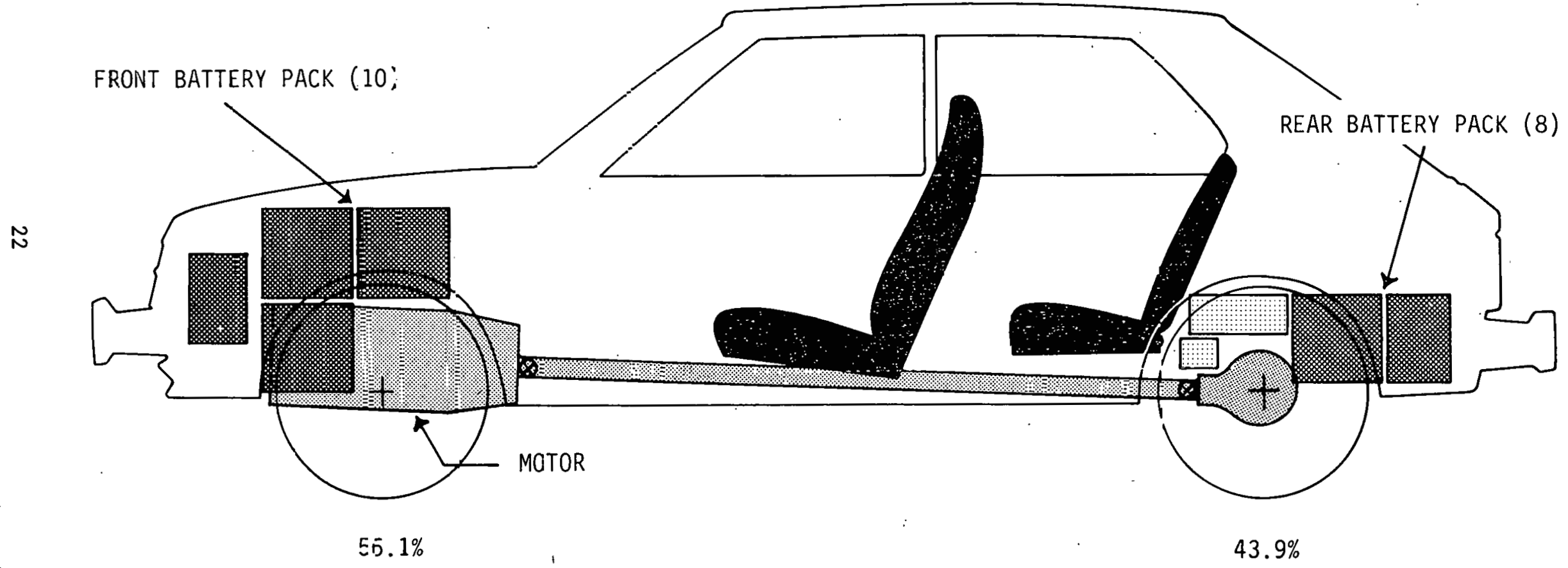

Figurie 3 FRONT MOTOR/REAR DRIVE LAYOUT 
The recommended optimum layout for electric drive vehicles is therefore the front power plant/front wheel drive configuration shown in FIG. 5. This layout generally meets all desired criteria. The minor exceptions uncovered in the final half size studies are:

o A concave depression in the dash must be provided for motor clearance, FIG. 9. This is above the normal foot position and therefore would not reduce leg room. It would require modification of the heater ductwork. In a new vehicle design it should be possible to design the front sheet metal to eliminate this condition.

- There is a slight interference between the speed control box and the motor. If the internal components cannot be rearranged to accommodate the revised area then a new box shape adapted to the available space would be necessary.

- To prevent possible damage to the batteries from ground objects, it was necessary to raise the floor of the cargo area approximately $6 "$. While this reduces total cargo volume it does result in a flat floor with the rear seat back folded down. An added guard structure would decrease the intrusion to about $3^{\prime \prime}$ but would add undesirable weight and increase rear weight distribution.

The basic configuration is equally suitable for utilization of an existing vehicle design or a completely new unique electric vehicle design. 


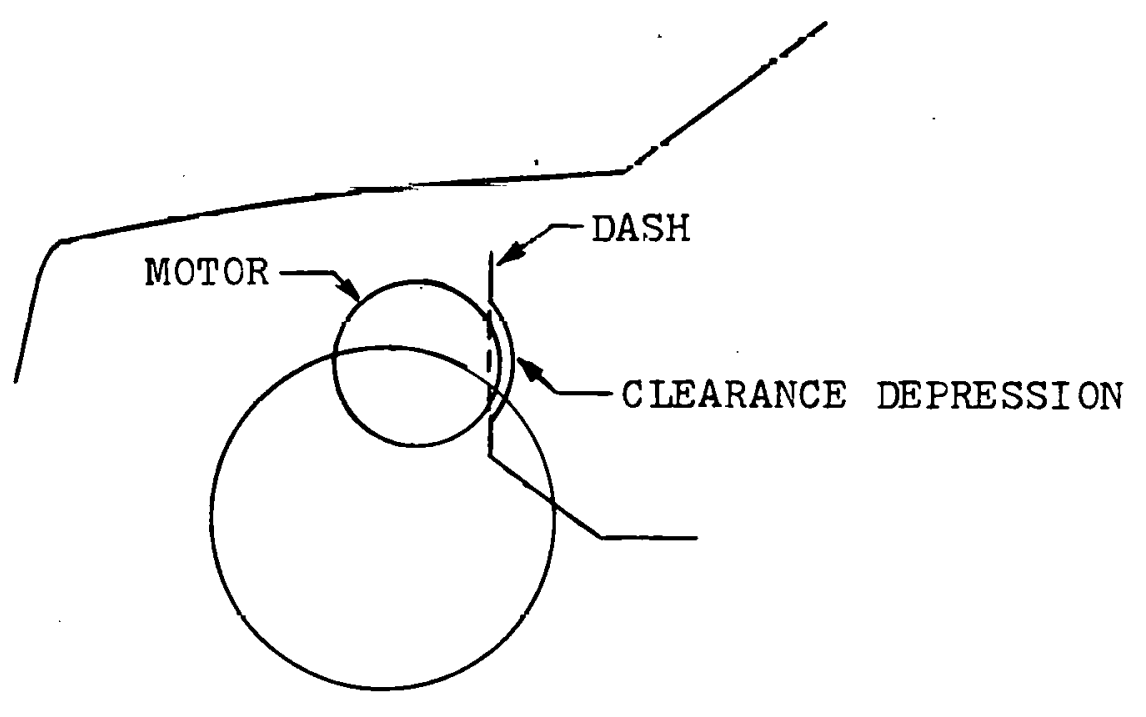

Figure 9 ELECTRIC MOTOR CLEARANCE REQUIREMENT. 


\subsection{Effect of Battery Shape}

The foregoing study to optimize battery locations from the standpoint of vehicle packaging (passenger and cargo space) and handling was conducted with the battery used for the ETV-1. (Globe-Union lead-acid EV2-13).

Extensive development work is being conducted on improving the energy/weight ratio of vehicle batteries of both the lead acid and alternate types. Because these batteries could have sizes considerably different from the current lead-acid and thus affect the packaging studies previously conducted, a separate study was made to establish what variation is size could be anticipated and what the packaging implications would be.

Because of the extensive development work in progress and the many organizations involved, it was decided to obtain a recommendation from the Argonne National Laboratory as to the most promising types to consider for near-term application (1980-1985). Argonne is the Program Manager for the Department of Energy on electric vehicle battery development.

The characteristics of the battery types recommended for consideration by Argonne are shown on TABLE 6. All of the listed types have dimensions and weights different from the original battery used. The number of batteries required per vehicle as specified by Argonne is based on maintaining a constant weight package and utilizing all increase in energy density to improve vehicle performance. The package weight selected by Argonne is about 100 lbs. heavier than that used for the base vehicle study which further increases the undersirable ratio of battery weight to vehicle weight.

Because of the variety of sizes and weights, Argonne was requested to recommend one battery from each type which they considered to have the greatest near-term potential for improved energy density. The selected units are identified on TABLE 6 . A comparison of sizes between the selected units and the base lead-acid type is shown in FIG. 10.

A comparison of the packaging requirements for the different types, maintaining the base lead-acid weight distribution as closely as possible, is shown in FIG. 11. The maximum space availability for battery packaging in the Omni base vehicle is shown 
TABLE 6 CAARACTERISTICS OF BATTERY TYPES

$\begin{array}{lclrr}\text { BATTERY TYPE } & \text { DIMENSIONS } & \text { WEIGHT } & \text { ENERGY } & \text { NUMBER } \\ \text { AND MANUFACTURER } & \text { L X W X H } & \text { (lbs.) } & \text { (WH) }\end{array}$

LEAD-ACID (Baseline)

Globe-Union

LEAD-ACID (Improved)

ESB

Eltra

(2) Globe-Union NICK EL-IRON

N

(2) Westinghouse

$10.25 \times 7.00 \times 10.75$

60

890

18

$\begin{array}{llll}10.48 & \times \quad 7.20 \times 11.44\end{array}$

$10.40 \times 7.20 \times 10.96$

$13.20 \times 15.24 \times 11.80$

62.5

104?

19

61

1062

19

160

$\therefore: 328$

7

NIFE

$10.44 \times 7.24 \quad$ K 11.44

$\begin{array}{lllll}10.44 & \square & 7.24 \quad \mathrm{X} \quad 11.44\end{array}$

$9.20 \times 7.76 \times 15.75$

$11.92 \times 7.12 \times 13.20$

$10.92 \times 7.12 \times 15.68$

$11.20 \times 6.92 \times 10.44$

$10.24 \times 7.12 \times 11.36$

Gould
ESB
Y ardney

(1)Based on approximate constant battery weight per vehicle

(2) Selected for packaging studies 
BASELINE LEAD-ACID
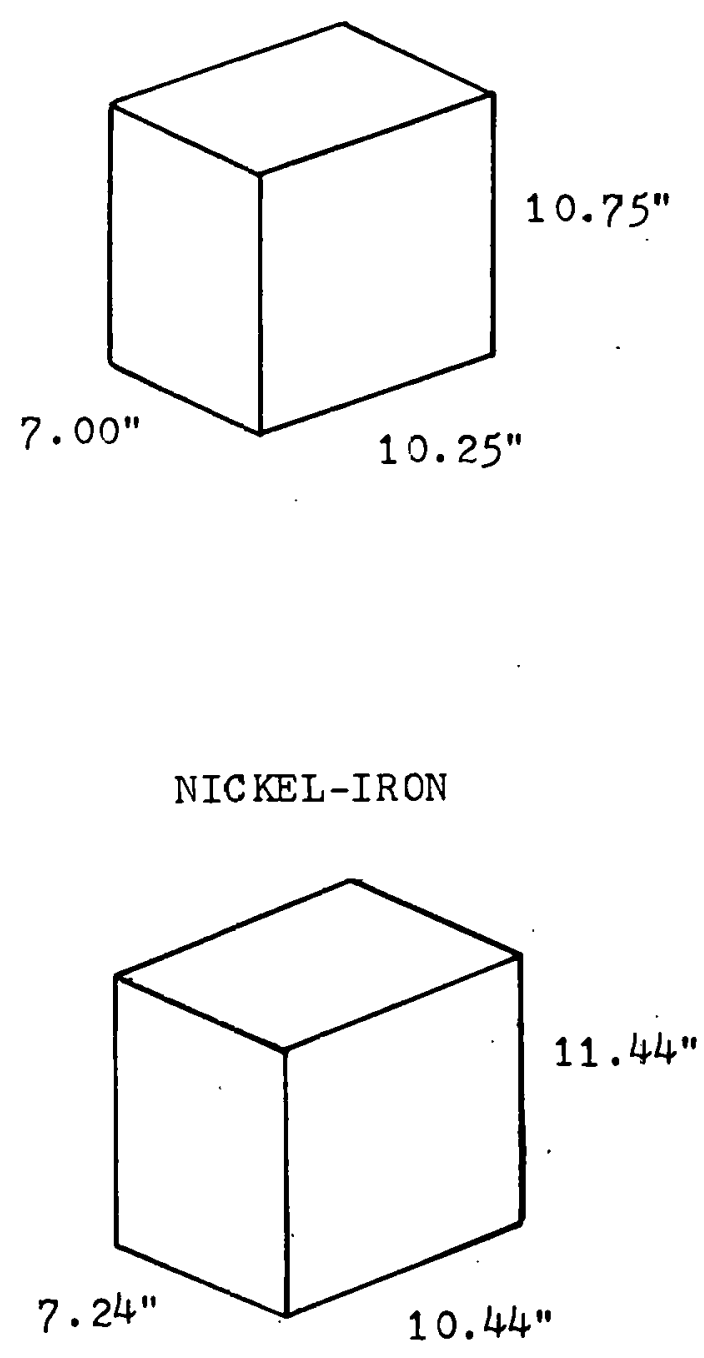

IMPROVED LEAD-ACID

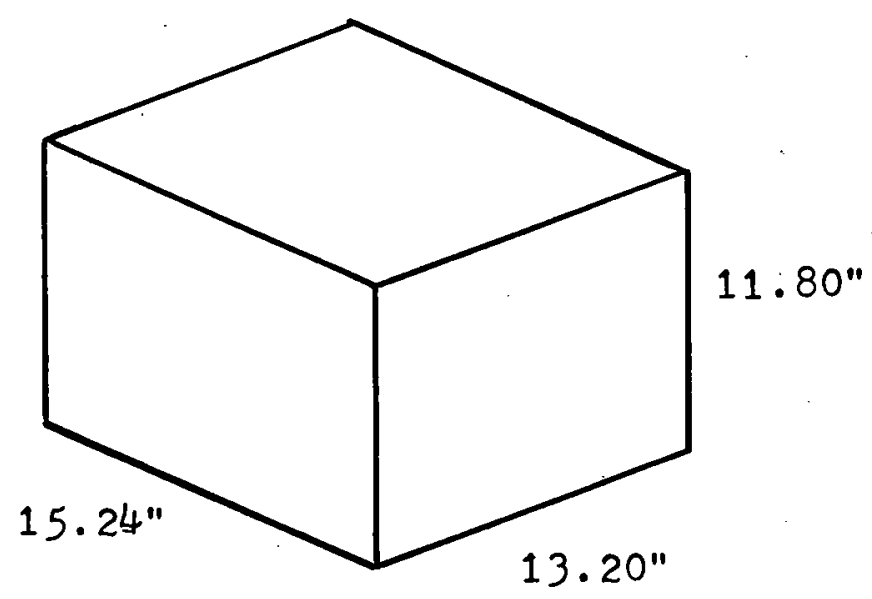

$13.20^{\prime \prime}$

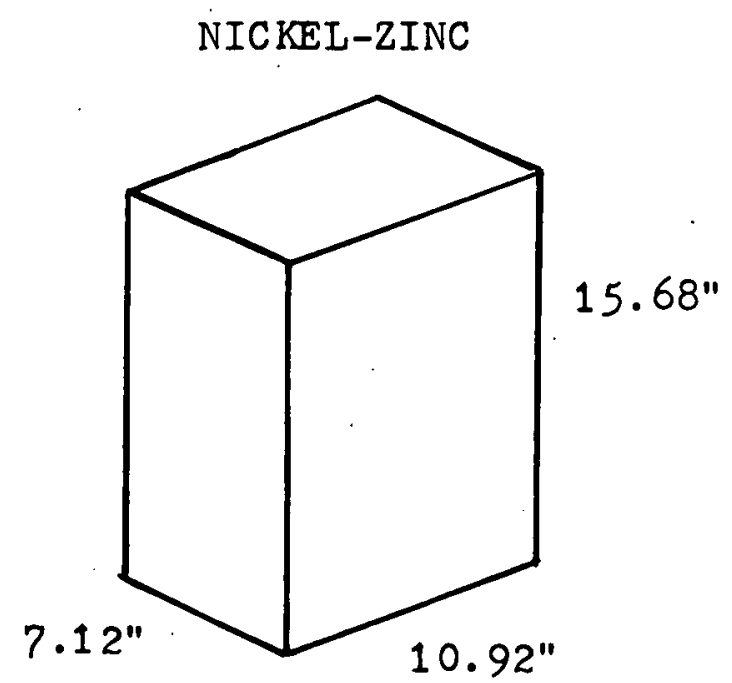

Figure 10 BATTERY SIZE COMPARISON 

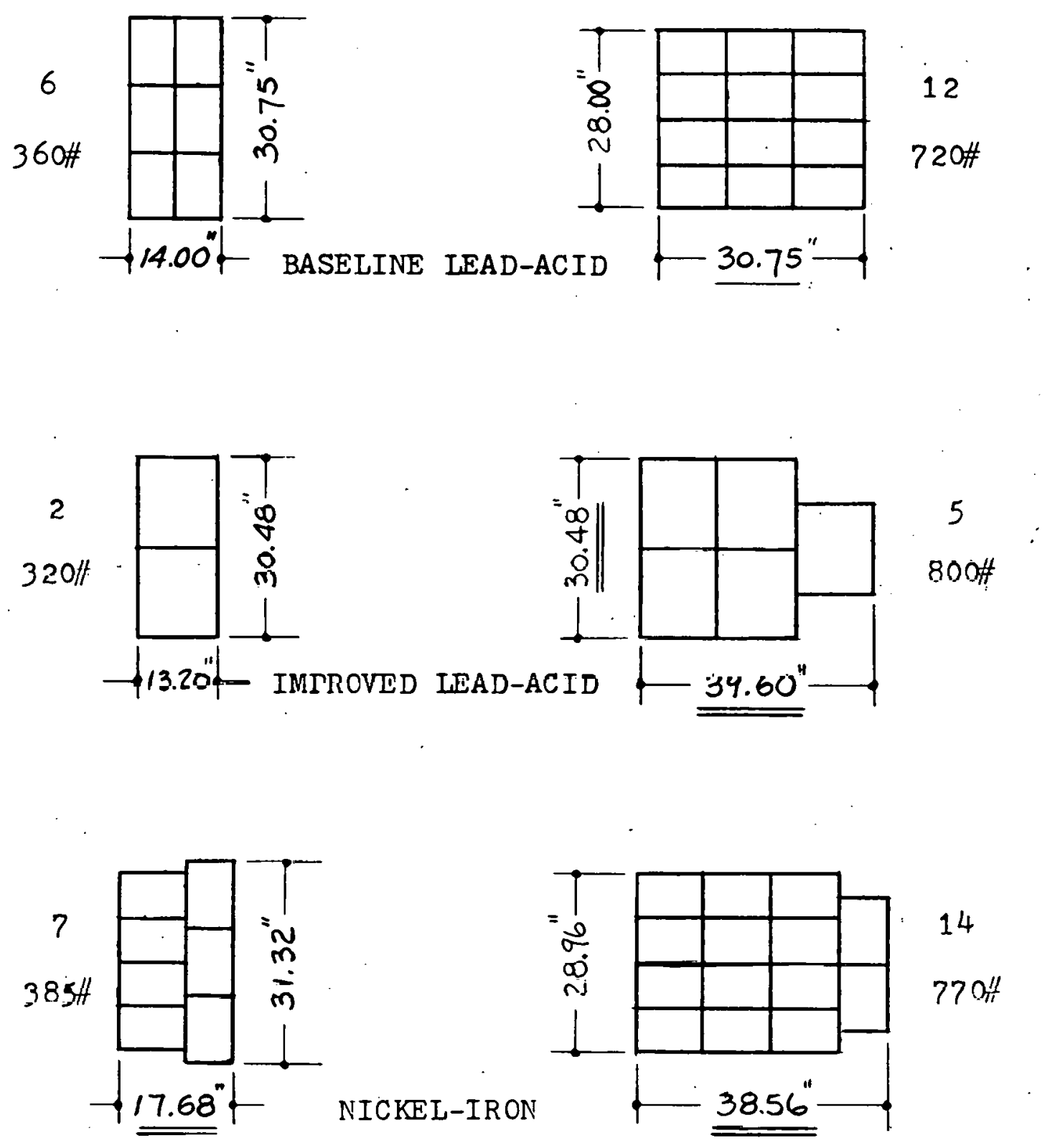

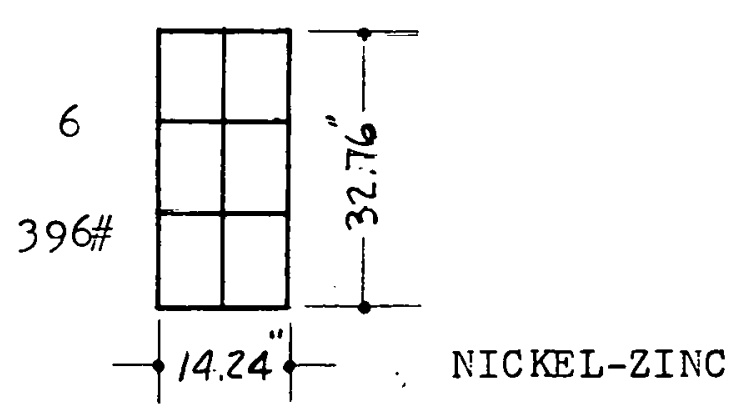

FRONT

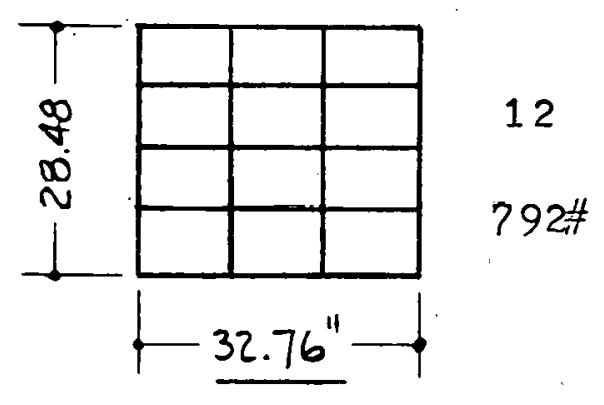

REAR

Figure 11 BATTERY PACKAGING COMPARISON 
in FIG. 12. Only the baseline lead-acid type can be packaged in the specified quantities in the space available. Furthermore, weight distribution is adversely affected with all the alternate types. The package dimensions which exceed the available space are underlined in FIG. 11. The small deviations could be accommodated with minor structural revisions but those with double underlining would require a major increase in vehicle length to accommodate them or the rear seating positions would have to be eliminated. Neither are considered acceptable for the vehicle package under consideration.

With regard to future battery sizes, the space available in the Omni would appear to be the maximum that can be anticipated in a vehicle size suitable for electric drive. The wheelbase at 99.2 is a maximum for the sub-compact size vehicle (90-100 in. wheelbase) and the tread at 56 in. also appears to be a practical maximum. Increase of wheelbase or tread also increases vehicle weight resulting in performance loss. The transverse front mounted engine and front wheel drive provide a maximum of passenger space for this size vehicle and it does not seem desirable to sacrifice passenger space for battery storage space. It appears, therefore, that future battery development should be directed toward module (single battery) size and quantities which can be packaged in the space shown in FIG. 12.

Part of the packaging problem encountered with the alternate battery types is the result of the number of modules specified. The installation could be achieved by reducing the gain in total energy and thus reducing the number of batteries required. Analysis of the battery characteristics (TABLE 6) indicated that the battery with the greatest potential for energy gain within the space available is the Nickel-Zinc type under development by Gould. It was agreed in a revlew with the JPL Tcchnical Manager that this would be the only type to be. considered for further packaging studies in this program.

Several possible combinations were analyzed and the best compromise is shown in FIG. 13. The number of battery modules is reduced from the specified 18 to 14 which reduces the total energy of the battcry set from $32,400 \mathrm{WH}$ to $25,200 \mathrm{WH}$. This still provides a $57.5 \%$ gain in energy vs the $16,000 \mathrm{WH}$ of the base lead-acid type and also provides a $156 \mathrm{lb}$. reduction in weight for the battery set vs. the base line package. The gain in energy per vehicle weight is therefore: 
FF:ONT

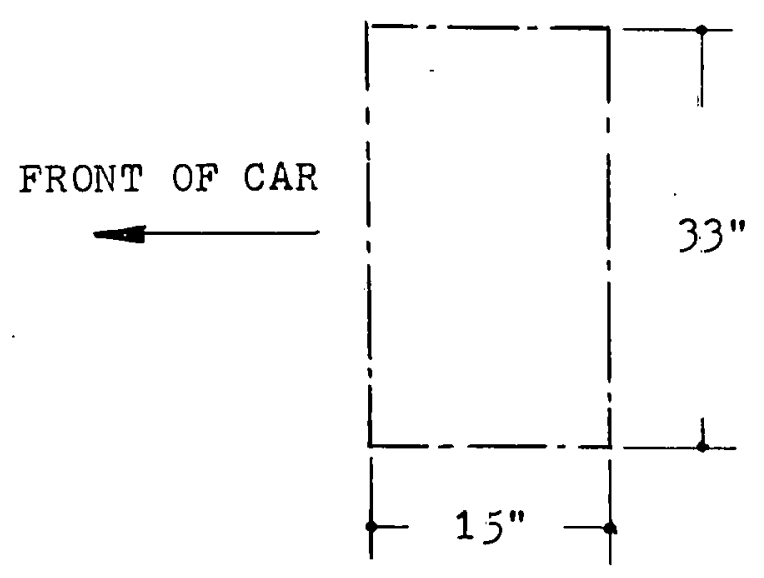

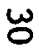

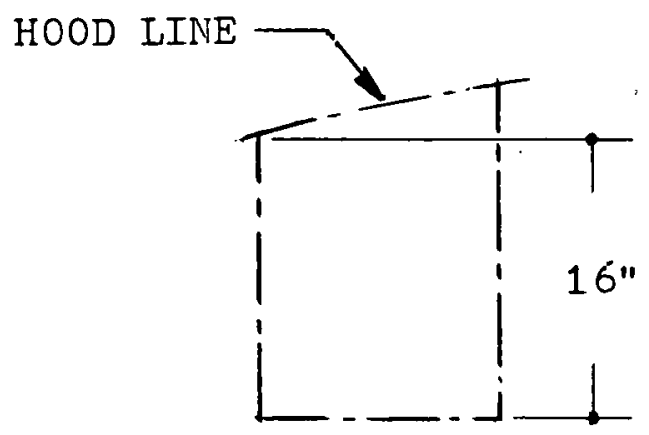

REAR
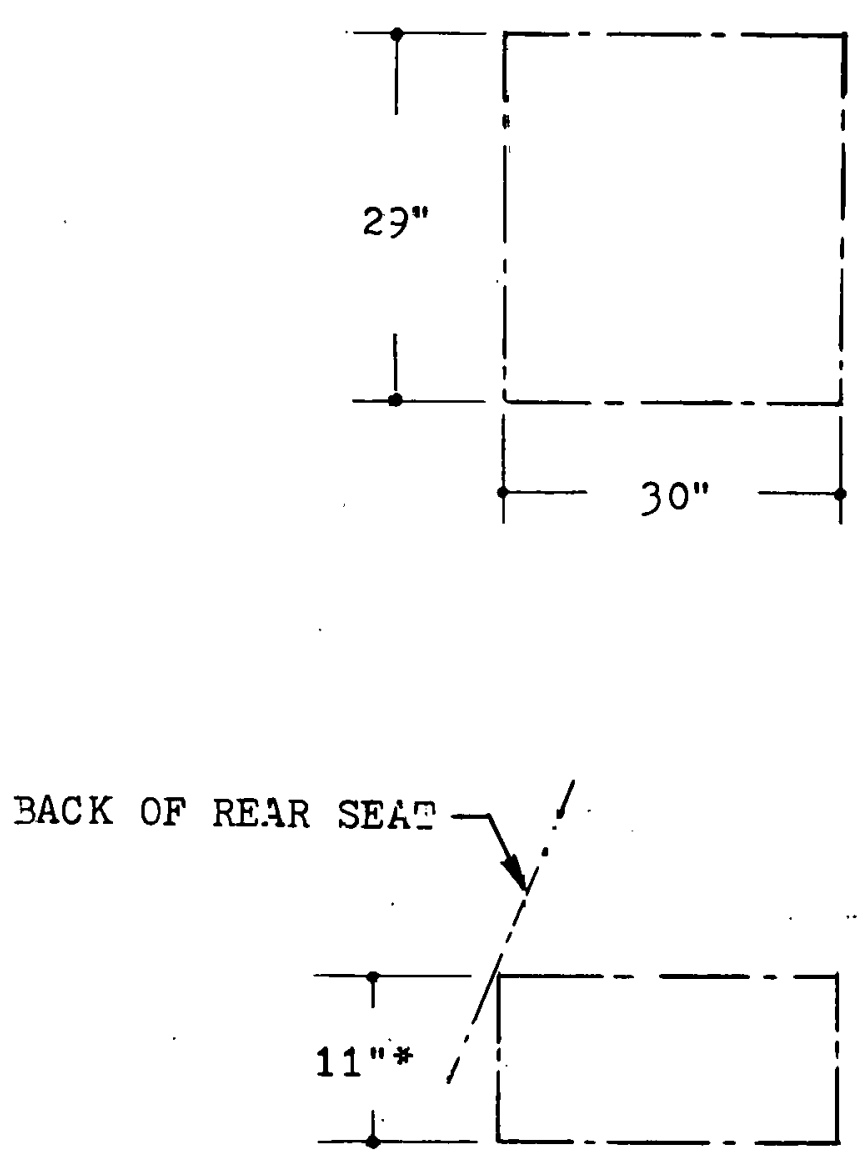

* REQUIRES RAISINg CARGO COMPARTMENT FLOOR 6" 


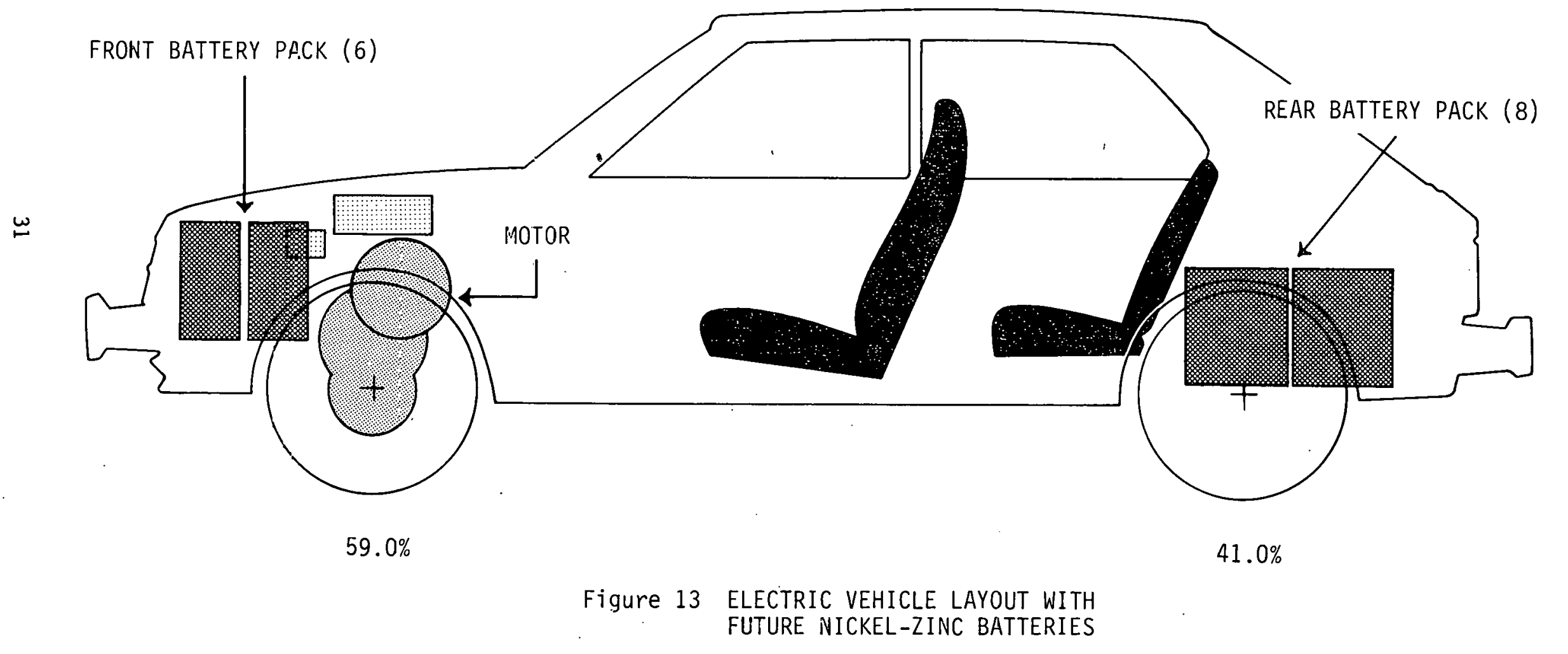




$$
\begin{aligned}
& \frac{16000}{3102}=5.15 \mathrm{WH} / \mathrm{lb} . \\
& \frac{25200}{3102-156}=8.55 \mathrm{WH} / \mathrm{lb} . \\
& \frac{8.55-5.15}{5.15}=0.66 \% \text { gain }
\end{aligned}
$$

In spite of the reduction in number of batteries recommended by Argonne, a two-thirds improvement in watt hours per pound of vehicle weight can be accomplished plus an acceptable installation package can be achieved. This would appear to be a deșirable compromise.

From the previous analysis it is apparent that battery module size is extremely important to the optimizing of electric vehicle component packaging. The present lead-acid module size of approximately $10 \times 7 \times 11$ in. (L. X $W \times H$ ) is optimum for installation in a current production vehicle conversion and furthermore would also be optimum for unique electric vehicle designs since additional hattery space could only be achieved by additional vehicle size and weight. Therefore it is recommended that future battery development be directed toward a module size similar to the current lead-acid type. Other dimensional configurations are possible if the total battery set can be effectively grouped in the spaces designated in FIG. 12 . It is essential that front and rear battery mounting areas be utilized since an acceptable vehicle weight distribution cannot be achieved with batteries located at only one end of the vehicle. It is also important that a major improvement in battery energy/pound be achieved so that the proportion of battery weight to vehicle weight be reduced.

The optimum battery mounting locations for the nickel-zinc type in the front and rear of the vehicle are bașed on use of a combination of battery modules simllar in total volume requirement to the current lead-acid. In the many location studies conducted no other suitable locations were found.

A final analysis of the effect of battery shape involved the potential for using more radical module configurations. Two areas sometimes mentioned for battery location are under the floor and in the sill. Neither of these locations would appear to have any future potential. The space under the floor as shown in FIG. 14, does not have adequate height in a small car to accommodate batteries. Battery heights 


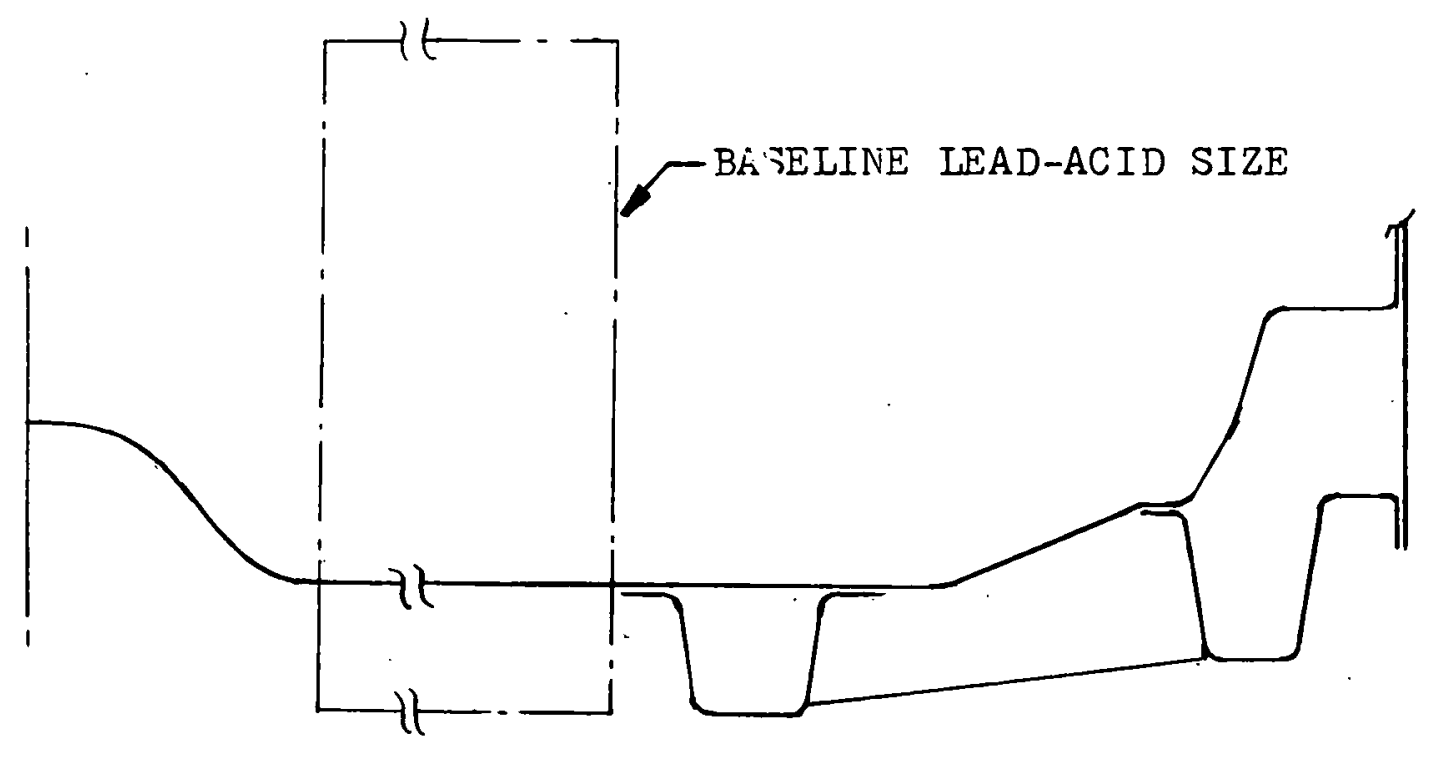

FRONT FLOOR
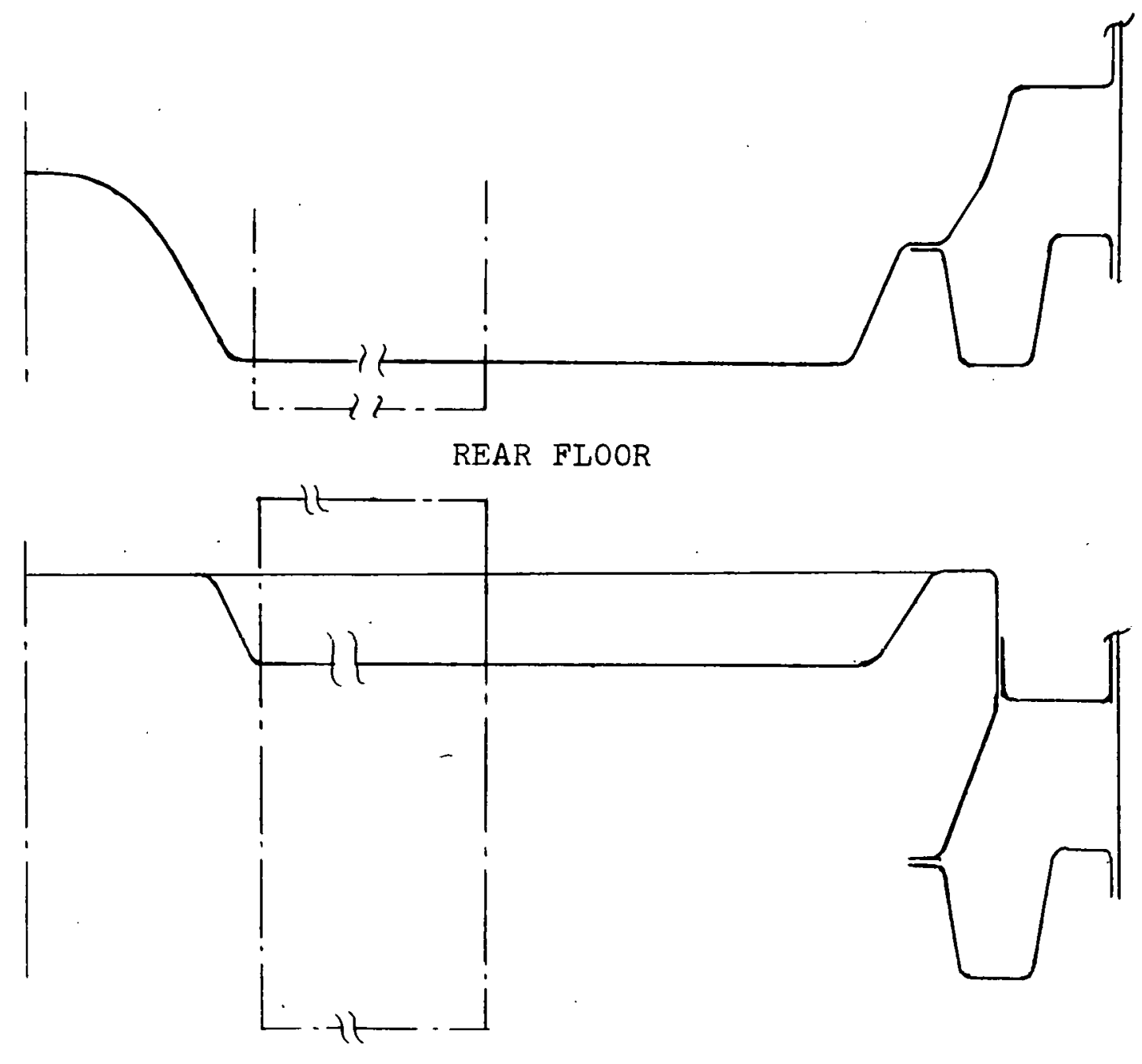

UNDER REAR SEAT

Figure 14 UNDERFLOOR BATTERY MOUNTING CONDITIONS 
of 2" are obviously not practical and a portion of the area (rear seat foot well) has even less height. The only practical area would be under the rear ser ${ }^{+}$which is limited to about $3800 \mathrm{cu}$. in. Compared to a volume requirement of $14,000 \mathrm{cu}$. in. for the lead-acid package and 17,000 cu. in. for the nickel-zinc, this area would not warrant serious consideration as it could only be used as a third pack complicating the packaging problem and adding to weight. Furthermore, since it would limit the battery height to about 6", the total battery area requirement would be increased and packaging further complicated. A reduction of battery height is not considered feasible by battery development groups since the top and bottom structures of the module are relatively fixed dimensions and reducing height reduces the working height of the plates and electrolite which cannot be recovered effectively by larger area. The module therefore becomes increasingly inefficient as height is decreased and structure and therefore weight are increased. This relationship is exactly the opposite from the goal of the battery developers which is to increase the efficiency of the module at reduced weight.

Raising the floor height to accommodate a higher battery module would decrease legroom or raise car overall height and weight - both undesirable results. Furthermore, to accommodate an efficient battery module height, floor height would have to be raised about $9 "$ " an impractical amount to raise the car height from the standpoint of appearance and entry and exit as well as weight. In addition, current battery weight in this position (under the floor) results in a distribution of $61 \%$ front with $A$ resultant front weight of about 1900 lbs. As previously discussed this is unacceptable for steering effort. Some batteries would still have to be mounted under the cargo compartment floor. This approach is not recommended for consideration unless some. major breakthrough in battery construction and internal operation occures.

Mounting batteries in the sill would seriously restrict entry and exit conditions and passenger seating space. FIG. 15 shows the increase in sill height and width required to uccommodate a practical battery module. Furthermore, the available volume would still only be about $6000 \mathrm{cu}$. in. - less than half of the requirement for a lead-acid module and one third for a nickel-zinc. Some batteries would still have to be mounted in both front and rear areas to maintain proper weight distribution. Because of the negative effects on comfort and convenience without improvement in battery packaging, this approach is not recommended. 


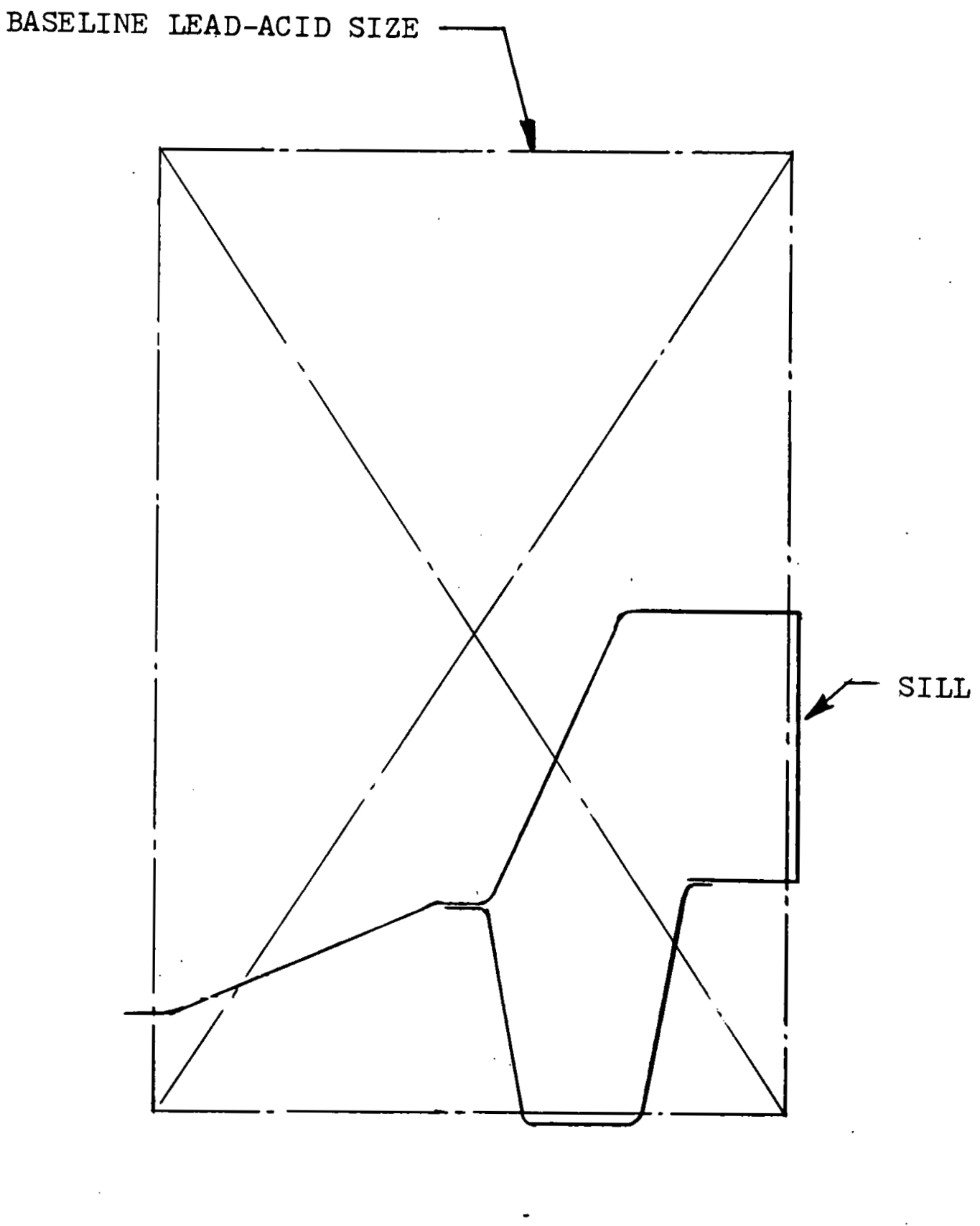

Figure 15 SILL BATTERY MOUNTING CONDITIONS 


\subsection{Dynamic and Static Analysis}

In order to verify that the selected electric vehicle layout would be acceptable for dynamic handling characteristics, an analytical study was conducted by MGA Research Corporation. MGA had previously conducted an analytical study of electric vehicle handling dynamics under contract to JPL (Contract No. 955312). The program utilized was a computer simulation of two basic vehicle dynamic maneuvers:

- Trapezoidal Steer Input - This maneuver characterizes the transient response of a vehicle to a suddenly applied steer input of a specific angle. The steering angle is held constant after the rapid input. An initial velocity of 40 MPII is used. Tle magnitune of steer angle can be incrcascd until the limit of laterial adhesion is reached resulting in either a plowing condition (understeer), laterial drift (neutral steer), or spin out (oversteer). For the purpose of comparison in this analysis steer angles were not increased to the limiting condition.

- Sinusoidal Steer Input - This input simulates a rapid lane change steering maneuver and consists of two symmetrically opposite steering angle inputs. Initlal speed is $45 \mathrm{MPH}$ and the stecring input is defined as a sine wave with a period of 2 seconds and various angular amplitudes.

These maneuvers are recognized in the vehicle dynamics field as being indicative of the handling characteristics of a vehicle encountered in normal driving situations. However, it is important to recognize that vehicle handling qualities are highly subjective in nature and it is difficult to determine by simulation whether a given vchiclc will handle "good" or "bad" cxecpt in a general sense. Pioduulion passcngcr cars exhibit a wide range of dynamic characteristics and the development of a vehicle requires design compromises in several areas including handling. The handling characteristics of the selected EV configurations were therefore evaluated by comparing recognized dynamic response values with those of the base vehicle using the same control inputs. The evaluation was therefore relative to a production vehicle which possesses handling qualities suitable for the general public. 
MGA's experience in the dynamics field also provided them with the necessary expertise to statically evaluate various vehicle characteristics with respect to their effect on vehicle handling. Eighteen possible electric vehicle component installation studies were reviewed with MGA, all of which were based on using the Dodge Omni base vehicle. Two were selected by static characteristics analysis as representing the range of weight distribution that would be expected to reflect good EV component packaging while at the same time providing acceptable vehicle handling characteristics. (i.e., similar to the Omni.) One of the configurations " $N$ " utilized the optimum approach from a packaging standpoint (Ref. FIG. 4) and has a weight distribution close to that of the base vehicle. The other layout "J" has batteries located in the tunnel area as well as front and rear. The two were selected to provide not only a range of weight distribution but also the effect of battery distribution in the vehicle.

The engineering characteristics of the Omni base vehicle required for the handling simulations were obtained from the Chrysler Corporation. The dynamic handling characteristics of the base vehicle and the two selected electric drive derivations were then evaluated by means of the computer simulation program.

In both of the selected simulated maneuvers the two EV configurations performed in a manner generally similar to the base car. It was necessary of course to revise suspension spring rates and provide appropriate tires to accommodate the additional weight of the electric vehicles. While configuration " $N$ " (weight distribution closest to base vehicle) responded in a manner more similar to that of the base car than configuration "J", there is really no significant difference in their dynamic characteristics. Both electric vehicles were within the response characteristics envelope of current production vehicles. Responses of the vehicles to the simulated trapezoidal maneuver at steering inputs of $2^{\circ}$ and $8^{\circ}$ are shown in FIG. 16. Responses to the sinusoidal inputs of $2^{\circ}$ and $8^{\circ}$ are shown in FIG. 17. Additional comparisons of the relative responses of the EV proposals compared to the base vehicle in the trapezoidal maneuver are shown in FIGS. 18 thru 22. FIGS. 20, 21 and 22 indicate the performance levels to be not only similar but within the envelope of existing production vehicles. Additional comparisons of responses in the sinusoidal maneuver are shown in FIGS. 23 and 24. Again response characteristics are generally similar to the base vehicle and within production vehicle limits. A more complete discussion of the theory and comparitive results of these simulations will be found in the complete report of MGA on their work which is provided in APPENDIX A. 


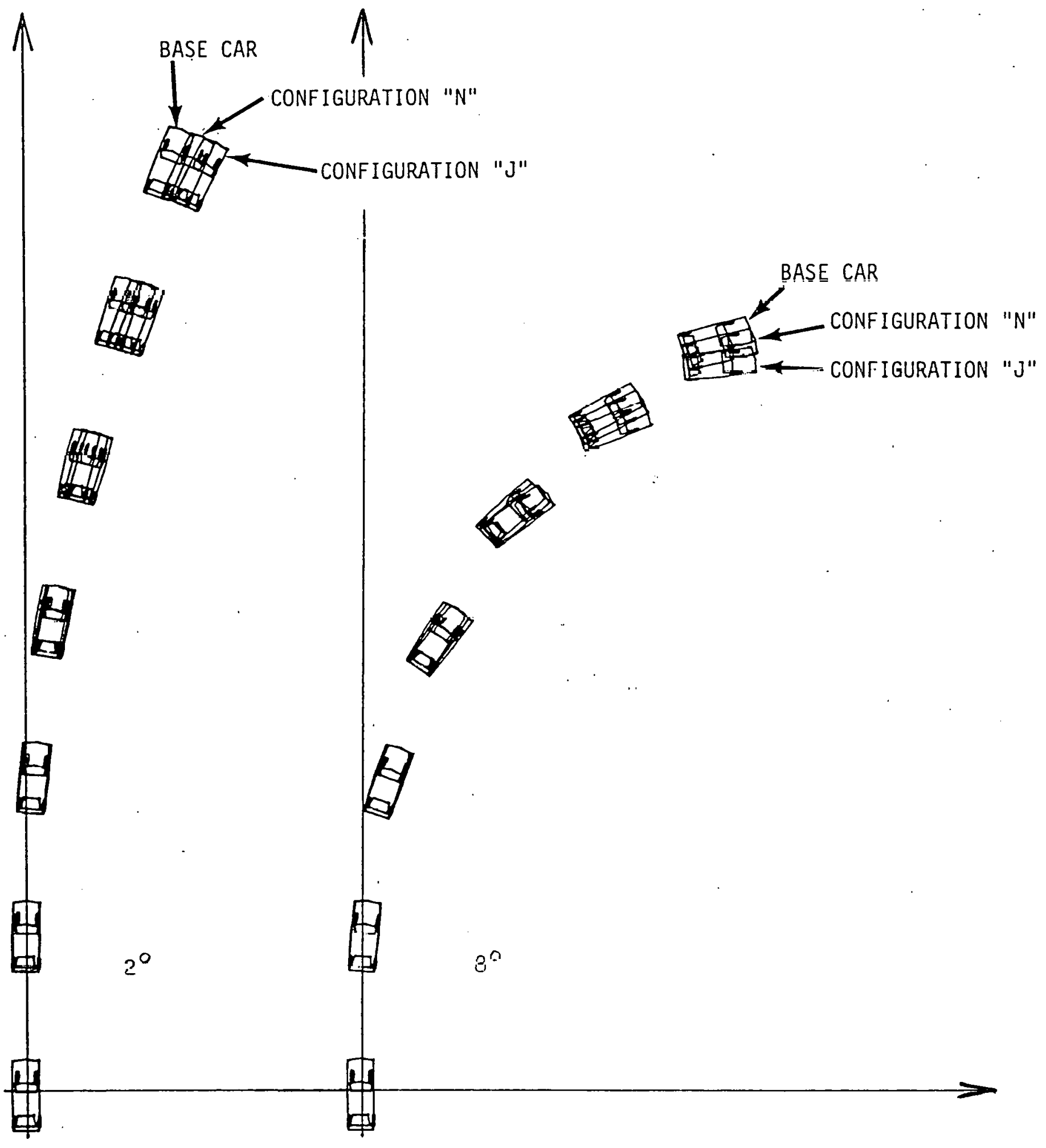

Figure 16 RESPONSE TO TRAPEZOIDAL STEER INPUT 


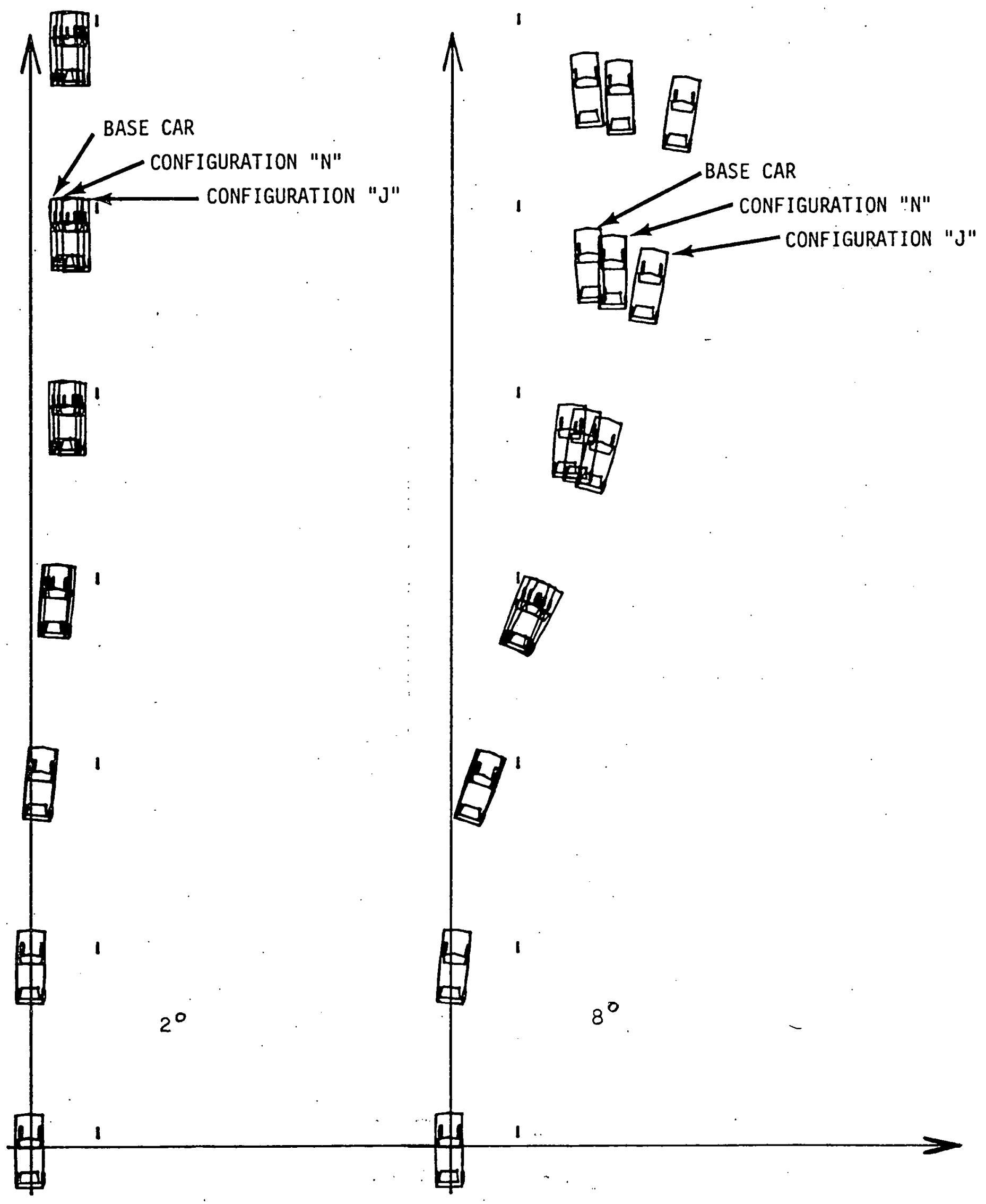

Figure 17 RESPONSE TO SINUSOIDAL STEER INPUT 


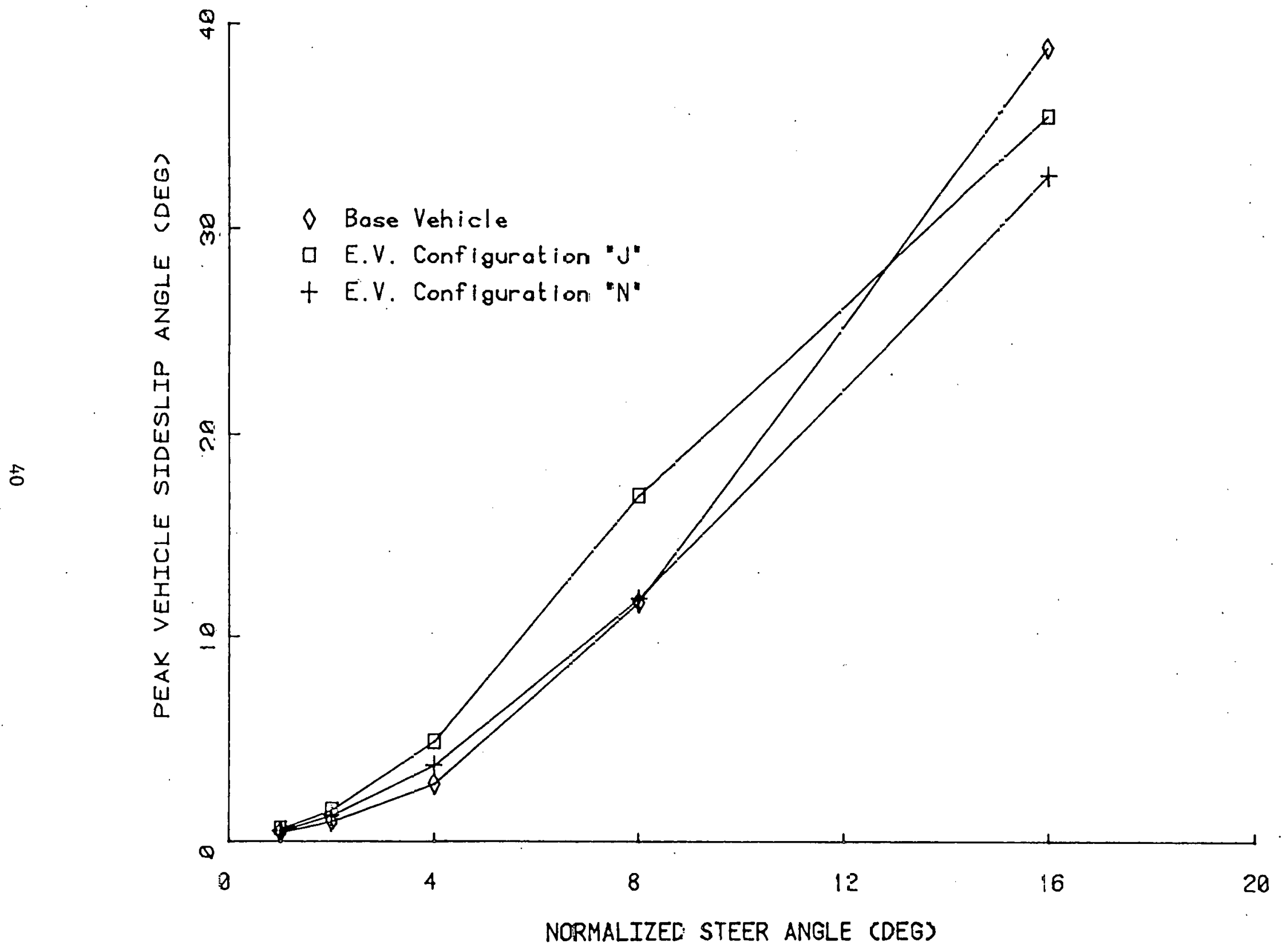

Figure 18 RESFONSE CHARACTERISTICS IN TRAPEZOIDAL STEER MANEUVER - 


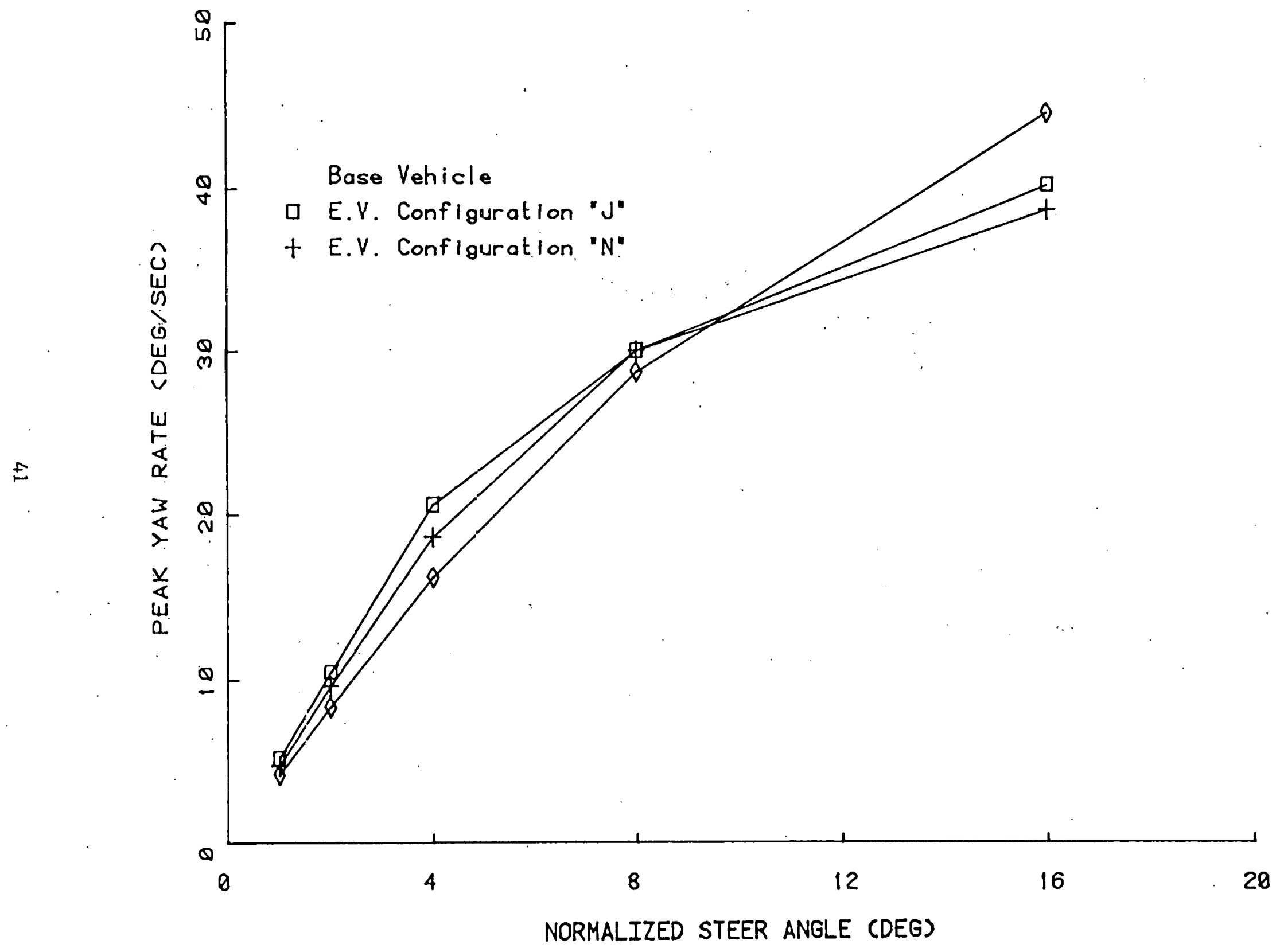

Figure 19 RESPONSE CHARACTERISTICS IN TRAPEZOIDAL STEER MANEUVER 


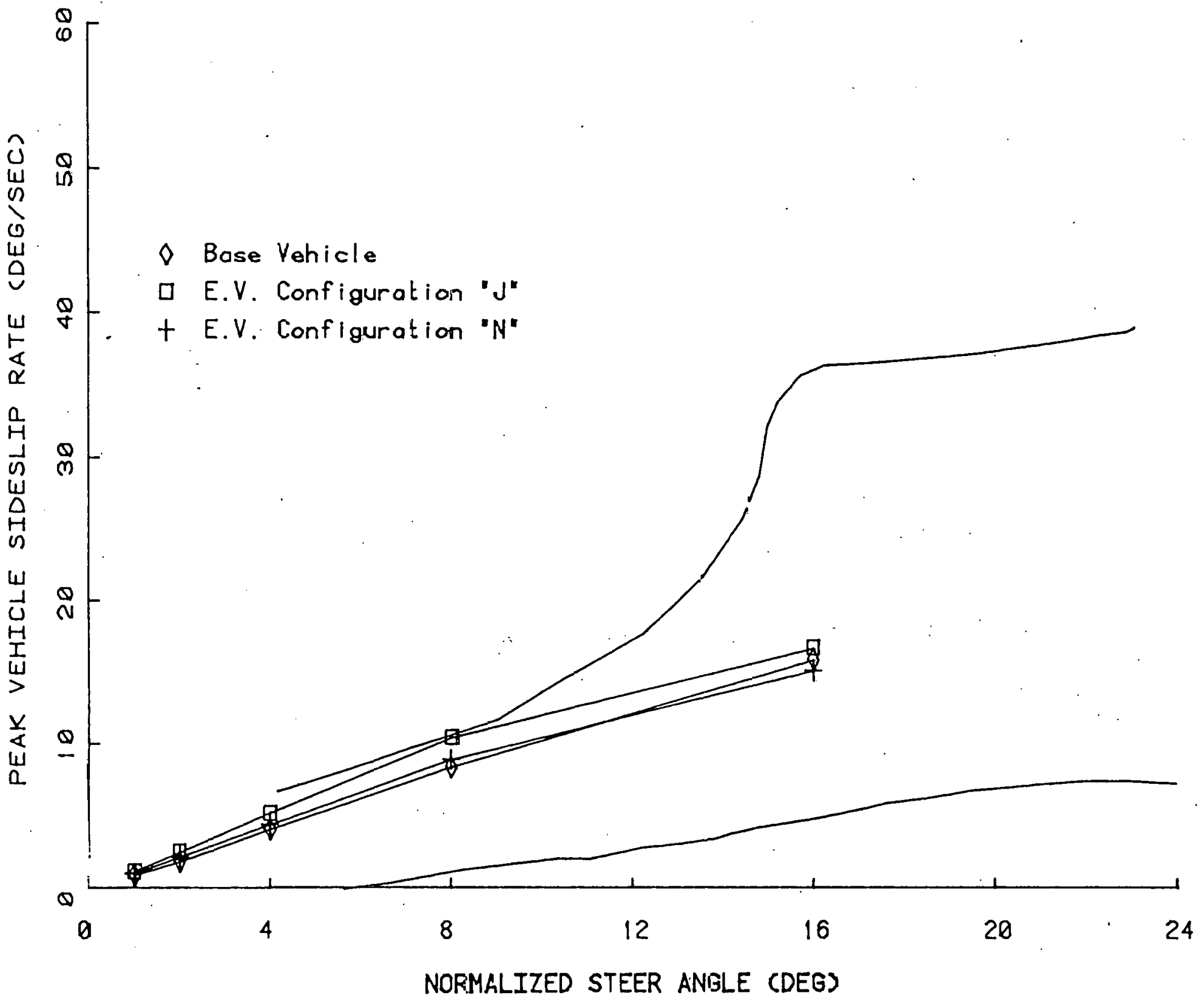

Figure 20 RESPONSE CHARACTERISTICS IN TRAPEZOIDAL STEER. MAMEUVER 


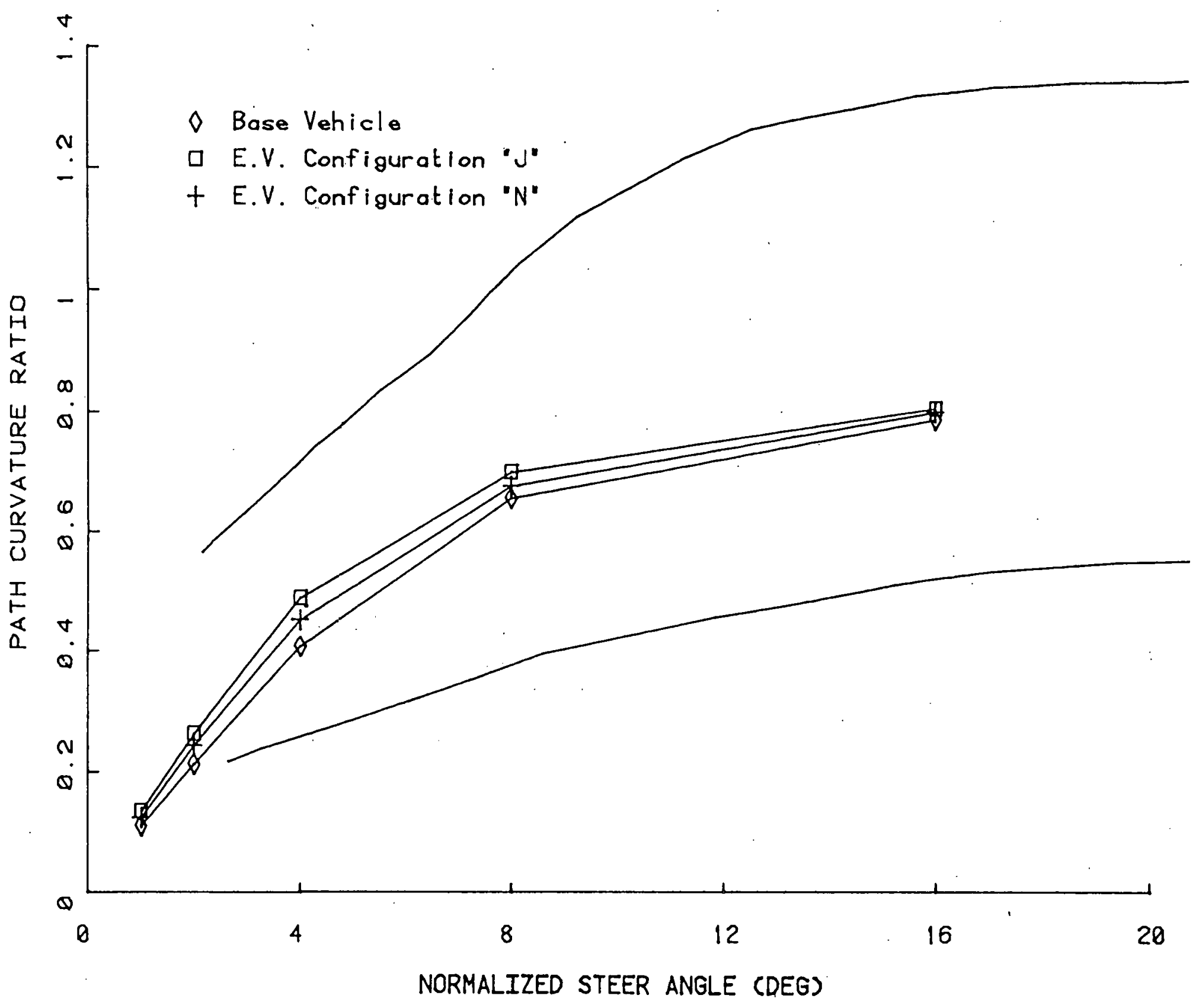

Figure 21 RESPONSE CHARACTERISTICS IN TRAPEZOIDAL STEER MANEUVER 


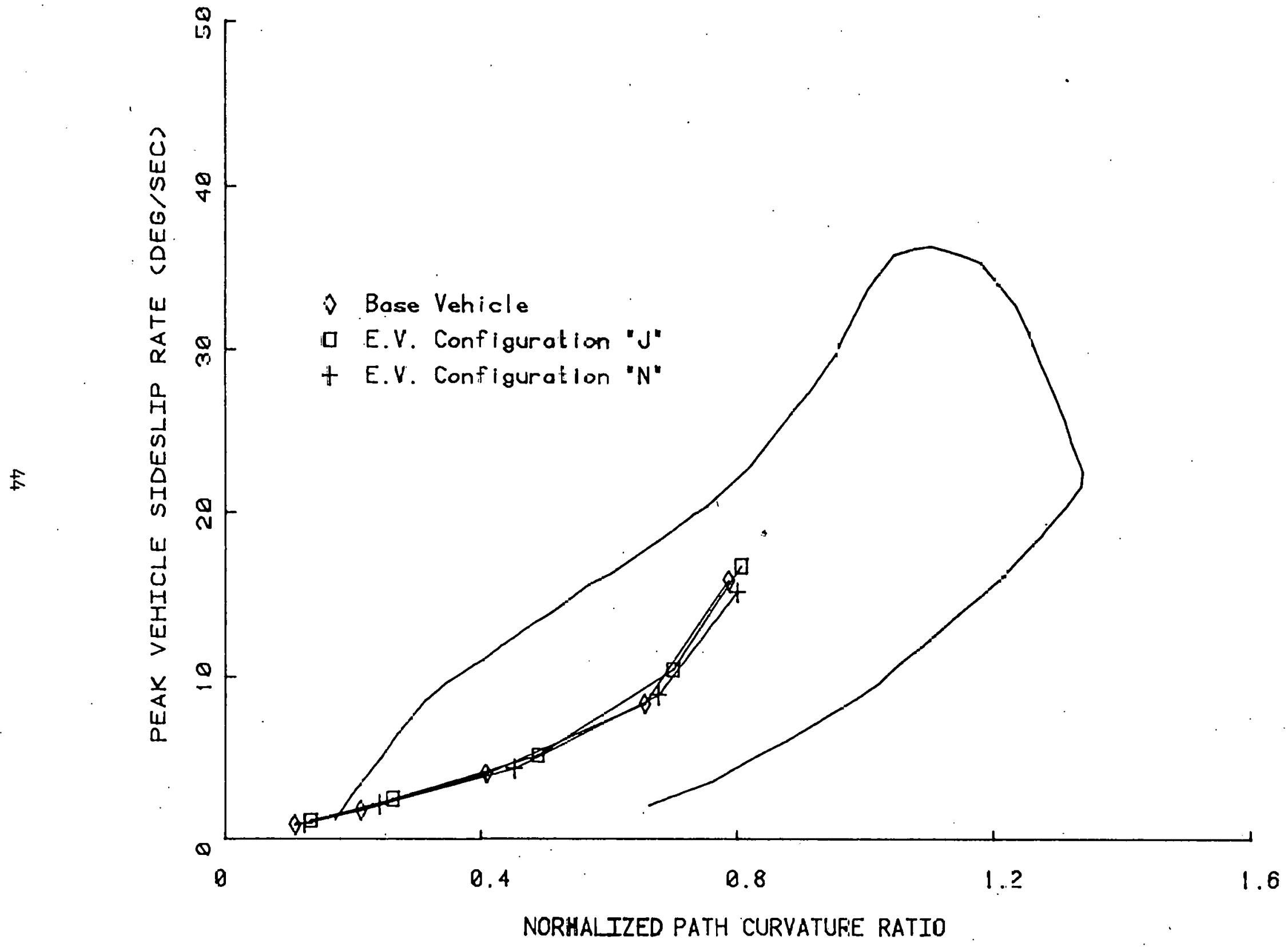

Figure 22 RESPONSE CHARACTERISTICS IN TRAPEZOIDAL STEER MANEUVER 


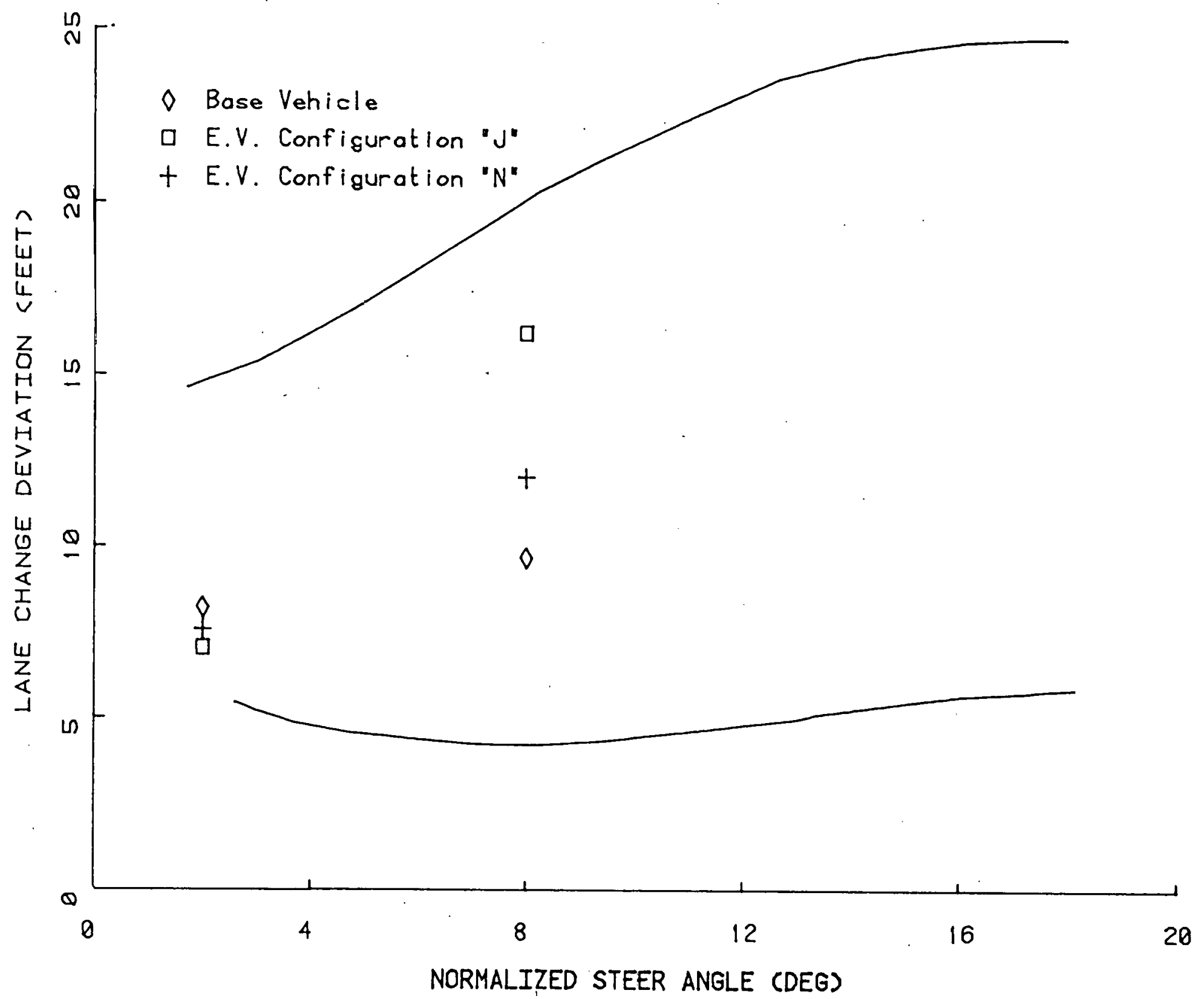

Figure 23 RESPONSE CHARACTERISTICS IN SINUSOIDAL STEER MANEUVER 


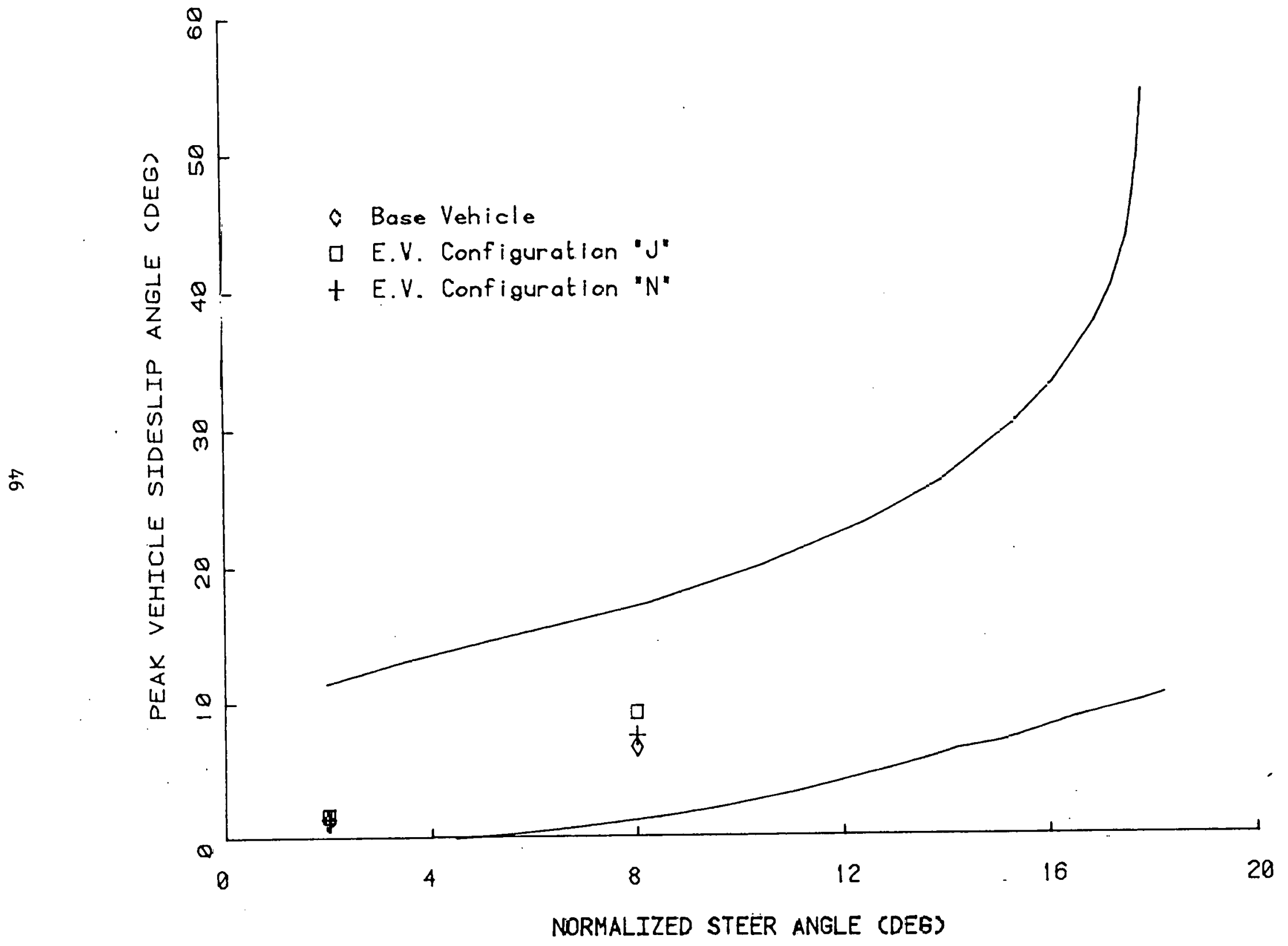

Figure 24 RESPGNSE CHARACTERISTICS IN SINUSOIDAL STEER MANEUVER 
In general, it would not be anticipated that a typical driver would notice any difference in the handling characteristics of the electric vehicles compared to the base vehicle. It should also be noted that the Omni suspension characteristics are fine tuned for a weight bias of $62 / 38$ front/rear. Appropriate fine tuning of the electric vehicle suspension for a bias of $57 / 43$ could be utilized to swing the response characteristics back to approximately the same as the base vehicle. The important factor is that the weight distribution be in the correct range (53/62 front) before utilizing fine tuning to achieve the exact response characteristics desired.

As reported in section 2.1 of this report, the recommended electric vehicle configuration has a lower percentage of weight on the front wheels than either of the layouts selected for computer simulation analysis. The final selection was based on a compromise to reduce front wheel loading for a more acceptable level of steering effort and to provide a more compact and lighter front battery pack mounting. The lower front weight bias was reviewed with MGA personnel and it was agreed that it would not have a significant effect on vehicle handling characteristics. This was based on:

- Very little difference exists between the base vehicle characteristics and those of either of the previously selected configurations. The latest distribution therefore, could be extrapolated to be within the range of existing production vehicles. This is substantiated by the large number of current production vehicles with the same level of front weight bias.

$n$ It is recognized that the results of this simulation are not expected to optimize vehicle handling characteristics but rather to insure that the selected configuration can be expected to perform in a manner generally similar to current production vehicles.

- As long as handling characteristics as indicated by the simulations are in the general range of a target vehicle then final "tuning" of suspension and tires can be expected to provide optimum characteristics.

MGA was sufficiently confident of their assessment of the acceptable handling 
characteristics of the recommended configuration that an additional simulation was not considered necessary.

The recommended electric vehicle layout is therefore judged to be an acceptable compromise from the standpoint of vehicle dynamic handling characteristics and manual steering effort. It can also be concluded that it is possible to package electric vehicle drive system components in a production vehicle (Dodge Omni as an example) in a manner that does not significantly degrade the handling qualities of the base car, without resorting to a central tunnel location for the batteries.

As previously indicated, the complete repnrt of MGA on thoir analysis of electric vehicle dynamies in support of component layout optimizations is included as APPENDIX A. 


\subsection{Battery Support Structure Integration}

The optimum electric vehicle packaging of batteries and other electric drive components is shown in FIG. 5 (p. 17). The final selection of battery locations was based on:

- Weight distribution to provide dynamic handling characteristies similar to the base internal combustion engine vehicle, and front weight limited to a magnitude that would not result in excessive manual steering effort. - Space available in the vehicle envelope without increase of size or significant intrusion into passenger or cargo areas.

The foregoing stipulations required the division of the required 18 batteries into two packages. The front pack of 6 batteries is under the hood directly behind the grill. The rear pack of 12 batteries is located under the cargo area floor. FIG. 25 illustrates the relative locations of the two packs.

The support structures developed to mount the battery packs in the Omni base vehicle are shown in FIGS. 26 and 27. The same general method of supporting the batteries is utilized for both front and rear mountings. Each battery is supported by a channel section around the base and is clamped in position by a lighter channel section around the hold down ledge of the battery case. FIG. 28. The channel supports are welded together to form a single frame for supporting the pack. The upper hold down channels are also joined to form a single frame. The lower support frame and upper hold down frame are clamped together by long bolts. The weight of the pack is supported in the vehicie by cross channels welded to the bottom of the frame. These in turn are bolted to the body structure rails. The rear pack is removed from the bottom. The front pack must be lifted upward through the hood opening for removul. Removal from the bottom would require a bolt-in front vehicle structure crossmember as the battery pack overlaps it. Since this is a key structural member is is recommended that it be left welded insuring a more secure joint. The offset between rows of batteries in the front pack is necessary to clear the transmission 


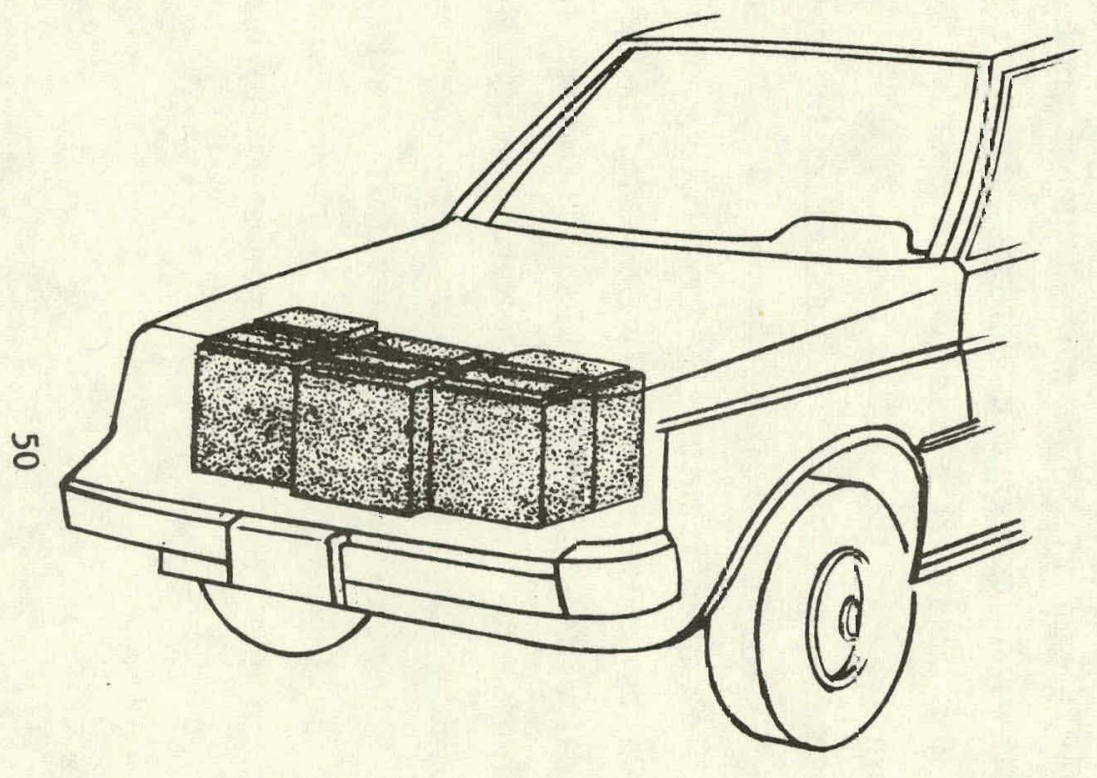

FROINT

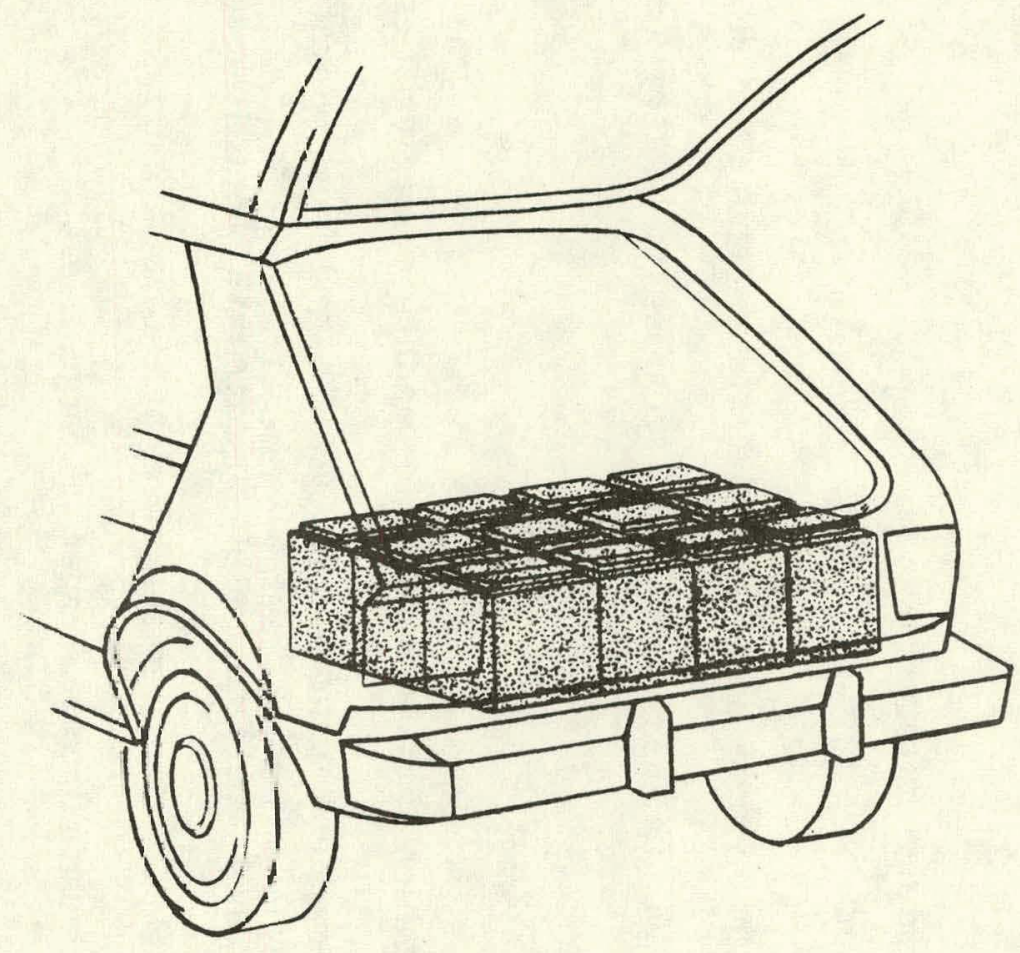

REAR

Figure 25 BATTERY PACKAGING LOCATICNS 

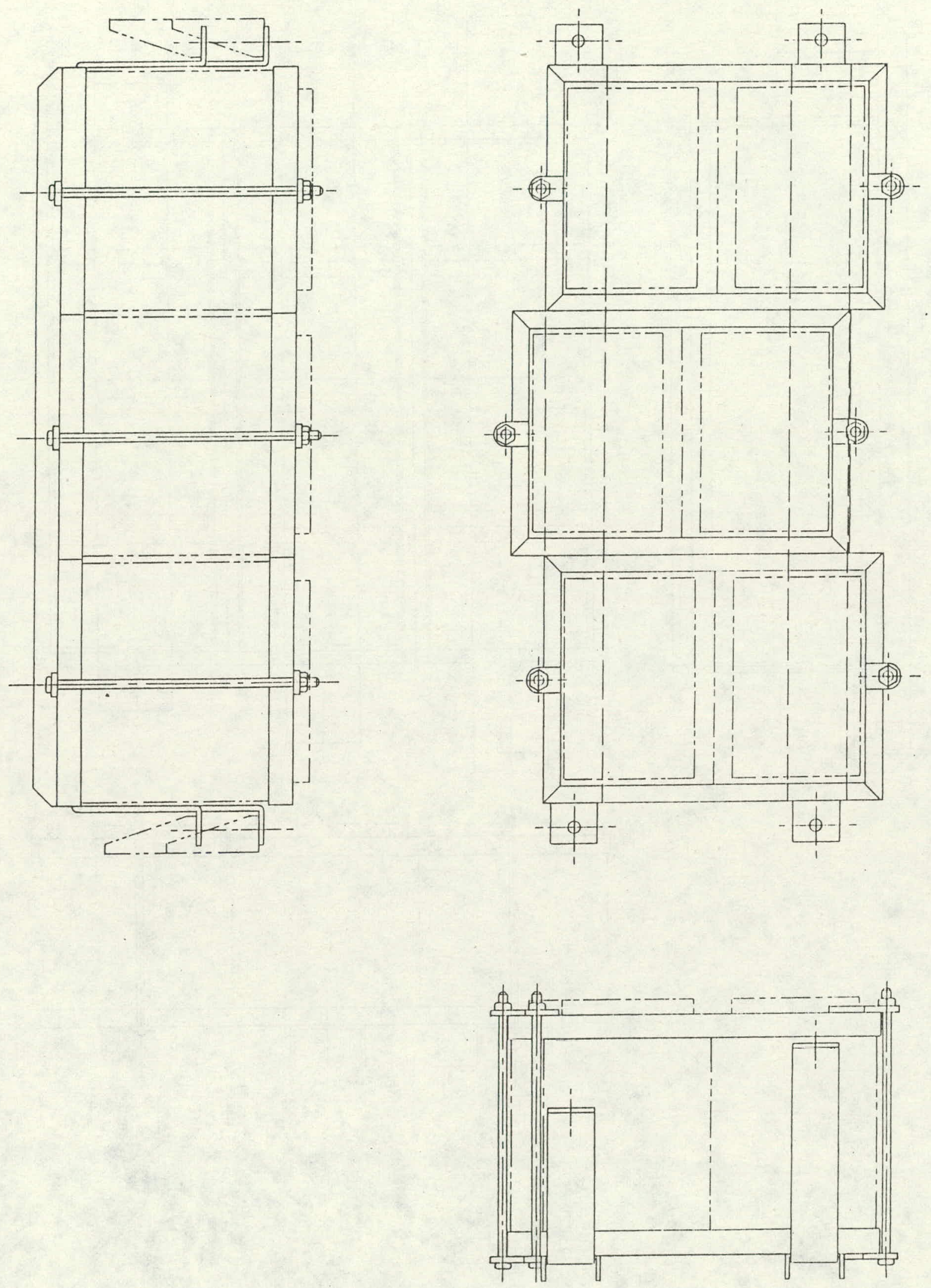

Figure 26 FRONT BATTERY PACK MOUNTING STRUCTURE 

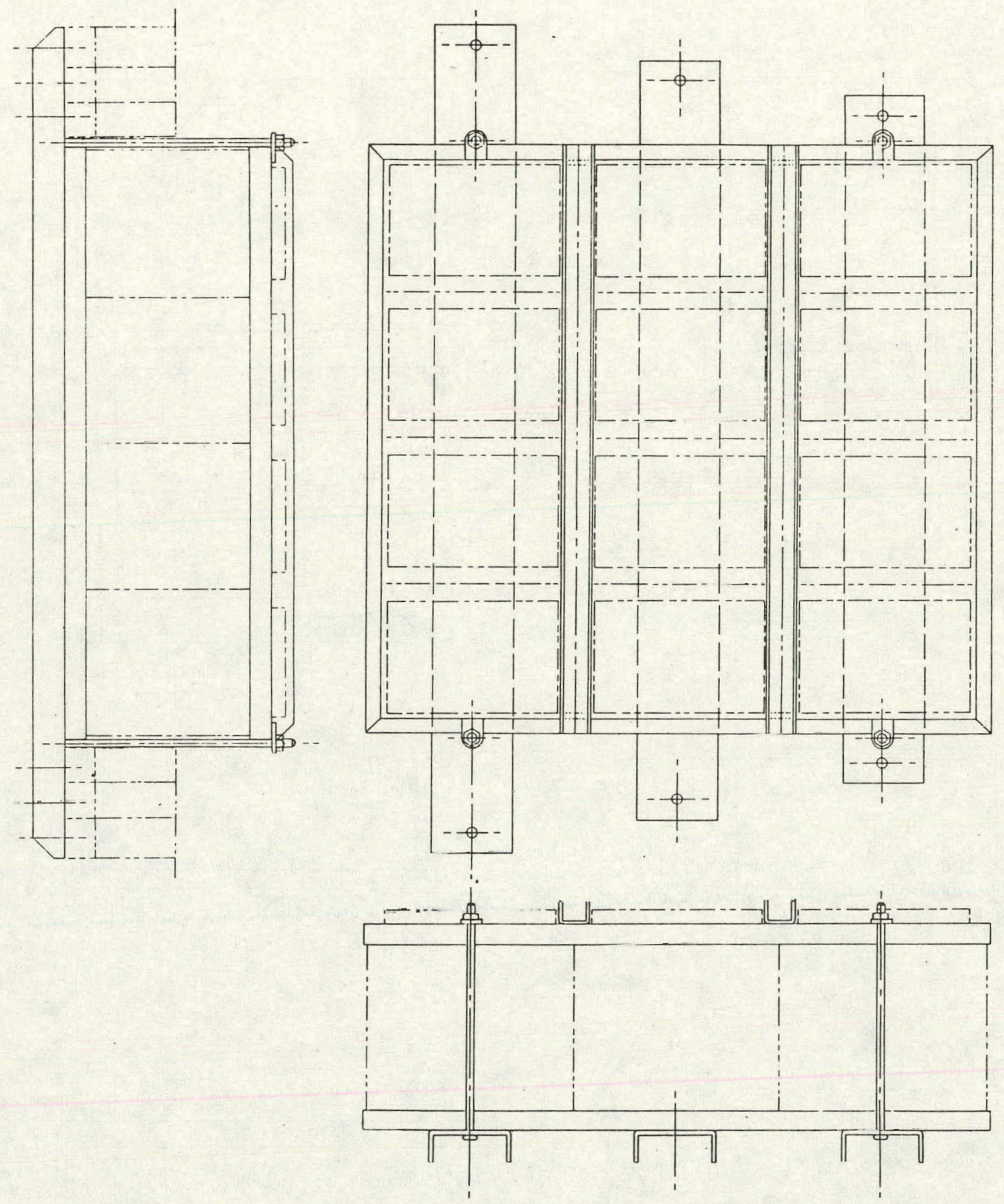

Figure 27 REAR BATTERY PACK MOUNTING STRUCTURE 


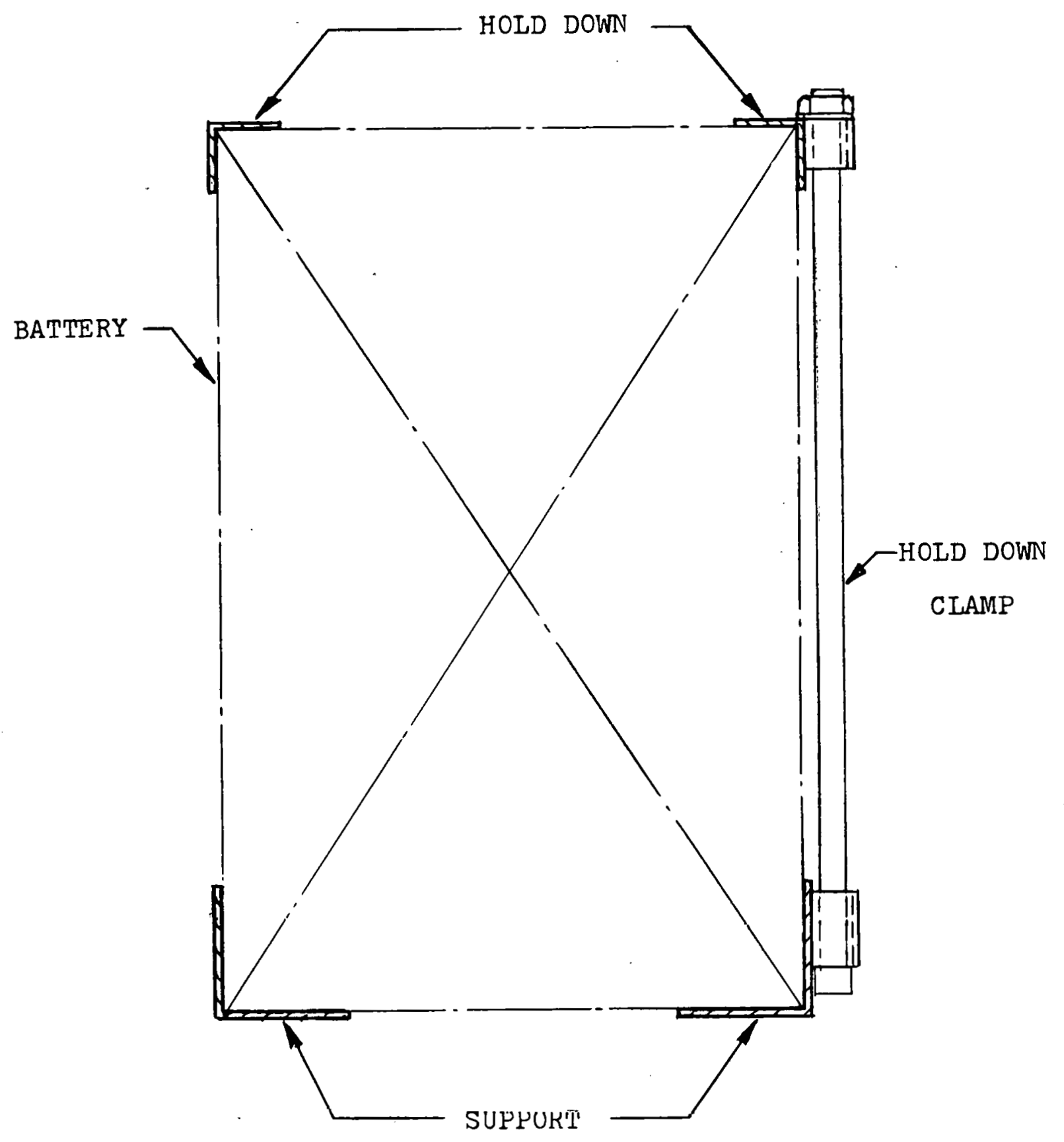

Figure 28 BATTERY SUPPORT AND HOLD DOWN STRUCTURE 
case in the middle and the headlight cans at the side. Weights of the battery supports are: (Using Hot Rolled Low Carbon Steel)

$\begin{array}{ll}\text { Front } & 25 \mathrm{lbs} . \\ \text { Rear } & 40 \mathrm{lbs} .\end{array}$

No structural changes are required at the front of the base vehicle to accommodate the battery pack. However, some stiffening of the front rails might be required because of the added weight of the batteries and electric drive components. This could be accomplished by heavier gage in a new design or addition of a reinforcing member for the base vehicle. At the rear, the structure crossmembers, ahead of and behind the pack, must be redesigned to modify their cross-section. They also must be moved slightly farther apart to accommodate the battery mounting. Heavier gage rear rails or the addition of reinforcements could be anticipated because of the addition of the load of the batteries $(720$ lbs.). The cargo floor must be raised 6 " to clear the battery pack. None of these changes are considered significant enough to alter the base vehicle's structural integrity. They will also add only a minor weight penalty of a few pounds.

Since the basic structure of the vehicle is not affected by the battery installations, the crash worthiness should be unimpaired. In fact, the addition of the battery pack mass and support structure should improve the ability of the vehicle to maintain the integrity of the passenger compartment in either a front or rear impact. The batteries themselves offer considerable energy absorbing capability in a crush resistance situation.

No specific vehicle layouts of the battery support systems were considered necessary since they are similar to the ETV-1 systems and did not appear to offer any installation problems. The three systems are:

- Elcctric Component Wiring Connections

Cables are required to connect the batteries to the motor and wiring connections between motor and controls must be provided. The location of the batteries and controls dircctly adjacent to the motor greatly simplifies the wiring. The cable from the rear battery pack can be routed down the small tunnel in the center of the vehicle along with the parking 
brake actuation cable. This tunnel was provided in the base vehicle to stiffen the underbody and provide space for the exhaust system.

o Battery Watering and Venting System

This is a dual function system and is provided to eliminate the need for individual battery fluid replacement and to vent any escaping gases away from the vicinty of the batteries. A schematic of the system as installed in the ETV-1 is shown in FIG. 29. Because of the separation of the battery packs between front and rear of the vehicle it is recommended that two separate systems, one for each end of the vehicle be provided. This would insure that a low spot could not occur in the line connecting front and rear packs which could collect fluid and prevent venting. Ample space is available to install the two systems. To insure safe venting a flame arrester is installed at the end of the vent tubes. The latest design as recommended by Globe is shown in FIG. 30 .

o Battery Charging System

Schematically this system would be similar to the ETV-1. The external connection could be behind the grill with a suitable access door provided.

In addition a battery cooling system might be required. Although the batteries are located where an optimum amount of natural air flow would occur and the supporting structure allows for a free flow of air around the modules, temperatures developed during charging might dictate the need for a forced air supply. No specific cooling requirement specifications are available but requirements could probably be met with a straightforward system as shown in FIG. 31. A plastic shroud attached to the front of the battery support cage would direct air flow from a fan over and between the batteries. The fan drive motor and mounting would be similar to the remote electric drive engine cooling fan used on the Omni. Each fan and motor could probably be smaller than the Omni depending upon the results of actual vehicle installation cooling studies. 


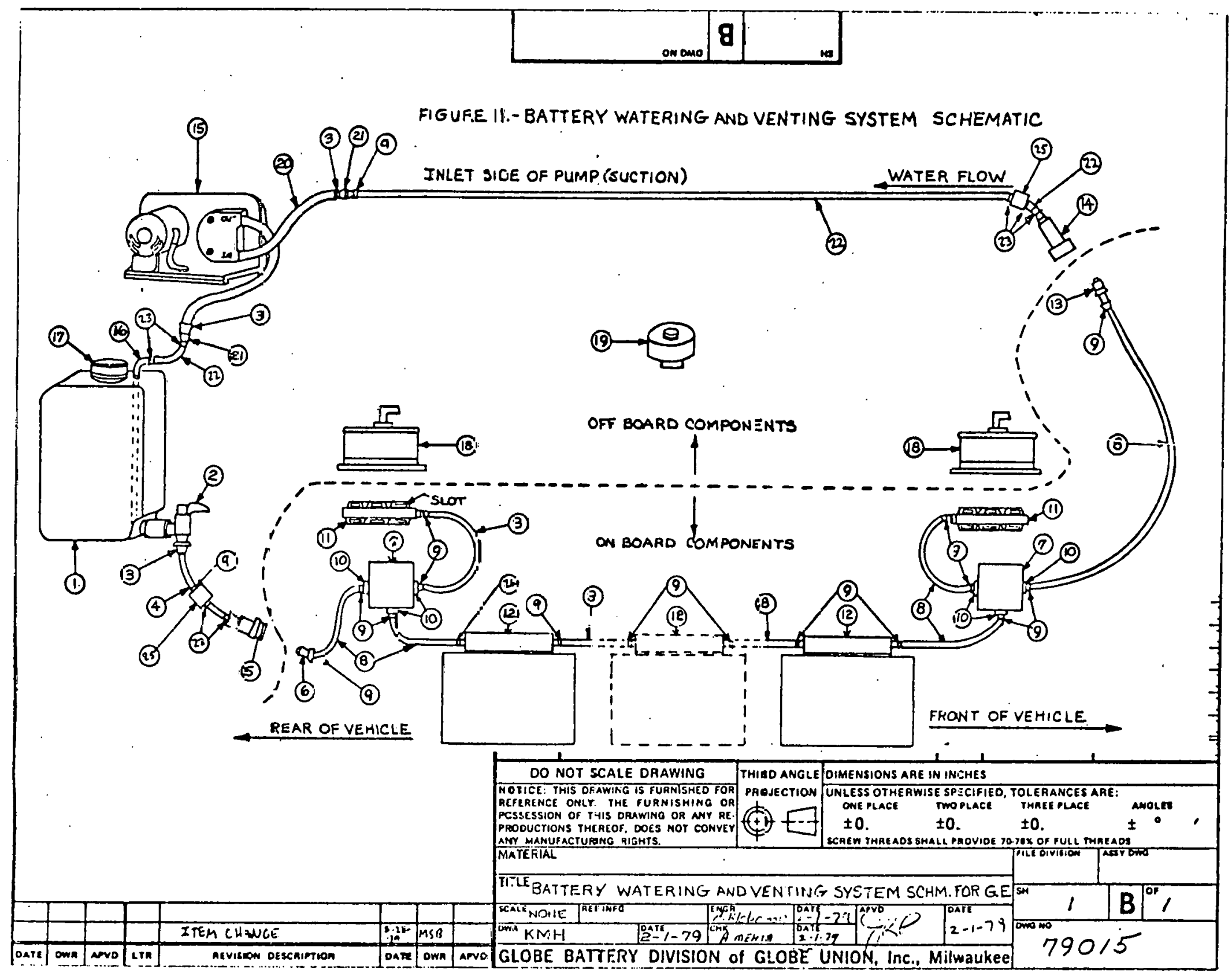

Figure 29 BATTERY WATERING AND VENTING SYSTEM 


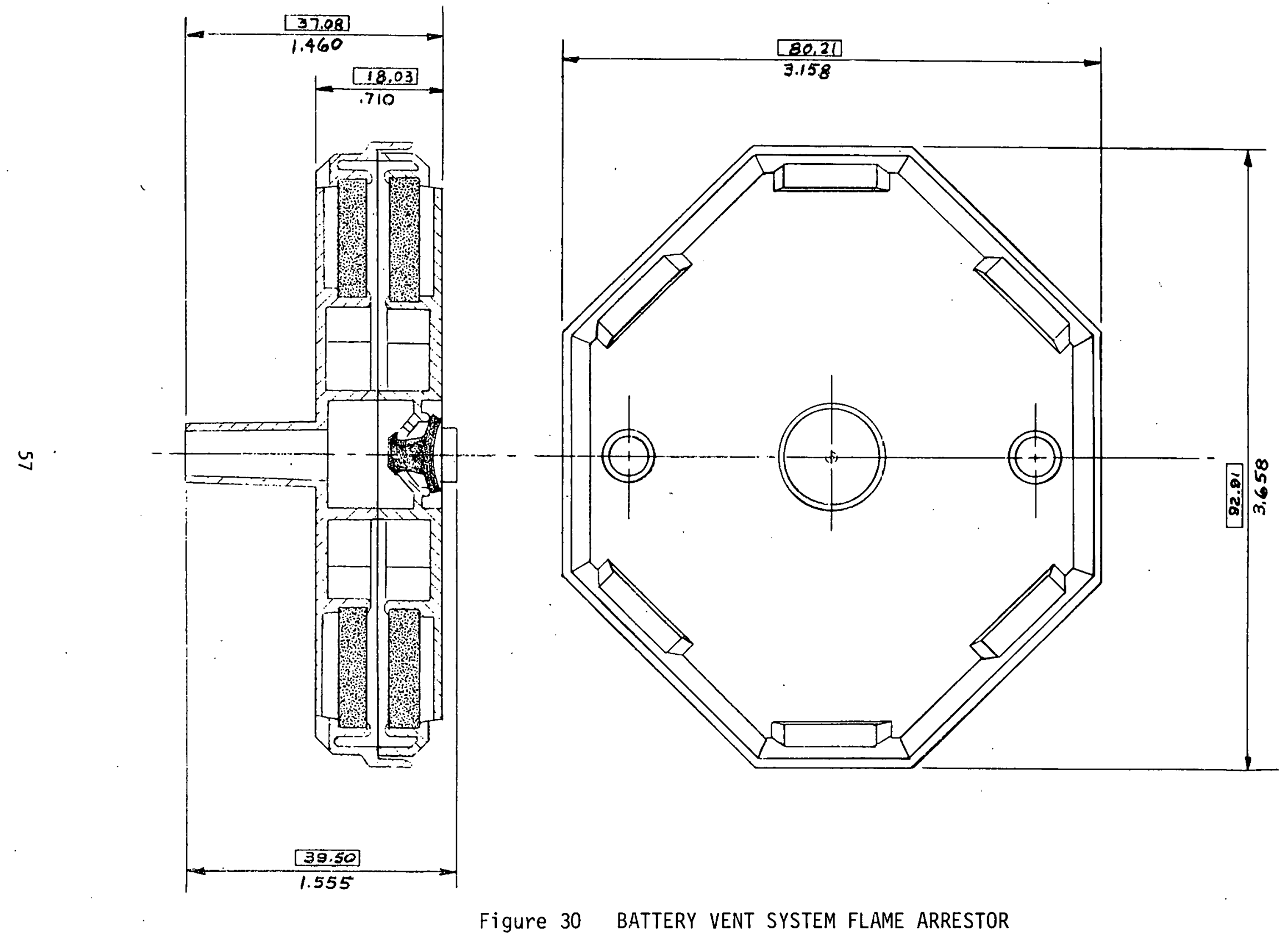




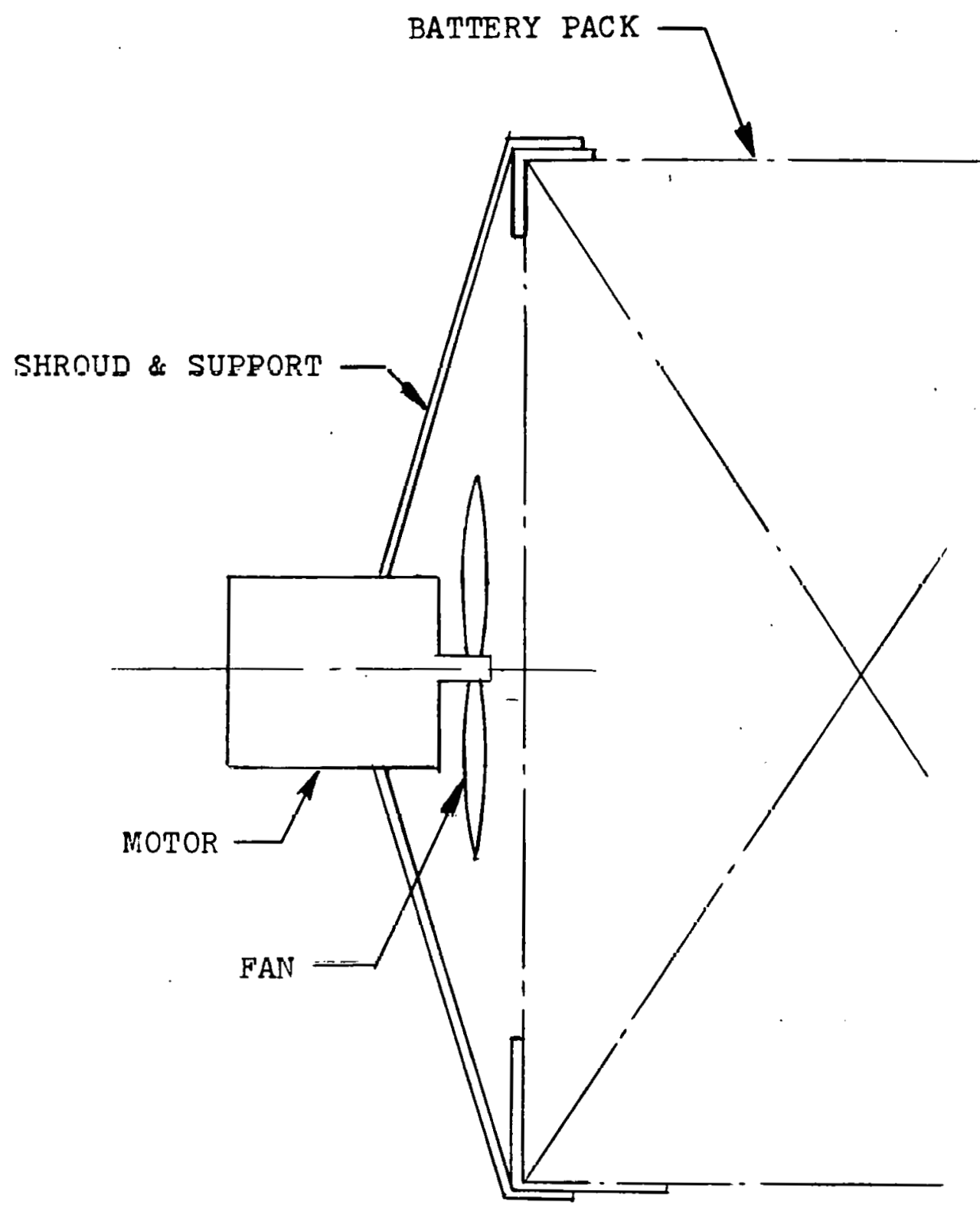

Figure 31 BATTERY COOLING S SYSTEM 
With respect to vehicle modifications to provide for the installation of electric drive components only minor changes are required. The structural changes are discussed on p. 54 of this section. As indicated in section 2.1 a concave depression in the dash panel must be provided for motor clearance.

Other modifications to base vehicle components were as follows:

- Front Suspension.

Analysis by Chrysler Engineering for the ETV-1 vehicle indicated that the suspension members and body supporting structure were adequate for the increased wheel load of that design. Since front wheel loads are approximately the same for this proposed vehicle no suspension modifications should be required except for higher load and rate springs. Springs designed for the ETV-1 should be suitable. In the event more load capacity should be required, the G. M. X-Car suspension, a similar design, could be substituted with only minor modifications. It has considerably higher capacity. A slightly larger diameter sway bar might be required as part of the final fine tuning of the suspension characteristics. A depression must be added to the top of the front suspension crossmember to provide dynamic clearance to the transmission case. Shock absorbers would undoubtedly require retuning because of the added weight and changed weight distribution.

- Rear Suspension

Installation of the rear battery pack was accomplished without interference with the rear suspension. The semi-independent layout of the Omni rear suspension which does not have a conventional rear axle beam made this possible. However, weight increase on the rear was considerably higher. than on the front. A heavier strut would be required in addition to a spring with higher load capacity and rate. Since only the strut (basically 
an extended shock absorber) would be involved, increasing capacity should not be a problem. Again X-Car strut components could be utilized. Body supporting structure at the point of strut attachment is extremely rigid but might require heavier gage material in the support tower. A new tower would probably be required to provide clearance for the heavier load rear spring. The magnitude of spring load increase would undoubtedly require a larger coil diameter. The increased structure of the rear rails to support the battery load would probably provide adeyuale stiength for the support of added wheel loads. Kear shock absorbers would require reluning. Based on information supplied by Chrysler, the rear suspension arms and mountings would probably be adequate since their structure requirement is not directly related to load. The roll resistance provided by the member connecting the two independent trailing arms might need to be modified as a final tuning of suspension dynamic characteristics.

\section{o. Brakes}

The increase of total vehicle weight by approximately $50 \%$ would normally indicate that a major hrake change would be required. However, review of the brake system for the ETV-1 with Chrysler Engineering indicated that no major changes were necessary. This favorable situation resulted from:

- The use of a regenerative bralcing eyetem in conjunction with the electric motor drive. This automatically proportioned system tuned to requirements through the microprocessor relieves the brakes of much of their work.

- The rear brakes are in effect oversized on the Omni because they are the smallest currently available in large scale production. The 
high front weight bias of the Omni plus weight transfer during high speed stops places most of this mode of braking load on the front wheels. The rear brakes, as they exist, are therefore capable of providing a much higher level of braking capacity. Evaluation of the ETV-1 indicated only an increase in rear wheel cylinder size was required to provide braking capacity adequate to meet the Federal Brake Standard performance level. This change might not be required for this proposal because of the reduced weight on the rear wheels vs. the ETV-1. The brakes are designed to operate satisfactorily in the manual application mode since a suitable power source for braking is not available.

- Wheels and Tires

Wheels must be increased in gage to support the additional load. Tire load capacity also needs to be improved. Since only a one size larger tire could be accommodated in the wheel wells, a higher load range tire was required. The ETV-1 for example uses a P175/75R13 extra load range (D equivalent) tire which is adequate for the weight of this design. Since the $P 175 / 75$ tire is standard on the Omni coupe it will fit in the available space of the electric vehicle. Since the maximum tire load is slightly less than on the ETV-1 a lower tire pressure would be used for this vehicle. The maximum load occures on the front rather than on the rear for the ETV-1. Uniform front/rear tire pressures could probably be used rather than the significantly different values specified for the ETV-1.

The steering system can be utilized exactly as on the Omni. The electric motor drive was positioned so that it did not interfer with the steering gear in Omni position. Omni steering linkage and steering column also can be used without change. Power 
steering would not be available because" of the lack of a suitable power source.

Engine mounts for the internal combustion power plant were removed and replaced with electric drive mounts similar to those used for the ETV́-1.

In order to better demonstrate the installation of the electric components, a vehicle mock-up was constructed utilizing an Omni structure which was available at Pioneer from a previous weight analysis conducted for the Department of Transportation. The main areas of the mock-up are shown in FIGS. 32 thru 36. The mock-up verified the suitability of the physical placement of components.

In summary no serious installation problems were encountered in converting an Omni internal combustion engine vehicle to electric drive. The added weight of the electric components increased vehicle weight by about $50 \%$. This very large increase requires numerous minor modifications in the load carrying members but no serious problems were encountered. This installation appears to be very suitable for electric drive development work without incurring the cost of creating a totally new and unique vehicle at this stage of development. 


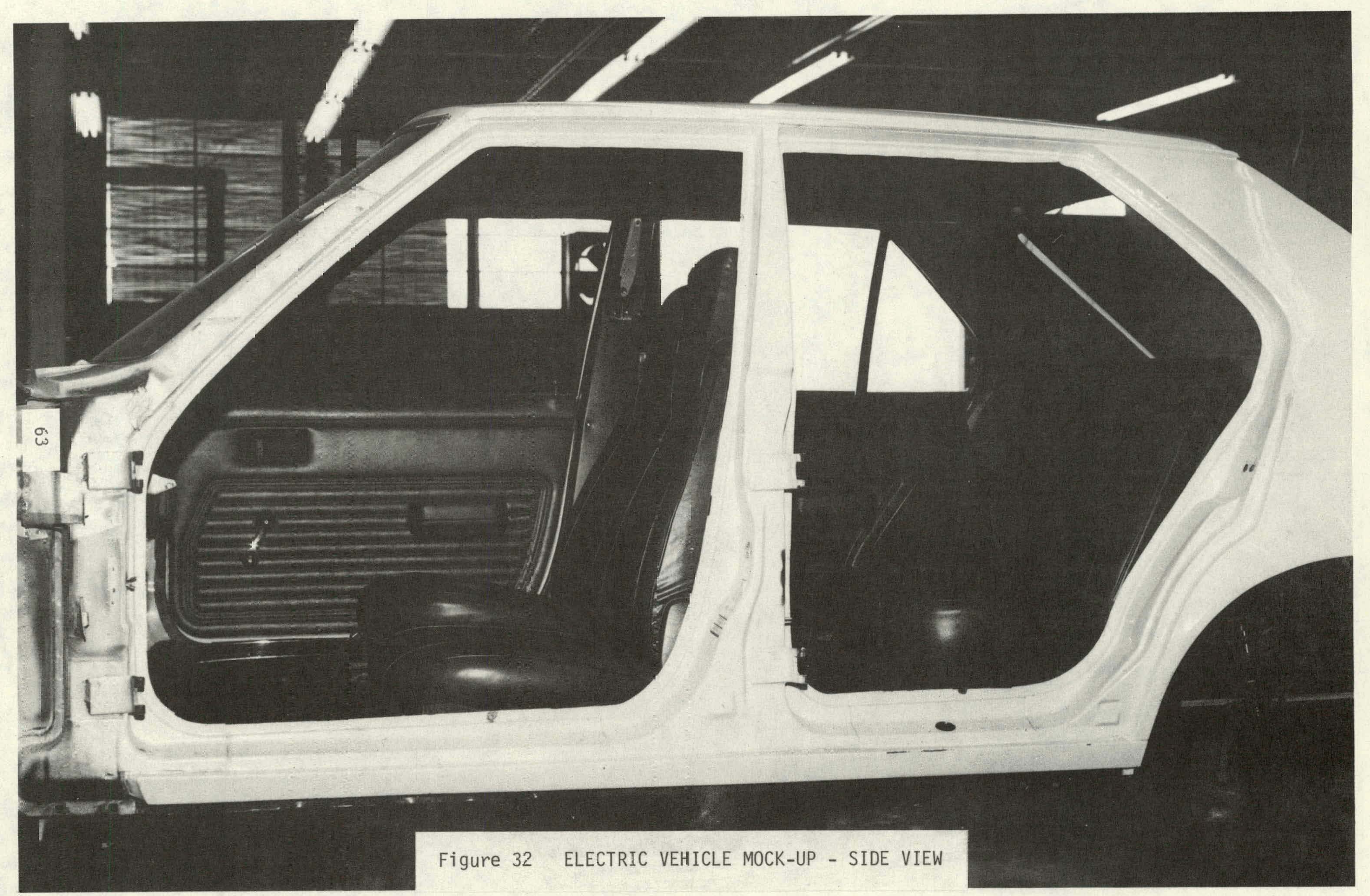




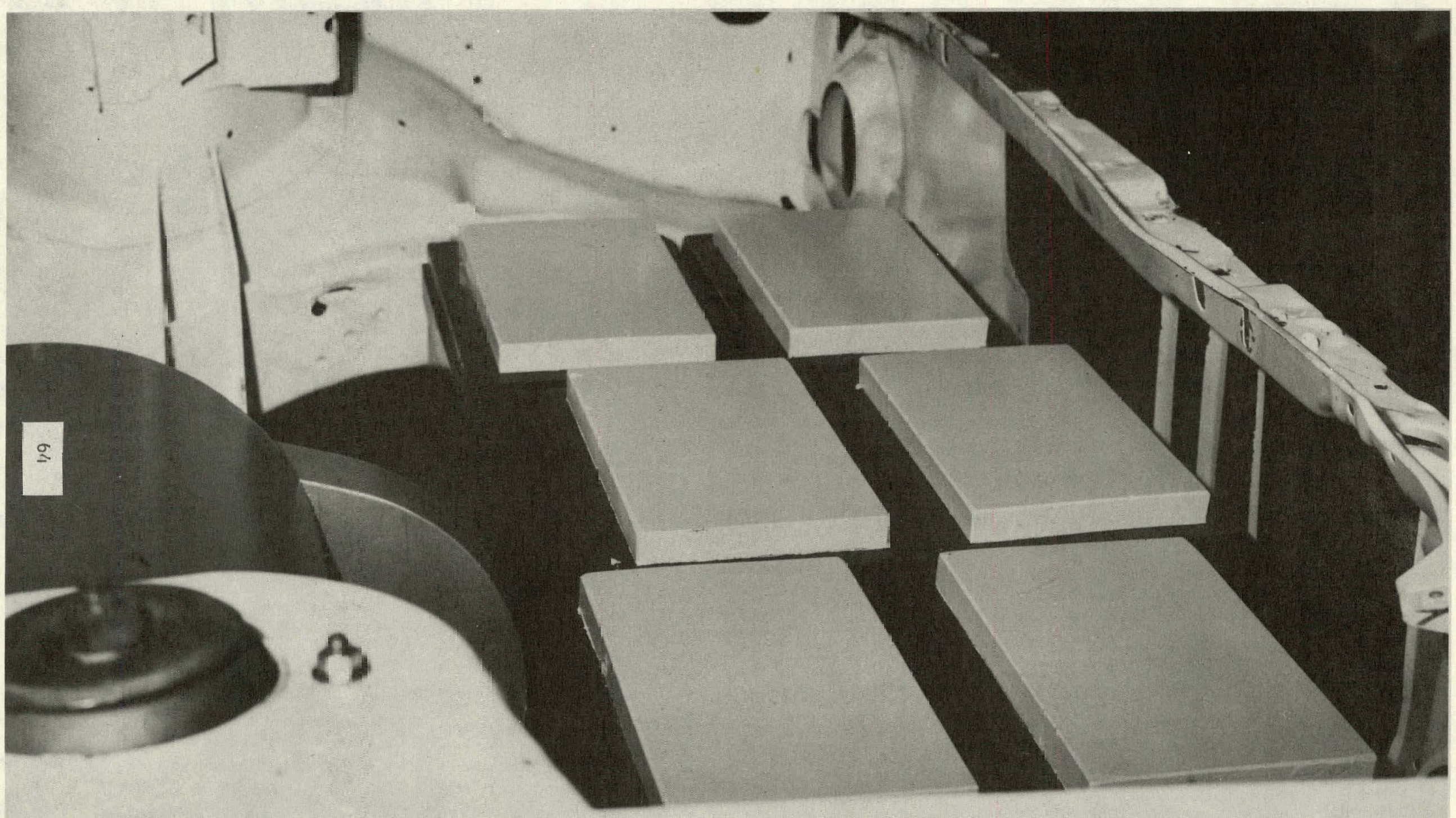

Figure 33 ELECTRIC VEHICLE MOCL-UP - FRONT BATTERY PACK 


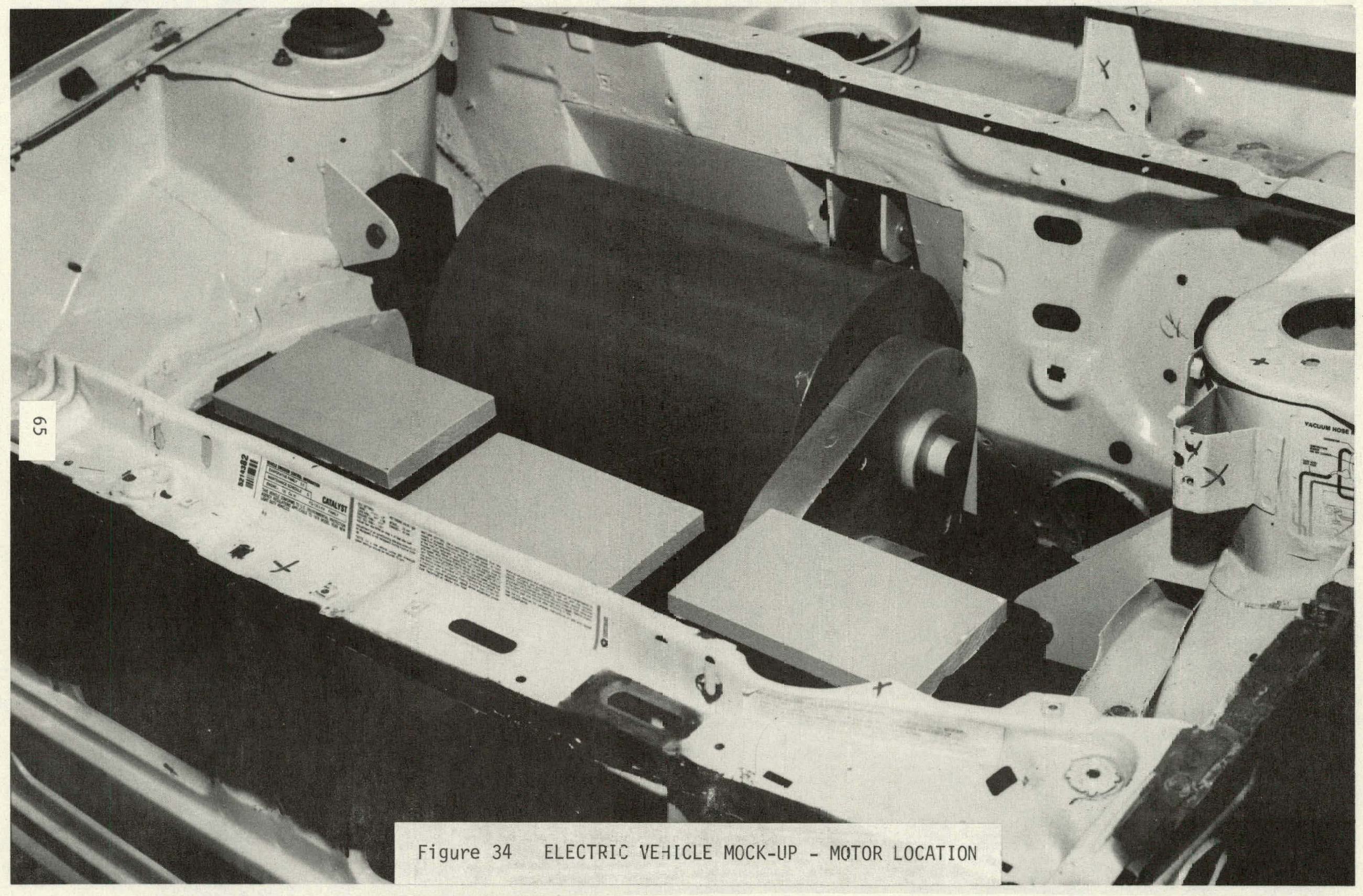




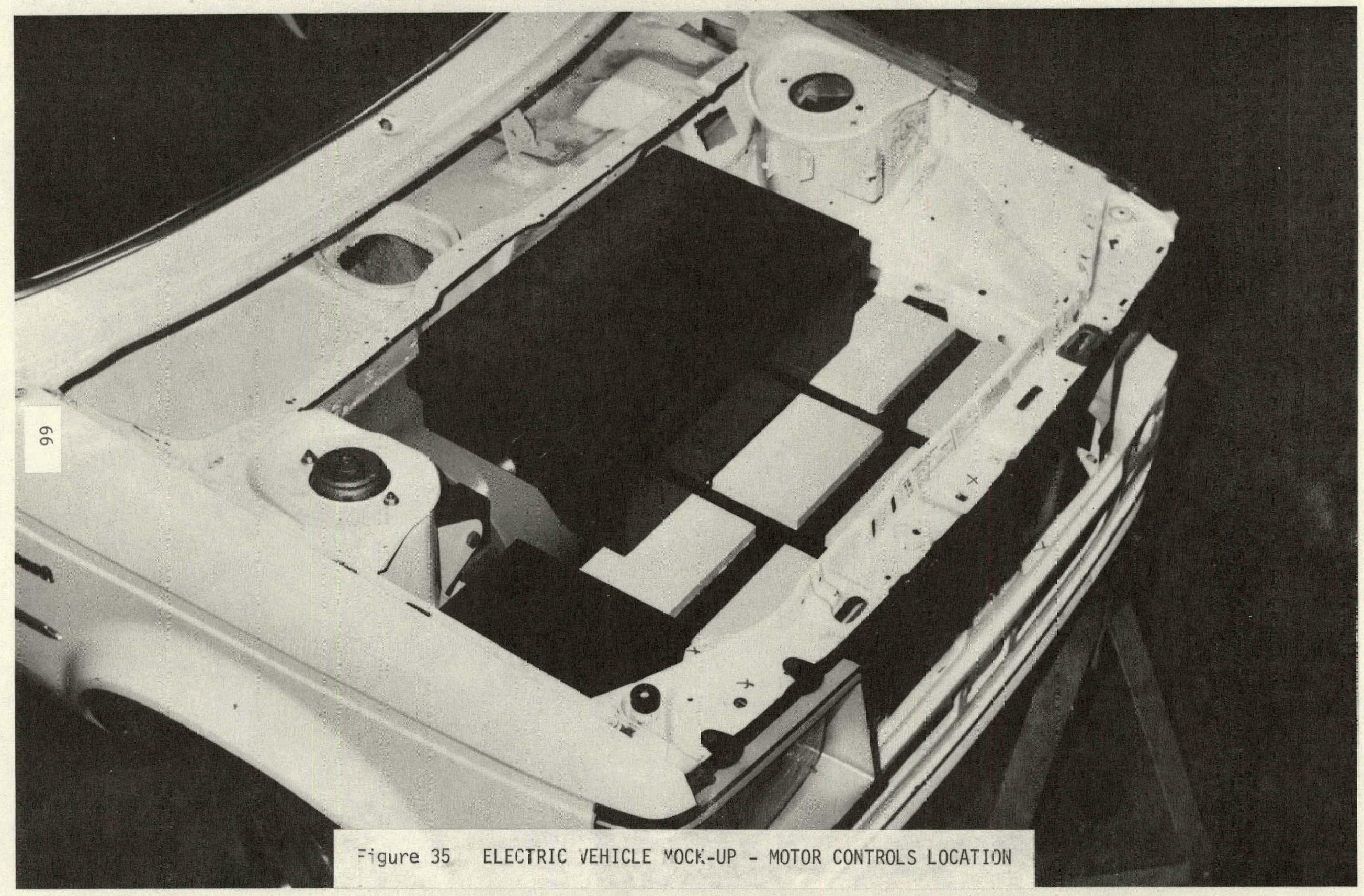




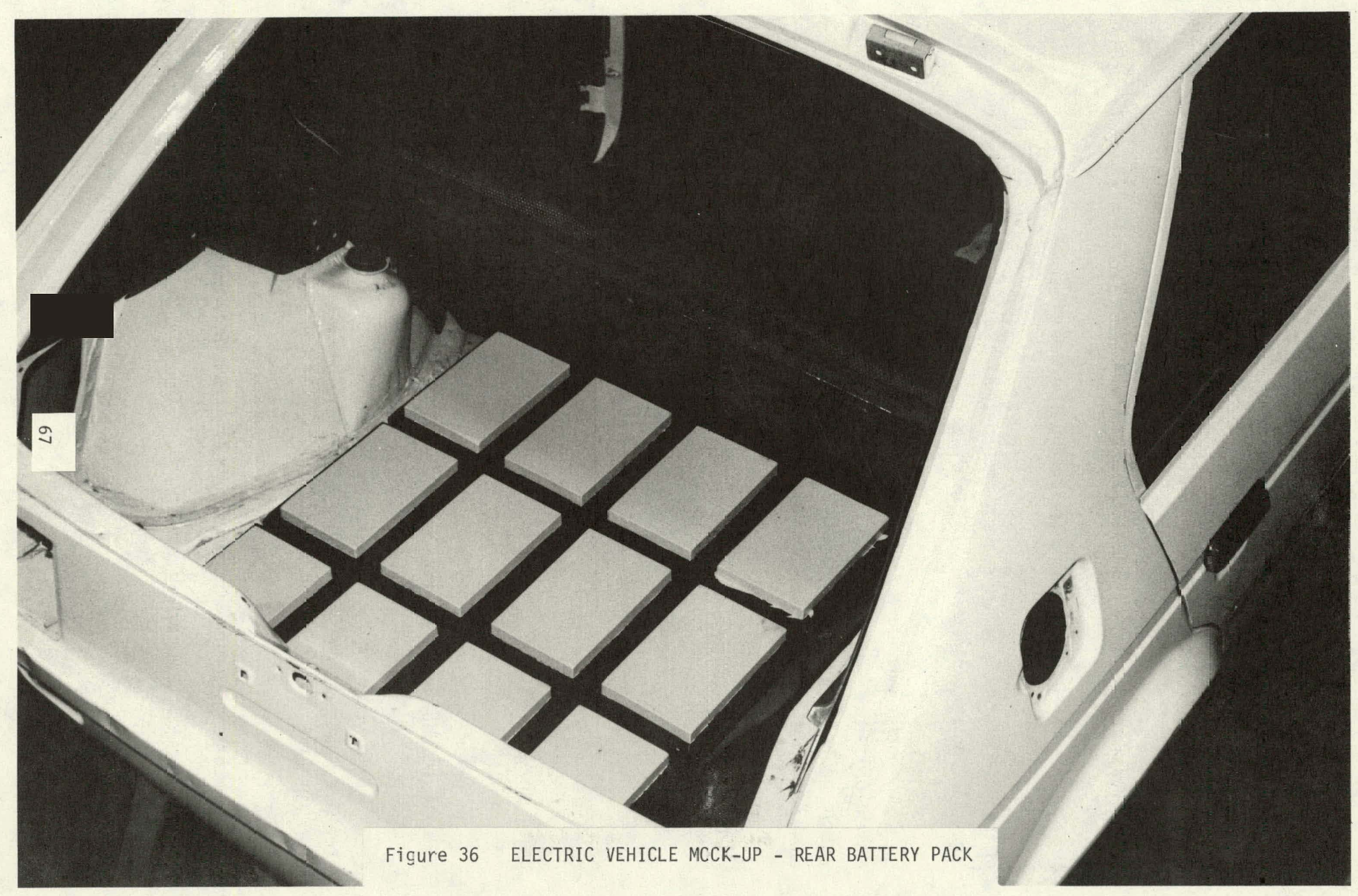


Design studies and analysis indicate that it is feasible to design an optimum packaging of electric drive components in a sub-compact size car and retain:

- The dynamic handling characteristics
- The passenger space (4-passenger) and cargo area

of the base internal combustion engine vehicle. The same basic packaging would also apply to a new unique electric vehicle design.

To obtain dynamic handling characteristics which are within the envelope of current production vehicles it is essential that the weight distribution of the electric vehicle be between $53 / 47$ and $62 / 38$ front/rear. Correct weight distribution is the most important single factor in achieving acceptable handling characteristics.

The optimum layout for the electric vehicle consists of:

Front motor/front wheel drive

Battery mounting divided between front and rear vehicle locations

No major structural or running gear changes are required to convert the selected base vehicle to electric drive.

Current battery weights and volume seriously restrict the design of an optimum size and weight electric vehicle.

Alternate battery types now under development do not significantly improve the excessive weight problem. Most of them cannot be packaged as easily as the current lead-acid type. 


\section{RECOMMENDATIONS}

The necessity for proper vehicle packaging be disseminated to organizations entering the electric vehicle design field.

Developers of new battery types be apprised of the need of optimizing battery module size based on vehicle packaging considerations.

One or more prototype vehicles be constructed to demonstrate the feasibility of converting current production vehicles for use as electric component test vehicles. Static and dynamic characteristics of the converted vehicle should be determined and fed back through the dynamic simulation program to gain additional correlation for future analysis. 
THIS PAGE

\section{WAS INTENTIONALLY LEFT BLANK}




\section{REFERENCES}

1. Greene, J. E. and Segal, D. J., "An Analytical Study of Electric Vehicle Handling Dynamics", MGA Research Corporation Report No. G8-006, JPL Contract No. 955312, May 1979.

2. "Weight Study - 1978 Chrysler Omni, Pioneer Engineering and Manufacturing Company for National Highway Traffic Safety Administration, DOT-TSC-1045, September 1978. 


\section{APPENDIX A}

This appendix to the primary report consists of a report by MGA Research Corporation covering related dynamic studies performed as a sub-contract in support of the Pioneer contract. The MGA report also has an A \& B Appendix. 
THIS PAGE

\section{WAS INTENTIONALLY LEFT BLANK}


AN ANALYTICAL STUDY OF ELECTRIC VEHICLE DYNAMICS IN SUPPORT OF COMPONENT

LAYOUT OPTIMIZATION

\author{
BY \\ D. J. Segal and N. Balasubramanian
}

November 1979

MGA Report No. C9-004

Prepared for:

Pioneer Engineering and Manufacturing Company 2500 East Nine Mile Road

Warren, Mir.higan 48091

Under

Purchase Order No. 85669

$(A-3)$ 
Page No.

1. INTRODUCTION 1

2. CONCLUSIONS 3

3. DISCUSSION OF RESULTS 5

3.1 Vehicle Configurations studied b

3.2 Iincon Vraiple stability and Control Analyeie 11

3.3 HVOSM Simulation Study Kesults 26

4. REFERENCES 45

APPENDIX A: HIGHWAY VEHICLE INTERACTION SIMULATION A-I

APPENDIX B: SIMULATED VEHICLE INPUT DATA B-1

APPENDIX C: TRAPEZOIDAL STEER RESPONSE PLOTS C-

APPENDIX D: SINUSOIDAL STEER RESPONSE PLOTS D-1 
10 Peak Yaw Rate vs. Steer Angle for Trapezoidal

11 Peak Sideslip Rate vs. Steer Angle for

Path Curvature Ratio Vs. Steer Angle for Trapezoidal Steer Maneuver 


\section{LIST OF TABLES}

Table No.

Title

Page No.

1

Comparison of Base Car and EV Configuration Characteristics

2

Base Car and EV Configuration Parameters

3

Summary of Steer Effects

21

4

Comparison of Stoor Effocts

22

Summary of Linear Theory Results

25

HVOSM Steady State. Analysis Results

38 
Pioneer Engineering and Manufacturing Company (PEM) was awarded a contract to perform an electric vehicle design study for the Jet Propulsion Laboratory of the California Institute of Technology (JPL). The objectives of this study were to evaluate and select electric vehicle drive system components and to package the selected components in an existing vehicle in a more nearly optimum manner than is generally done in retrofit EV conversions: MGA Research Corporation (MGA) assisted PEM in their study by evaluating various. EV component layouts with respect to their influence on vehicle stability and control.

Under the first task of the overall program, PEM developed a number of alternate EV component layout designs, all packaged within the confines of the selected base car, a Chrysler Corporation Omni/Horizon. MGA then assisted in an evaluation of these designs by conducting static analyses which provided an indication of the potential impact fifteen selected designs might have on . handling response variations from the base car. This information, coupled with other design considerations, resulted in the selection of two EV configurations that would be expected to reflect good EV component packaging while at the same time maintain acceptable vehicle handling characteristics.

It is important to recognize that vehicle handling qualities are largely subjective and qualitative in nature, and very little information exists which can be applied to determine whether a given vehicle handles "good" or "bad", except in a gross sense. Production passenger cars exhibit a wide range of dynamic characteristics, and the development of a vehicle requires many design compromises which include handling as one of many aspects of automotive engineering which must be addressed.

With this in mind, the evaluation of the EV configuration handling qualities was made by comparing predicted dynamic response characteristics with those of the base car for identical control inputs. Thus, the impact of 
alternate packaging layouts on vehicle handling qualities was judged in a relative sense based on the responses of a production vehicle which possesses handling qualities suitable for the general public.

The comparative evaluations which are described in detail later in this report were carried out with a proprietary adaptation of the HighwayVehicle-Object Simulation Model (HVOSM), Reference 1, and were based on two simulated manuevers, a rapid steer input to a constant level and a sinusoidal steer input, both performed at varinus levels of input. The evaluations spanned the range of vehicle response from the linear regime to the limit performance regime. Additional linear vehicle dynamics analyses were conducted to expand upon the results obtained from the HVOSM simulation runs.

In general, the results of this study indicated that either of the two selected EV configurations would possess handling characteristics that are consistent with the ranges available within the existing vehicle population. One of the configurations does respond to control inputs. in a manner more similar to the base car than does the other, however.

The following section discusses the major conclusions resulting from this study. A Technical Discussion is then presented describing, in some detail, the electric vehicle configurations that were analyzed and the physical properties of the vehicles that were employed in the analyses. This is followed by a discussion of linear handling theory and results obtained for the base vehicle and two EV configurations. The vehicle maneuvers simulated with the HVOSM, together with the vehicle responses resulting from them are then presented.

Appendices containing a synopsis of the mathematical model used in the HVOSM, a summary of the HVUSM input data, and vehicle response plots for both. the trapezoidal and sinusoidal steer maneuvers. 
Since the primary thrust of the activity reported herein was with regard to the evaluation of the likely vehicle handling qualities resulting from various approaches toward retrofitting electric vehicle drive system components into an existing internal combustion engine vehicle, our conclusions are based primarily on a comparison of responses predicted for the base vehicle and electric vehicle configurations.

Two major conclusions arise from the results of this study. First, it is possible to package electric vehicle drive system components in a Chrysler Corporation Omni/Horizon in a manner that does not significantly degrade the handling qualities inherent in this car. It should, however, be recognized that the added weight of the EV drive system requires that careful consideration be given to base vehicle components and structure. Clearly, the suspension system requires, at a minimum, increased spring rates in order to maintain ride height and frequency equal to that of the base car. Additional damping and strengthened suspension members may also be necessary. When carrying the added load associated with the EV drive systems, the base vehicle tires are, at best, marginal in terms of reserve load capacity and cornering stiffness. Within the simulation study reported in the following section, we have assumed that, if actually constructed, both EV's studied would have modified suspension springing (so as to maintain the same front and rear ride frequencies as on the base car) and have been fitted with larger tires (CR70x13) with increased load carrying capacity and cornering stiffness. Furthermore, no consideration has been given to the effect that the added weight and the packaging layout might have on the crashworthiness response of the base vehicle structure. It is, of course, recognized that this aspect of the hypothetical conversions were not intended to be addressed by this study; nonetheless, future efforts must hegin to consider this vital aspect of electric vehicle safety.

The second major conclusion resulting from this study deals with the relative ranking of the two EV configurations studied in depth with 
respect to handling characteristics. Two configurations, " $J$ " and " $N$ " were selected for detailed handling analysis based on a preliminary static analysis and other packaging related considerations. While both of these configurations were judged to exhibit response characteristics well within the range observed in the vehicle population, configuration " $N$ " consistently responded to control inputs in a manner closer to the base car than did configuration " $J$ ". Note that the selection of tires used on the EV's would be expected to have a substantial effect on the absolute EV responses but given the same tires on both EV's, the relative ranking would be expected to be the same. 
This section provides a discussion of the results obtained in the study. The first subsection describes the vehicle configurations studied and includes a description of some of the data used to mathematically describe the base vehicle as well as the procedures employed for developing data for describing various hypothetical electric vehicle configurations. A comparison of some fundamental vehicle characteristics is provided for 15 vehicle configurations. Following is a brief discussion of the application of linear vehicle handling theory to the characterization of expected vehicle response behavior. The last subsection describes the application of the HVOSM computer simulation to the study of selected EV configurations in both the linear and non-linear ranges of operation.

\subsection{Vehicle Configurations Studied}

An initial step in this attempt toward optimization of electric vehicle component packaging was to select a base vehicle which would be a practical choice for conversion from internal combustion to electric drive. This approach towards layout optimization, that of basing the study on an existing vehicle, was taken for two reasons. First, it provided an existing vehicle structure and periphery within which to work rather than attempting to design a totally new vehicle package--an undertaking outside the scope of the project. Second, since vehicle handling evaluation is largely qualitative, judgements regarding the prediction of electric vehicle handling characteristics can be best made by comparison of response metrics with a known conventional vehicle. Indeed, a goal of any electric vehicle program should be to maintain handling qualities close to those of conventional vehicles to which people are accustomed.

The base vehicle selected by PEM in conjunction with JPL for use in this study was a Chrysler Corporation Omni/Horizon. Much of the engineering information required for vehicle handling simulations of this car was obtained from the Chrysler Corporation by PEM. 
Physical properties of interest in the initial stage of the study included the following:

- Weight

- Weight distribution

- Total vehicle center-of-gravity height (H)

- Roll moment of inertia $\left(I_{x}\right)$

- Pitch moment of inertia $\left(I_{y}\right)$

- Yaw moment of inertia $\left(I_{z}\right)$

- Roll-yaw product of inertia $\left(\mathrm{I}_{x z}\right)$

The nominal road weight for this car, aE supplicd by Clitysler Corporation was $2341 \mathrm{lbs}$. with a front to rear weight distribution of $64.8 / 35,2$. The reported total vehicle center-of-gravity height was given as 20.4 inches above the ground. Moment-of-inertia measurements for this car were, unfortunately, not available. However, estimates were made based on known values for similar sized cars.

A summary of the base car vehicle physical properties used in the first stage of the study is given below:

\section{BASE CAR PARAMETER}

\begin{tabular}{ll}
\hline Weight (1ha.) & 2341 \\
$\mathrm{a}$ (inches) & 34.90 \\
$\mathrm{~b}$ (inches) & 64.30 \\
$\mathrm{H}$ (inches) & 20.40 \\
$\mathrm{I}_{\mathrm{X}}\left(1 \mathrm{~b}-\mathrm{in}-\mathrm{sec}^{2}\right)$ & 4011.0 \\
$\mathrm{I}_{y}\left(1 \mathrm{~b}-\mathrm{in}-\mathrm{sec}^{2}\right)$ & 14471.0 \\
$\mathrm{I}_{z}\left(1 \mathrm{~b}-\mathrm{in}-\mathrm{sec}^{2}\right)$ & 14700.0 \\
$I_{x z}\left(1 \mathrm{~b}-\mathrm{in}-\mathrm{sec}^{2}\right)$ & 0.0
\end{tabular}

6 
It was then necessary to make a preliminary evaluation of some 18 possible electric vehicle component layouts, packaged within the available space in an Omni chassis, that were developed by PEM. The intent of this step was to narrow the many possible EV layouts to a limited number, based on both design considerations and on an estịmate of expected handing changes, so that detailed analytical evaluation could proceed. An estimate of the relative lateral responsiveness of the various configurations was made by comparing a calculated dynamic index, a ratio of the yaw radius of gyration to the product of the distances between the vehicle center-of-gravity and front and rear axles.

These computations were carried out with the INCAL computer program by first analytically removing internal combustion engine components and then adding EV components in locations corresponding to each EV layout.

The following weights and center of gravity locations for each ICE component, located with respect to the total vehicle center-of-gravity ${ }^{*}$ were then used to calculate a set of parameters that characterize the bare (i.e., without drive system) body and chassis.

\begin{tabular}{|c|c|c|c|c|}
\hline \multirow[b]{2}{*}{ Component } & \multirow[b]{2}{*}{ Weight (lbs.) } & \multicolumn{3}{|c|}{ Location (in.) } \\
\hline & & $\dot{x}$ & $y$ & 2 \\
\hline Engine/Transmission & 400 & 46.1 & 0.0 & 1.8 \\
\hline Battery & 36 & 50.1 & -18.2 & -7.4 \\
\hline Fuel Tank $(f u l 1)$ & 105 & -41.4 & 0.0 & 7.8 \\
\hline Spare Tire & 15 & -71.5 & 0.0 & 0.7 \\
\hline
\end{tabular}

* Locations given $w /$ to a right handed coordinate system; $x$ - forward, $y$ - to the right, $z$ - down. 
Note that the spare tire was analytically removed because it was subsequently added in different locations, depending on the specific configurations analyzed.

Once the base car with ICE components deleted was defined, it was possible to add EV components in different locations. The following component weights (as repurted in Ref. 2) were used in subsequent calculations:

Motor Syslem:

Motor

Misc. Jîive lomponents ....... 20 lbs.

237 lbs.
Transmission/Differential:

Controller (microprocessor):

Speed Control System:

Power Conditioning Unit ....... 97 lbs.

Misc. Power Components ....... 14 lbs.

On-board Charger . ......... 6 1bs.

117 lbs.

Spare Tire:

237 lbs.

48 1bs.

8 lbs.

117 lbs.

TOTAL
$151 \mathrm{bs}$.

$4251 \mathrm{bs}$.

Fighteen batteries, each weighing $60 \mathrm{lbs}$. wcrc also added in locations dependent on the specific layouts. 
Table 1 summarizes the results obtained. Note that all items listed in the table are for the total vehicle with the exception of $\mathrm{I}_{z S}$, the sprung mass moment of inertia, which was computed based on the assumption that the unsprung mass weight was $70 \mathrm{lbs} /$ wheel.

Based on several considerations, including results presented in the table, two EV layouts were chosen as being viable candidate designs. These were front wheel drive configurations " $J$ " and " $N$ ". Note that the dynamic index $\left(\mathrm{k}^{2} / \mathrm{ab}\right)$ for configuration " $\mathrm{J}$ " is less than that of the base car, indicating that the distribution of drive system masses tends to be closer to the total vehicle center-of-gravity. Configuration " $N$ ", on the other hand, has a higher dynamic index than the base car but maintains a weight distribution closer to it than does configuration "J".

Figure 1 shows schematic diagrams of the drive system component layouts for the base vehicle and the two EV configurations that were studied in more detail in subsequent analyses, and a summary of major vehicle parameters for these three vehicles is given in Table 2 .

Since axle loadings are increased for the two EV configurations by the addition of battery and drive system components, it was necessary to adjust both the front and rear spring rates to maintain same ride frequencies as in the base car. These values are also included in Table 2 .

In addition to the mass and inertia properties already discussed, the complex computer simulation used to simulate the base vehicle and EV configurations requires many other parameters to fully characterize a vehicle. Among the more important of these are dimensional information, suspension properties and tire properties.

The HVOSM includes a very sophisticated suspension system representation which encompasses all important suspension properties of the base vehicle. These effects include ride-steer, lateral force compliance steer, aligning torque compliance steer, lateral force compliance camber, and 
TABLE 1

CCMPARISON OF BASE CAR AND EV CONFIGURATION DHARACTERISTICS

\begin{tabular}{|c|c|c|c|c|c|c|c|c|c|}
\hline 5 . & $\% /$ Front & $\% /$ Rear & $\begin{array}{l}\text { Ci HT. } \\
\text { In:hes }\end{array}$ & $\begin{array}{c}I_{x} \\
\text { 1b } \sec ^{2} \text { in }\end{array}$ & $\begin{array}{c}I_{y} \\
16 \sec ^{2} \text { in }\end{array}$ & $\begin{array}{c}I_{z} \\
\cdot I b \equiv e c^{2} \text { in }\end{array}$ & $\begin{array}{c}I_{x z} \\
\text { lb } \sec ^{2} \text { in }\end{array}$ & $\begin{array}{c}I_{z s} \\
\text { Ib } \sec ^{2} \text { in }\end{array}$ & $\frac{k^{2}}{a b}$ \\
\hline & 64.8 & 35.2 & 20.4 & 4011 & 14471 & $14 \div 00$ & 0 & 11815 & \\
\hline
\end{tabular}

$\begin{array}{lllllllllll}\text { Base Car with ICE } & 1785 & \cdot 57.4 & 42.6 & 21.04 & 3823.9 & 11272.7 & 11410.8 & 57.32 & 8640 & 1.03\end{array}$

Component Deleted.

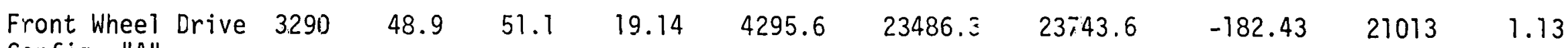

Config. "A"

Front Wheel Drive 3920

Config. "B"

51.5

$48.5 \quad 18.92$

$4189.2 \quad 23286.1$

23419.4

$\begin{array}{lll}-356.41 \quad 20688 & 1.12\end{array}$

Front Wheel Drive 3290

Config. "C"

$61.7 \quad 38.3$

$2 C .22$

4279.0

24081.0 .24398 .6

$\begin{array}{lll}-44.87 & 21482 \quad 1.23\end{array}$

Front Wheei Drive 3290

Config. "D"

$\begin{array}{llllll}54.4 & 45.6 & 20.22 & 4330.55 & 25287 . & 2573.3\end{array}$

$\begin{array}{lll}-8.18 & 22990 \quad 1.23\end{array}$

Front Wheel Drive 3290

Config. "E'

$\begin{array}{lll}52.4 & 47.6 \quad 19.88\end{array}$

4458.7

25654.1

$261: 6.2$

$-184.71$

$23443 \cdot 1.25$

Front Wheel Drive. 3290

Config. "J"

$57.2 \quad 42.8$

$42.8 \quad 18.59$

4182.8

$20150.4 \quad 203 \div 8.9$

$203: 18.9 \quad-165.22$

$17542 \cdot 0.99$

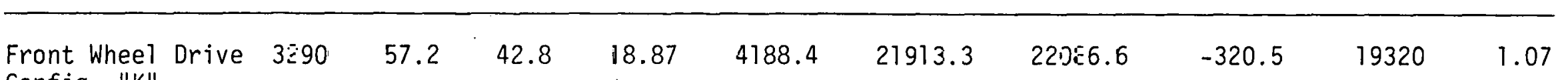

Config. "K" 
TABLE 1 (CONTO.)

\begin{tabular}{|c|c|c|c|c|c|c|c|c|c|c|}
\hline & $\begin{array}{l}. \\
\text { WT. } \\
\text { LBS. }\end{array}$ & $\% /$ Front & $\% /$ Rear & $\begin{array}{l}\text { CG HT. } \\
\text { Inches }\end{array}$ & $\begin{array}{c}I_{x} \\
\text { Ib } \sec ^{2} \text { in } \\
\end{array}$ & $\begin{array}{c}I_{y} \\
1 b \cdot \sec ^{2} \text { in } \\
\end{array}$ & $\begin{array}{c}I_{z} \\
1 b \sec ^{2} \text { in } \\
\end{array}$ & $\begin{array}{r}I_{x z} \\
\text { lb } \sec ^{2} \text { in } \\
\end{array}$ & $\begin{array}{c}I_{z s} \\
\text { Ib } \sec ^{2} \text { in } \\
\end{array}$ & $\frac{k^{2}}{a b}$ \\
\hline $\begin{array}{l}\text { Frant Wheel Drive } \\
\text { Corfig. "M" }\end{array}$ & 3290 & 66.1 & 33.9 & 19.44 & 4212 & 21667.3 & 21804.9 & -257.89 & 18889.0 & 1.16 \\
\hline $\begin{array}{l}\text { Front Wheel Drive } \\
\text { Config. "N" }\end{array}$ & 3290 & 61.3 & 38.7 & 19.83 & 4261.8 & 22362.3 & 22553.8 & -518.04 & 19733.0 & 1.14 \\
\hline $\begin{array}{l}\text { Rear Wheel Drive } \\
\text { Config. "A" }\end{array}$ & 3290 & 67.0 & 33.0 & 18.78 & 4253.7 & 21387.1 & 21649.7 & 356.71 & 18713.0 & 1.17 \\
\hline $\begin{array}{l}\text { Rear Wheel Drive } \\
\text { Config. "B" }\end{array}$ & 3290 & 53.1 & 46.9 & 19.66 & 4349.6 & 23501.8 & 23901.5 & -29.28 & 21165.0 & 1.14 \\
\hline $\begin{array}{l}\text { Rear Wheel Drive } \\
\text { Config. "C" }\end{array}$ & 3290 & 64.7 & 35.3 & 19.73 & 4281.5 & 22230.3 & 22457.0 & -36.84 & 19574.0 & 1.18 \\
\hline $\begin{array}{l}\text { Conv. Rear } \\
\text { Drive "A" }\end{array}$ & 3307 & 54.8 & 45.2 & 19.97 & 4280 & 24604.2 & 25119.3 & -215.62 & 22375.0 & 1.20 \\
\hline $\begin{array}{l}\text { Conv. Rear } \\
\text { Drive "B" }\end{array}$ & 3307 & 55.8 & 44.2 & 19.45 & 4198.2 & 22471.6 & 22927.5 & -56.16 & 20176.0 & 1.10 \\
\hline
\end{tabular}




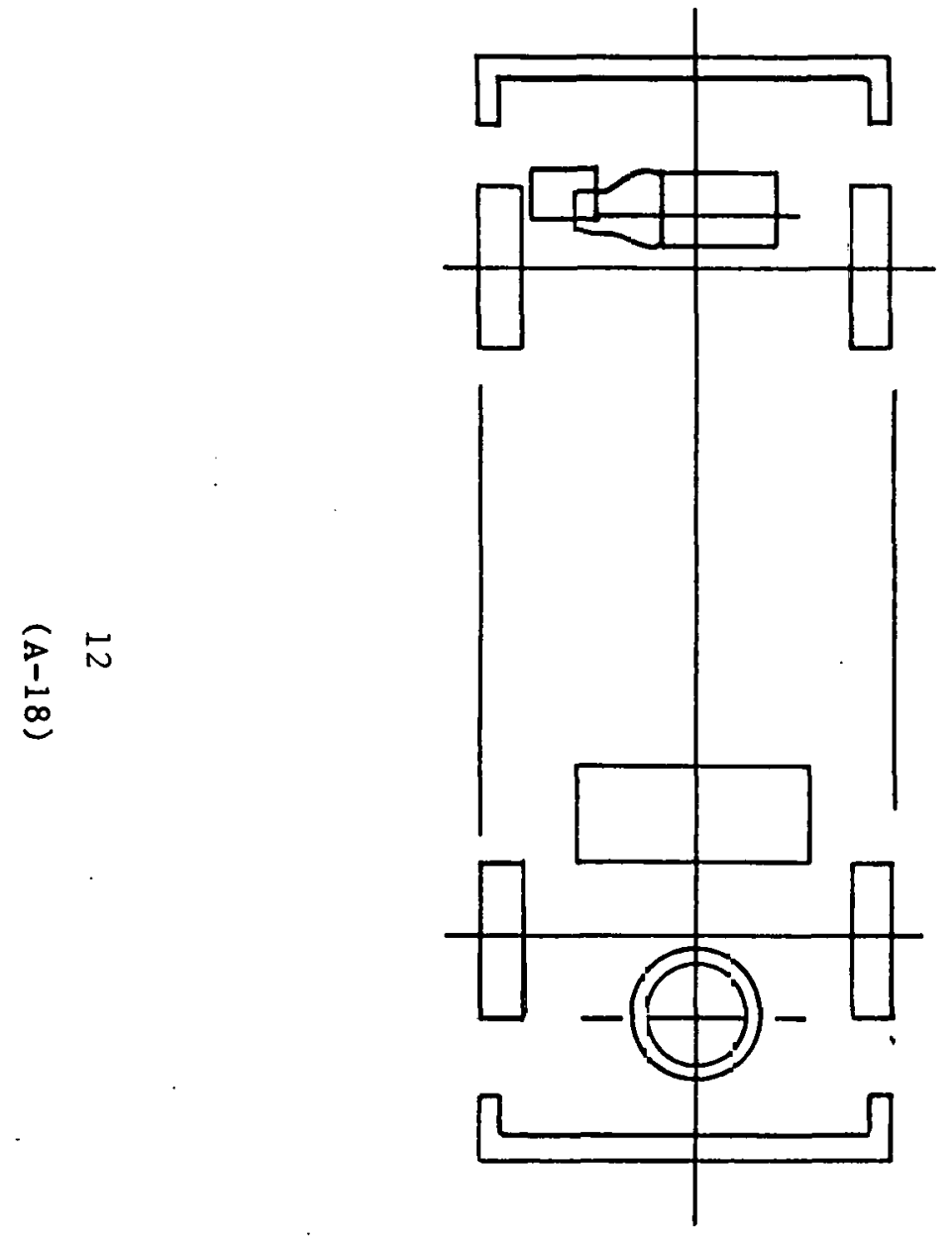

BASE

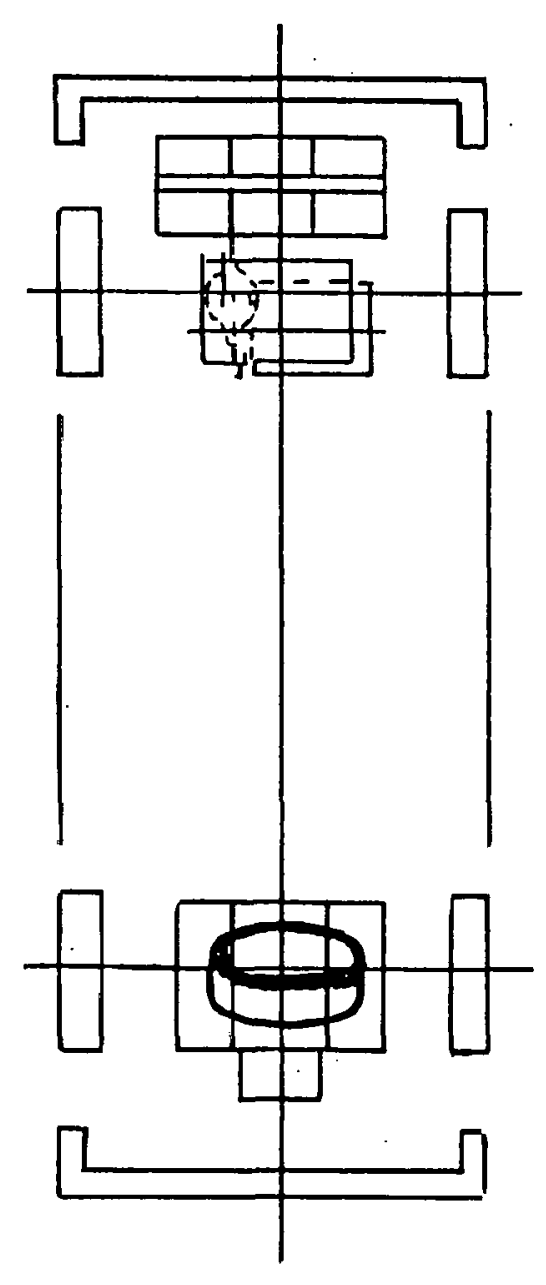

CONFIG. "N"

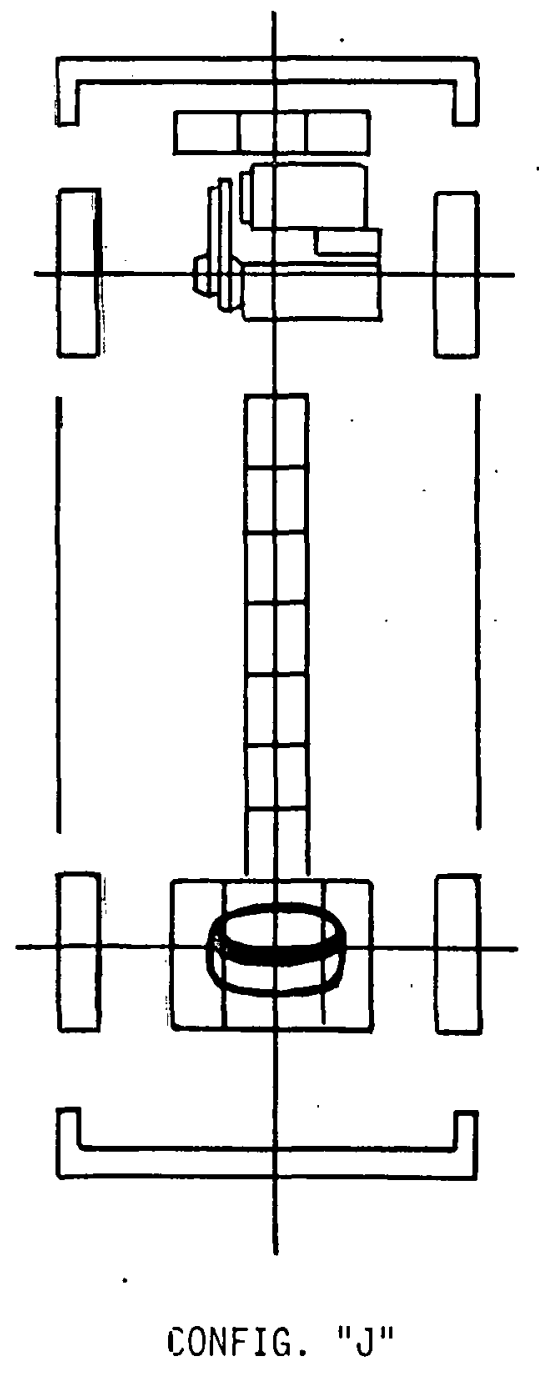

CONFIG. "J"

Figure 1 SIMLLATED EASE CAR AND EY CONFIGURATIC VS 
TABLE 2

BASE CAR AND EV CONFIGIJRATION PARAMETERS

\section{PARAMETER} Weight (Ibs.)

a (inches)

b (inches)

$H$ (inches)

$\overbrace{i} I_{x}\left(1 b-i n-\sec ^{2}\right)$

$I_{y}\left(1 b-i n-\sec ^{2}\right)$

$I_{z}\left(1 b-i n-\sec ^{2}\right)$

$I_{x z}\left(1 b-i n-s e c^{2}\right)$

$K_{F}$ (front suspension rate $1 \mathrm{~b} /$ in)

$K_{R}$ (rear suspension rate $1 \mathrm{~b} / \mathrm{in}$ )

\begin{tabular}{|c|c|}
\hline & ASE CAR \\
\hline TOTAL & SPRUNG MASS \\
\hline 2341 & 2063.2 \\
\hline 34.90 & 33.54 \\
\hline 64.30 & 65.66 \\
\hline 20.40 & 21.580 \\
\hline 4011.0 & 3394.74 \\
\hline $14<71.0$ & 12838.76 \\
\hline 14700.0 & 12777.16 \\
\hline 0.0 & 67.05 \\
\hline
\end{tabular}

100.7

98.5

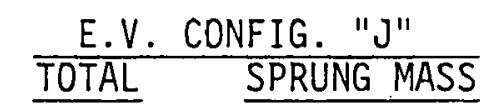

3290

42.46

56.74

18.59

4183

20150

20309

$-165.0$

130.1

175.0
E.V. CONFIG. "N" TOTAL SPRUNG MASS

$3290 \quad 3012.2$

38.39

37.82

60.81

61.38

19.83

20.61

4262.0

3652.99

$22362.0 \quad 20525.98$

$22554.0 \quad 20220.14$

$-518.00 \quad-482.19$

139.2

157.9 
aligning torque compliance camber. These compliance effects occur because suspension systems are intentionally designed with a certain amount of flexibility by the use of rubber bushings, for vibration isolation and other reasons. These compliances play a very important role in the handling properties of a vehicle, and handling behavior can actually be modified by properly incorporating a certain amount of suspension system flexibility.

The standard tire installed on the base car is a P155xR13. Mechanical properties of this size tire are not known to be available within the public domain; hence; an $\Lambda R 78 \times 13$ tirc, for which properties were available, was substituted for the simulation study described subsequently. A carpet plot. of lateral force as a function of slip angle and normal load for this tire is shown in Figure 2. Since the additional weight of the two electric vehicle configurations required a tire with greater load carrying capacity, a CR70x13 tire was simulated on these vehicles. Lateral force properties of this tire are shown in Figure 3. Complete HVOSM data sets for the configurations simulated are given in Appendix B.

\subsection{Linear Vehicle Stability and Control Analysis}

In order to provide a basis fur more fully understanding the results obtained through simulating the various vehicle configurations with the HVOSM--a complex, nonlinear vehicle dynamics simulation--limited investigations were conducted with simplified, linear automobile models. Such closed form analyses result in a better appreciation for the fundamental relationships between various physical parameters than can be obtained through simulation results alone. Although a number of investigations have been conducted with linear automobile models, the following discussion is based mainly on the wnrk reported in References 3 and 4 . Figure 4 gives the nomenclature for an automobile (bicycle model) in a steady-state turn of radius $\mathrm{R}$ with body slip angle $(B)$, yaw rate $(r)$ and front wheel steer angle $(\delta)$ held constant. The body slip angle and steer angle are treated as small angles. The simplified system represented in the figure can be described by a lateral force and a yaw moment equation: 


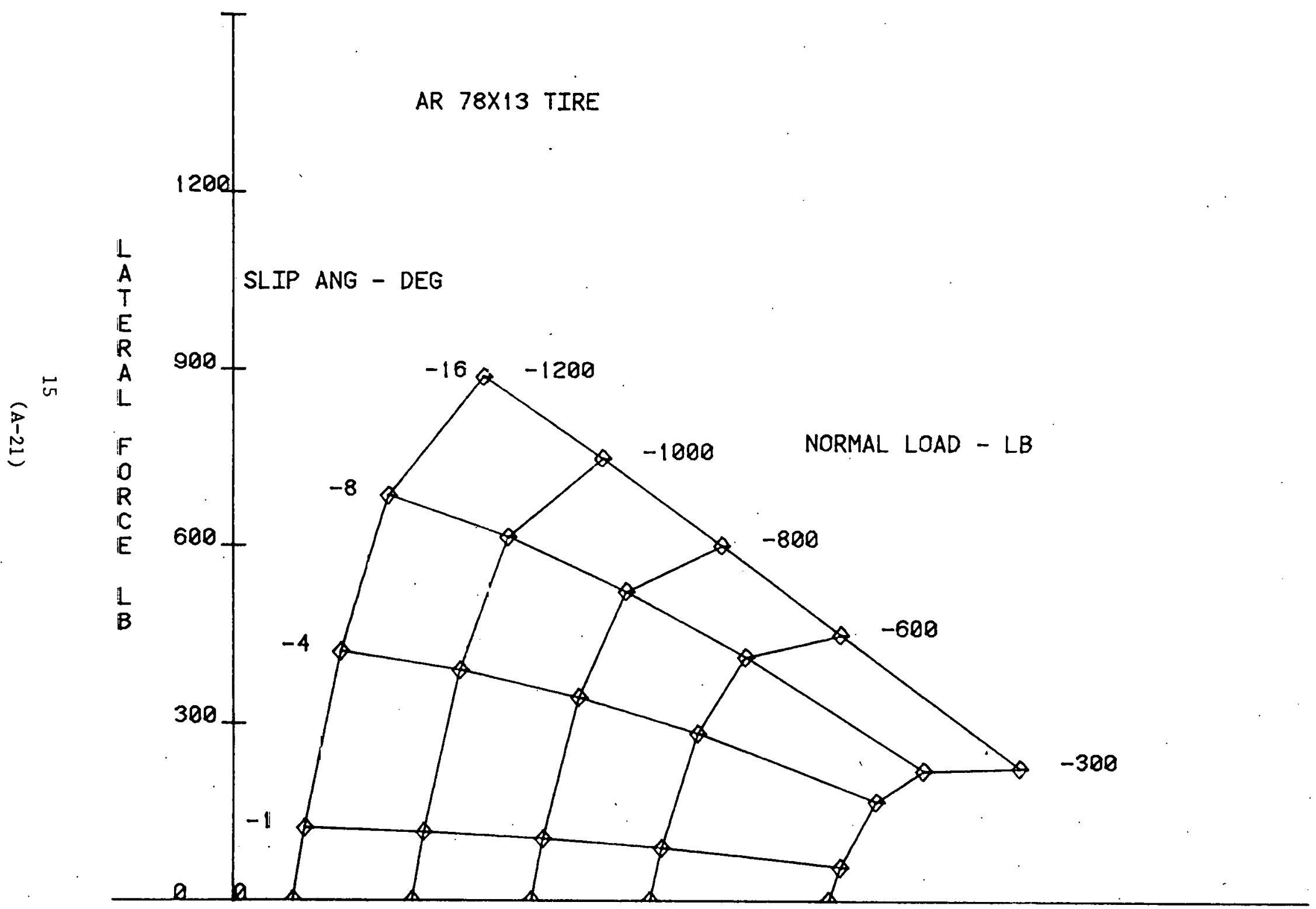

Figure 2 AR $78 \times 13$ TIRE CARPET PLOT 


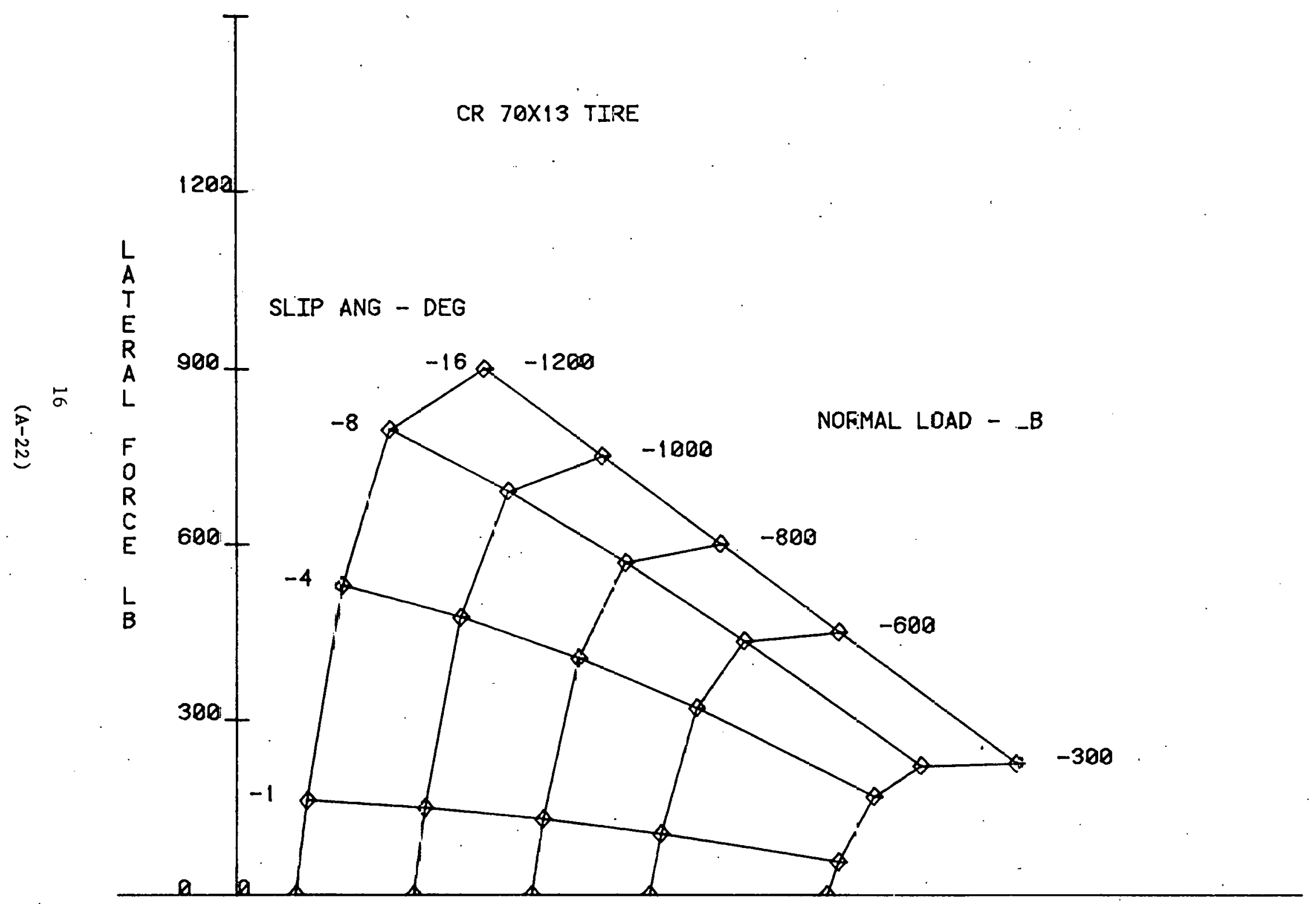

Figure 3 CR 70X13 TIRE CAR'DT PLOT 


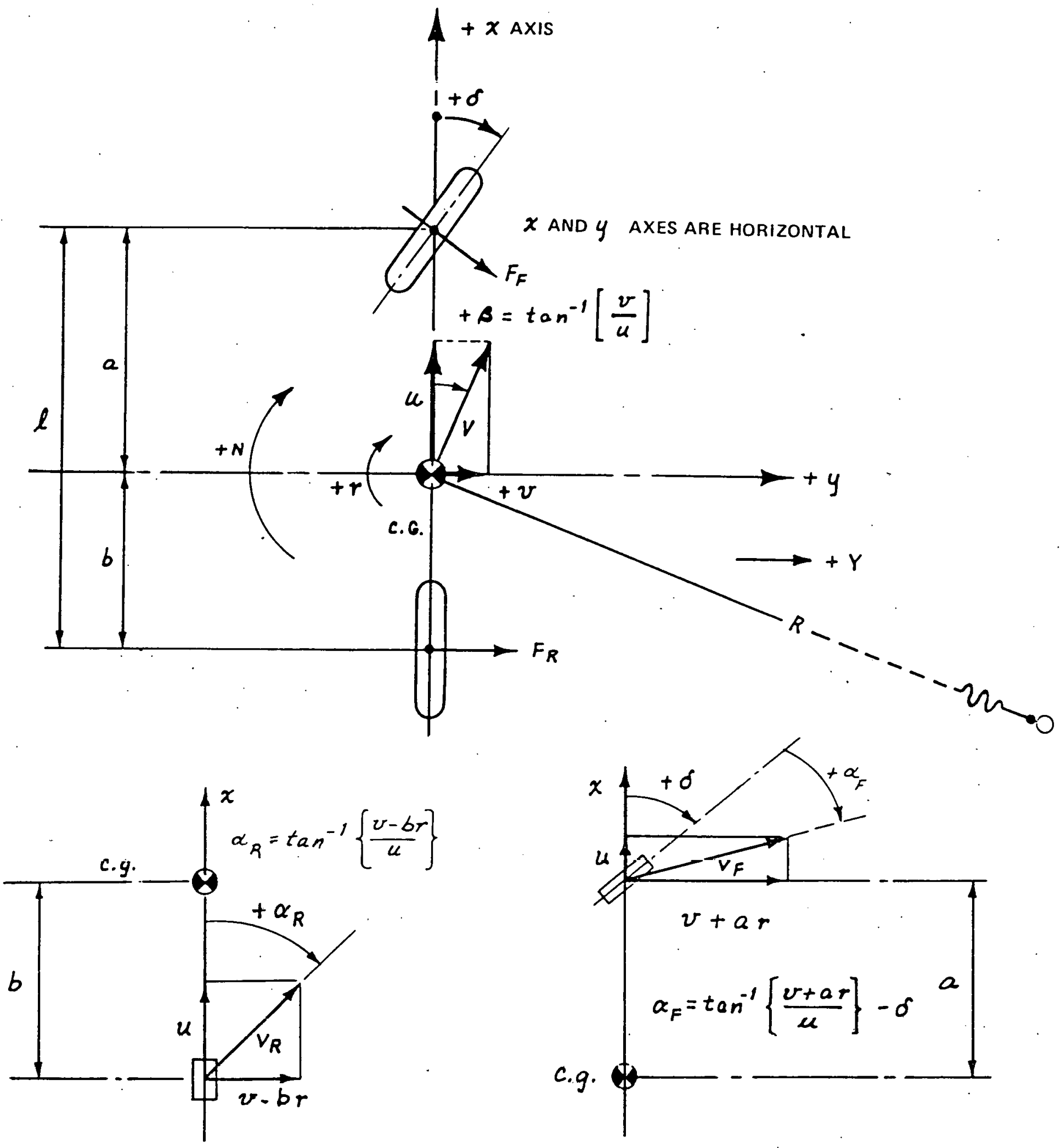

Figure 4 TWO DEGREE OF FREEDOM MODEL OF THE AUTOMOBILE 


$$
\begin{gathered}
Y=F_{F} \cos \delta+F_{R}=F_{F}+F_{R} \\
N=a F_{F} \cos \delta-b F_{R}=a F_{F}-b F_{R}
\end{gathered}
$$

where $F_{F}$ and $F_{R}$ are the products of tire cornering stiffness and tire slip angle. Thus,

$$
\begin{aligned}
& F_{F}=C_{\alpha F} \quad \alpha_{F}=C_{\alpha F} \tan ^{-1}\left[\frac{v+a r}{u}-\delta\right] \\
& F_{r}=C_{\alpha R} \quad \alpha_{R}=C_{\alpha R} \tan ^{-1}\left[\frac{v-b r}{u}\right]
\end{aligned}
$$

Noting that $v / u=B$ and $u \approx V$, then:

$$
\begin{aligned}
& F_{F}=C_{\alpha F}\left(\beta+\frac{a r}{V}-\delta\right) \\
& F_{R}=C_{\alpha R}\left(B-\frac{b r}{V}\right)
\end{aligned}
$$

For steady-state turning, the resultant yaw moment, $N$, is zero and lateral force, $Y$, equated to MVr, the centrifugal force. With these conditions, the equations of the system become:

$$
\begin{aligned}
& c_{\alpha F}\left(\beta+\frac{a r}{V}-\delta\right)+c_{\alpha R}\left[\beta-\frac{b r}{V}\right]=M V r \\
& a c_{\alpha F}\left[\beta+\frac{a r}{V}-\delta\right]-b C_{\alpha R}\left[\beta-\frac{b r}{V}\right]=0
\end{aligned}
$$


Solving the above two equations for the front wheel steer angle results in

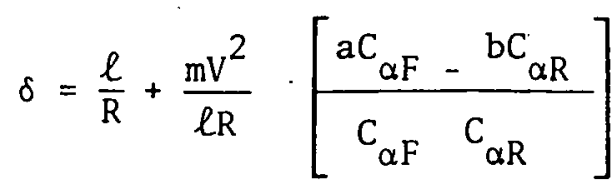

Denoting $h_{0}=\frac{C_{\alpha R}}{C_{\alpha S}}-\frac{a}{l}$ where $C_{\alpha S}=C_{\alpha R}+C_{\alpha F}, l=a+b$,

and $\frac{1}{C_{0}}=\frac{C_{\alpha S} W}{C_{\alpha F} C_{\alpha R}}$, and writing the steer angle equation in terms of $C_{0}$

and $h_{0}$ results in

$$
\delta=\frac{l}{\mathrm{R}}-\frac{\mathrm{h}_{\mathrm{O}}}{\mathrm{c}_{\mathrm{o}}} \frac{\mathrm{V}^{2}}{\mathrm{Rg}}
$$

Note that $h_{0}$ is the classic static margin parameter which provides an indication of lateral directional control of the simple two degree-of-freedom model. The above equation is often expressed as

$$
\delta=57.3 \frac{\ell}{R}+K \frac{V^{2}}{R_{g}}
$$

where $K=-57.3 \frac{h_{0}}{C_{0}} . C_{0}$ is always negative since the tire cornering stiffness is always negative. Therefore, $K$ is positive for positive $h_{0}$ and negative for negative $h_{0}$. A vehicle with a positive static margin requires an increase in steer angle to maintain a constant radius as the velocity is increased. This is the understeering characteristic with which most of the driver population is familiar. For negative static margin, the converse is true resulting in classical oversteering behavior.

Although this simplified model gives an indication of a vehicle's behavior in the linear range of operation, many other factors such as geometric roll steer, tire aligning torques, camber effects, steer effects due to suspension and steering compliances, strongly influence response. 
Milliken, et al. (Ref. 5) have included some of the additional effects in their analysis by ignoring their interaction with each other and treating them independently as separate "add on" factors. Each individual factor results in an incremental change in static margin, $h_{i}$, or an incremental change in cornering stiffness parameter $C_{i}$. For all of the effects considered, the steer equation (10) becomes

$$
\delta=\frac{\ell}{R}-\frac{h}{C} \quad a_{y} \text { where } \begin{aligned}
h & =h_{0}+\Sigma h_{i} \\
C & =C_{0}+\Sigma C_{i}
\end{aligned}
$$

Table 3 (from Ref. 5) gives the summary of the steer effects considered in that analysis by listing the factors and their effects on both static margin $h_{i}$ and cornering stiffness parameter $C_{i}$.

Since a goal of the present study is to design an optimized EV packaging layout which should, ideally, have a minimal impact on handling characteristics, an attempt was made to select different tires for the two EV configurations studied that would reasonably be expected to fit on the vehicle without modifications, would have sufficient load carrying capacity to handle the added weight, and would have a positive.effect on steady-state steering characteristics, hopefully maintaining properties similar to those of the base car. Table 4 gives a breakdown of the contribution of various steer effects to $h$ and $C$ for the three vehicles (base and $2 \mathrm{EV}$ configurations) with two different sets of tires. (AR78 $\times 13$, CR70 $\times 13$ ). It is noted that all six configurations ( 3 vehicles with 2 sets of tires) are intrinsically understeering (positive understeer factors) and the contribution of steer effects to the effective static margin is about $60 \%$ of the total. With both sets of tires, EV configuration " $\mathrm{J}$ " is somewhat less understeer than the base car, while configuration " $N$ " is slightly more understeer than the base car, as predicted by the simple two degree-of-freedom cornering stiffness and weight distribution model. Including compliance and steer effects results in both EV configurations being somewhat more understeer than the base car. Also, as is expected from the theory, the increased cornering stiffness of the larger tire results in a 
TABLE 3

SUMMARY OF STEER EFFECTS

\begin{tabular}{|c|c|c|c|c|}
\hline & FACTOA & $H_{1}$ & $c_{i}$ & REMARKS \\
\hline$\stackrel{N}{\sim}$ & 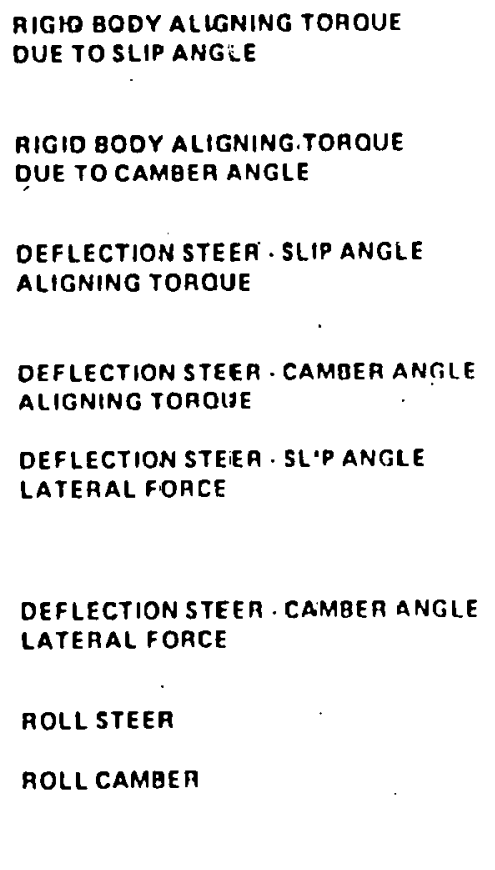 & 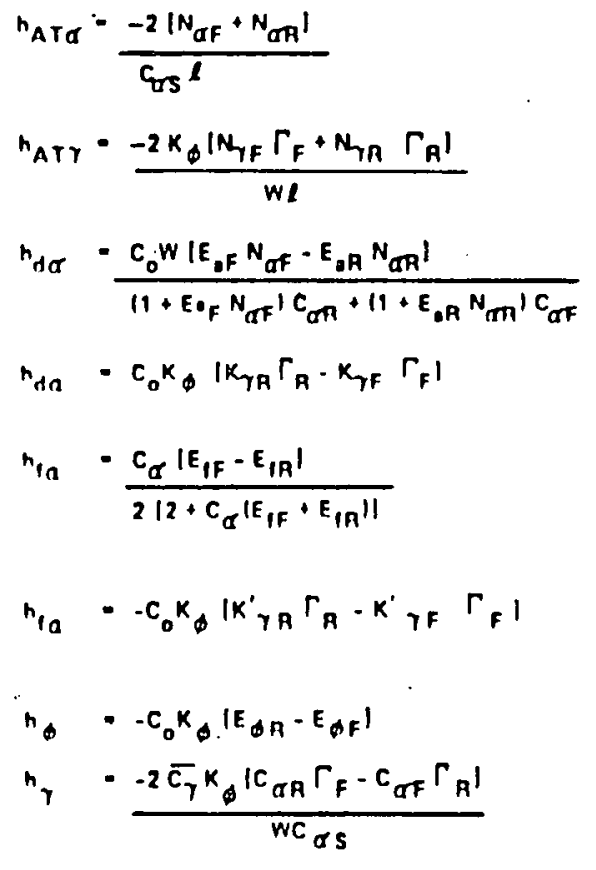 & 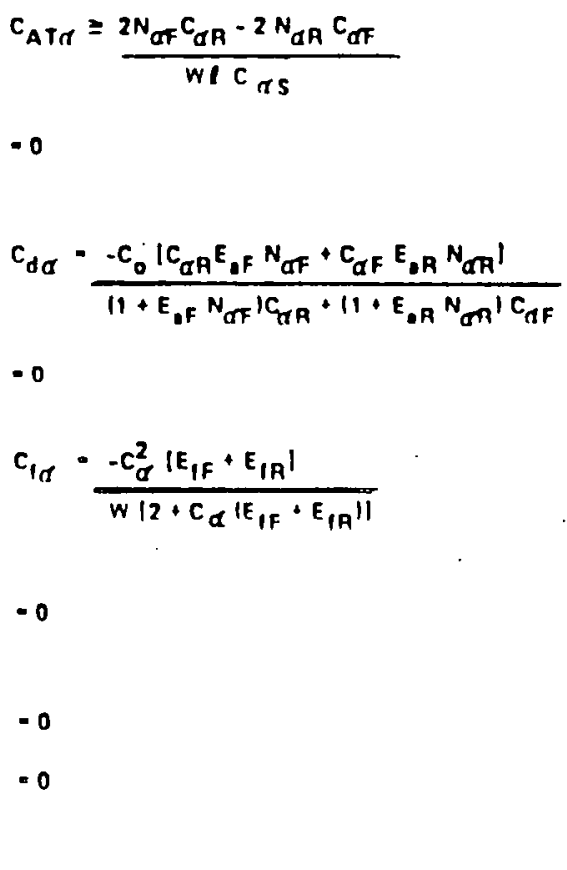 & $\bar{c}_{Y F} \cdot \bar{c}_{Y R} \cdot 2 \bar{c}_{Y}$ \\
\hline & \multicolumn{4}{|c|}{ 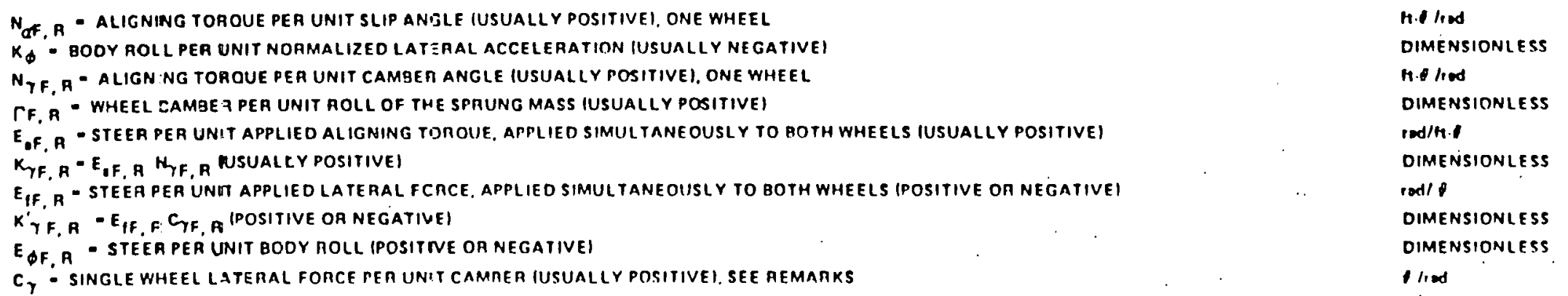 } \\
\hline
\end{tabular}


TABLE 4

COMPARISON OF STEER EFFECTS

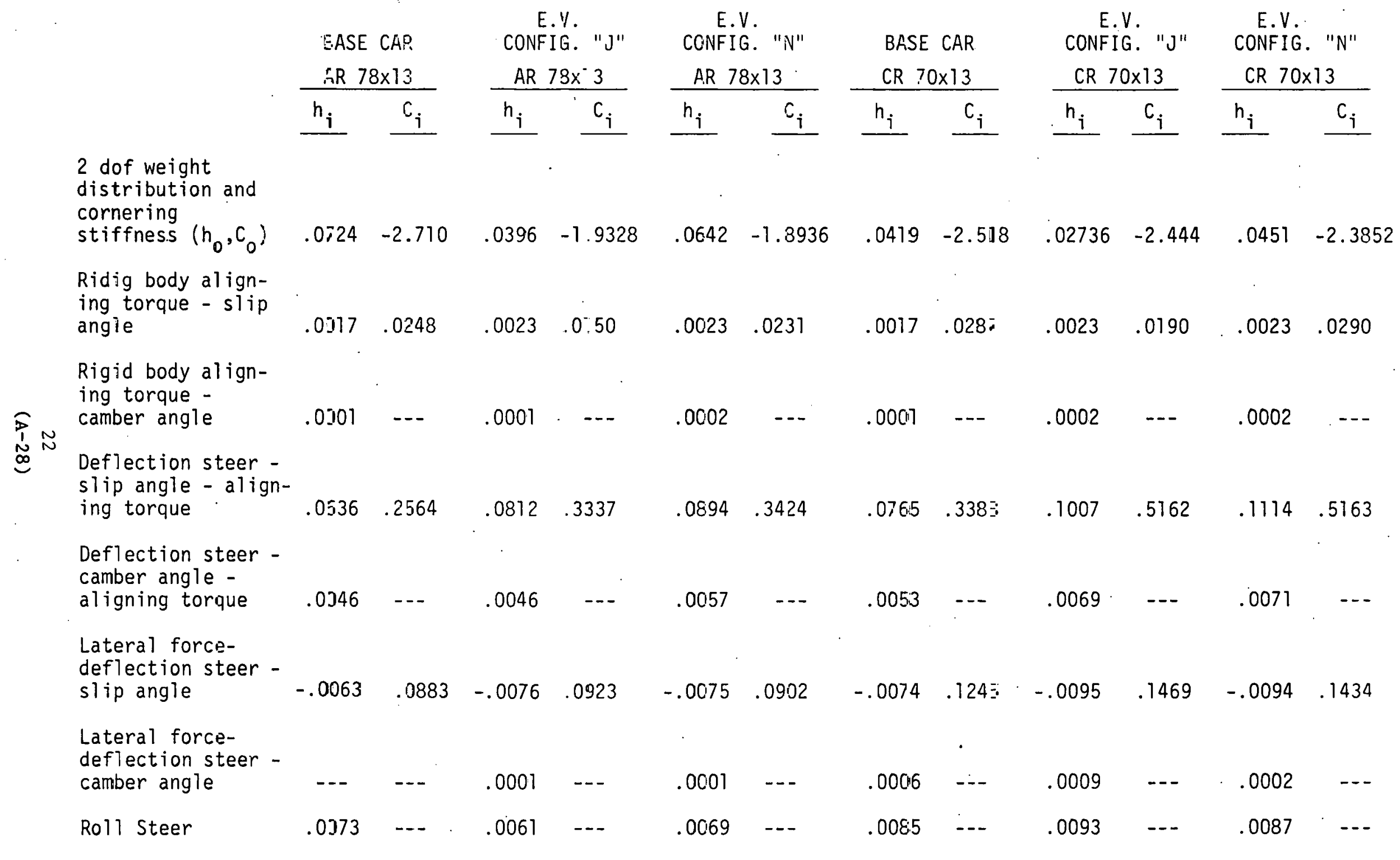


TABLE 4 (CONTD.)

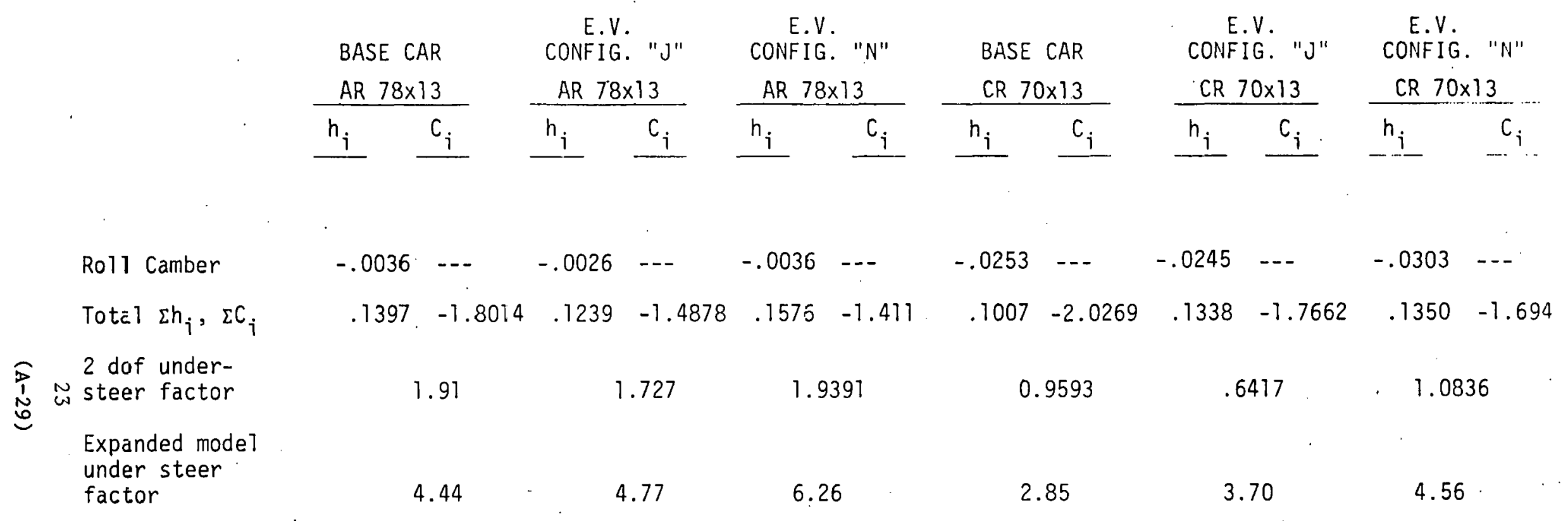


decrease in understeer for all vehicles. Comparing the EV configurations with CR $70 \times 13$ tires with the base car with AR78 $\times 13$ tires, it is seen that configuration " $N$ " has approximately the same understeer factor as does the base car, while configuration " $\mathrm{J}$ " is somewhat less understeer.

Although the foregoing analysis provides an approximation of a vehicle's steady-state behavior, additional understanding can be achieved by using linear theory to estimate the transient response of automobiles to varinus steer inputs. In two degree-of-freedom (yaw and side slip motion). models of vehicles, the equations of motion represent a second order damped system for yaw respunse. A number of response times are typically used to describe the vehicle's transient response, such as the time to attain $63 \%$ or $90 \%$ of the steady state value either in terms of yaw rate or lateral acceleration. Closer examination of the equations of motion leads to a general inference that as the understeer factor, $K$, decreases, the steady state yaw rate gain increases and the characteristic response time also increases. It is generally believed that vehicles with smaller response times are better in terms of vehicle handling than those with larger response times. This belief is supported by experimental studies reported in Ref. 6.

Yaw ratc time constants were computed by using a two dcgree-of-freedom simplified model for the above six configurations. Table 5 summarizes the results of this investigation. Included in this table are the simple and expanded two degree-of-freedom understeer factors, steady state yaw rate gain and three different response times. They are time to reach $63 \%$ and $90 \%$ of the steady state yaw response to a step steer input, and the effective time constant as determined by the frequency at which the yaw response lags the sinusoidal st.e.ering input by $45^{\circ}$.

It is quite clear from this sludy that changing to stiffer CR70 $\times 13$ tires reduces the response times for the two EV configurations. The same effect is not readily apparent for the base vehicle since the increase in cornering stiffness was offset by the reduction in understeer factor associated with the larger tires. The longer response time for configuration " $N$ " is a result of this configuration having the largest yaw moment of inertia. 
TABLE 5

SUMMARY OF LINEAR THEORY RESULTS

\begin{tabular}{|c|c|c|c|c|c|}
\hline $\begin{array}{l}\text { BASE CAR } \\
\text { AR } 78 \times 13\end{array}$ & $\begin{array}{l}\text { E.V. } \\
\text { CONF. "J" } \\
\text { AR } 78 \times 13\end{array}$ & $\begin{array}{l}\text { E.V. } \\
\text { CONF. "N" } \\
\text { AR } 78 \times 13\end{array}$ & $\begin{array}{l}\text { BASE CAR } \\
\text { CR } 70 \times 13\end{array}$ & $\begin{array}{l}\text { E.V. } \\
\text { CONF. "J" } \\
\text { CR } 78 \times 13\end{array}$ & $\begin{array}{l}\text { E.V. } \\
\text { CONF."N" } \\
\text { CR. } 70 \times 13\end{array}$ \\
\hline
\end{tabular}

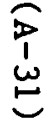

Simple 2 dof

indersteer factor

1.91

1.173

1.94

0.959

0.647

1.086

Yaw rate gain (deg/deg)

4.96

$5.61^{\circ}$

4.94

5.84

6.19

5.70

Yaw Rate Response

Times (sec)

$63 \%$ of steady state

0.755

0.177

0.179

0.155

0.157

0.171

$90 \%$ of steady state

0.298

0.358

0.353

0.319

0.337

0.340

Effective Time

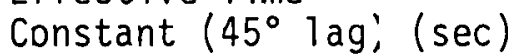

0.186

0.211

0.218

0.179

0.182

0.195 


\subsection{HVOSM Simulation Study Resulis}

In order to provide a basis for comparing the response characteristics of the two selected electric vehicle configurations to those of the base vehicle, the HVOSM was programmed to simulate two different types of maneuvers at varying levels of steering input. The two maneuvers were a trapezoidal steer maneuver and a sinusoidal steer maneuver, similar to Vehicle Handling Test Procedures (VHTP's) No. 4 and 5 developed by the University of Michigan (Ref. 7) for the NHTSA.

Each of these maneuvers are described briefly in the following:

Trapezoidal Steer (VHIP No. 4) -

This manuever simulates a vehicle making a "J" turn at an initial speed of $40 \mathrm{MPH}$. The vehicle is given a sudden steer input and steer angle is held constant thereafter. A typical steer angle (average steer angle of the front wheels) - time history is shown in Figure 5.

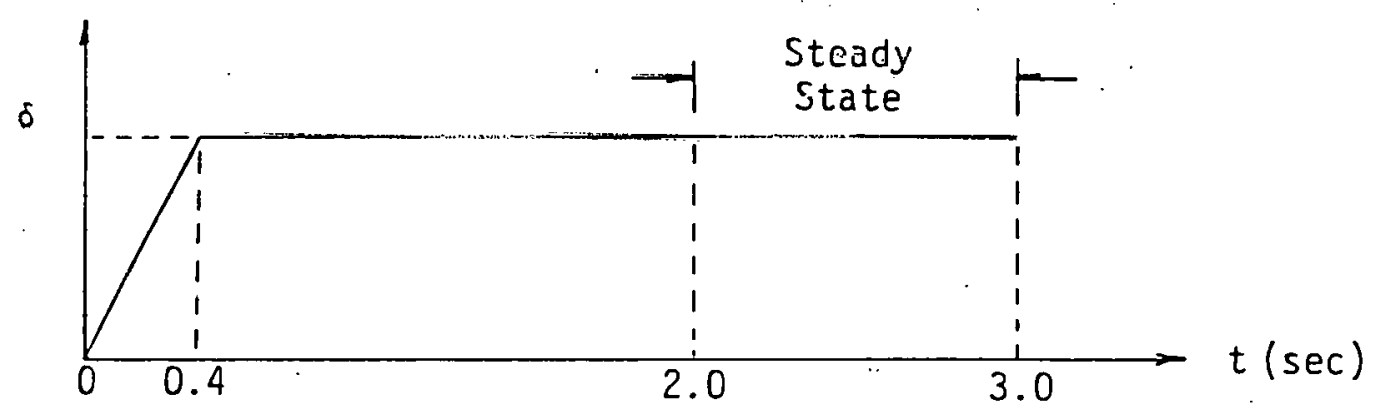

Figure 5 TYPICAL TRAPEZOIDAL STEER INPUT

The magnitude of steer angle is increased until tire side forces saturate resulting in a plowing condition (understeer) láteral drift (11eutral steer), or spinout (oversteer). The constant steer angle is determined from a reference steer angle $(\sigma)$ and wheelbase $(l)$, normalized to 10 feet: 


$$
\delta=\frac{\ell}{10} \sigma \text { where } \ell \text { is in feet }
$$

Simulations were performed for the following reference steer angles:

$$
\sigma=1,2,4,8,16^{\circ}
$$

The actual constant steer angles for the vehicles under study are as follows:

$$
\delta=.8267,1.6533,3.3067,6.6133,13.2267^{\circ} .
$$

The performance evaluation numerics for this maneuver are:

$$
\begin{aligned}
& \text { - } \quad \text { Max. yaw rate }\left(r_{p}\right) \\
& \text { - } \quad \text { Max. lateral acceleration }\left(a_{y_{p}}\right) \\
& \text { - } \quad \text { Peak side slip angle }\left(\beta_{p}\right) \\
& \text { - } \quad \text { Average path curvature ratio as defined by } \frac{\mathrm{R}_{S}}{\mathrm{R}_{a v e}}
\end{aligned}
$$

Where $\left(\frac{1}{R}\right)$ ave $=\frac{1}{2} \int_{0}^{2}\left(\frac{1}{R}\right) d t$ and $R_{S}=$ radius for $1 \mathrm{~g}$ lateral acceleration at
$40 \mathrm{MPH}$.

Sinusoidal Steer (VHTP No. 5) -

This procedure simulates a vehicle in a rapid lane change type of manuever at $45 \mathrm{MPH}$. The ideal performance is one in which the vehicle is displaced iaterally by approximately 12 feet with a final heading direction parallel to the original direction. The steering input is a sine wave of a period 2 seconds with various amplitudes. The general time history of the steer angle is shown in Figure 6. 


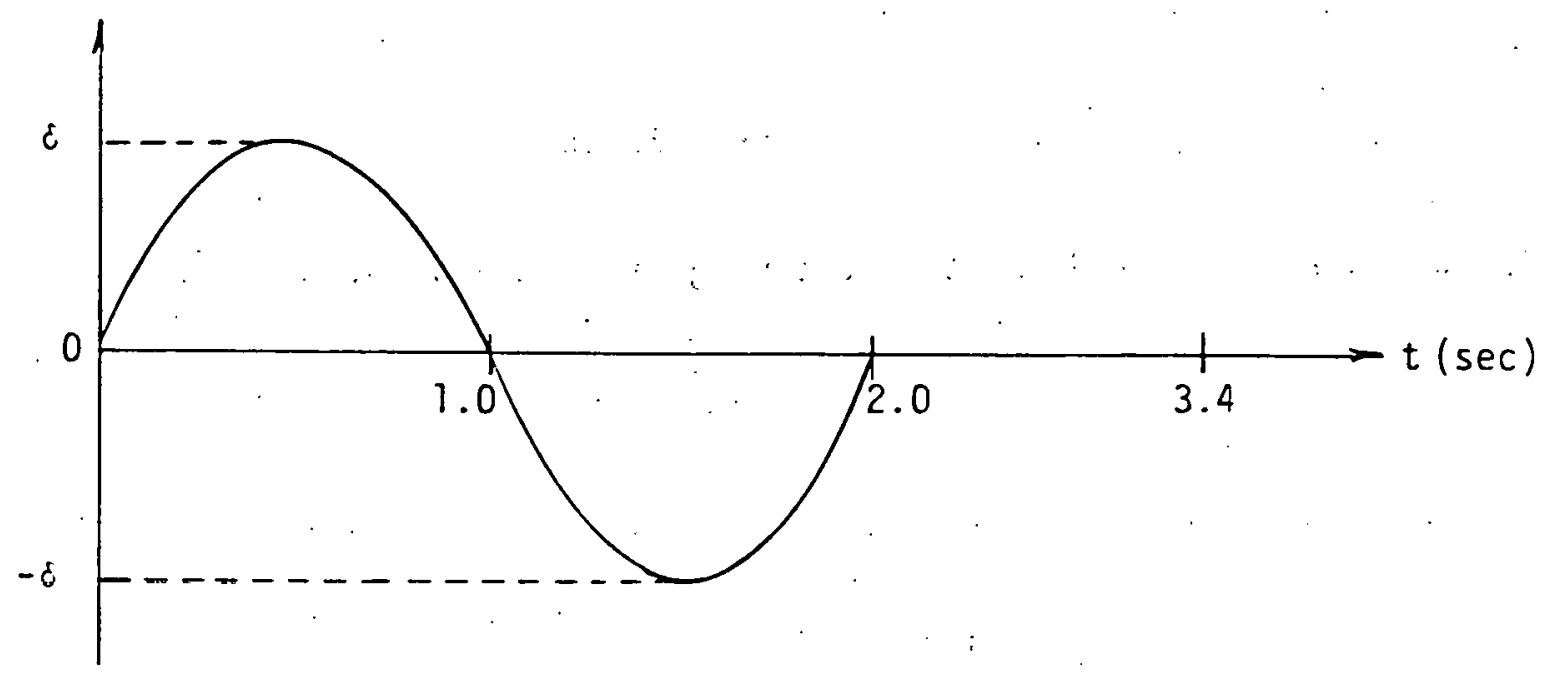

Figure 6 , TYPICAL SINUSOIDAL STEER INPUT

The amplitude $(\delta)$ is determined, as before, from a reference steer angle $(\sigma)$ and a normalized wheelbase $(\ell):$

$$
\delta \cdot=\left(\frac{\ell}{10}\right) \alpha \quad \ell \text { in feet }
$$

The reference steer angles for HVOSM simulation used were:

$$
\sigma=2 \text { and } 8
$$

The evaluation numerics for this maneuver are as follows:

a. Lane change deviation $\Delta$ as defined by

$$
\Delta=\frac{1}{3.4} \int_{0}^{3.4}|y-12| d t
$$

where $y$ is the lateral displacement of sprung mass center of gravity

b. Maximum sideslip angle $\left(B_{p}\right)$

c. Final heading angle at $t=3.4 \mathrm{sec}(\Delta \psi)$ 


\section{Trapezoidal Steer Results}

As described above, this maneuver results from a rapid application of steering. input to a constant level which is normalized with respect to wheelbase. The resulting vehicle response is generally similar to a "J" turn of varying degrees of curvature depending on the input level. Graphic displays of the three simulated vehicles at time intervals of 0.5 seconds are shown in Figures 7 and 8 for normalized steer inputs of $\sigma=2$ and $\sigma=8$ degrees, respectively. Note that for both steer input levels, the electric vehicle configurations attain a greater degree of curvature than does the base vehicle. Furthermore, the response of EV configuration " $N$ " lies between that of the base vehicle and configuration "J". As will be shown on later figures, all vehicles are generally well behaved, exhibiting response behavior well within bounds determined from a sample of the vehicle population. A tire lateral force saturation condition was reached by at least one tire on all vehicles at the $\sigma=8$ steer input.

. The peak vehicle sideslip angles achieved as a function of normalized steer angle are shown in Figure 9. It is interesting to note that, at the lower input levels, the base vehicle responds with a lower peak sideslip angle than do either of the EV's. However, at the $\sigma=16$ steer input, the base vehicle achieves a higher sideslip angle than the EV's. The base vehicle has a tendency to spin at the limit of cornering performance that is influenced by the manner in which the limit condition is achieved. Rnth EV configurations exhibit tendencies toward drift out at the limit. The peak yaw rates shown in Figure 10 also show these same tendencies.

Comparisons of the responses of these three vehicles with performance boundaries devcloped for a bruad sample of vehicles in Ref. 7 are shown in Figures 11 through 13 . In Figure 11 it is seen that the peak sideslip rate for EV configuration " $J$ " approaches the observed upper boundary at an input lovel of $\sigma=8$, but otherwise, the responses for all vehicles are well 


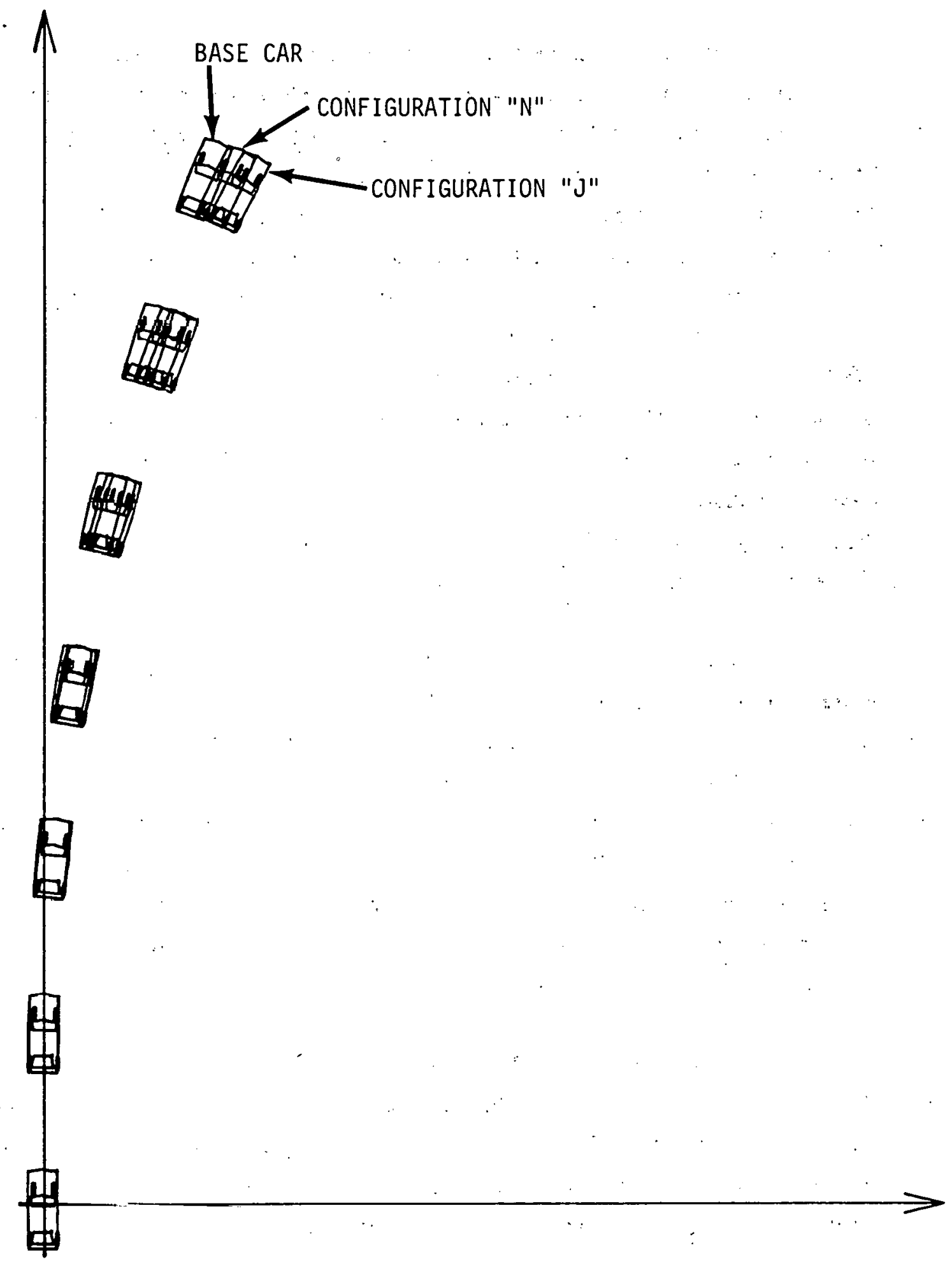

Figure 7 TRAPEZOIDAL STEER TRAJECTORIES FOR $\alpha=2^{\circ}$ 


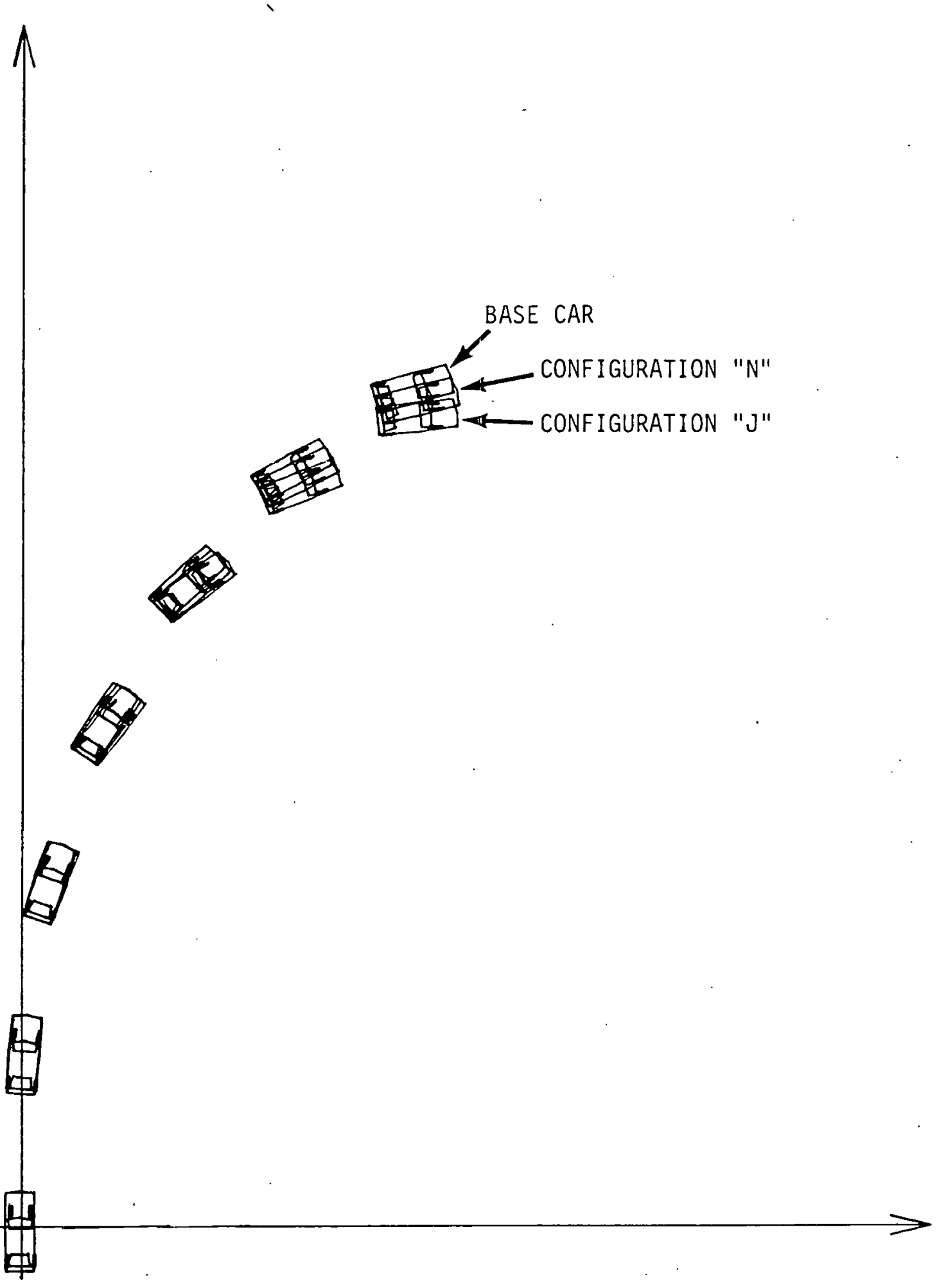

Figure 8 TRAPEZOIDAL STEER TRAJECTORIES FOR $\sigma=8^{\circ}$ 


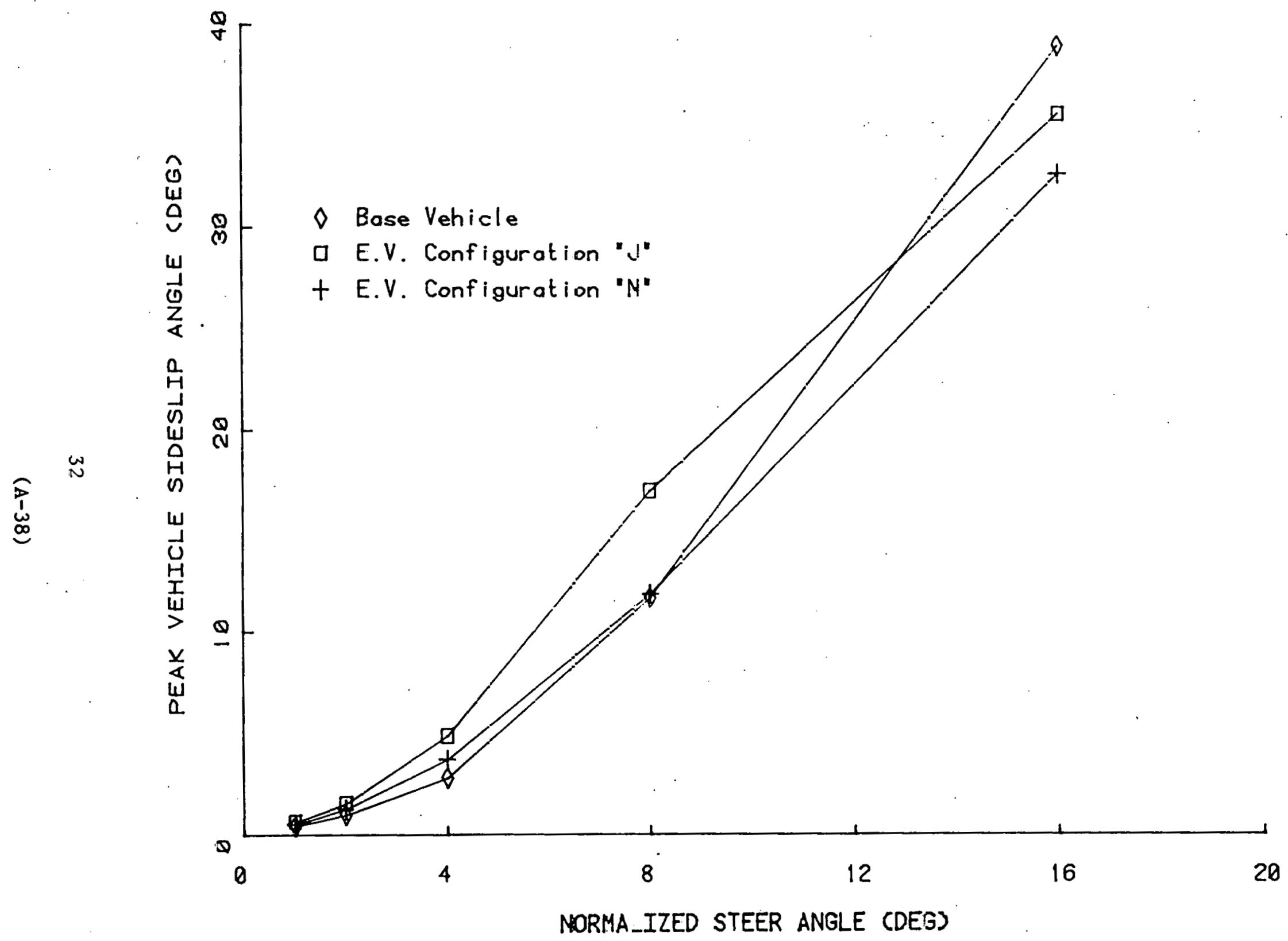

Figure 9 PEAK SIDESLIP ANGLE VS. STEER ANGLE FOR TRAPEZOIDAL STEER VIANEUVER. 


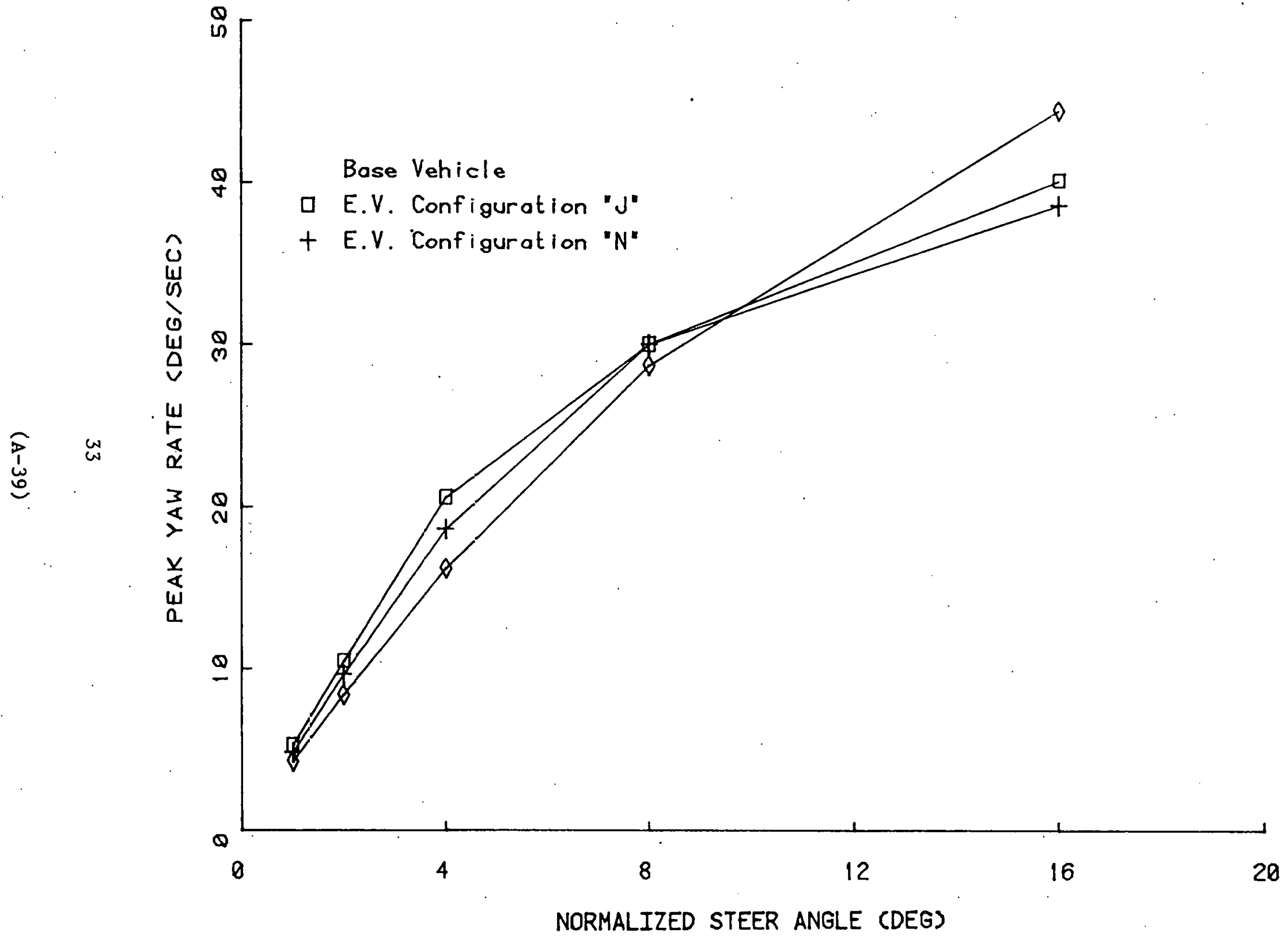

Figure 1.0 PEAK YAW RATE VS. STEER ANGLE FOR TRAPEZOIDAL STEER MANEUVER. 


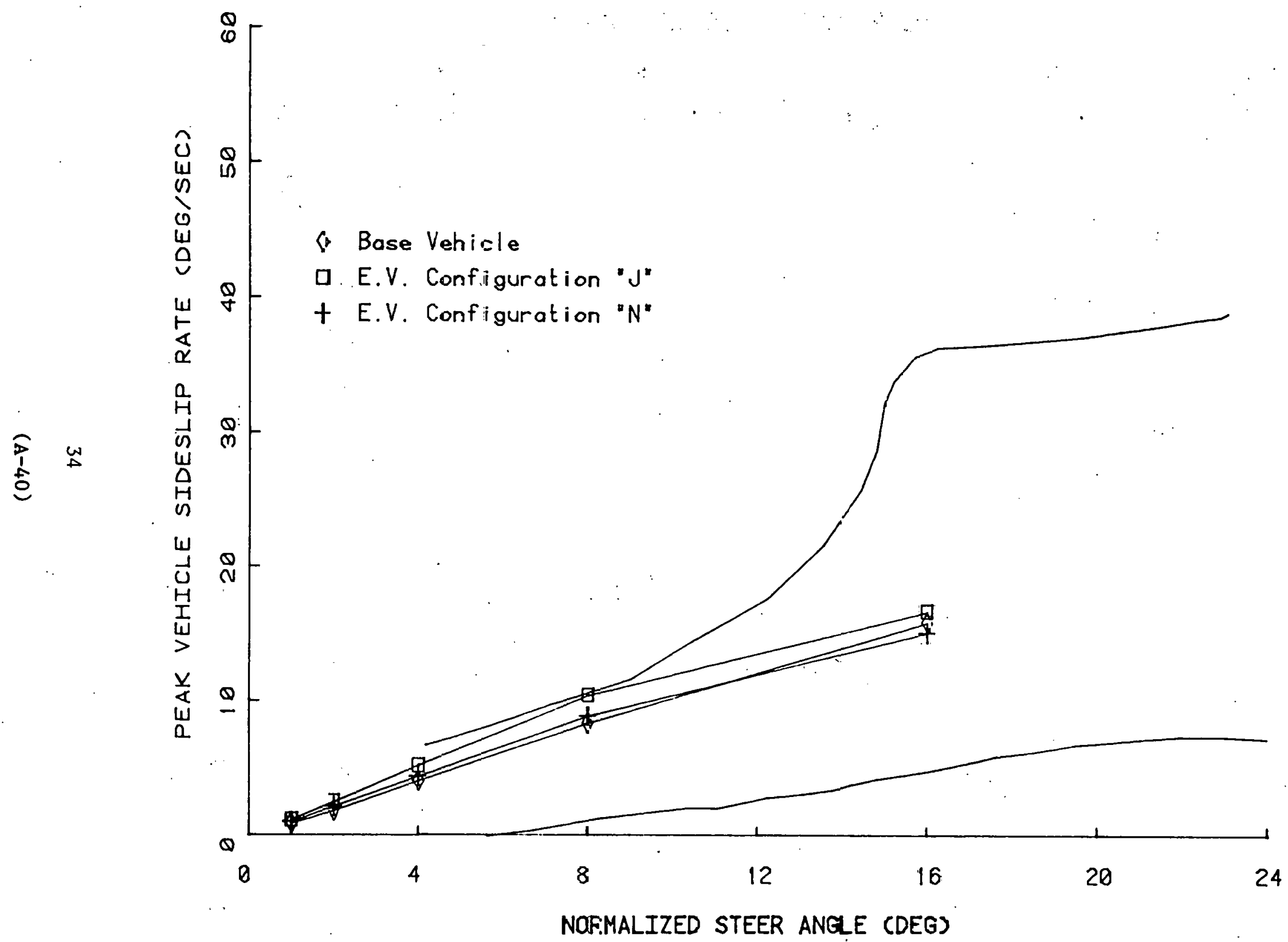

Figure il PEAK SIDESLIP RATE VS. STEER ANGLE FOR TRAPEZOIDAL STEER MANEUVER 


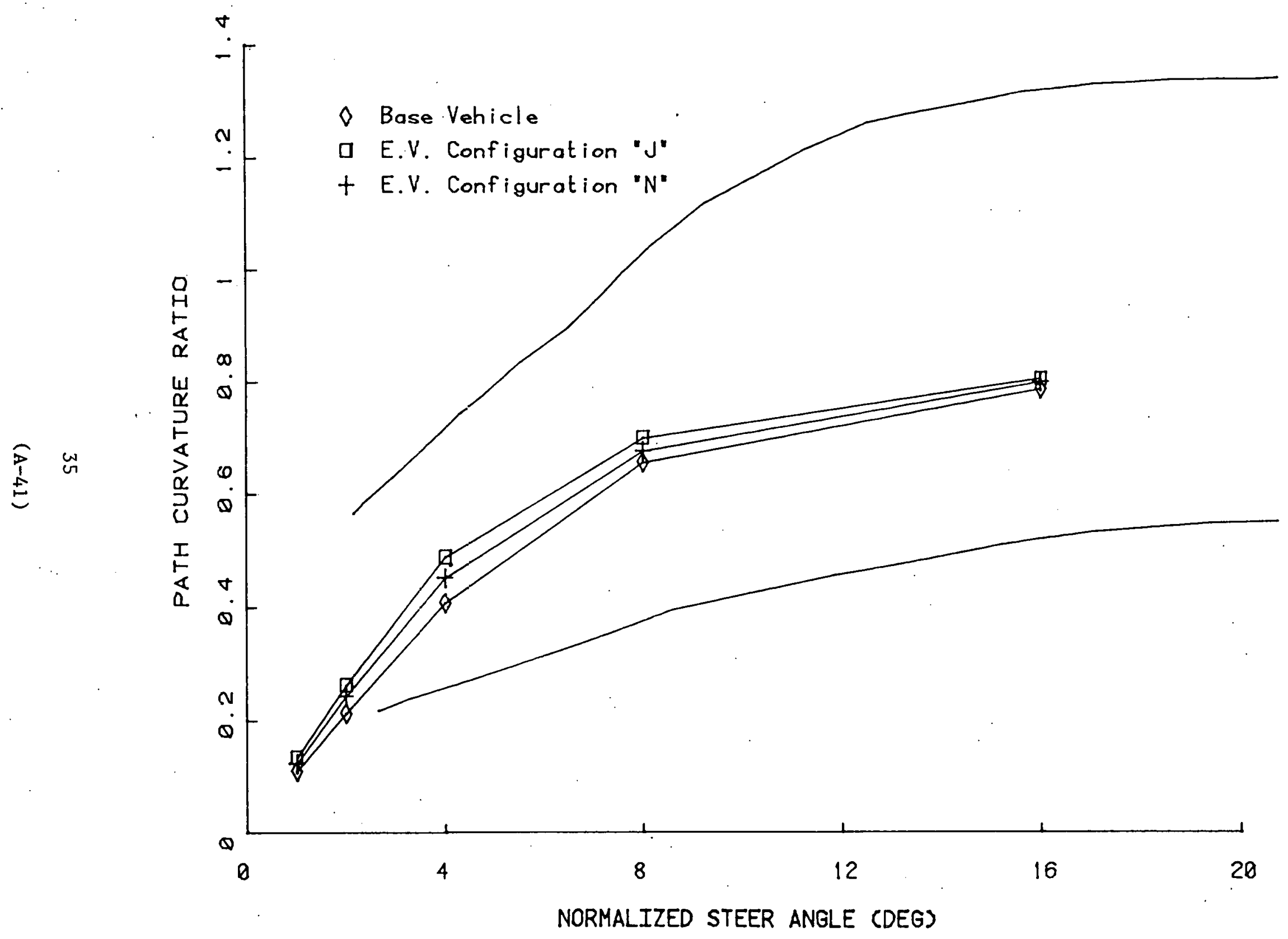

Figure 12 PATH CURVATURE RATIO VS. STEER ANGLE FOR TRAPEZOIDAL STEER MANEUVER 


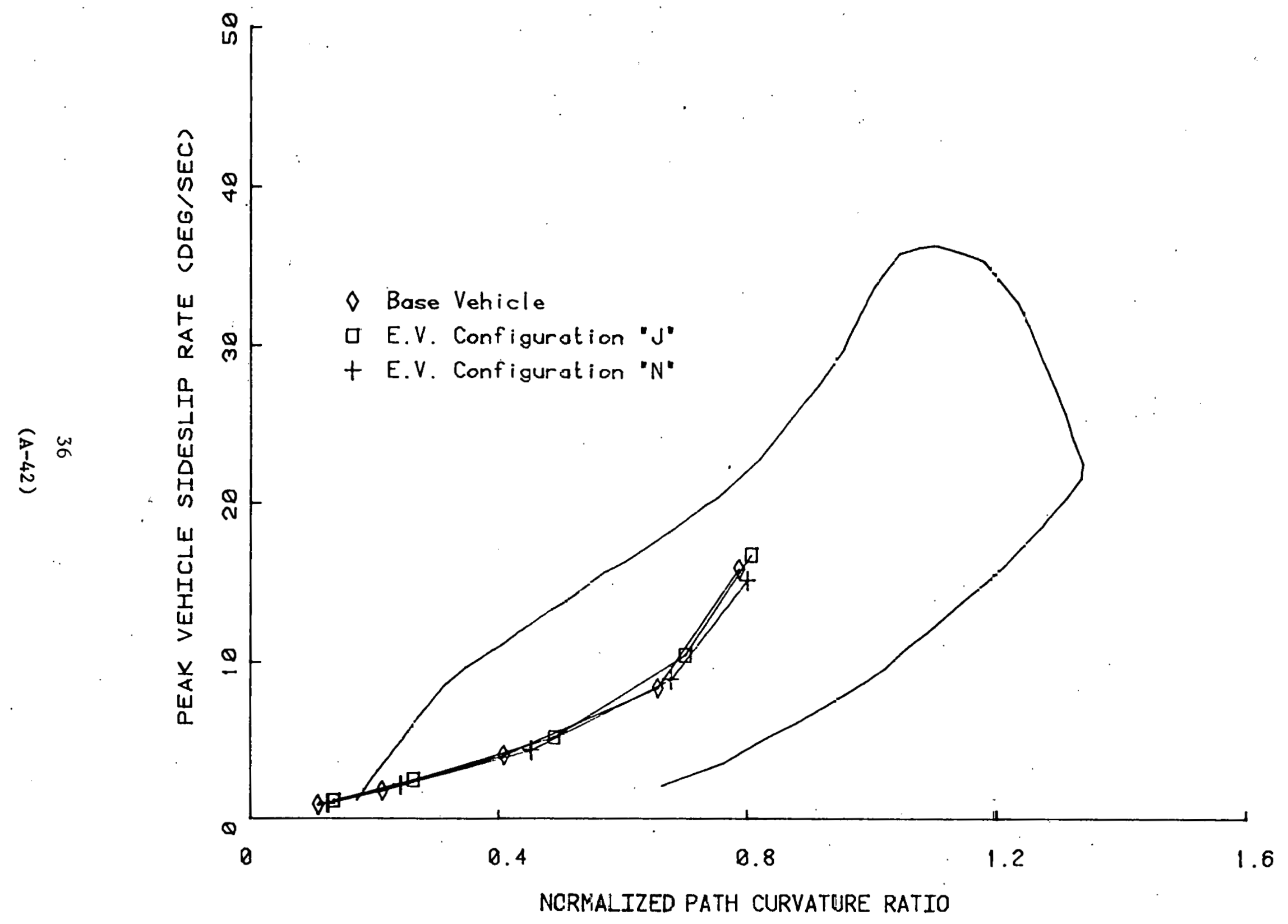

Figure 13 FEAK SIDESLIP RATE VS. FATH CURVATURE RATIO FOR TRAFEZOIDAL STEER MANEUVER 
within the bounds. Similarly, the path curvature response shown in Figure 12 indicates response behavior near the mean of the bounds developed from the vehicles sampled in Ref. 7 except near the low end of the input range. Note that the test program reported in Ref. 7 did not include experimental runs at $\sigma=1$. Figure 13 illustrates the peak vehicle sideslip rate plotted against the normalized path curvature ratio for all three simulated vehicles. Again, the predicted responses are nicely within the experimental bounds indicating that neither the base car nor the two EV configurations are uncharacteristic of the vehicle population in response to this type of steering input.

Predicted responses from the low level trapezoidal steer maneuver also result in a number of steady state turning response metrics. These are summarized in Table 6 for the base and electric vehicles simulated. Of most significance for the purposes of this study is the fact that neither of the EV configurations differ markedly from the base vehicle in terms of these metrics. Both EV's are less understeer than the base car, a fact which is reflected throughout the values in the table, with configuration " $J$ " being somewhat closer to neutral steer than configuration " $N$ ". The metrics, for all three vehicles are believed to be within "nornal" ranges characteristic of the current vehicle population.

\section{Sinusoidal Steer Results}

As described previously, this maneuver results from a steer imput represented by a single cycle sine wave of period 2.0 seconds and various amplitudes. Peak normalized steer inputs of $2^{\circ}$ and $8^{\circ}$ were selected for the simulations. "Ideal" response is characterized by a lateral displacement of 12 feet and a final heading parallel to the initial direction of travel.

Figures 14 and 15 are computer generated graphics which illustrate the trajectories predicted by the simulation for the three vehicles at the two normalized steer angles used. For the lower steer angle case, all three vehicles 


\section{TÁBLE 6}

HVOSM STEADY STATE ANALYSIS RESULTS

\begin{tabular}{|c|c|c|c|}
\hline & BASE CAR & $\begin{array}{c}\text { EV } \\
\text { CONFIG. "J" } \\
\end{array}$ & $\begin{array}{c}\text { EV } \\
\text { CONFIG. "N" }\end{array}$ \\
\hline $\begin{array}{l}\text { LATERAL ACCELERATION GAIN } \\
\dot{3} \Lambda_{y} / 38=g /^{\circ}\end{array}$ & 0.1512. & 0.1935 & 0.1814 \\
\hline $\begin{array}{l}\text { YAW RATE GAIN } \\
\partial r / \partial \delta \text { sec: }-1\end{array}$ & 4.868 & 6.242 & 5.667 \\
\hline $\begin{array}{l}\text { ROLL ANGLE SENSITIVITY } \\
\partial \phi / \partial A_{y}-\% / g\end{array}$ & 7.16 & 7.10 & 7.57 \\
\hline $\begin{array}{l}\text { SLIP ANGLE SENSITIVITY } \\
\partial \beta / \partial A_{y}=0 / g\end{array}$ & 3.72 & 4.72 & 4.00 \\
\hline $\begin{array}{l}\text { YAW RATE RESPONSE TIME } \\
(90 \% \text { SS) sec. }\end{array}$ & 0.386 & 0.399 & 0.396 \\
\hline $\begin{array}{l}\text { LATERAL ACCELERATION } \\
\text { RESPONSE TIME - SEC. }\end{array}$ & 0.660 & 0.686 & 0.073 \\
\hline $\begin{array}{l}\text { UNDERSTEER FACTOR, } \\
\mathrm{K}-\mathrm{deg} / \mathrm{g}\end{array}$ & 3.1 & 1.7 & 2.0 \\
\hline
\end{tabular}




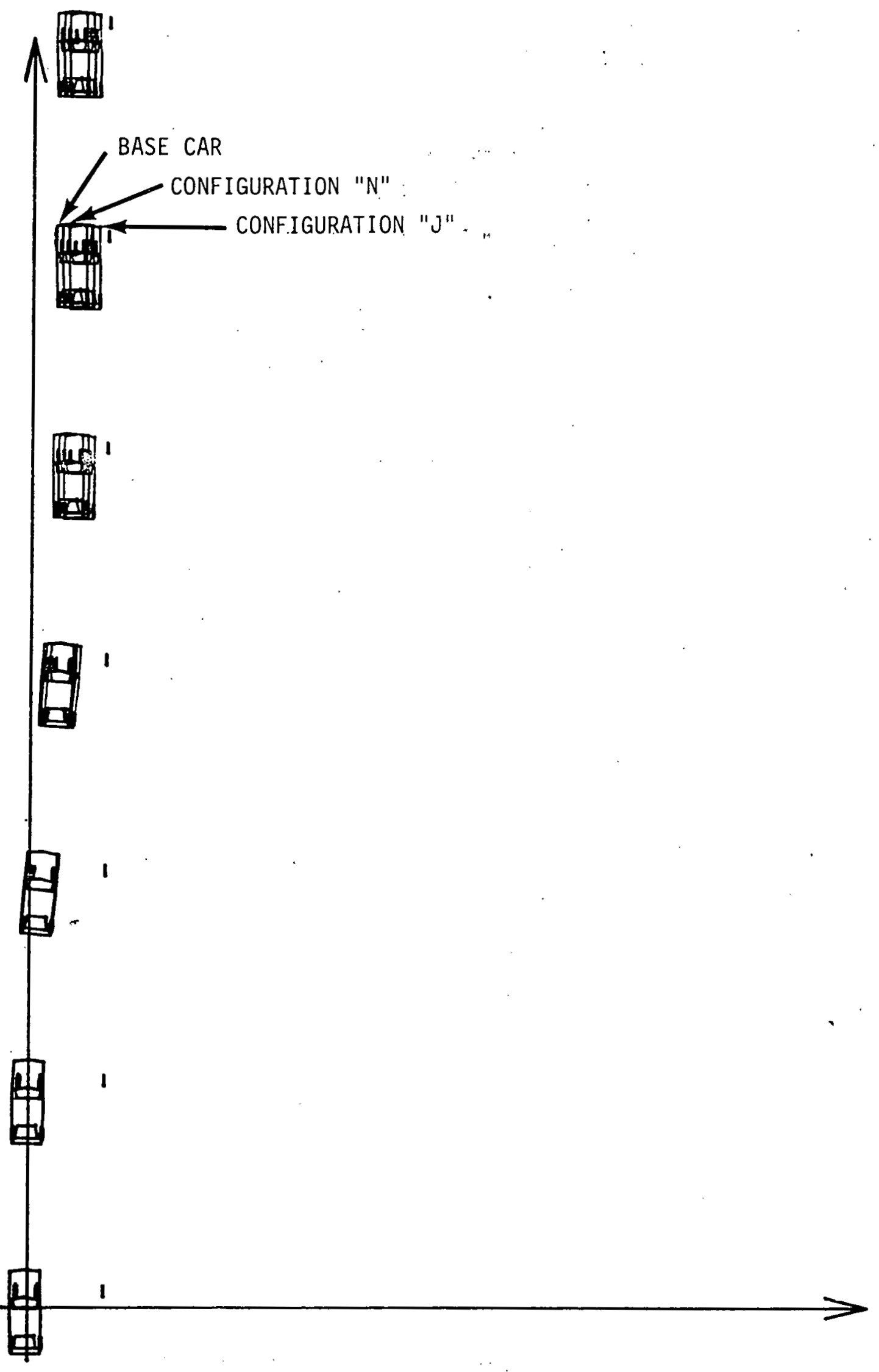

Figure 14 SINUSOIDAL STEER TRAJECTORIES FOR $\sigma=2^{\circ}$

$$
\begin{aligned}
& 39 \\
& (A-45)
\end{aligned}
$$




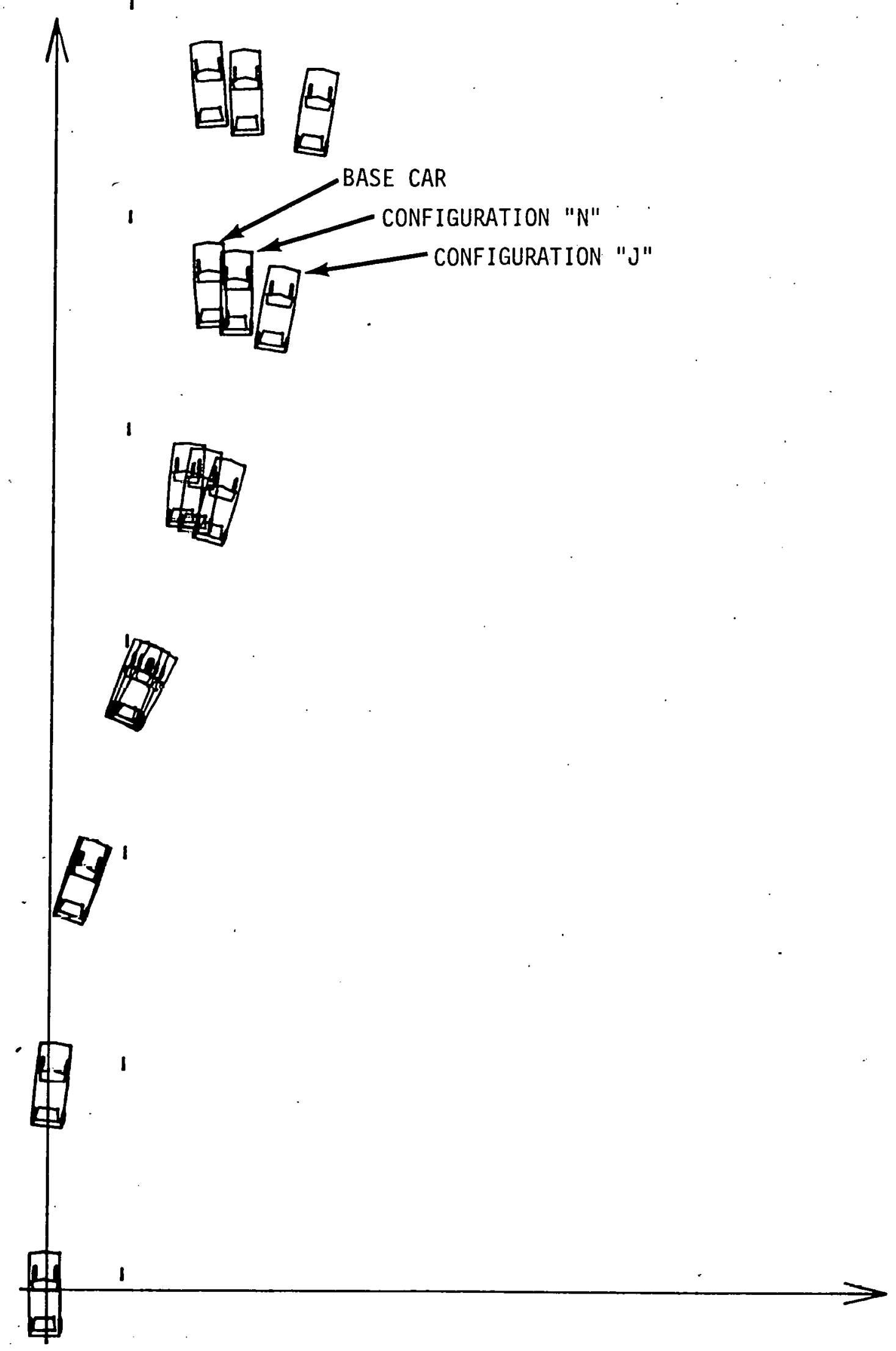

Figure $15 \cdot$ SINUSOIDAL STEER TRAJECTORIES FOR $\sigma=8^{\circ}$ 
exhibit generally good behavior with the final heading essentially parallel to the initial direction. Small differences are seen to exist in the path offsets attained with the base vehicle achieving the greatest deviation from the 12' ideal. Conversely, at the larger steer angle (Figure 15), the base car achieves the least offset and tends to overcorrect (head back toward the original path) slightly. Electric Vehicle configuration "N" achieves a near parallel path while configuration " $\mathrm{J}$ " undercorrects, or fails to recover from the first half of the sine steer input and continues moving away from the original path.

Figures 16 and 17 illustrate two response metrics, lane change deviation and peak vehicle sideslip angle as a function of normalized steer angle. Note that all three vehicles are well within the response boundaries of the current vehicle population (shown as solid lines) as established in Ref. 7.

\section{SUMMARY}

The reported study reflects a limited attempt at evaluating alternate electric vehicle drive system component layouts with regard to their impact on vehicle handing characteristics. The results are intended to supplement other aspects of the overall design study with the goal of optimizing component layout within an existing vehicle structure. It has not been a goal to optimize vehicle handling characteristics but rather to insure that selected configurations can be reasonably expected to perform in a manner to whirh the driving population is accustomed. The primary evaluation of handiing characteristics was therefore based on comparisons between simulated electric vehicles and a simulated ICE base car.

The results of this study indicate that the two EV configurations selected for dynamic analysis can be expected to perform in a manner not unlike that of the base car assuming that appropriate tires are selected for use and spring rates are adjusted to accommodate the added weight. Furthermore, configuration " $N$ " responds in a manner that is more similar to that of the base car than does configuration "J". 


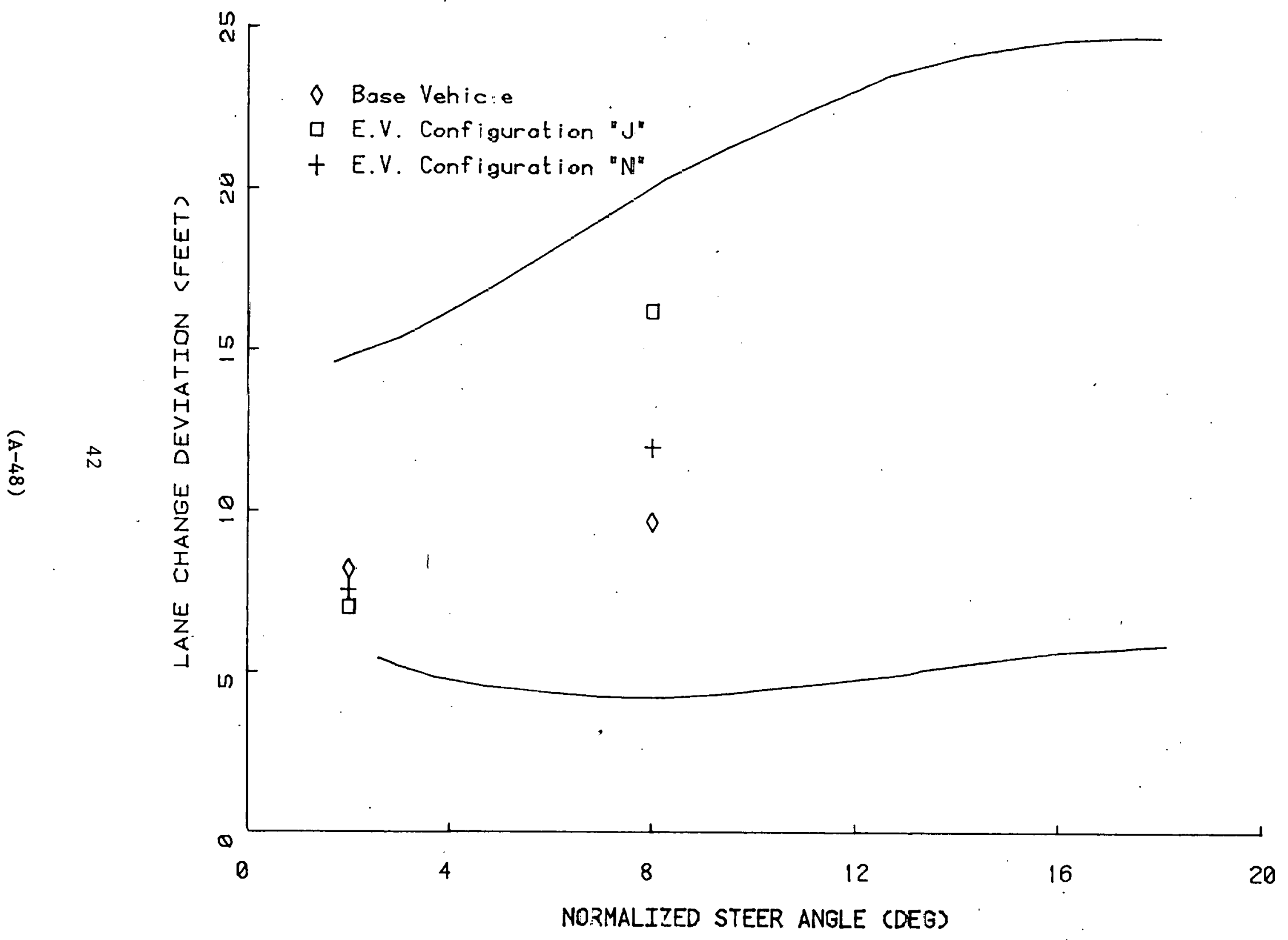

F:gure 1б LANE CHANGE DEVIATION VS. STEER AMPLITUDE 


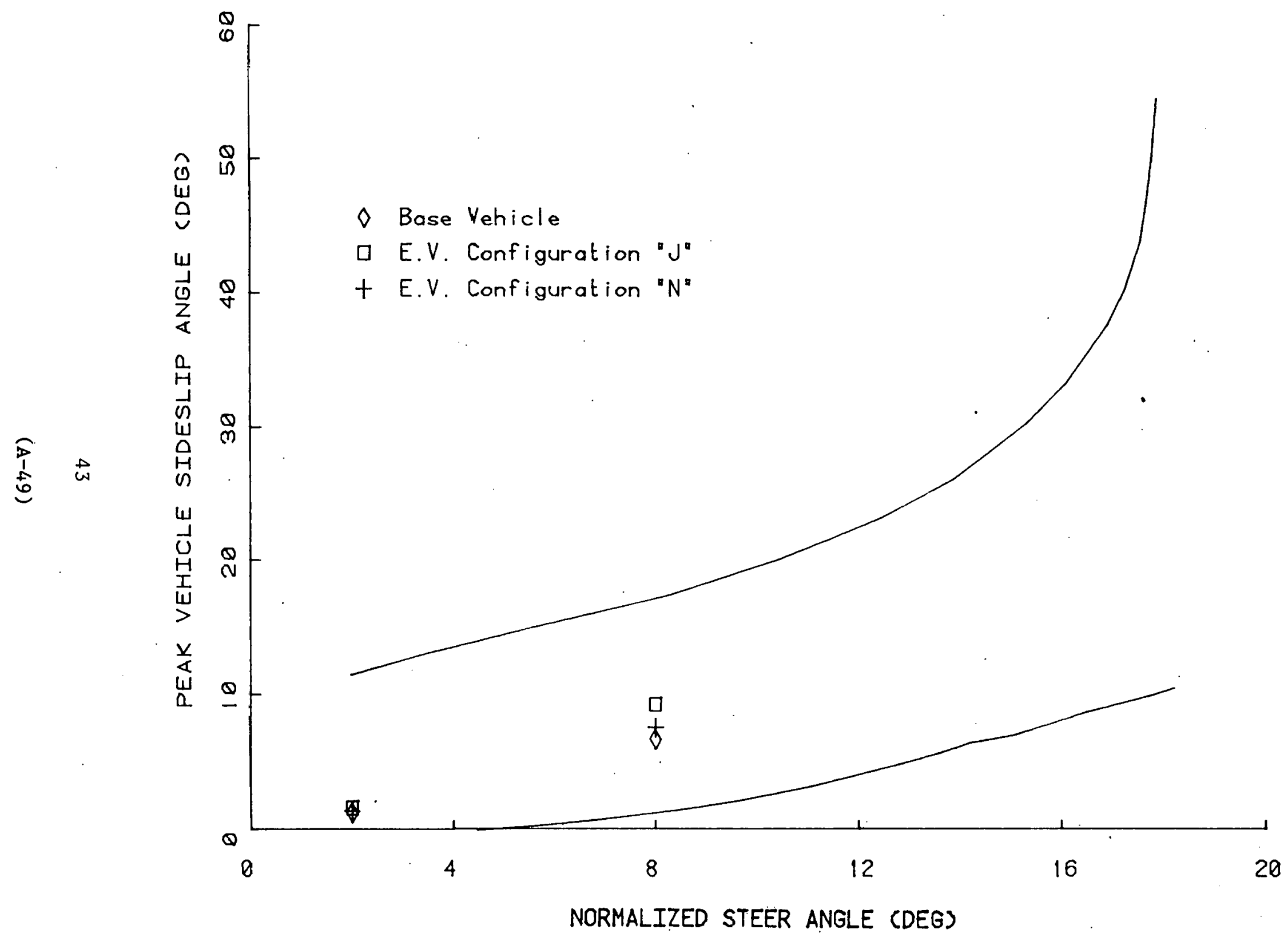

Figure 17 PEAK SIDESLIP ANGLE VS. STEER AMPLITUDE 
Although the HVOSM, which was used to simulate the vehicles in this. study, has undergone extensive checks of its validity in the past through comparisons of predicted responses to those measured in carefully controlled testing, certain aspects of its use within this type of study should, at some point, receive additional attention. In particular, much of the detailed suspension data that is required is measured under load conditions characteristic of a standard ICE vehicle, and is generally measured only in the linear range. The addition of substantial battery weight may result in load conditions which change suspension compliance characteristics. It would therefore be desirable that a limited confirmation of the applicability of such base cur dulu tu electric vehicles be undertaken through comparisons with test results. 
4.

1. Segal, D. J., "Highway-Vehicle-Object Simulation Model - 1976," (4 Volumes), Calspan Corp. Federal Highway Administration Report No. FHWA-RD-76-162, 163, 164, 165, February 1976.

2. Greene, J. E. and Segal, D. J., "An Analytical Study of Electric Vehicle Handling Dynamics," Contract No. JPL-955312, MGA Report No. G8-006, May 1979.

3. Milliken, W. F., et al., "Research in Automobile Stability and Control and in Tire Performance," published by the Institution of Mechanical Engineers, London, 1956.

4. De1l'Amico, F., "Steady-State Stability of the Automobile--An Approach Based on a Method of Tethered Vehicle Testing Using a Yaw Constraint," Cornell Aeronautical Laboratory Report No. YC-3004-K-1, August 1971.

5. Milliken, W. F., et al., "The Static Directional Stability and Control of the Automobile," SAE Paper No. 760712, October 1976.

6. Weir, D. H. and McRuer, D. T., "Review and Correlation of Driver/Vehicle Data," Systems Technology, Inc. (no number).

7. Ervin, R. D., et al., "Vehicle Handling Performance," Highway Safety Research.Institute, The University of Michigan, Contract DOT-HS-031-1-159, November 1972. 
APPENDIX A

HIGHWAY VEHICLE INTERACTION SIMULATION

A-1

$(A-53)$ 
The Highway/Vehicle. Interaction Simulation (HVIS) is an MGA Research Corporation adaptation of the Highway-Vehicle-Object Simulation Model (HVOSM). The HVOSM was originally developed for the Federal Highway Administration by Calspan Corporation (Refs. 1 and 2) and other organizations to provide an analytical means of studying the interaction between a vehicle and its environment. Two versions of the HVOSM were developed--one intended for usc in evaluating roadside barriers and roddway and/ur ruadside geometrics; the other intended for detailed studies ot hraking systems and driver behaviur. The HVIS is a modification to the HVOSM which includes detailed suspension charactcristic representation (e.g., compljances, ride-steer, steer-steer, etc.) that make the model suitable for vehicle dynamics studies.

The analytical. representation of the vehicle (Figure 1 ) is an assembly of three, four, or five rigid bodies (depending on suspension options in use) consisting of the sprung mass (chassis and body) and unsprung masses (the wheels and/or axles) which move relative to the sprung mass. Since the sprung mass $\left(M_{s}\right.$ in the figure) is assumed to behave as a rigid body, six degrees of freedom $\left(X_{C}^{\prime}, Y_{C}^{\prime}, Z_{C}^{\prime}, \emptyset, \theta, \psi\right)$ are required for its specification. If the independent front suspension is ini use, the two front whecl3. ( $M_{1}, M_{2}$ ) are assumed to move vertically with respect to the vehicle body and thus require one degree of freedom each $\left(\delta_{1}, \delta_{2}\right)$. For a solid front axle $\left(M_{1}\right)$, a vertical degree-of-freedom $\left(\delta_{1}\right)$ and a rotational degree of freedum $\left(\emptyset_{F}\right)$ are required to describc its position and orientation. Similarly, for an independent rear suspension the wheels $\left(M_{3}, M_{4}\right)$ have a degree of freedom each $\left(\delta_{3}, \delta_{4}\right)$ and lie solid rear axlc $\left(M_{3}\right)$ has a vertical $\left(\delta_{3}\right)$ and rotational $\left(\emptyset_{R}\right)$ degree of freedom. The steer angle of the frunl whesls ( $\psi_{f}$ ) ia an optional degree of freedom which may be specified.

An optional program version includes rotational dcgrees of freedom for the fnur wheels. Thus, the effects on tire forces of rotational wheel slip due to traction or braking can be approximated. The wheel rotational degrees of freedom are assumed to be isolated from the coupled differential equations of the sprung and unsprung masses but inertial coupling between the pair of drive whet is included. 


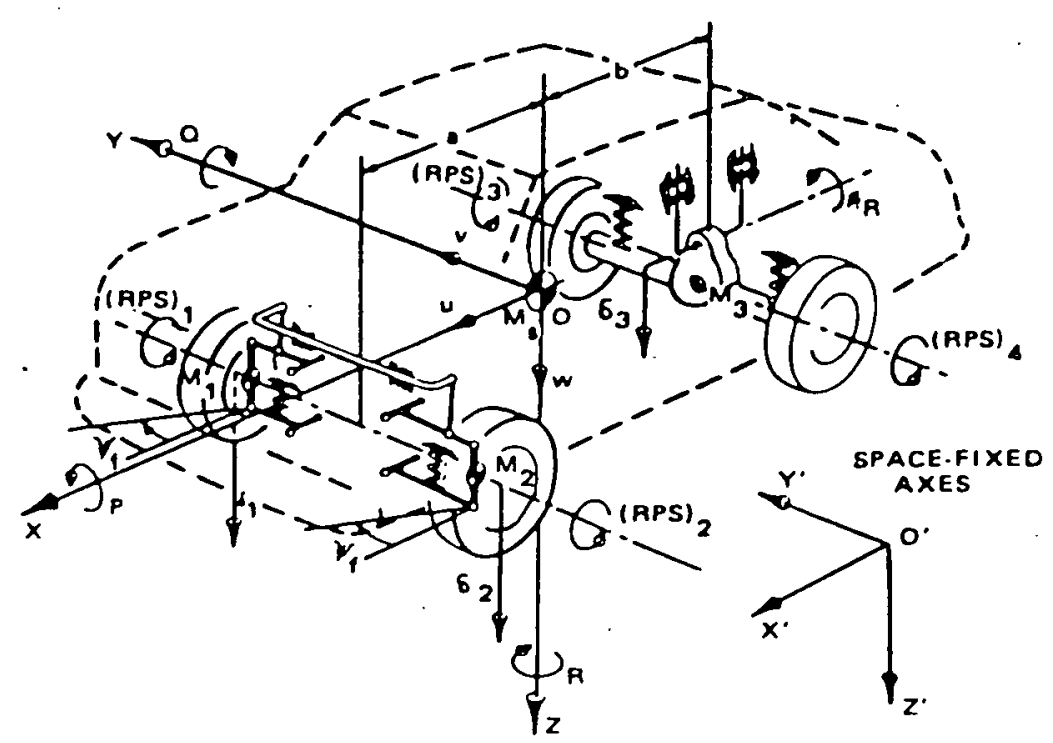

(a) INDEPENDENT FRONT - SOLID AXLE REAR SUSPENSION

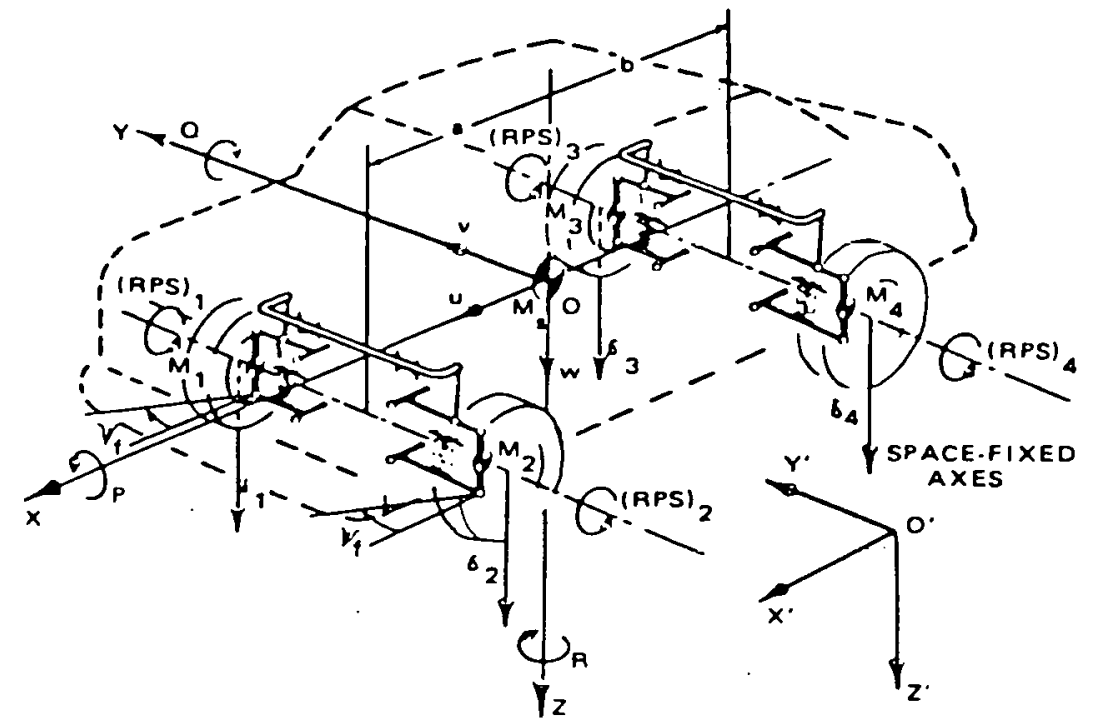

(b) INDEPENDENT FRONT AND REAR SUSPENSION

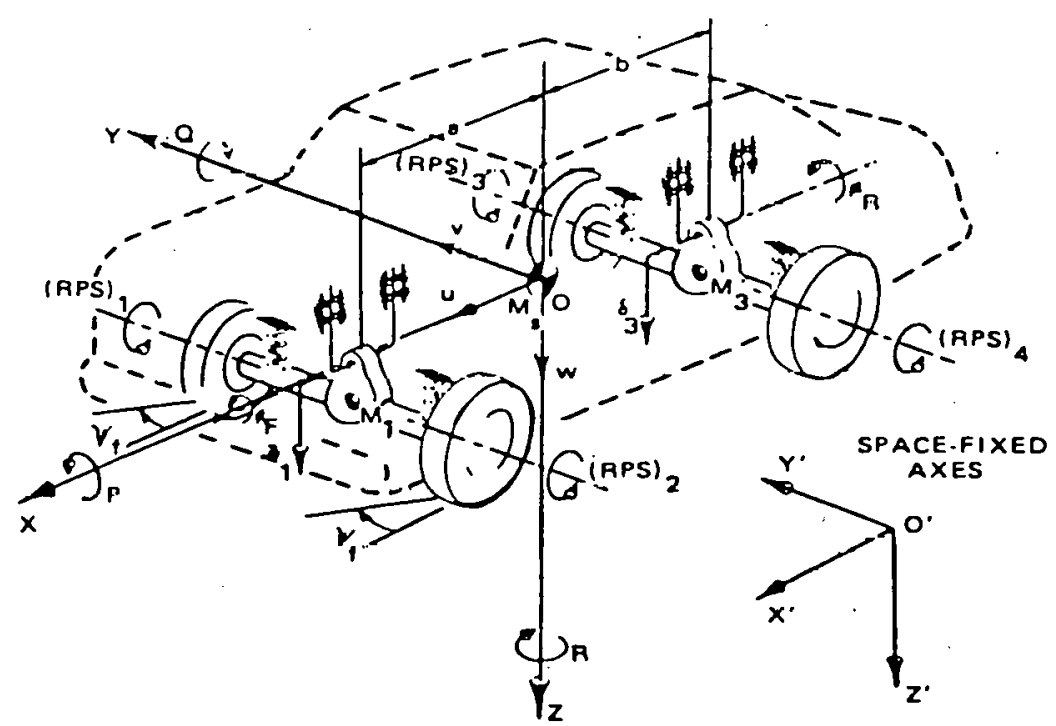

(c) SOLID AXLE FRONT AND REAR SUSPENSIONS

Figure 1 ANALYTICAL REPRESENTATION OF VEHICLES $A-3$

$(A-55)$ 
A description of features of the mathematical model appropriate for simulation of vehicle stability and performance follows.

\section{Inertial Properties}

Plane OXZ in Figure 1 is assumed to be a plane of mirror symmetry for the sprung mass.

The centers of gravily of independently suspended unsprung masses are assumed to coincide with the wheel centers. 'l'he wheels aite tracad as puinl masses, i.e., the fractional contribution of the suspension parts is approximated by a simple addition to the wheel mass.

The centers of gravity of solid axle unsprung masses are assumed to coincide with the geometric center of the axle. In the treatment of inertial coupling between the sprung mass and solid axle unsprung masses the axle is approximated by a thin rod.

\section{Suspension Properties}

Camler angles and half track changc of independently suspended wher 15 relative to the vehicle are determined by interpolation of a tabular input of camber angle and track change as a function of suspension deflection. Camber angles are further modified to reflect suspension compliances.

Steer angles of the front. wheels include a number of effccts that are common in actual automobiles. A reference steer angle is determined at any point in: timc from cither the steer equation of motion or a tahular interpolation procedure. This reference steer angle is defined as the average front wheel steer angle that would exist given a perfectly rigid steering system and no vehicle roll. This steer angle is then modified to include effects of Ackerman steering geometry, ride-steer, camber-steer and suspension compliances. 
Rear axle roll steer is treated as a lincar function of the angular degree of freedom of the rear axle, $\emptyset_{R}$ (see Figure 1). Inertial effects are neglected in the steer mode of rear axle motion. Independent rear suspension ride-steer is treated as a third order polynomial function of suspension position, and further modified to reflect effects of suspension compliances.

Anti-pitch effects of suspension geometry are simulated with tabular coefficients as a function of suspension deflection for the front and rear suspensions. Anti-roll effects (roll center height) may be included as a function of suspension ride position and tire lateral force.

The simulated suspensions bumper properties include progressively' stiffening load-deflection rates and an adjustable amount of energy dissipation. Provision has also been incorporated for unsymmetrical placement of the jounce (compression) and rebound (extension) bumpers with respect to the design positions of the wheels. The combined spring and bumper forces are calculated in the manner depicted in Figure 2.

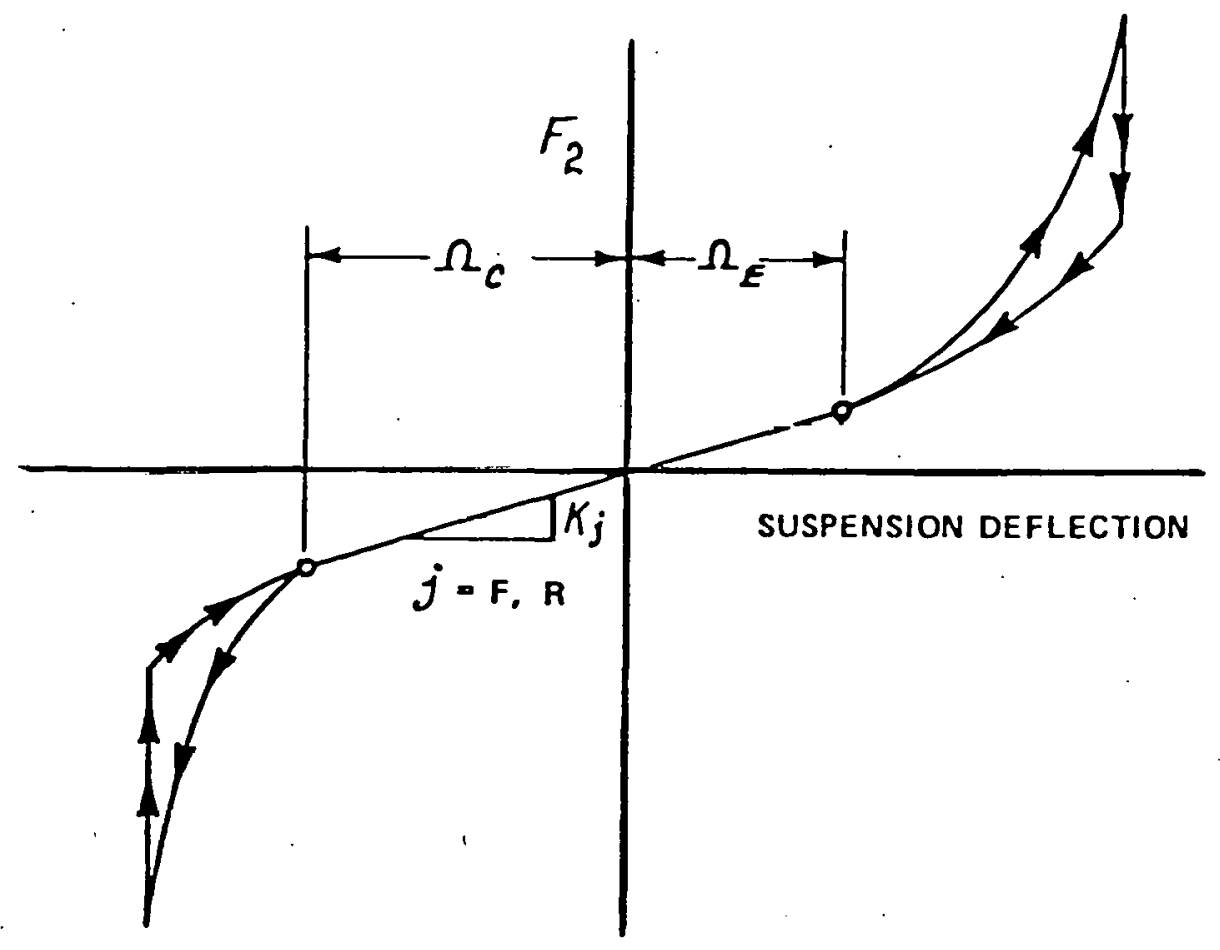

Figure 2 GENERAL FORM OF SIMULATED SUSPENSION BUMPER CHARACTERISTICS 
The assumed form of damping is depicted in Figure 3 . Velocity dependent damping is provided by a piecewise linear fit to known shock absorber data transformed to be effective at the wheel. Coulomb friction is also included as a component of the total suspension force.

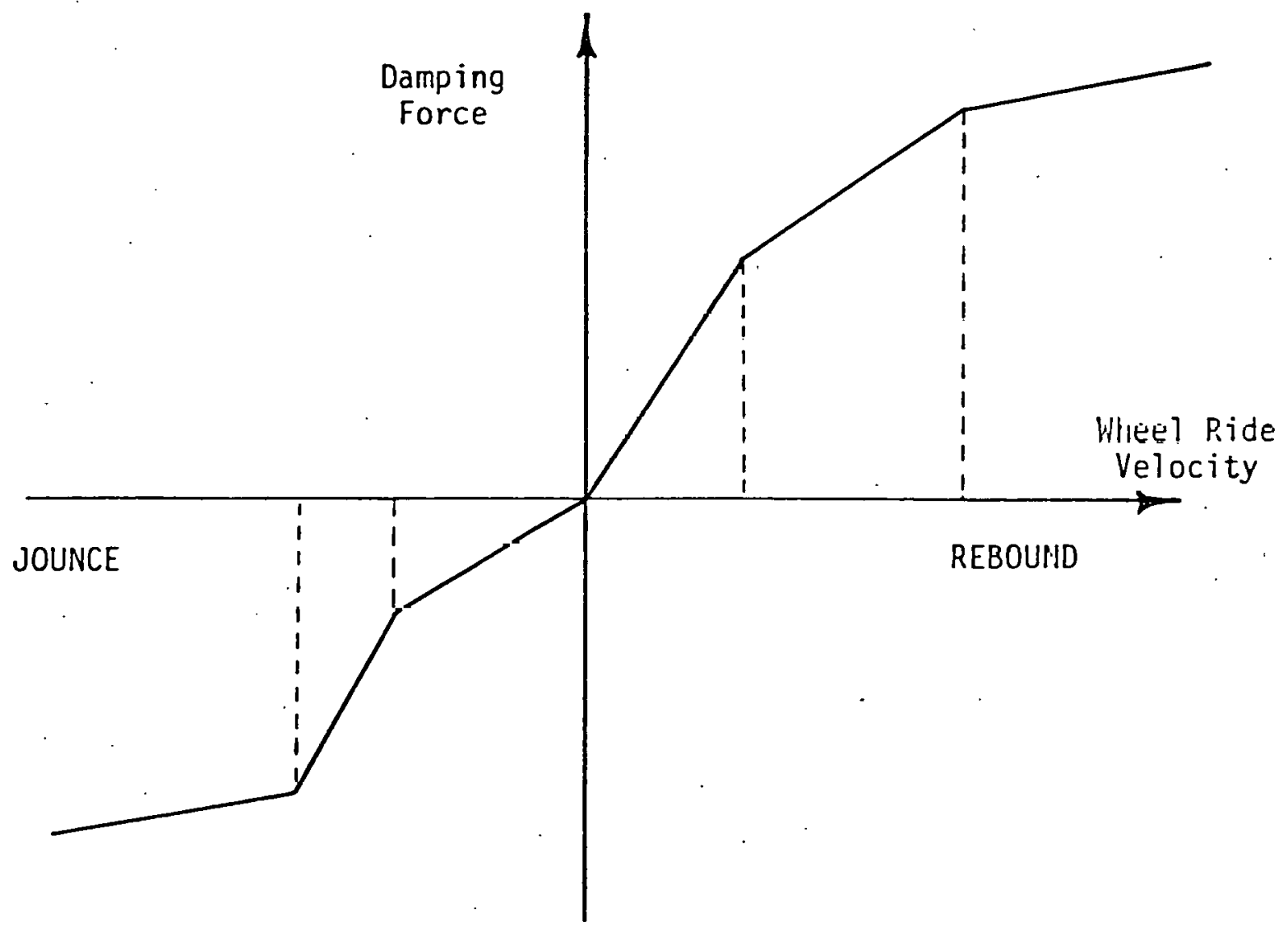

Figure 3 ASSUMED FORM OF DAMPING

Provision is made for the entry of auxiliary roll stiffness at both the front and the rear suspensions (i.e., roll stiffness in excess of that corresponding to the suspension ride rates acting in a roll mode). While the anti-roll torsion bar which is frequently included in the independent front suspensions of conventional automobile designs constitutes an obvious form of auxiliary roll stiffness, it should be noted that torsional effects in the leaf springs of a conventional Hotchkiss rear suspension also produce a significant amount of auxiliary roll stiffness, as do increasingly common rear anti-roll torsion bars. 


\section{Tire Forces and Moments}

In correspondence with the general nature of the HVIS, the tire models used are designed to handle a complete range of loading conditions, from a loss of contact with the ground to a condition of extreme overload. Provision is made for up to four different sets of tire data, therefore, each tire on the vehicle may have different characteristics at the option of the user.

The tire coordinate system employed is illustrated in Figure 4 and is consistent with the SAE definitions of tire forces and moments. Two tire models are available, the more detailed considering all variables illustrated in Figure 4. A somewhat simplified tire model is also used when wheel spin dynamics are not significant in determining vehicle response (i.e:, constant speed or longitudinal steady-state events). In this simplified model, the rotational velocity of the wheels are neglected as is the. rolling resistance moment.

The calculation of tire forces and moments begins with the determination of the radial force acting on the tire which is based on the geometrical interference between the undeformed tire radius and the terrain beneath the tire. This radial force is then transformed to the tire normal force knowing the tire inclination angle and the previous value of side force. All tire calculations are then based on the normal force, slip angle, inclination (camber) angle and whecl spin velocity (or torque if the simplified version is used).

The tire circumferential force (tractive or braking force) is computed by two methods depending on the tire model use. For the detailed model, it is based on the relative slip between the tire tread and ground (computed from the rotational velocity of the tire and the tire center linear velocity along the wheel heading) and an empirical fit to data in the form of circumferential furce as a function of slip, speed and normal load. In the simplified tire model, circumferential force is determined by the input value of wheel torque and the instantaneous rolling radius. In either 


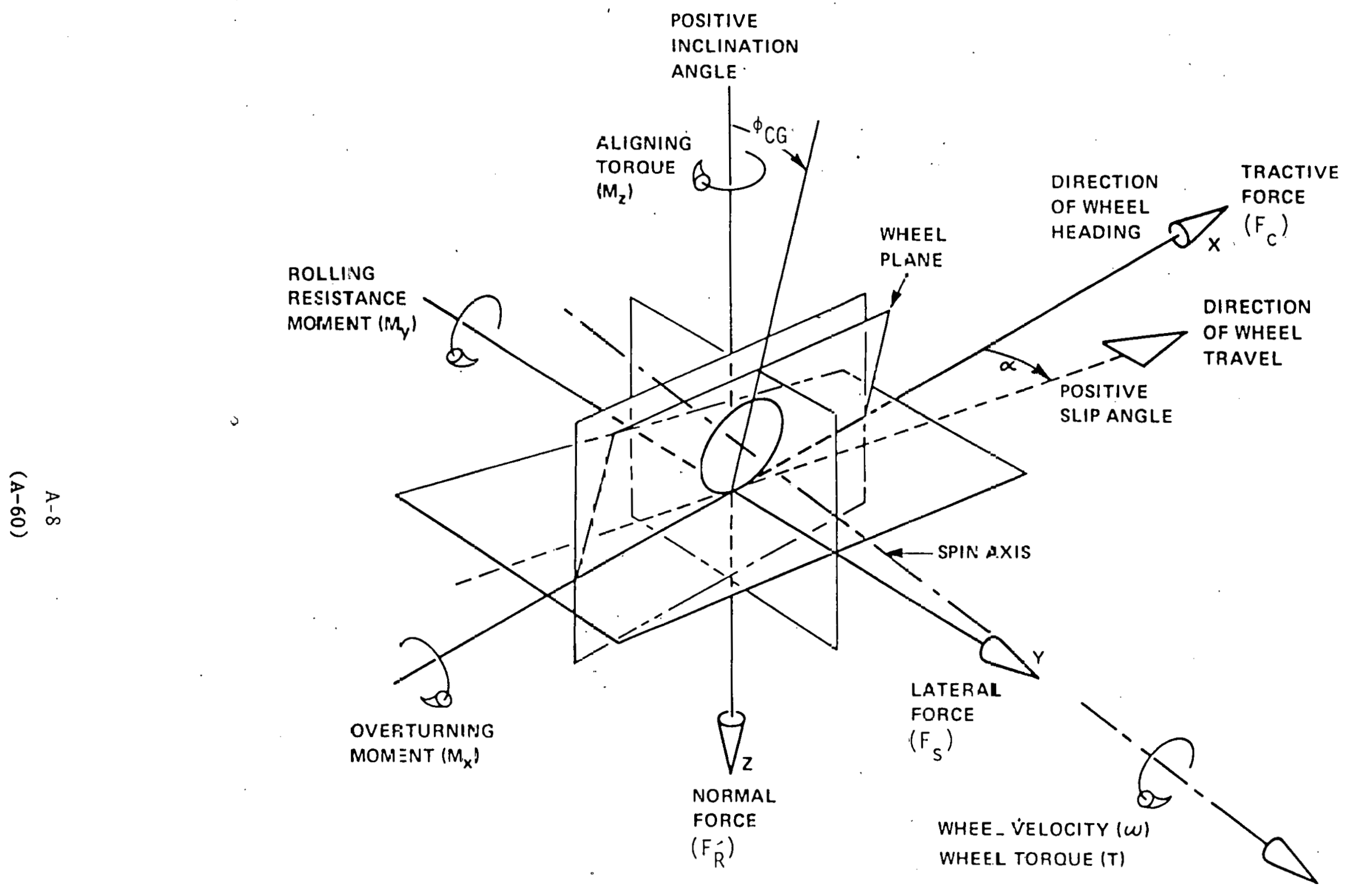

Figure 4 SIGN CONVENTION OF TIRE FORCES, MONENTS APDD IEOMETRY 
model, care is taken to limit maximum values to that permitted by availablc tire/ground friction.

Tire lateral forces are then computed based on a semi-empirical relationship between slip angle, inclination angle, normal load and circumferential force. Coefficients required for this relationship are derived from tire test results. An example of the resulting tire side force as a function of slip angle and normal force is shown in the carpet plot of Figure 5 . Note that the tire model considers the variation of cornering stiffness with normal load and provides saturation of side force at high slip angles.

The tire model employed makes use of either the "friction circle" or the "friction ellipse" concept in establishing the relationship between side and circumferential forces. This choice allows the user to employ the most cost-effective tire representation consistent with the degree-of-detail required for any given application. 
THIS PAGE

\section{WAS INTENTIONALLY LEFT BLANK}




\section{APPENDIX B}

SIMULATED VEHICLE INPUT DATA

B-1

$(A-63)$ 
THIS PAGE

\section{WAS INTENTIONALLY LEFT BLANK}




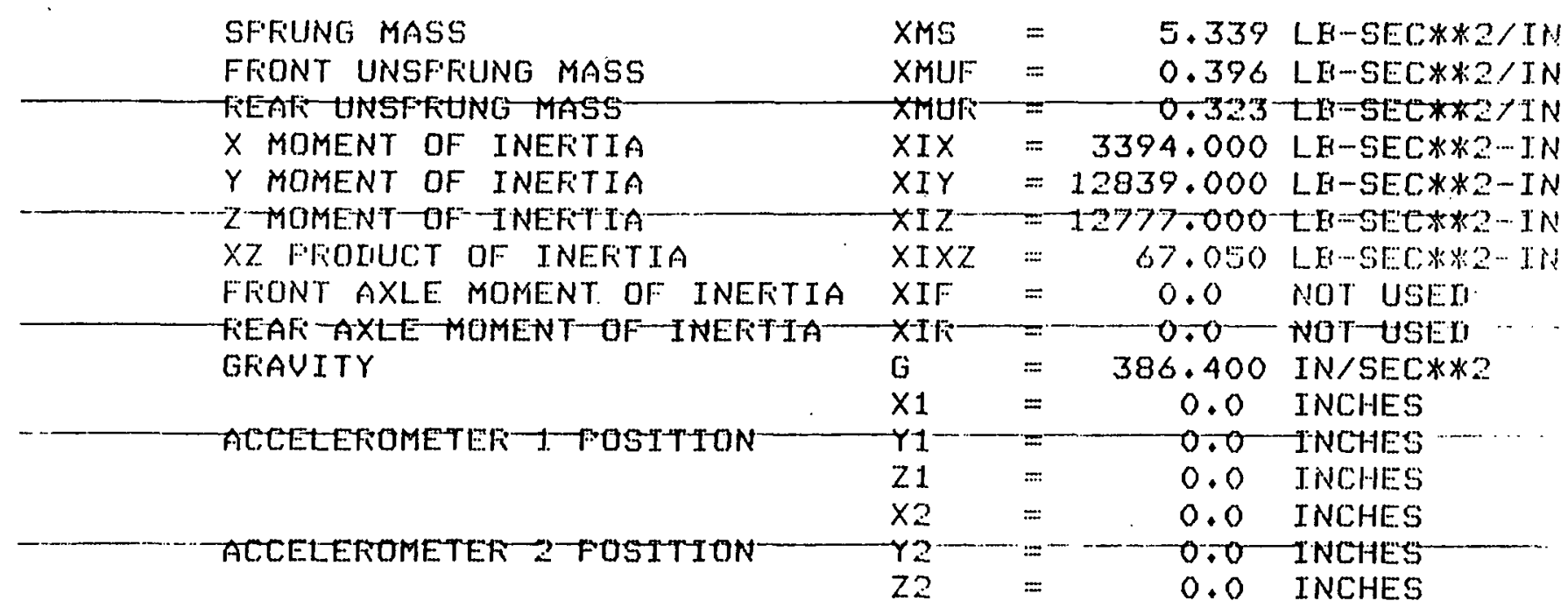

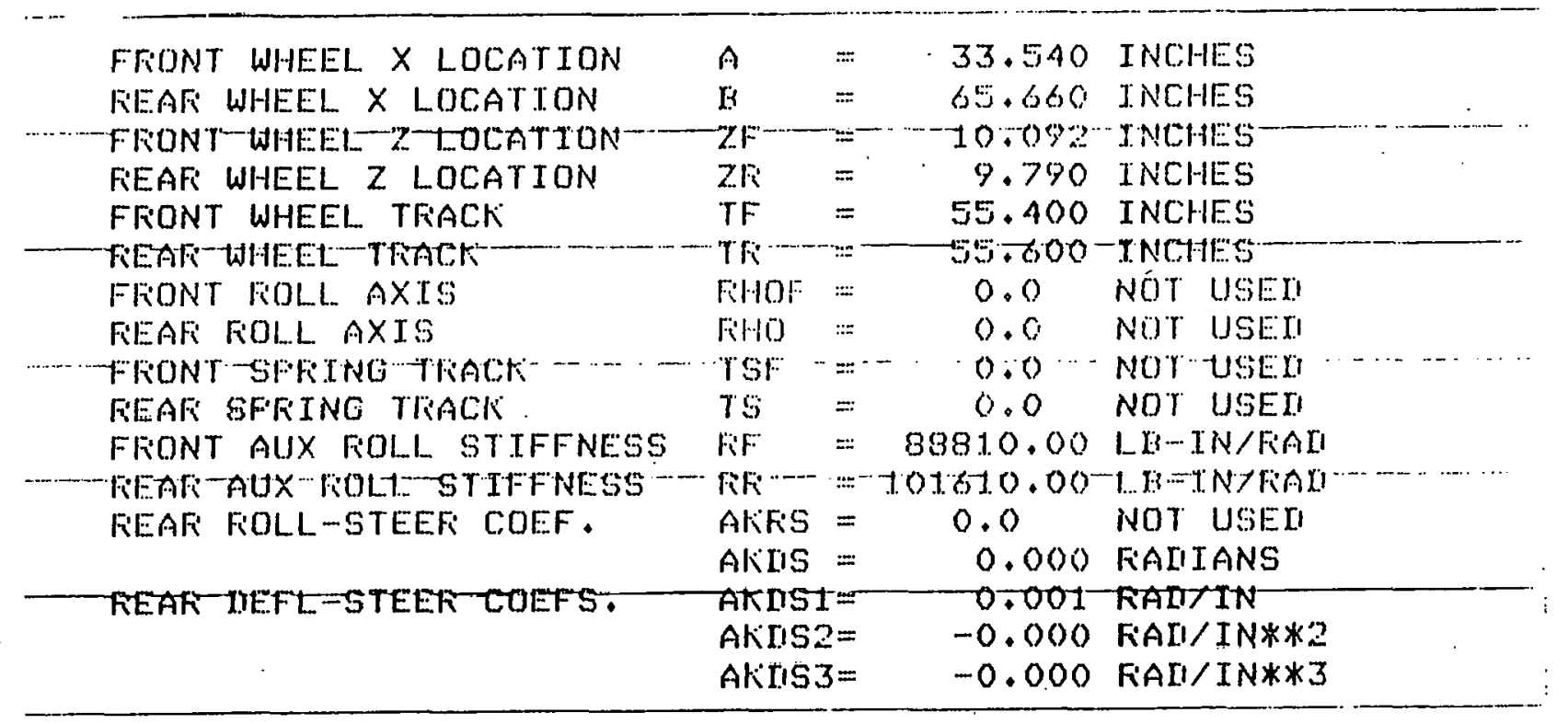




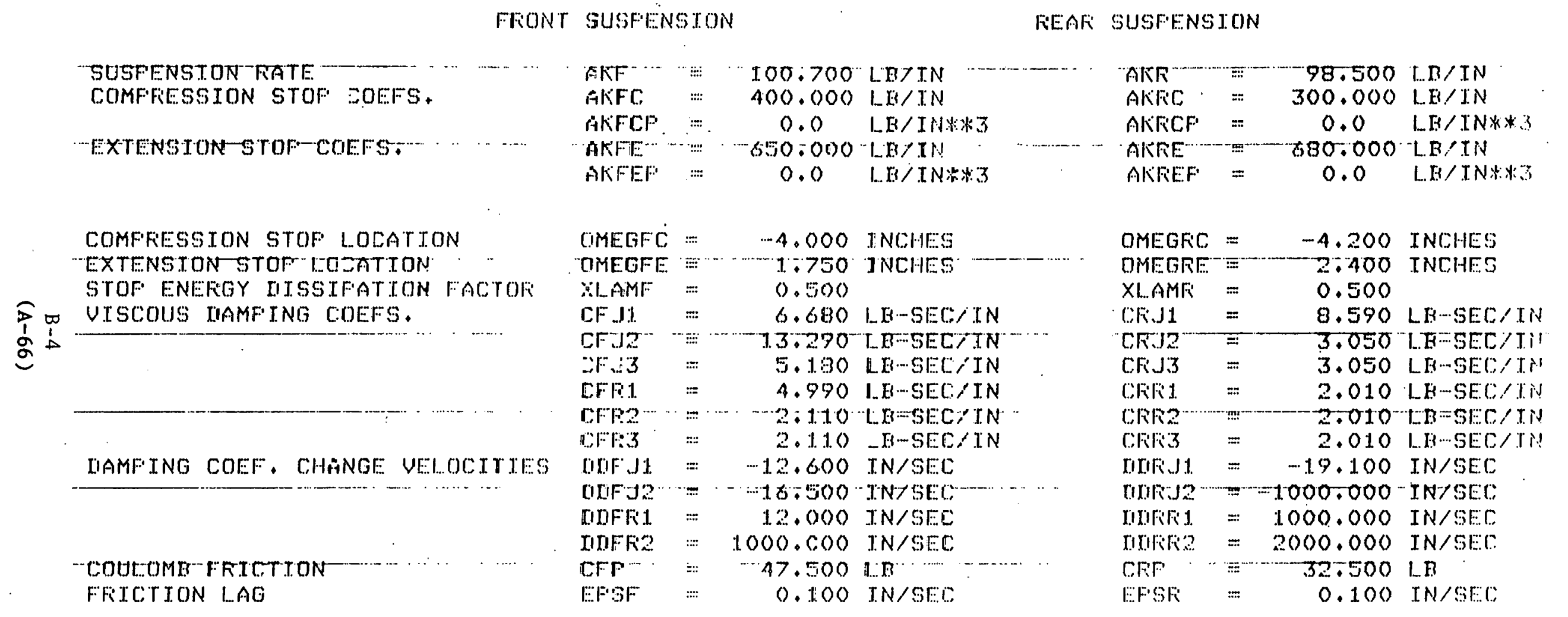




\begin{tabular}{|c|c|c|c|c|}
\hline & FFENT- thit & EEt CAMEF & FEAF WTAE & $\begin{array}{l}\text { EL CAMEEF } \\
\text { S }\end{array}$ \\
\hline & SUSFENSION & IIEFLECTION & SUSFENGION & CIEFLECTION \\
\hline & IIELTAF: & FHIC & IIELTAF' & FHIFC \\
\hline & INCHES & IIEGFEES & INCHES & IIEGFEES \\
\hline & -3.00 & 2.25 & $-=3.00^{-}$ & $-1,20$ \\
\hline - & $\cdots 2.50$ & 2.30 & -2.50 & $-1,17$ \\
\hline & -2.00 & 2.40 & -2.00 & -1.14 \\
\hline & -1.50 & $2.50^{-}$ & $-1+50$ & $-1 \cdot 10$ \\
\hline & -1.00 & 2.68 & -1.00 & -1.06 \\
\hline . & $-0,50$ & 2.78 & -0.50 & -1.03 \\
\hline & $-(1), 0$ & -3.00 & 0.0 & 1.00 \\
\hline & 0.50 & 3.24 & 0.60 & -0.98 \\
\hline & 1.00 & 3.56 & 1.00 & $\cdots 0.96$ \\
\hline & 1.50 & $3 \rightarrow 7 t$ & $1 \div 50$ & $=0.93$ \\
\hline & 2.00 & 4.10 & 2.00 & -0.90 \\
\hline
\end{tabular}




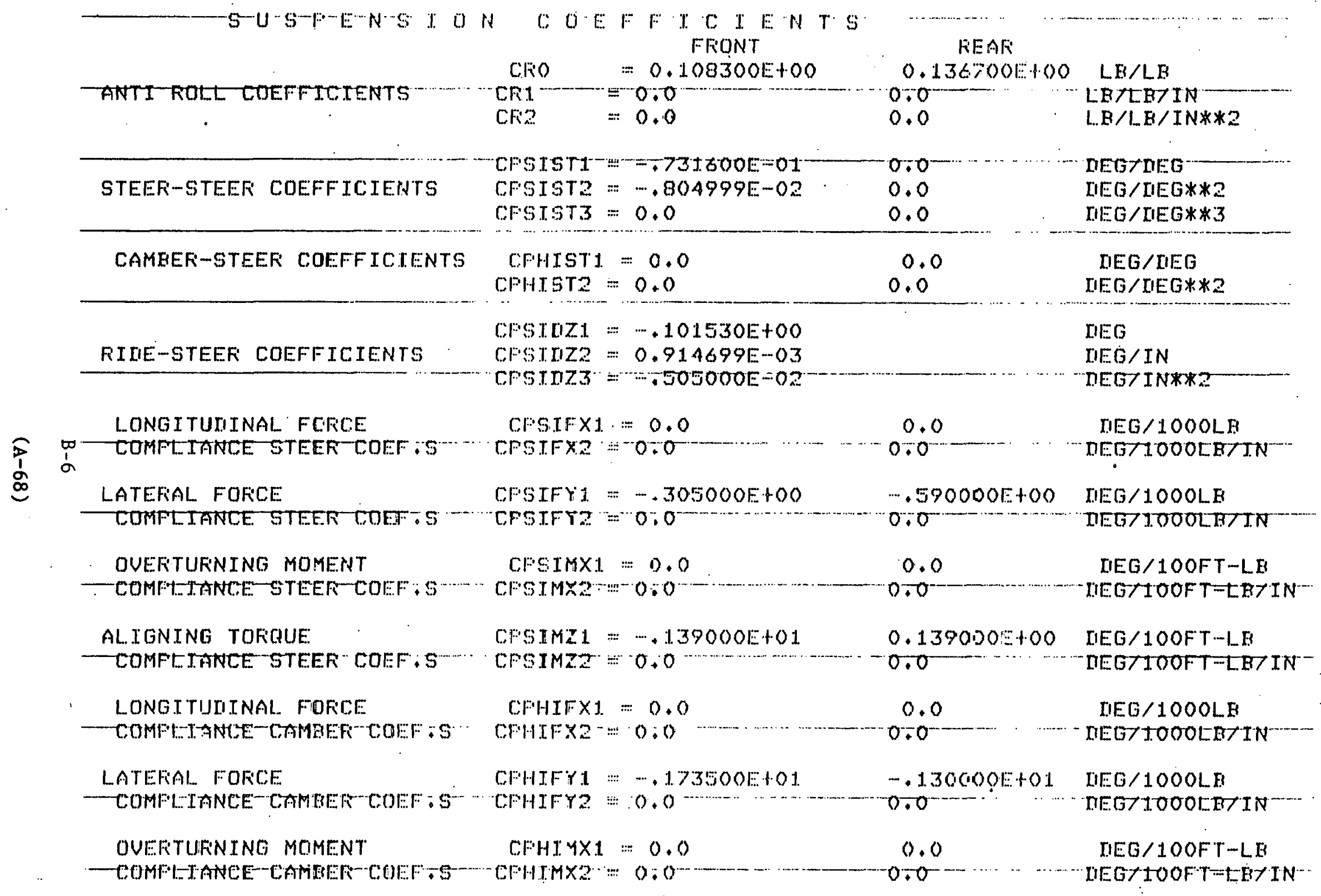




\begin{tabular}{|c|c|c|c|c|c|c|}
\hline TIFE LINEAF SFFING FIATE & AK゙T & $\begin{array}{c}\text { FiF } \\
1150.000\end{array}$ & $\begin{array}{l}\text { L.F } \\
1.150 .000\end{array}$ & $\begin{array}{l}\text { Fifi } \\
\text { 1. } 150.000\end{array}$ & $\begin{array}{l}\text { LF } \\
1150.000\end{array}$ & LE/IN \\
\hline $\begin{array}{l}\text { TEFIL. FUK INCREASED RATE } \\
\text { SFRTNG FATE INCFEASING FACTOF }\end{array}$ & $\begin{array}{l}\text { SIGT } \\
\text { XLAMT } \\
\text { AO. }\end{array}$ & $\begin{array}{r}=10.000 \\
=\quad 1.000 \\
=\quad 974.740\end{array}$ & $\begin{array}{r}10.000 \\
1.000 \\
974.740\end{array}$ & $\begin{array}{r}10.000 \\
1.000 \\
974.740\end{array}$ & $\begin{array}{r}10.000 \\
1.000 \\
974.740\end{array}$ & INCFIES \\
\hline SIIIE FOFCE COEFFICIENTS & $\begin{array}{l}A 1 \\
A 2 \\
A 3\end{array}$ & $\begin{array}{r}=9.580 \\
=\quad 2683.270 \\
=\quad 0.167\end{array}$ & $\begin{array}{r}9.580 \\
2683.270 \\
0.167\end{array}$ & $\begin{array}{r}9.580 \\
2683.270 \\
0.167\end{array}$ & $\begin{array}{r}9.480 \\
2683.270 \\
0.167\end{array}$ & \\
\hline TIFE OUEFILOAII FACTOFi & $\begin{array}{l}\text { AA } \\
\text { OMEOT }\end{array}$ & $\begin{array}{r}-756.560 \\
0.750\end{array}$ & $\begin{array}{c}=756.560^{-} \\
0.750\end{array}$ & $\begin{array}{r}.756 .560 \\
0.750\end{array}$ & $\begin{array}{c}=756.560^{-} \\
0.750\end{array}$ & $\cdots$ \\
\hline TIFE UNDIEFLECTEII FIAIITUS & FiW & $=1.2 .150$ & 12.150 & $12+150$ & 12.150 & INCHES \\
\hline 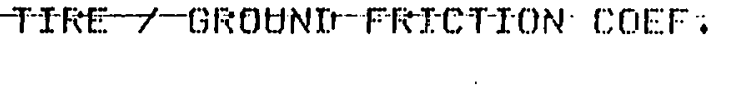 & $\begin{array}{l}\text { AMUN } \cdots \cdots \\
\text { CATI }\end{array}$ & $=0.750$ & $\begin{array}{r}0.750 \\
\cdots .3240 E \cdots 03\end{array}$ & $\begin{array}{r}0.750^{-} \\
\cdots .3240 \mathrm{OE}-03\end{array}$ & $\begin{array}{r}0.750 \\
\cdots .3240 E \cdots 03\end{array}$ & \\
\hline ALIGNING TOFQUE COEFFICTENTS & CAT2 & $=0.2570 E-03$ & $0.2570 E-0.3$ & $0.2970 E-03$ & $0.2570 E-03$ & \\
\hline & $\begin{array}{l}\text { CAT3 } \\
\text { COMO }\end{array}$ & $\begin{array}{l}=0.41001 . .=01 \\
=0.0\end{array}$ & $\begin{array}{l}0.4100 E=01 \\
0.0\end{array}$ & $\begin{array}{l}0.1100 E=01 \\
0.0\end{array}$ & $\begin{array}{l}0.4100 E-01 \\
0.0\end{array}$ & \\
\hline OUERTUFINING MOMENT COEF.S & COM1 & $=-111 \mathrm{OE} \cdots \cdots 3$ & $\cdots .1110 E-03$ & $\cdots .1110 \mathrm{OE}-03$ & $\cdots .1110 E-03$ & \\
\hline & $\begin{array}{l}\operatorname{com} 2 \\
\operatorname{com} 3\end{array}$ & $\begin{array}{l}\cdots .2400 E: 03 \\
\cdots-.4800 E+00\end{array}$ & $\begin{array}{l}-2400 E=03 \\
-.4300 E+00\end{array}$ & $\begin{array}{l}.2400 E-03 \\
\cdots .4800 E+00\end{array}$ & $\begin{array}{l}-2400 E=03 \\
\cdots .4800 E+00\end{array}$ & \\
\hline
\end{tabular}


THIS PAGE

\section{WAS INTENTIONALLY LEFT BLANK}




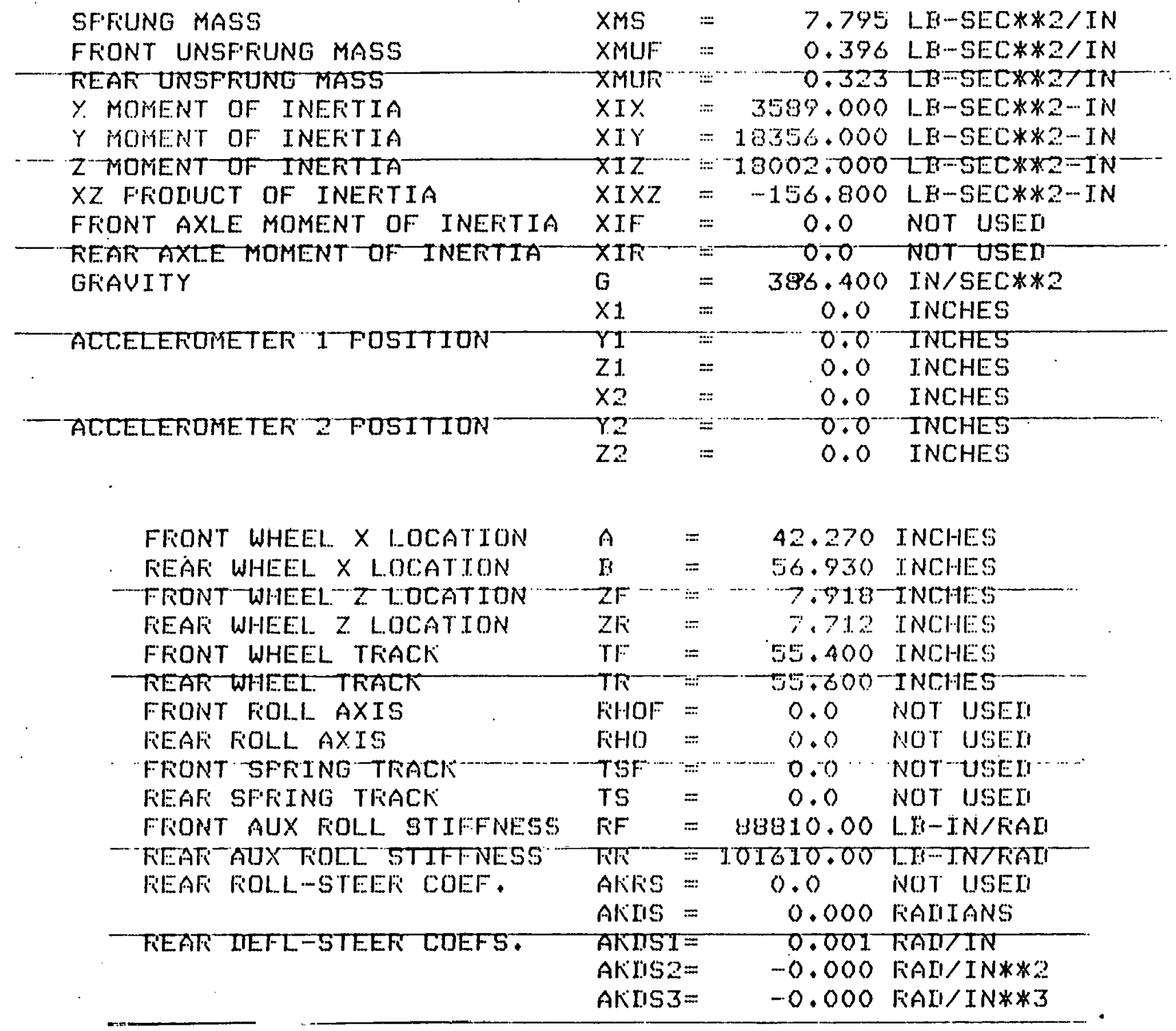


FFONT :JUSFENSTON

\section{SUSFENSTON FATE}

COMFFESSION STOF COEFS.

-EXTENSTON STOF-COEFG.

COMFFESSION STOF H.OCATTON

EXTENSION STOF TOCATION

STOF ENETIGY UISSIFATION FACTOK

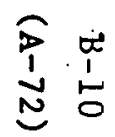

IIAMFING COEF, CHANGE VEI..OCTTTES

TOUEOMB FFTCTION

FFICITION L..AG

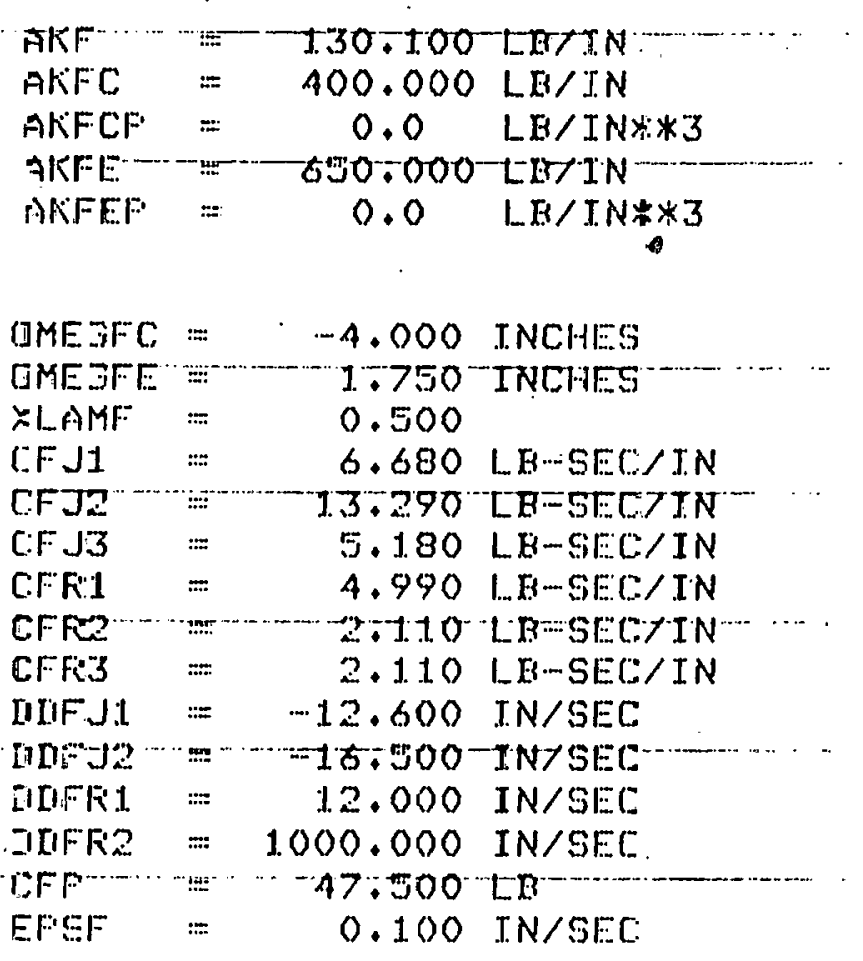

FiEAR SUSFENSTON

\begin{tabular}{|c|c|c|c|}
\hline AKF & $=$ & 175.000 & TB/IN \\
\hline AKFFIC & $:=$ & 300.000 & LE/IN \\
\hline AドFCF & $=$ & 0.0 & $L B / I N * * 3$ \\
\hline AKRE- & \pm & $\% 80.000$ & $\mathrm{LE} / \mathrm{IN}$ \\
\hline AR゙Fi: & $:=:$ & 0.0 & LH/TN**3 \\
\hline OMEGFC & $=$ & -4.200 & INCHES \\
\hline OMEGFE & $=$ & 2.400 & TRCHES \\
\hline XI..AMF & $=$ & 0.500 & \\
\hline Clís1 & $=:$ & 8.590 & I.IB-SEC/TN \\
\hline CFI. & $=$ & 3.050 & 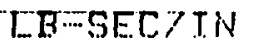 \\
\hline CFIJ 3 & $=$ & 3.050 & LR-SEC/TiN \\
\hline CFFiL & $=$ & 2.010 & LEB-SEC/IM \\
\hline CRR2- & $-m$ & $2.010^{-}$ & ER $=S E C / T N$ \\
\hline CFFi & $=$ & 2.010 & LB-SEC/Tiv \\
\hline IIIIFidel. & $=$ & $-19 \cdot 100$ & $\mathrm{IN} / \mathrm{SEC}$ \\
\hline IMRJ? & $=$ & $=1000.000$ & INTSEO \\
\hline dilifil & $=$ & 1000.000 & IN/SEC \\
\hline IIIIFFE & $=$ & 2000.000 & IN/SEC \\
\hline CRF & ㄴ? & 32.500 & tB \\
\hline EFSF & $=$ & 0.100 & IN/SEC \\
\hline
\end{tabular}




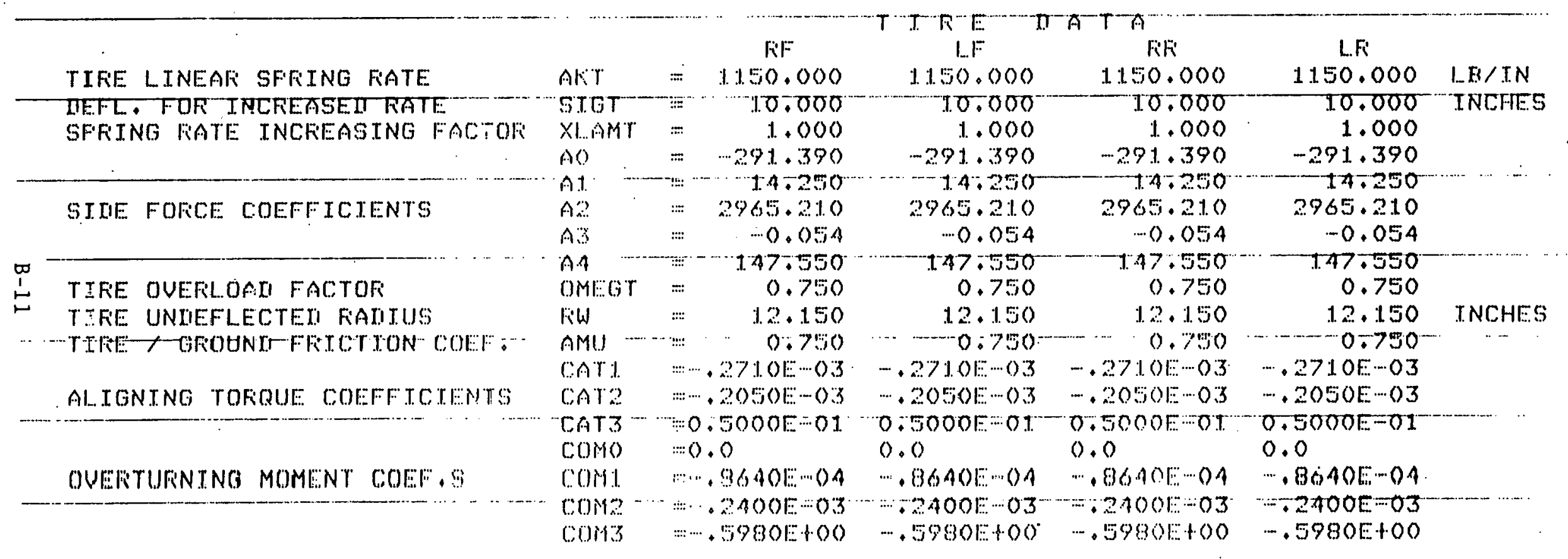




\section{ELECTRIC VEHICLE CONFIGURATION "N" INPUT DATA *}

"Tire data for electric vehicle configuration " $N$ " is the same as electric vehicle configuration "J". 


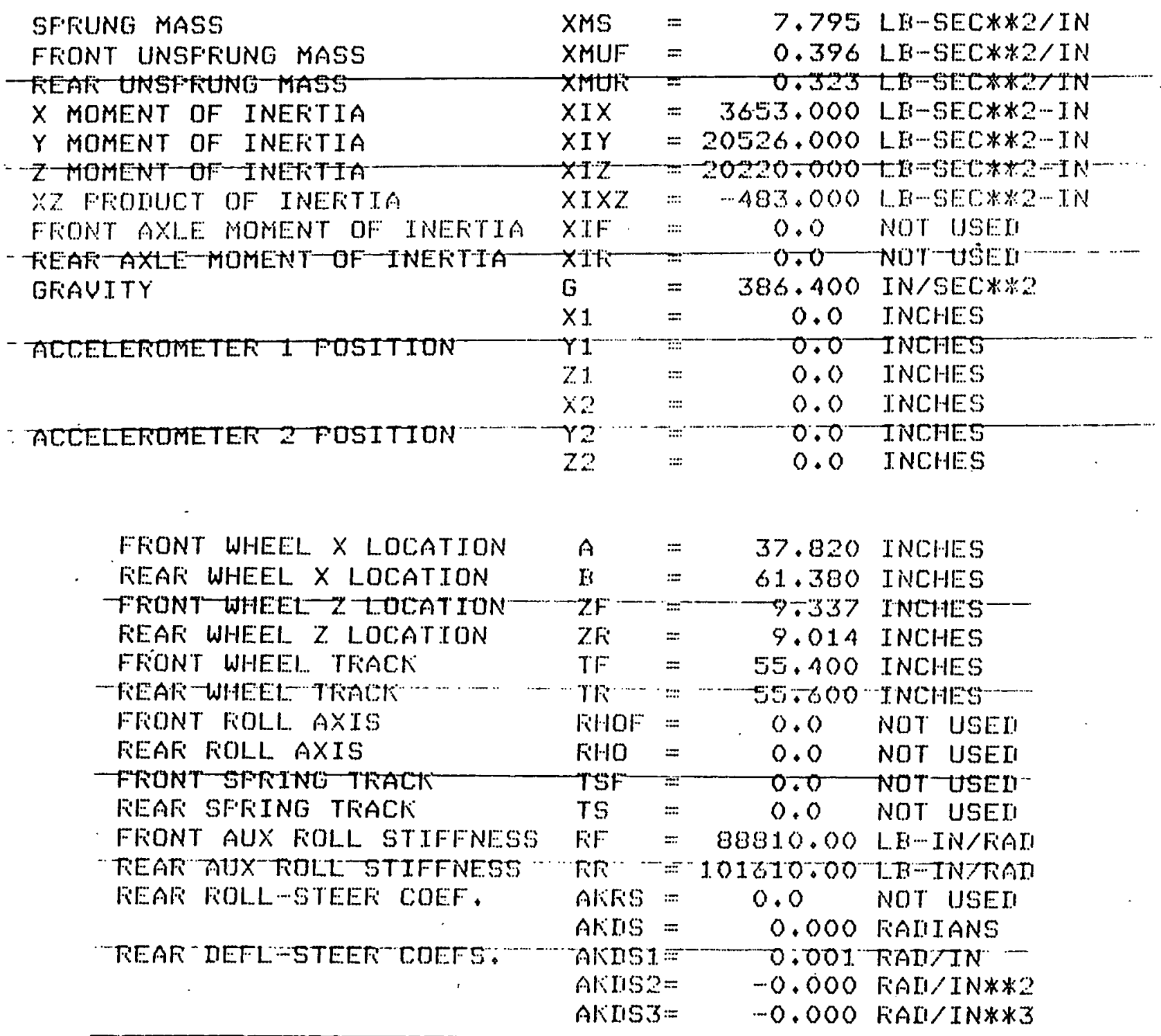




SUSFENSTUR RATE
COMFFESSTON STOF EOEFS.
EXTENSTON STOF COEFS.

AKF
AKFC
AKFCF
AKFE: AKFFF=:

\begin{tabular}{|c|c|}
\hline $\begin{array}{l}139.200 \\
400.000\end{array}$ & $\begin{array}{l}\text { LB/IN } \\
\text { LIS/IN }\end{array}$ \\
\hline 0.0 & LI/IN*k3 \\
\hline $\begin{array}{c}650.000 \\
0.0\end{array}$ & 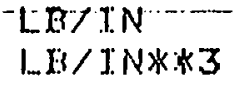 \\
\hline
\end{tabular}

\begin{tabular}{|c|c|c|c|}
\hline $\begin{array}{l}\text { ARKR } \\
\text { AKFEC }\end{array}$ & $\equiv$ & $\begin{array}{l}157.900 \\
300.000\end{array}$ & $\begin{array}{l}\text { LBTIN } \\
\text { LB/IN }\end{array}$ \\
\hline$A K F C F$ & $=$ & 0.0 & $L B / I N * * 3$ \\
\hline AKRE & $\equiv$ & 680.000 & IB/IN \\
\hline & $=$ & & \\
\hline
\end{tabular}

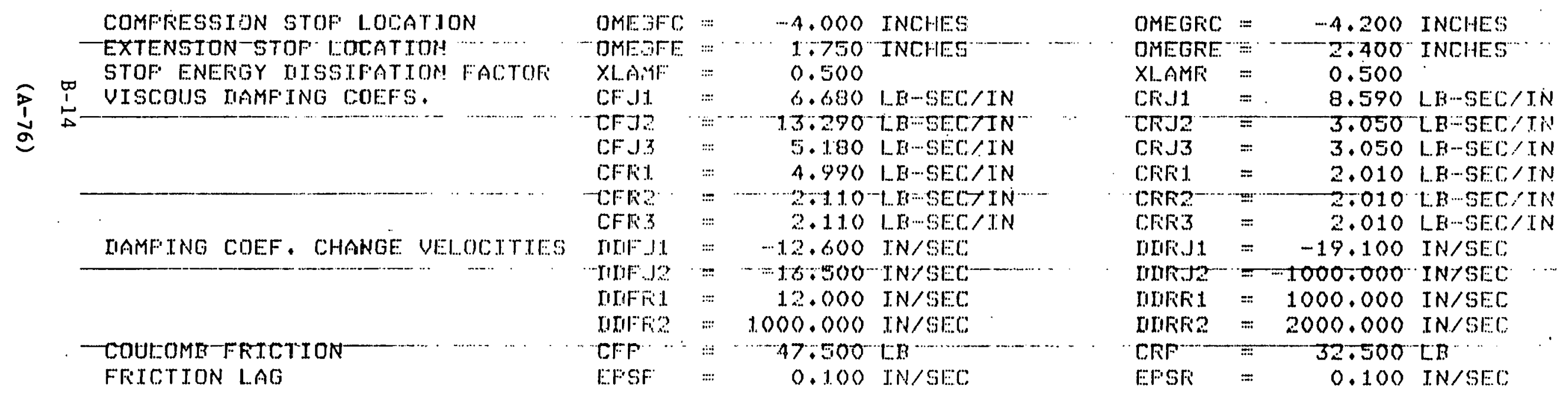




\section{APPENDIX C}

TRAPEZOIDAL STEER RESPONSE PLOTS

$$
\text { C-1 }
$$

$(A-77)$ 


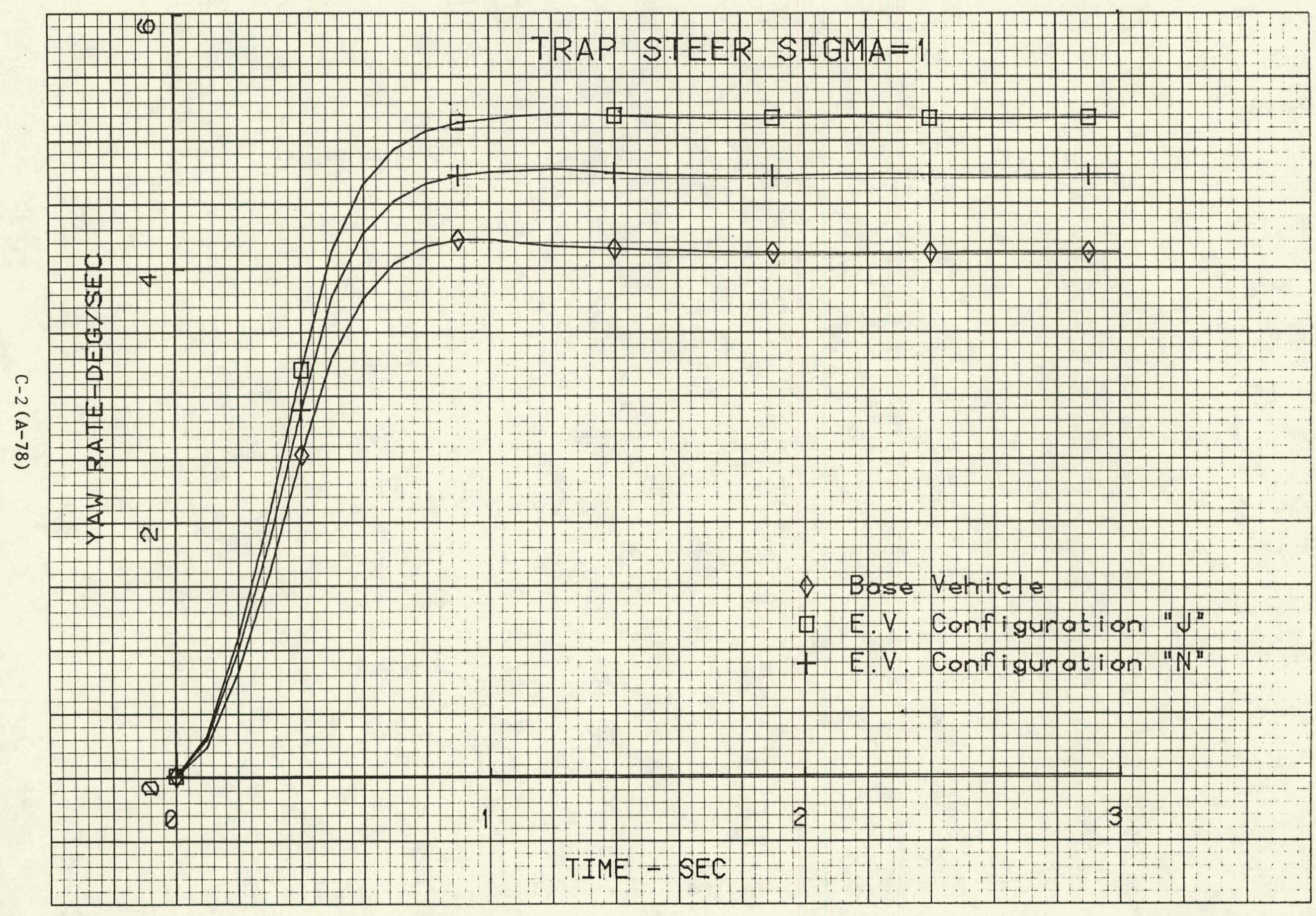




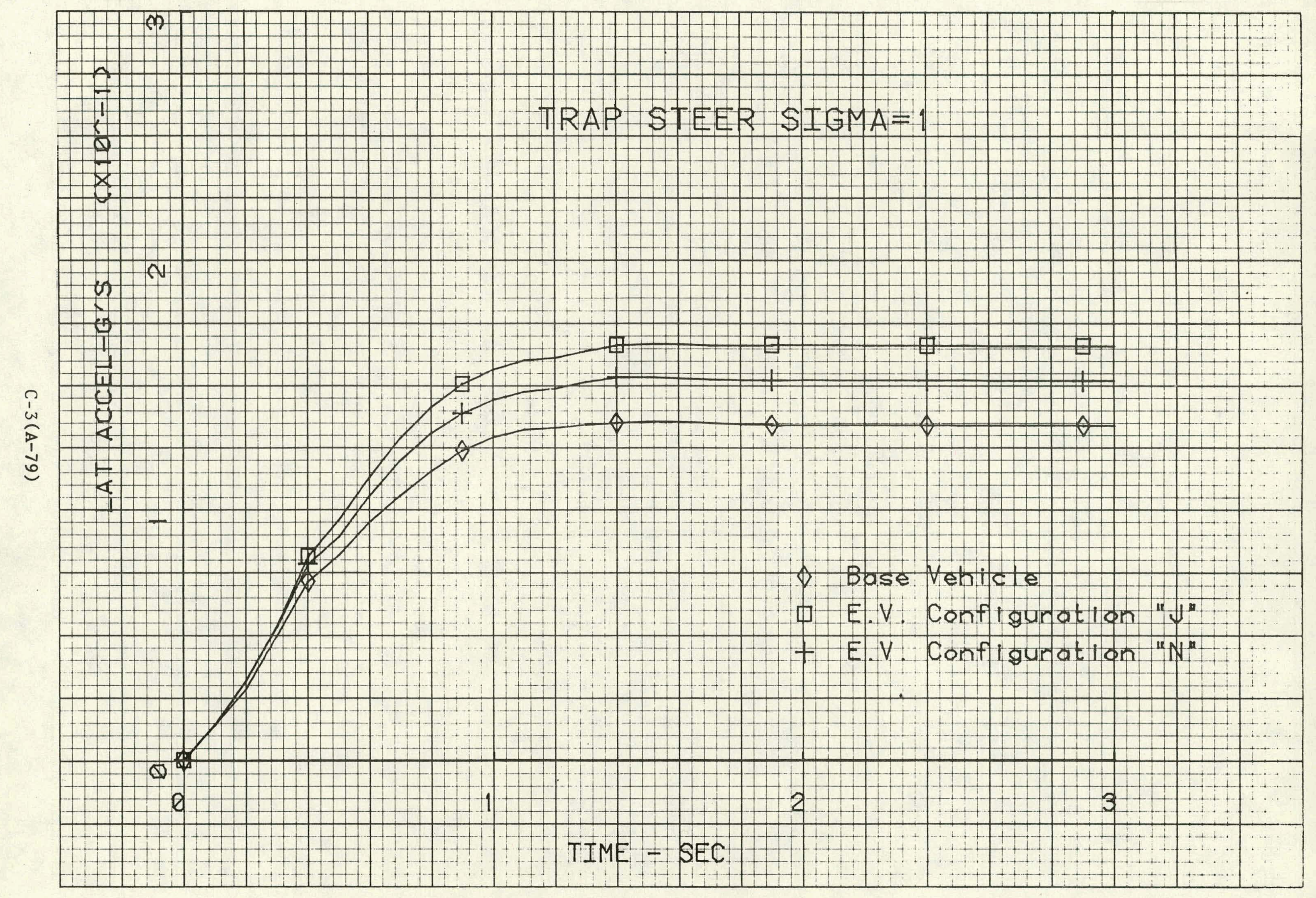




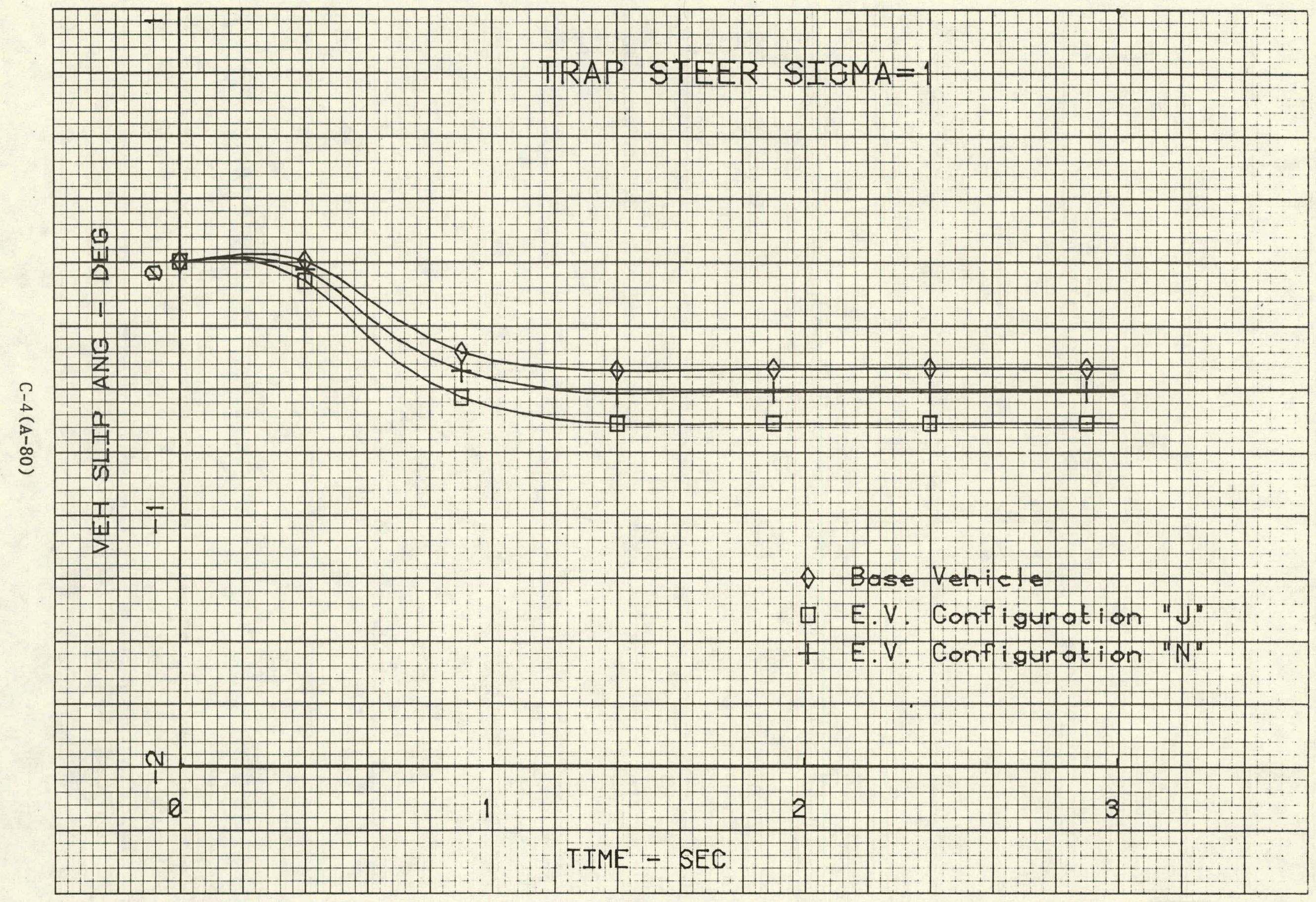


N

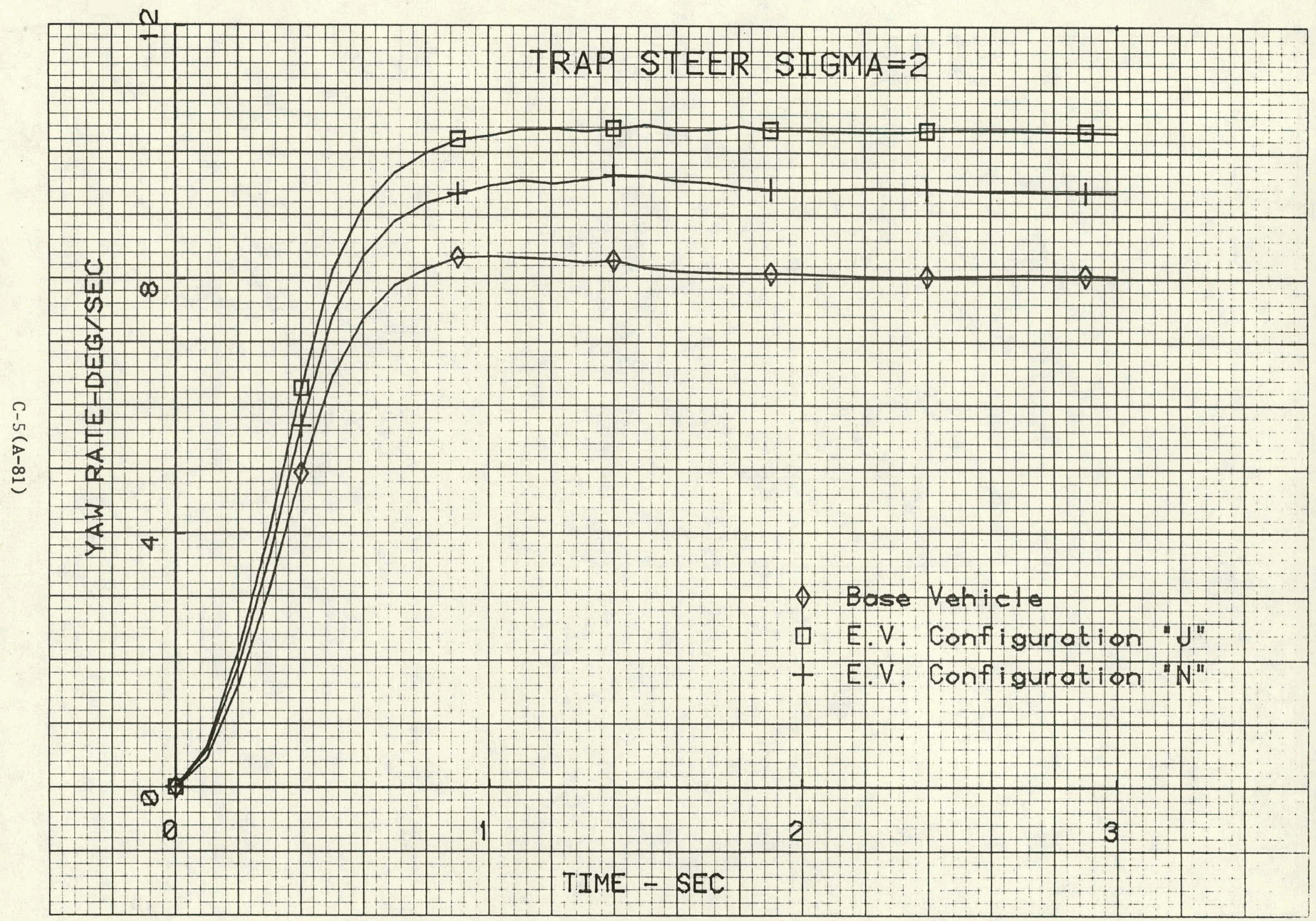




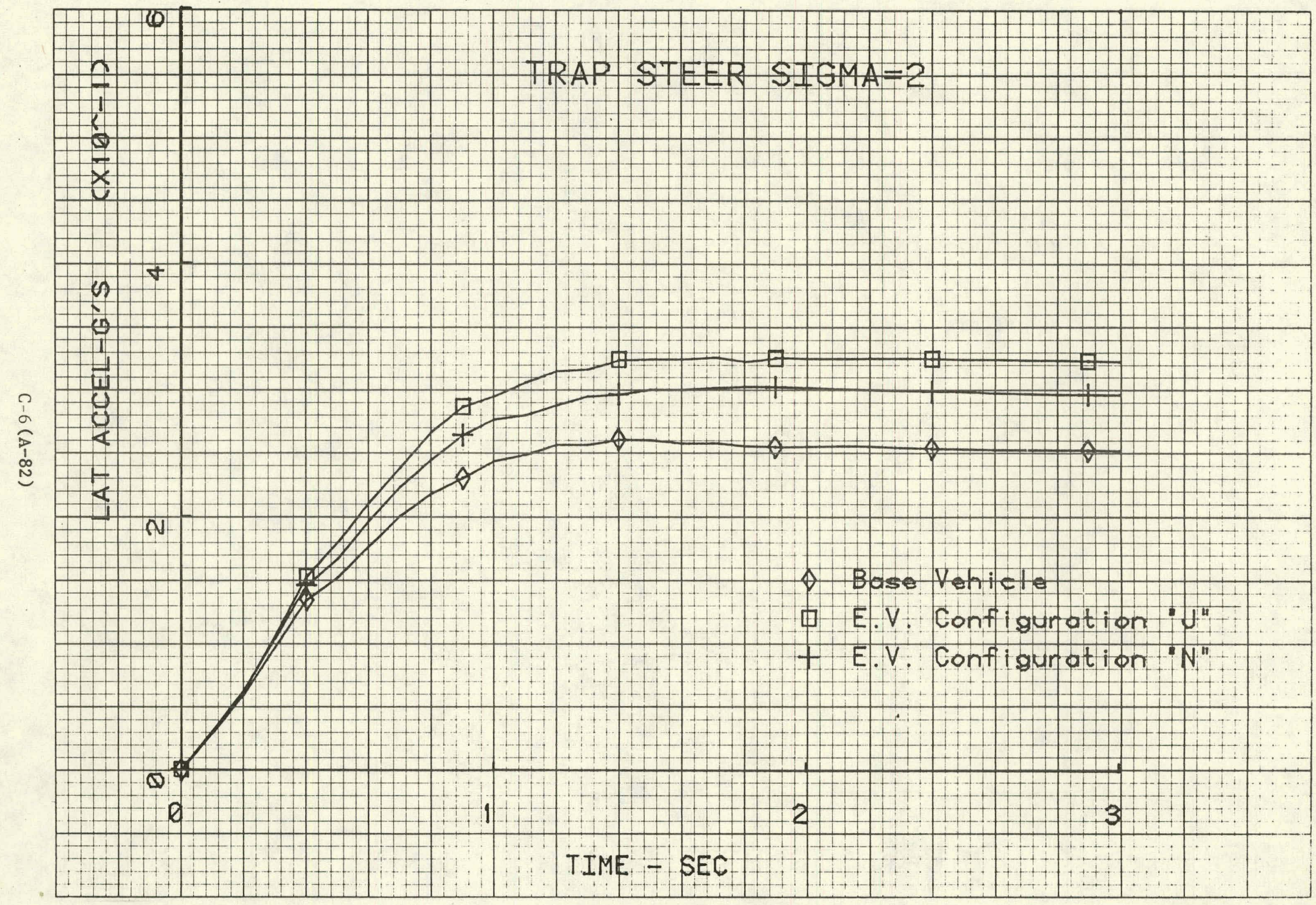




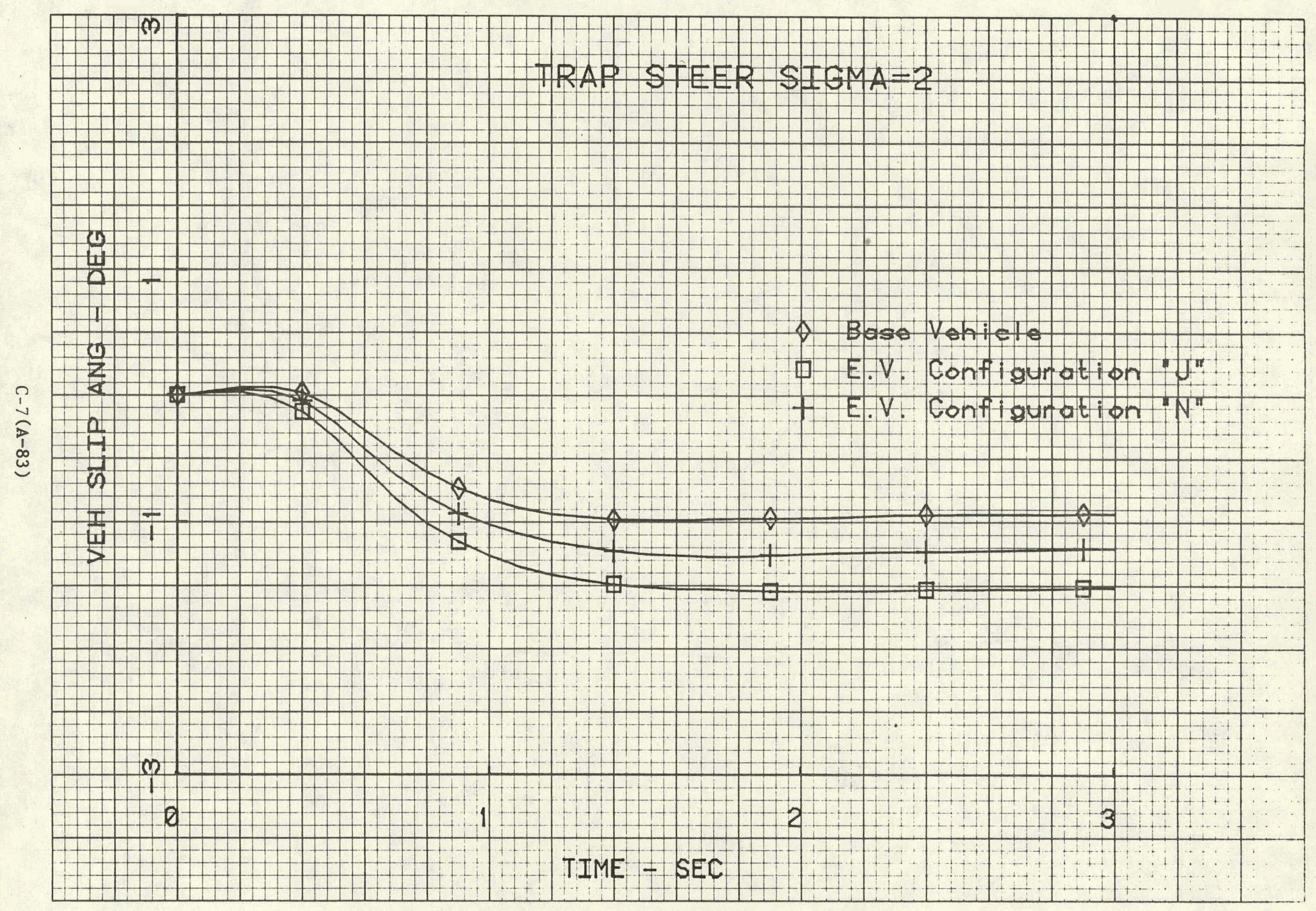




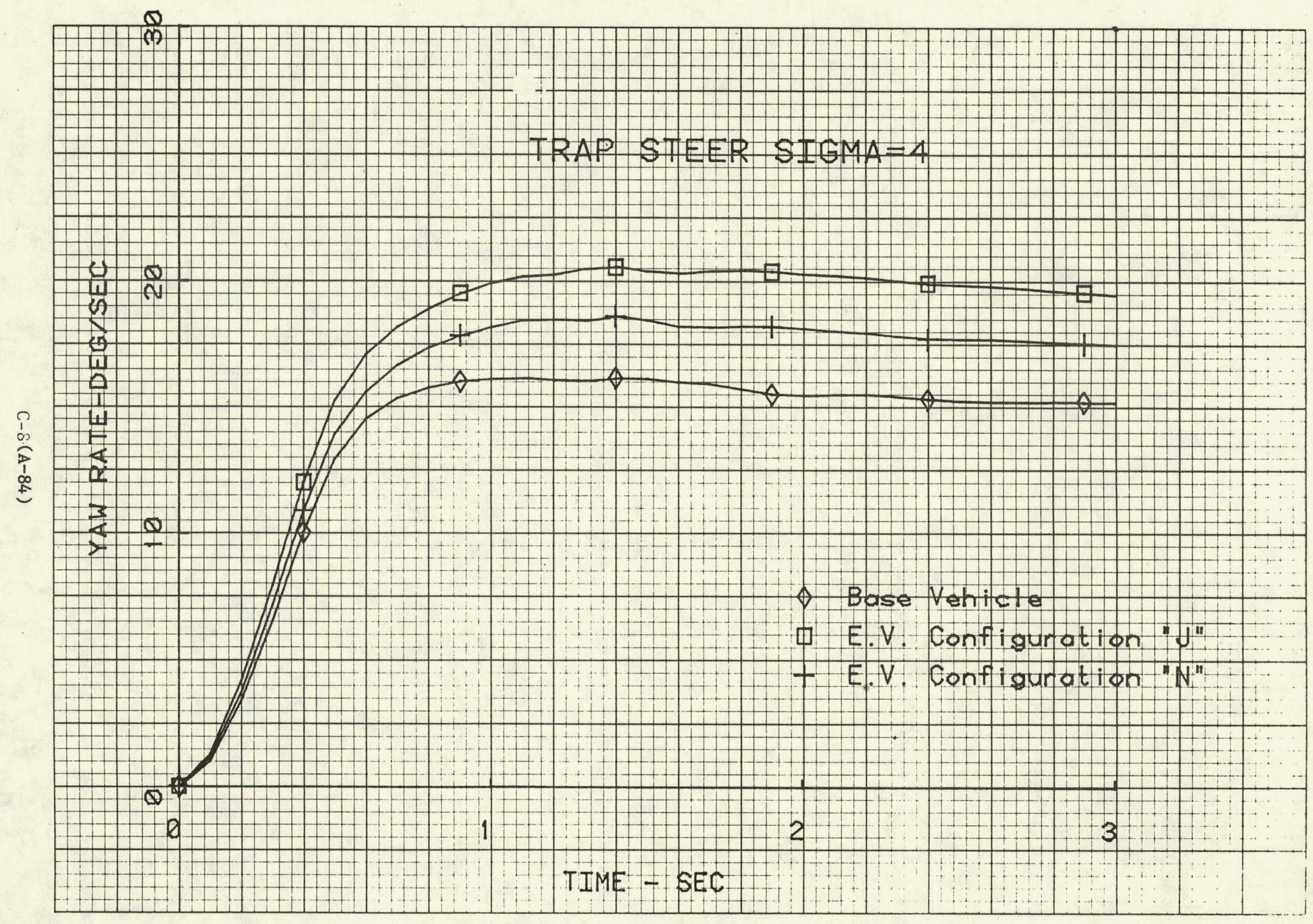




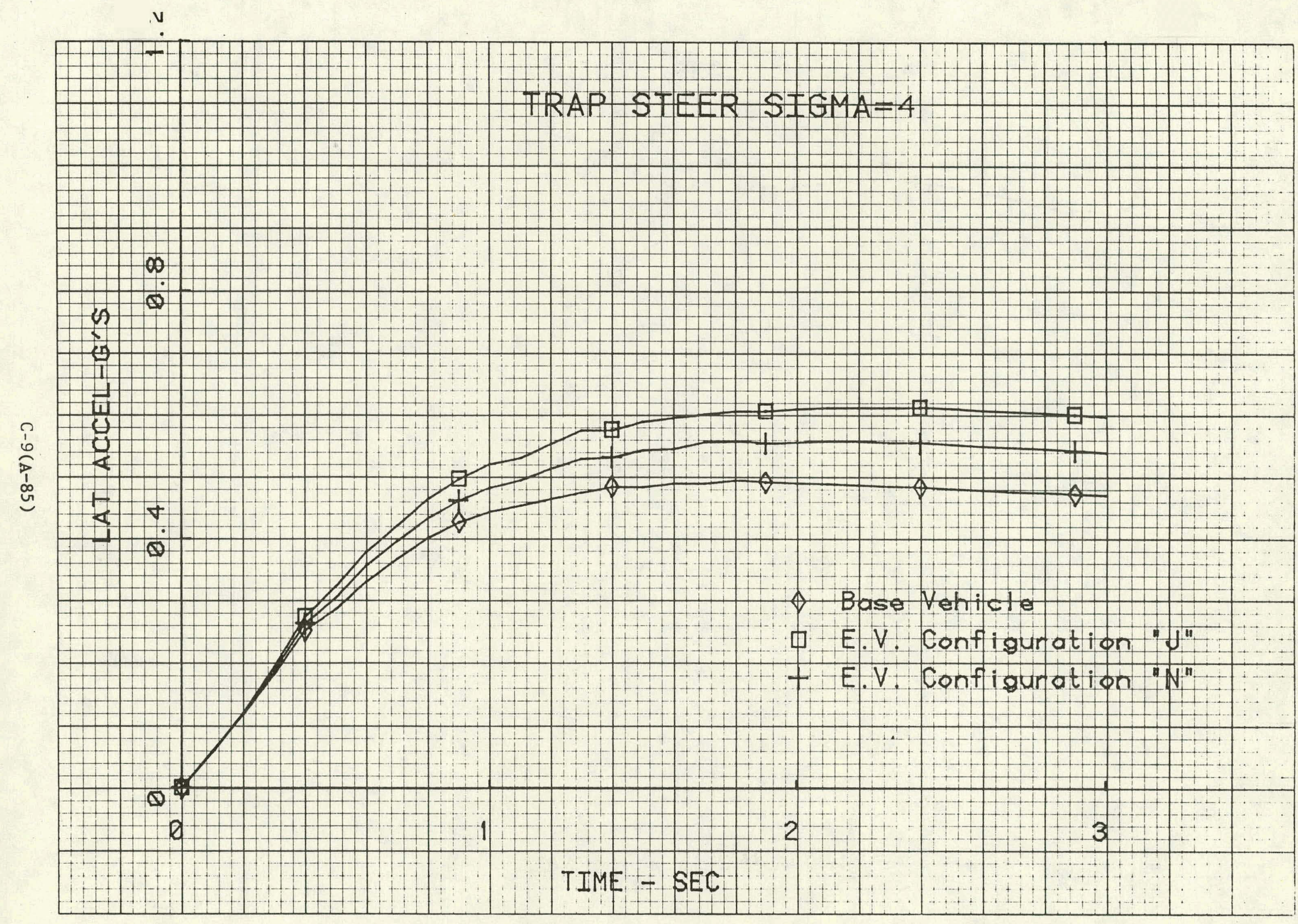




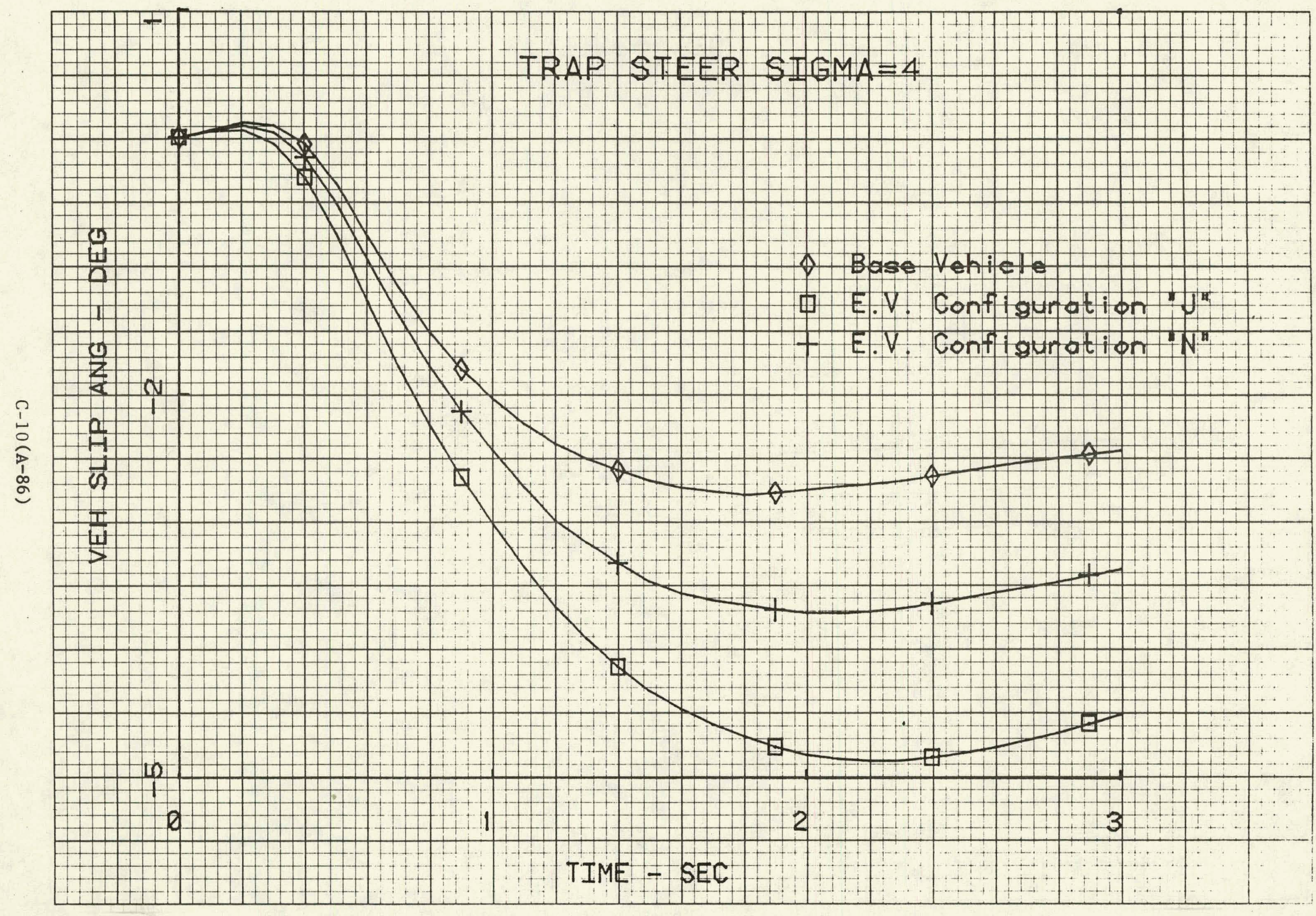




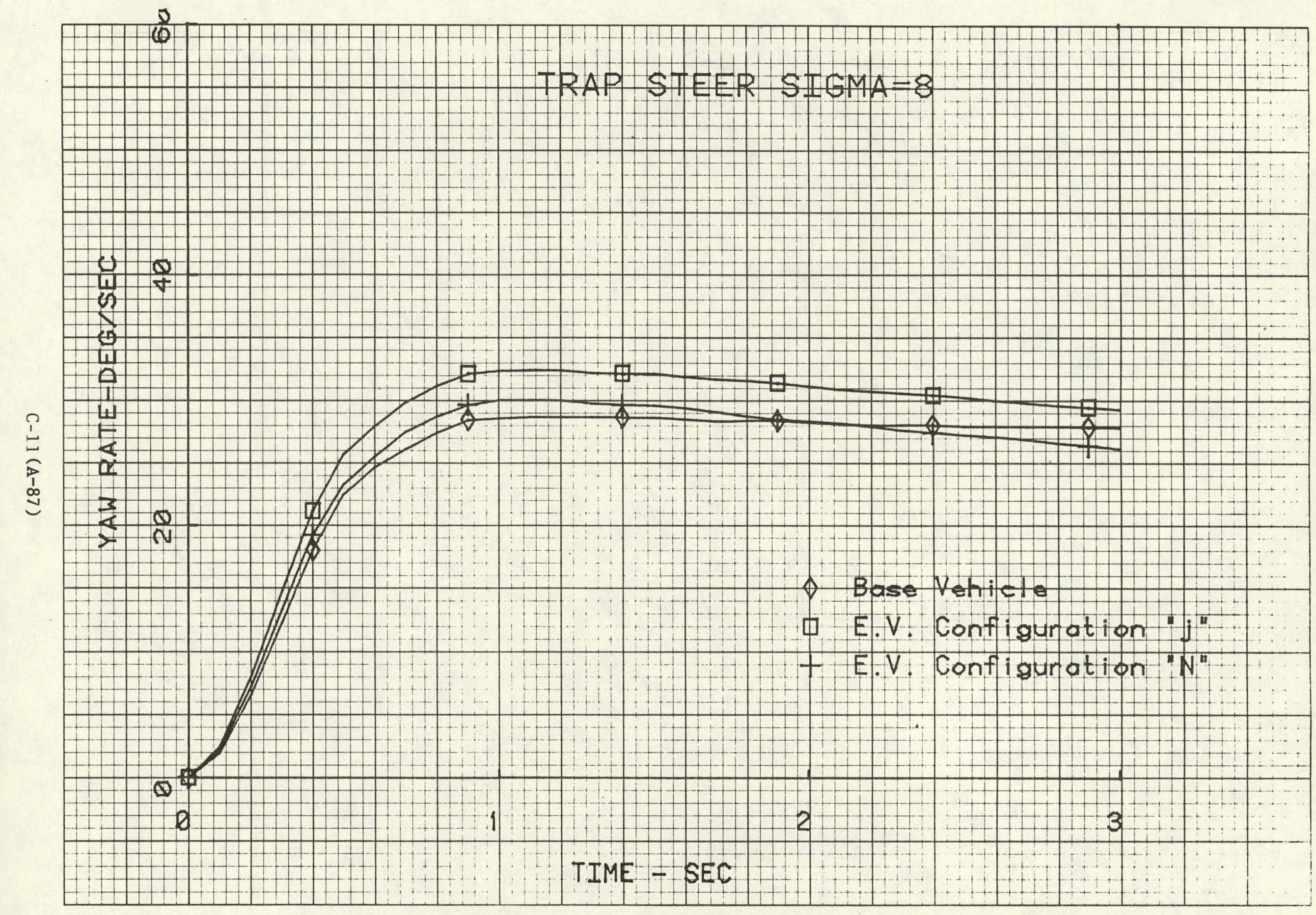




\section{$N$}

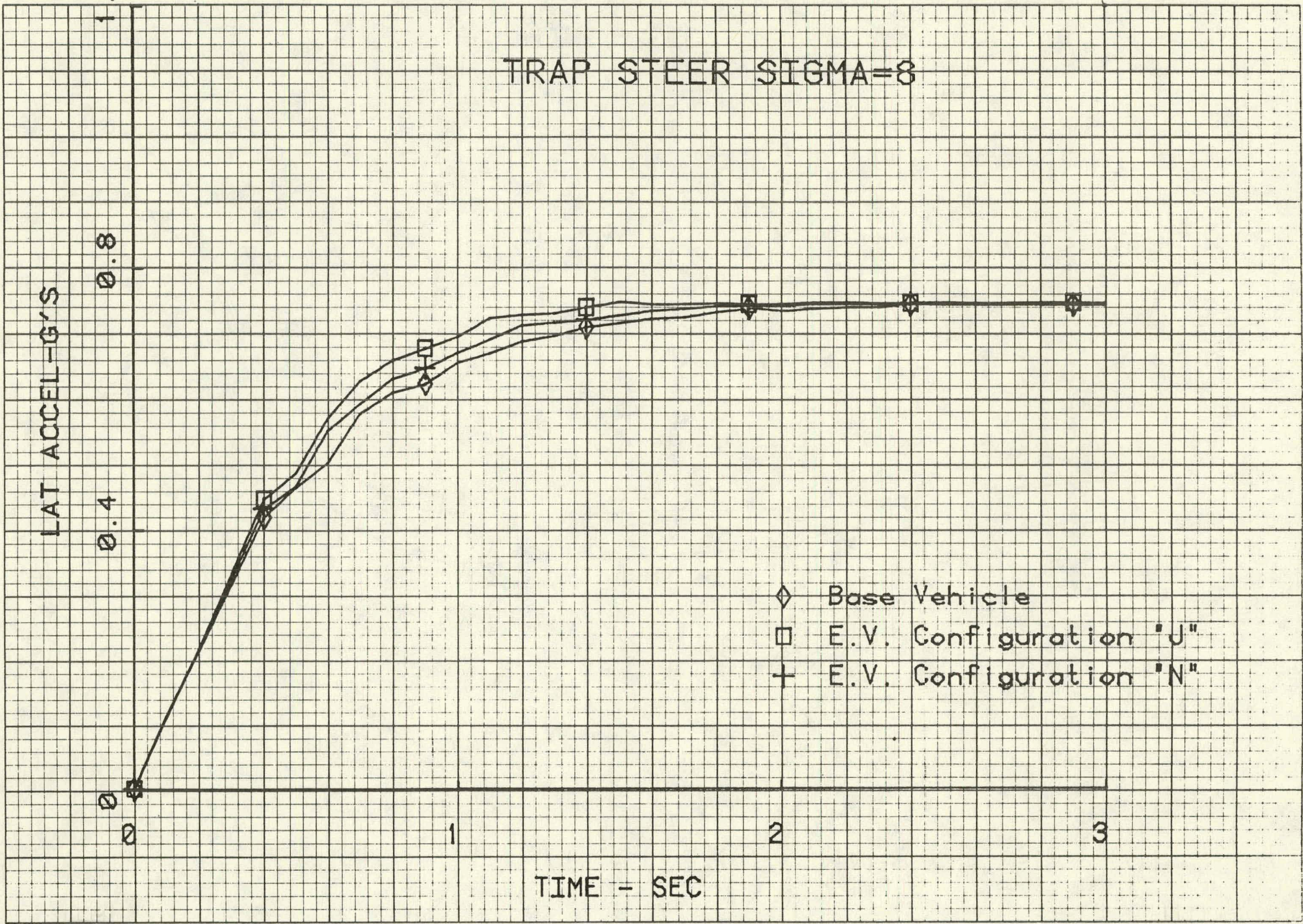




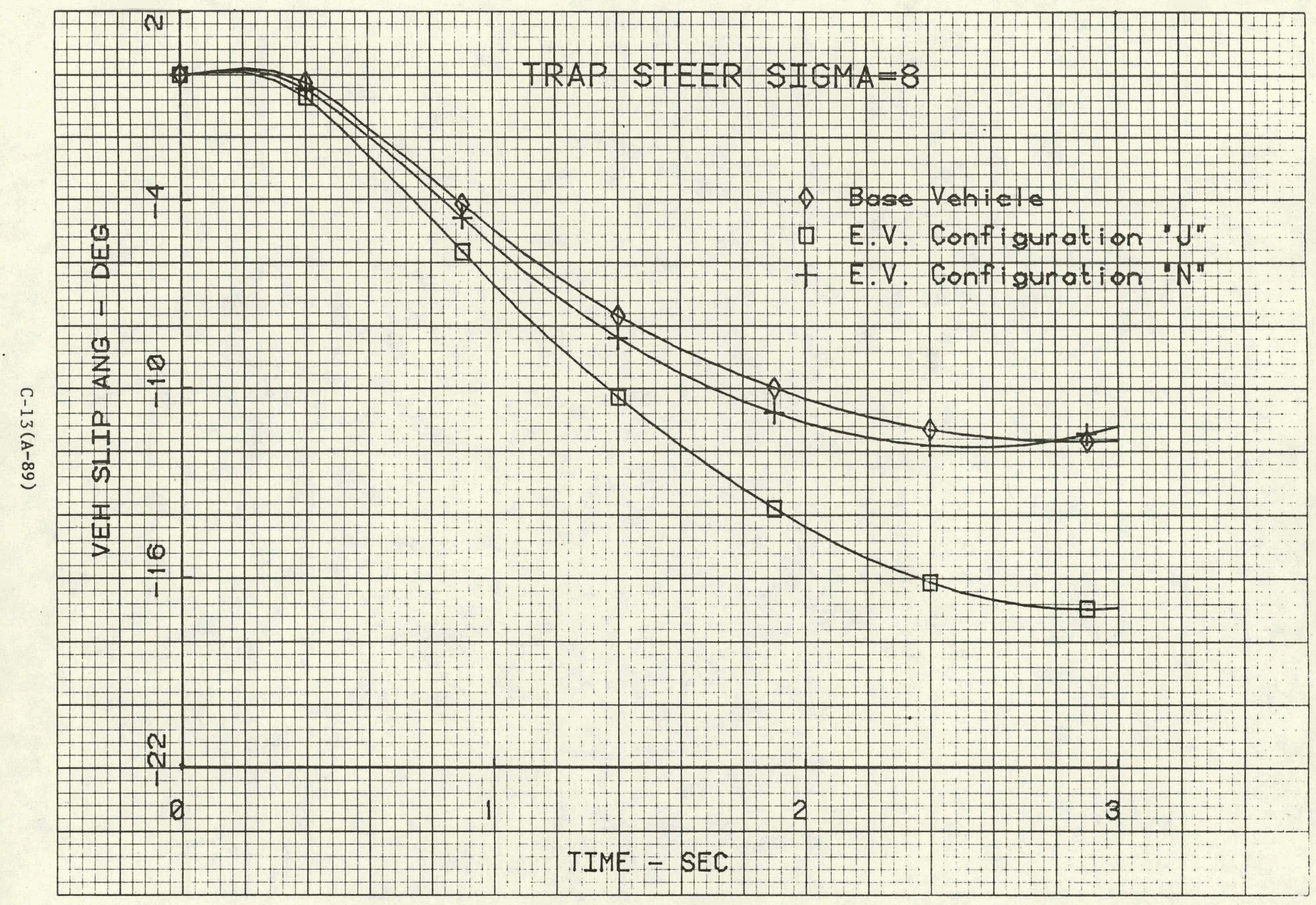




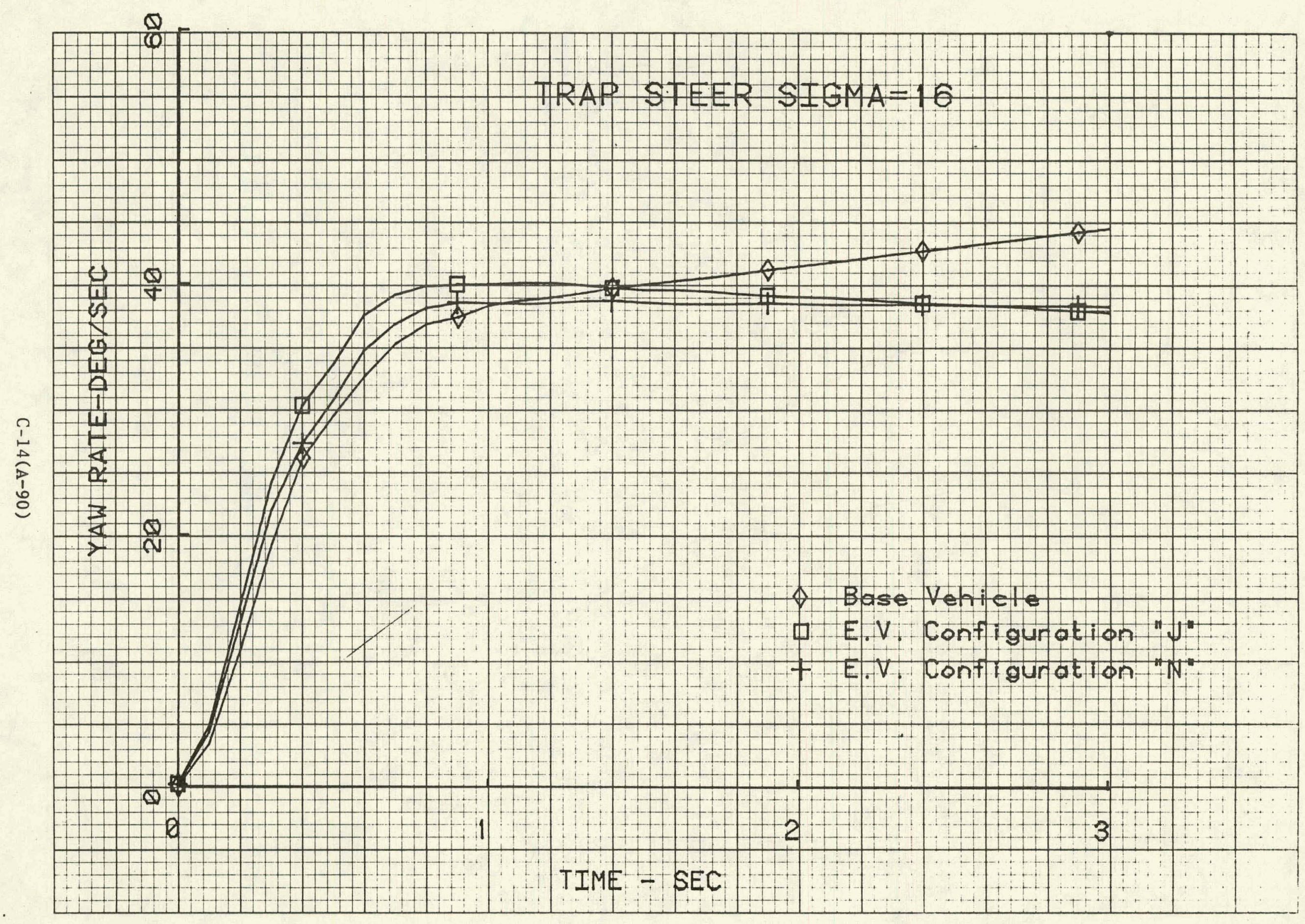




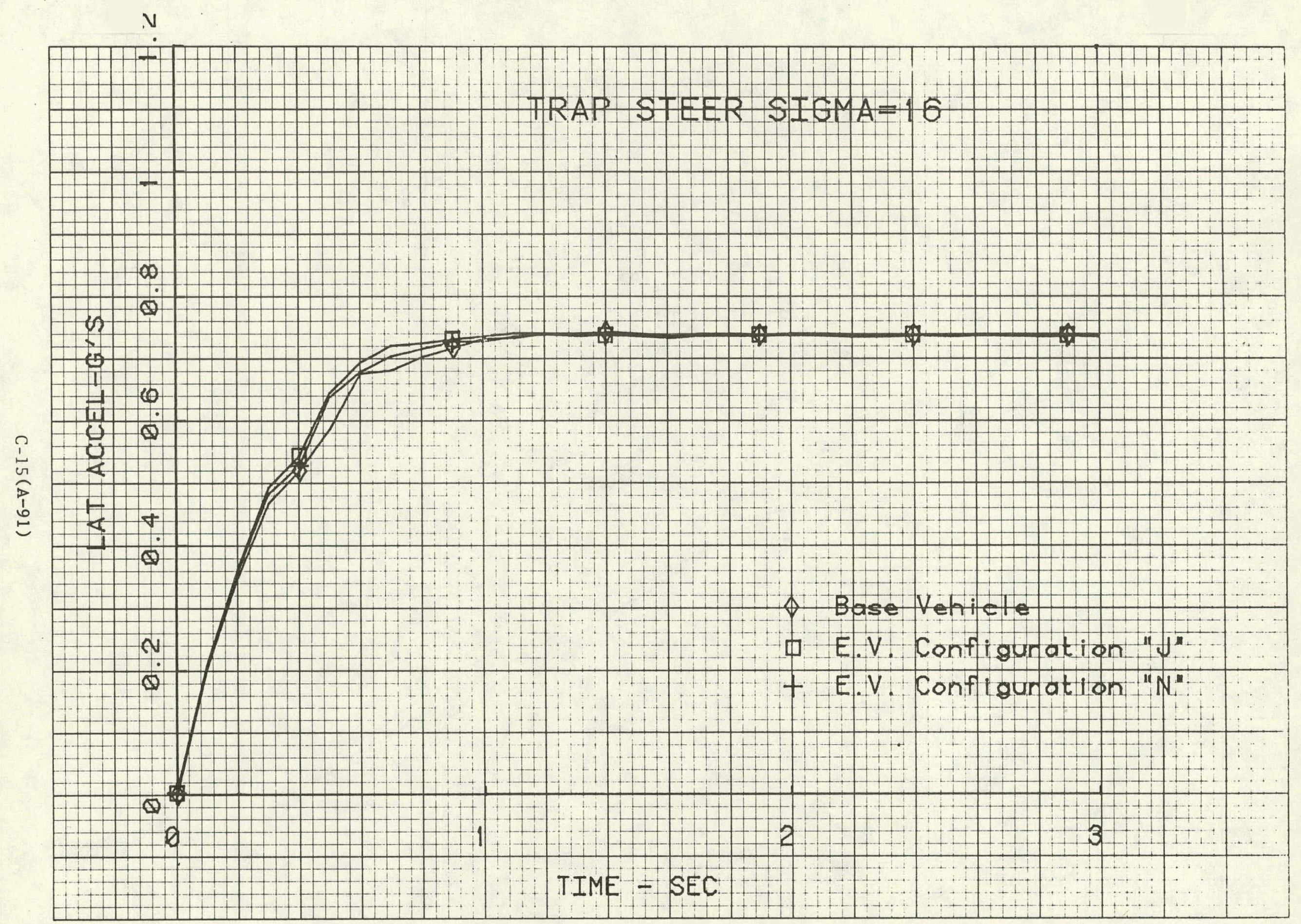




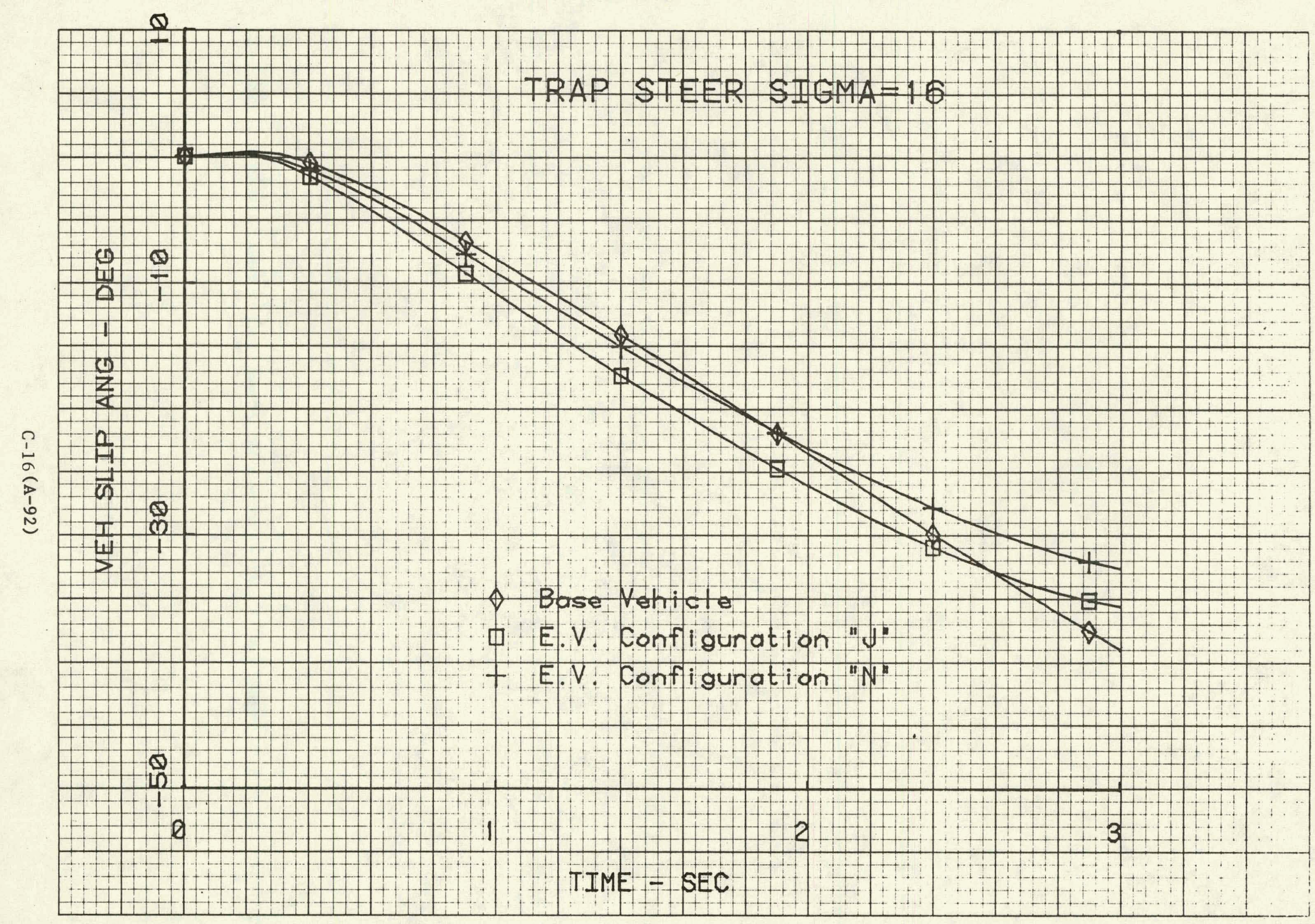




\section{APPENDIX D}

SINUSOIDAL STEER RESPONSE PLOTS

D-1

(A-93) 


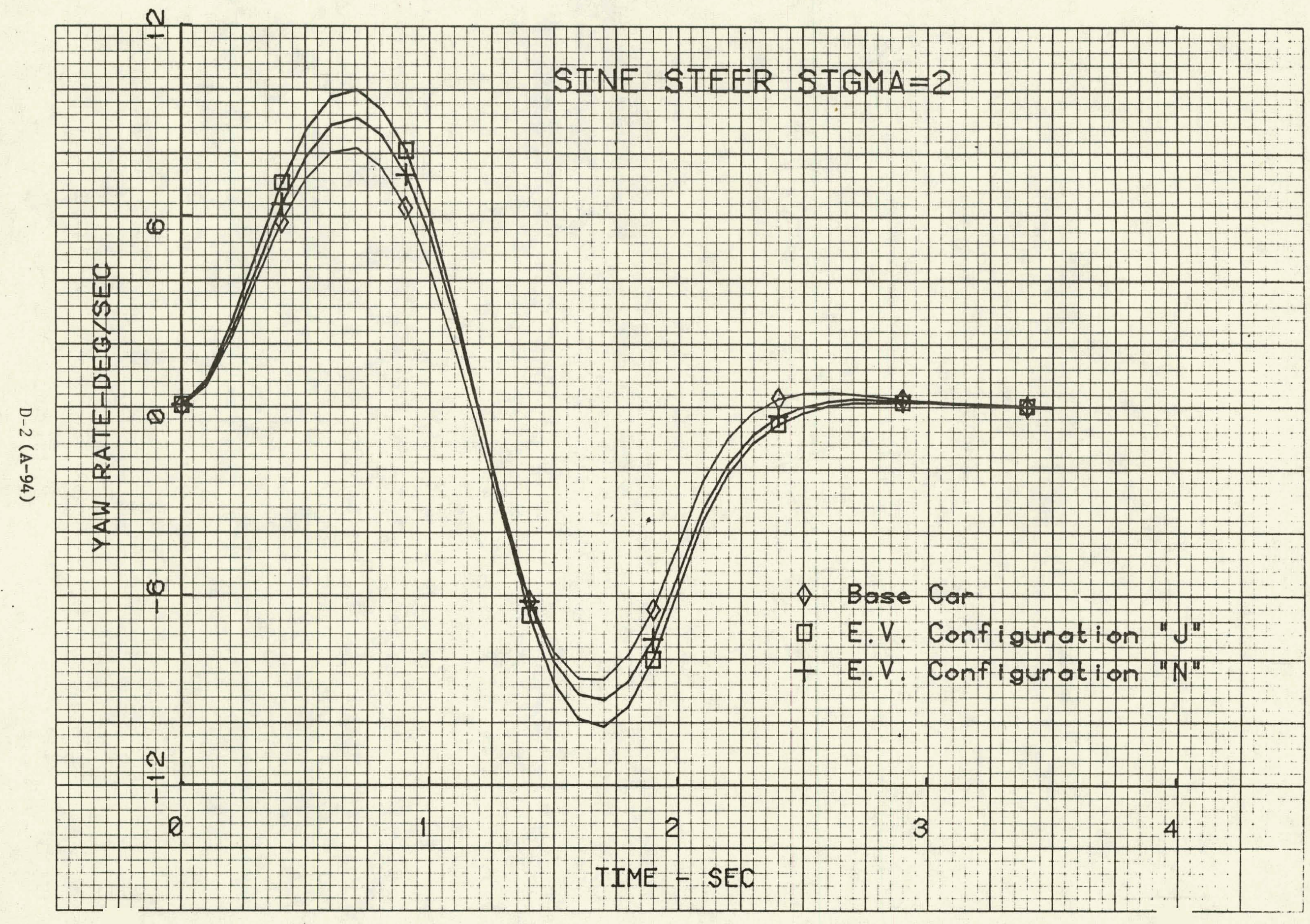




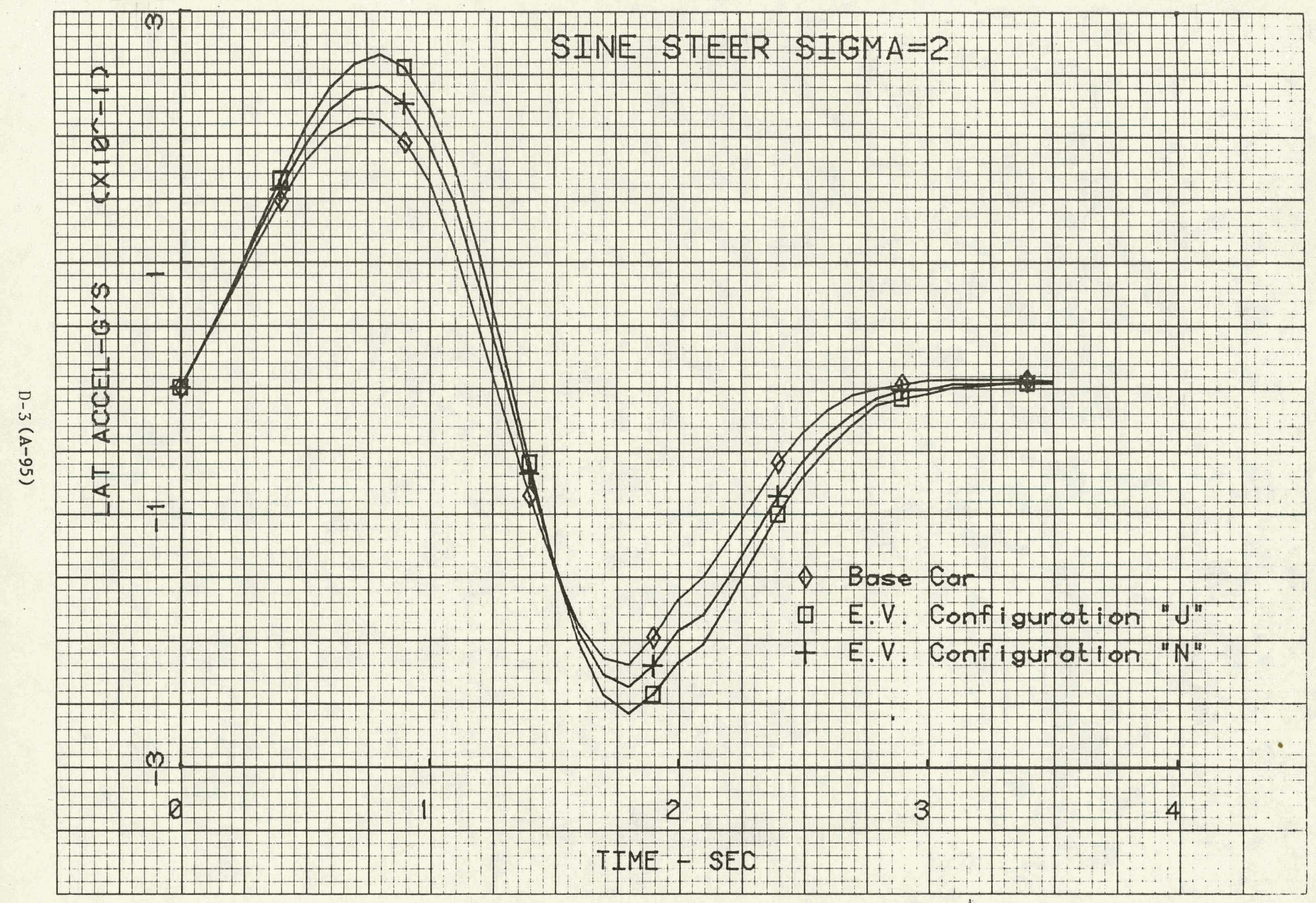




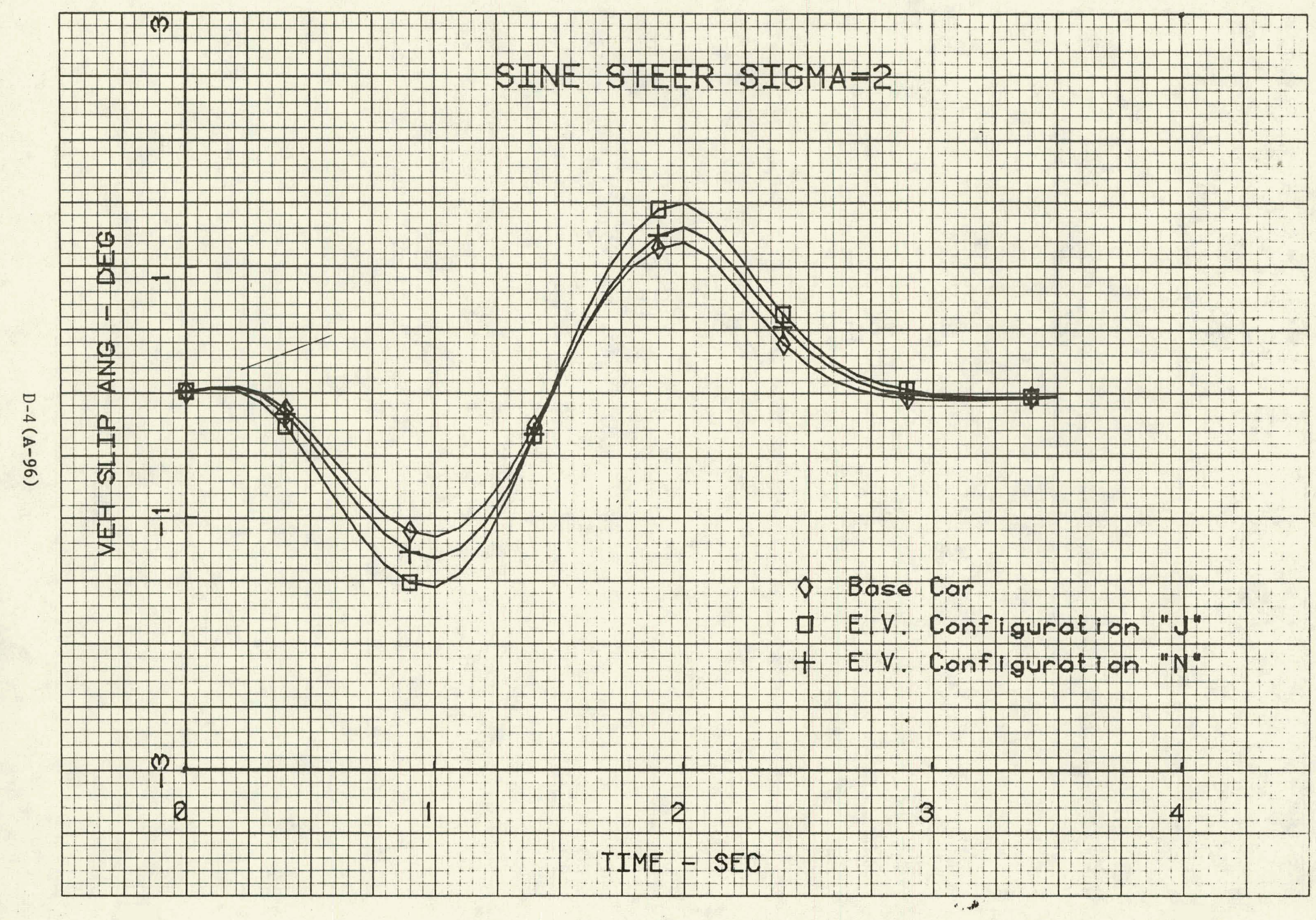




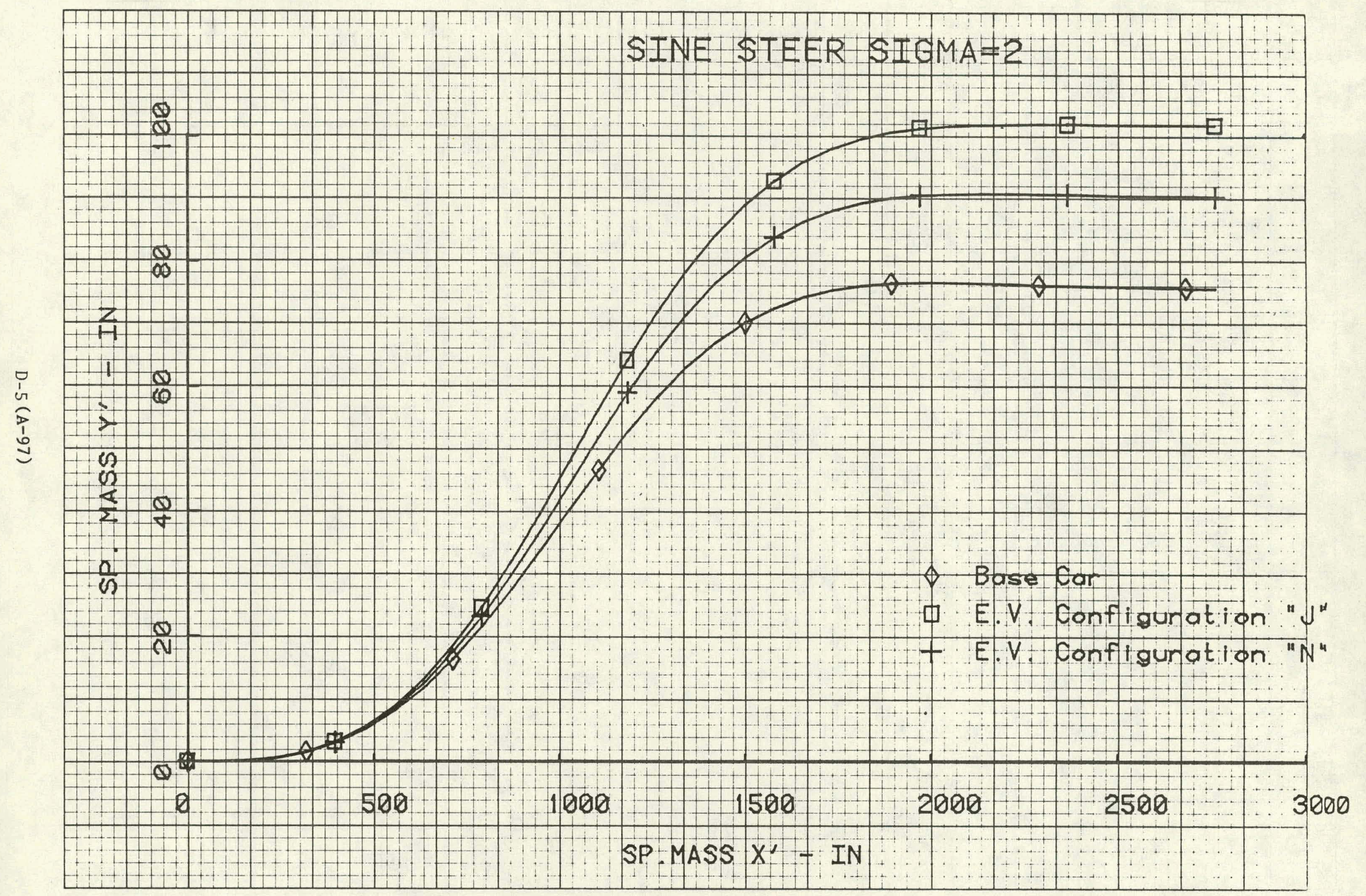




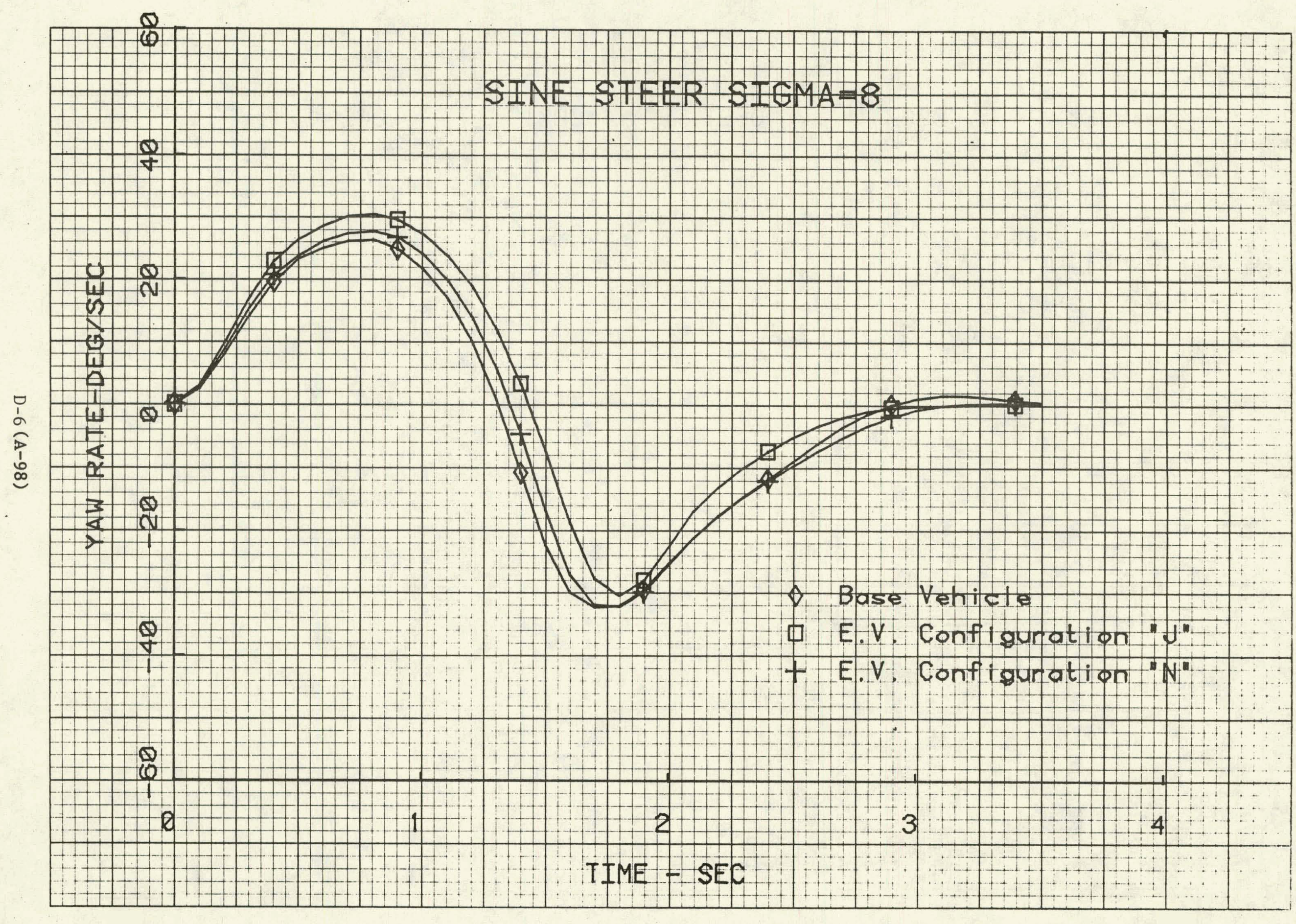




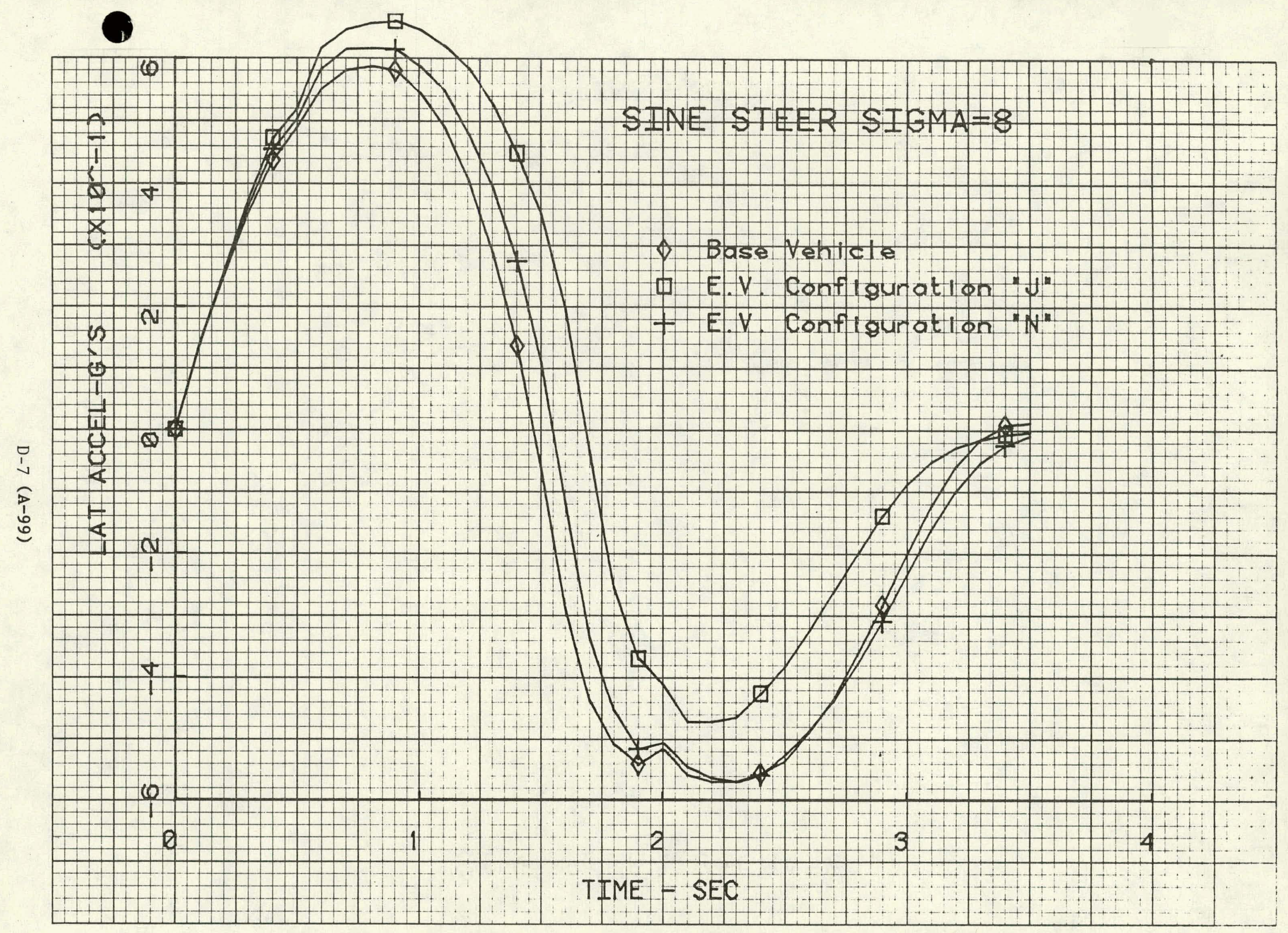




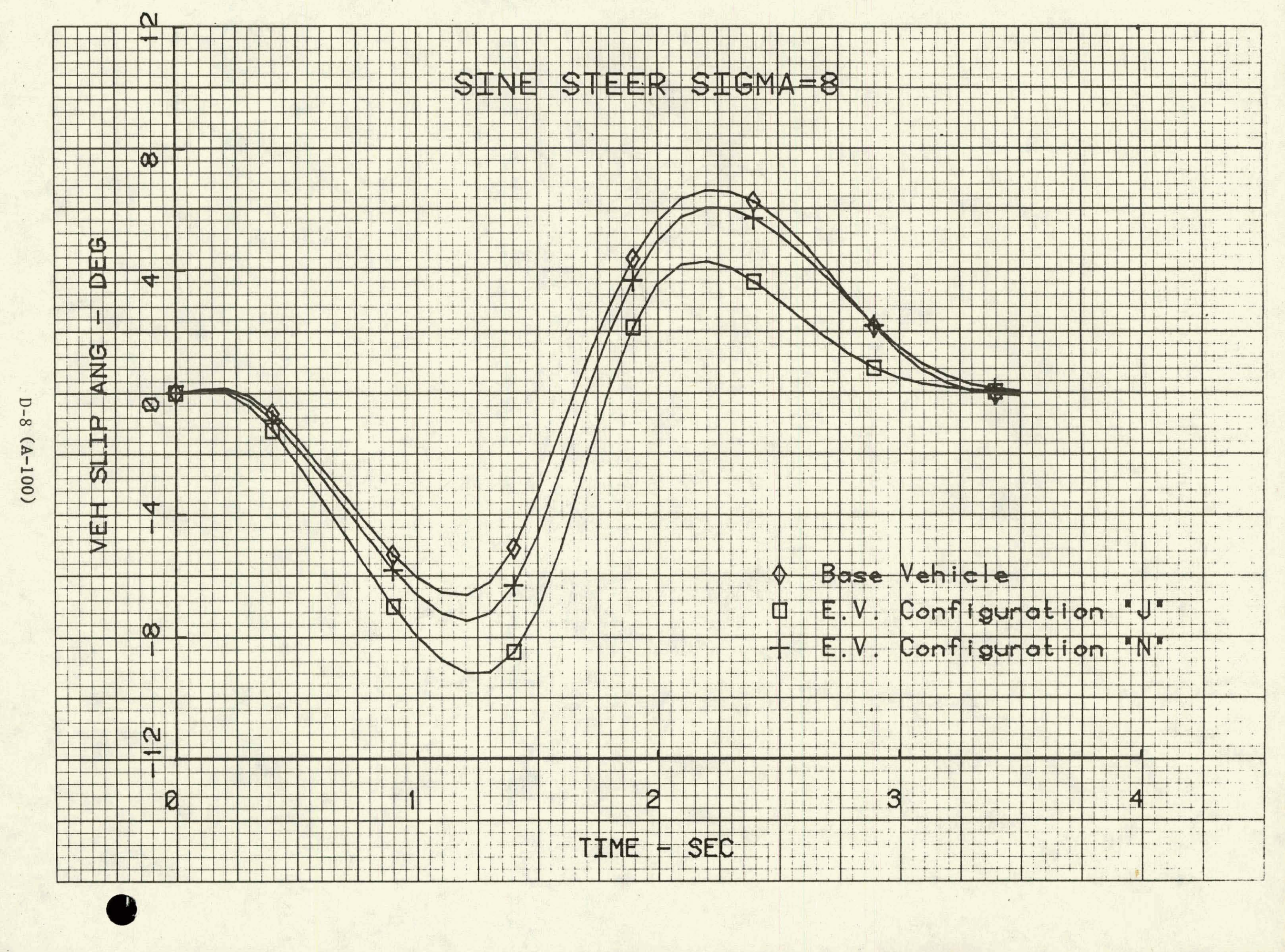




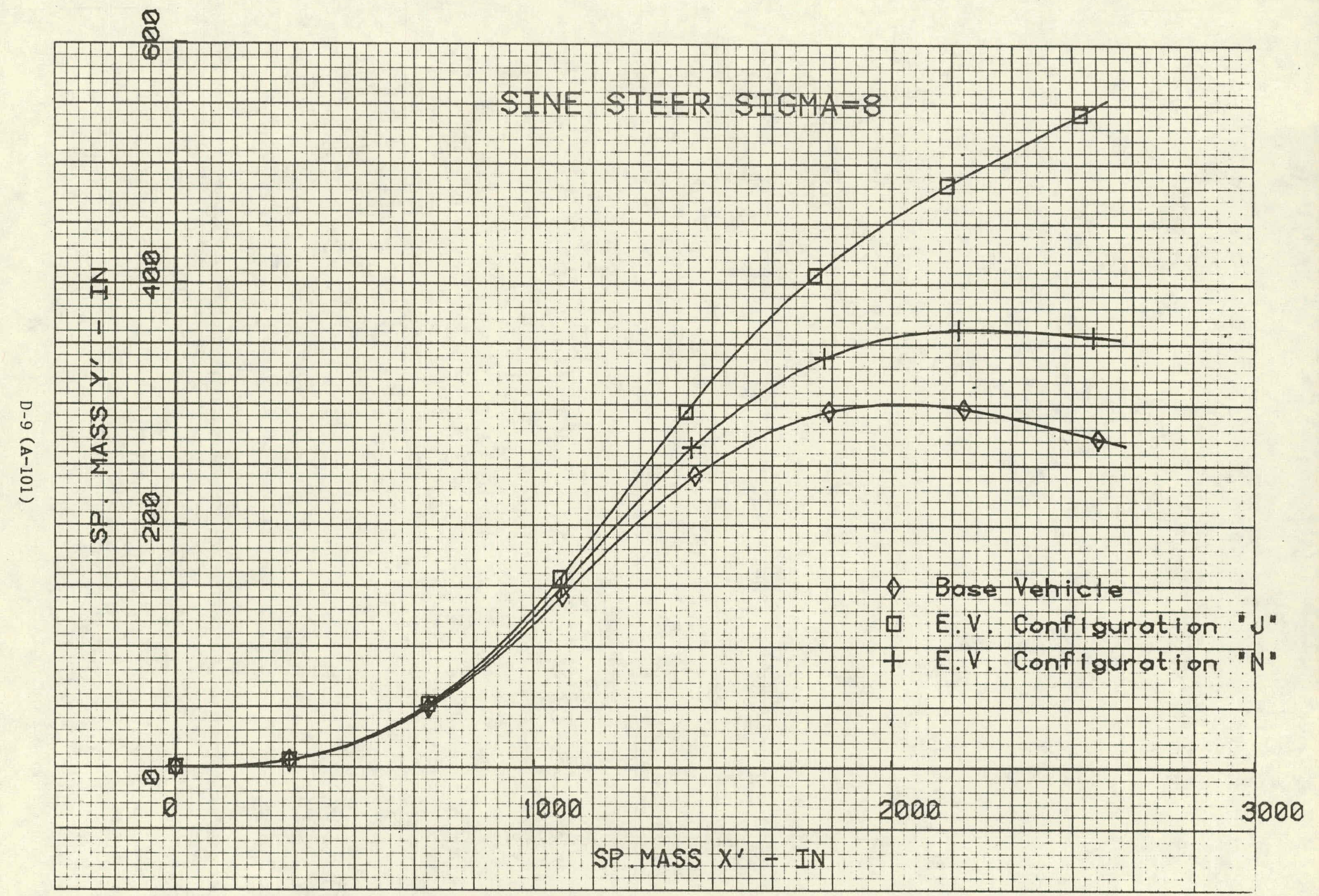

